\title{
MODELAGEM NUMÉRICA DO CRESCIMENTO DE FRATURAS ATRAVÉS DO MÉTODO DOS ELEMENTOS DE CONTORNO
}

MÁRIO CÉSAR LOPES JÚNIOR

Dissertação apresentada à Escola de Engenharia de São Carlos, da Universidade de São Paulo, como parte dos requisitos para obtenção do Título de Mestre em Engenharia de Estruturas.

ORIENTADOR: Prof. Dr. Wilson Sérgio Venturini

São Carlos

1996 


\section{Lopes Jr., Mário César}

L854m Modelagem numérica do crescimento de fraturas através do método dos elementos de contorno / Mário César Lopes Júnior. -São Carlos, 1996.

$261 p$.

Dissertação (Mestrado) -- Escola de Engenharia de São CarlosUniversidade de São Paulo, 1996

Orientador: Prof. Dr. Wilson Sérgio Venturini

1. Método dos elementos de contorno. 2. Mecânica da fratura. 3. Concreto (Estruturas). I. Título. 
Aos meus pais, Mário e Ana, por me incentivarem a seguir a carreira de engenheiro e, sobretudo, por me apoiarem suficientemente para tornar esse objetivo - e muitos outros - uma realidade. 
Em algum lugar do Brasil, em um passado não muito distante:

—“Júnior, você está vendo esse prédio?"

_."Estou, pai. "

—-É bonito, não é?"

- "É ..."

—"É grande, não é? "

- "É ..."

— "Você sabe quem foi que fez?"

- "Não ..."

_."Foi um engenheiro, viu? ..."

-

"Isso é fácil, Mário, senta lá na mesa que, em uma tarde, você faz."

Teorema de Venturini.

"May what we study be well studied."

J. N. Reddy

"It has been said that "an author never finishes a book, he merely abandons it." I have come to appreciate vividly the truth of this statement and I dread to see the day when, looking at the manuscript in print, I am sure to realize that so many things could have been done better and explained more clearly. If I abandon the book, nevertheless, it is in the modest hope that it may be useful to others, despite its shortcomings." 


\section{AGRADECIMENTOS}

A Deus, por todos os beneficios e oportunidades que me tem concedido.

Ao Governo Brasileiro, através da Coordenadoria de Aperfeiçoamento de Pessoal de Nível Superior - CAPES, pelo suporte financeiro, sem o que a realização deste trabalho não seria possível.

A todos os professores, colegas e funcionários do Departamento de Engenharia de Estruturas da EESC - USP

Ao Professor Wilson Sérgio Venturini, por ter se mostrado capaz de orientar com competência e objetividade. Também por sempre estar acessível e por ter se mostrado tolerante aos ajustes que se fizeram necessários durante o desenvolvimento do trabalho. Como se isto não bastasse, os exemplos de dedicação e profissionalismo foram vários.

Ao mestre, futuro colega, e sobretudo amigo, Professor João Carlos Cordeiro Barbirato, pela orientação e apoio durante a graduação, por ter me apresentado o Método dos Elementos de Contorno e pelo incentivo ao ingresso em um programa de pós-graduação.

Ao Professor e amigo Flávio Barboza de Lima, pela solicitude constante e, sobretudo, pelo apoio nos momentos dificeis. 
Aos Professores João Batista de Paiva, João Bento de Hanai, José Samuel Giongo, Roberto Luiz de Arruda Barbato e Sérgio Persival Baroncini Proença, por sempre se mostrarem dispostos e preocupados em tornar o Departamento de Engenharia de Estruturas um ambiente propício ao desenvolvimento de atividades de pesquisa e pela atenção que sempre me dedicaram.

Aos amigos Alexandre Araújo Bertini, Dermival Paula Bezerra, João Augusto de Lima Rocha, José Fernando Moretti, Paulo Gustavo Cavalcante Lins e Válter Lúcio de Pádua, pelo companheirismo e pelas experiências de vida partilhadas.

À Sra. Maria N. Minatel pelo apoio na elaboração das referências bibliográficas. Ao Sr. Francisco C. G. Brito pela elaboração de parte dos desenhos e pela auxílo na adaptação dos demais. Às Sras. Rosi Ap. J. Rodrigues e Marta R. C. Faria e ao Srs. Antônio V. Carneiro e Rui R. Casale, pela atenção com que sempre me atenderam.

Aos impagáveis Guilherme Amorim Braga e Gustavo Silva de Carvalho, companheiros e co-fundadores da República das Alagoas II. O mestrado não teria sido o mesmo sem vocês. Bons tempos, estes de mestrado!

À Família Fontes, em especial aos irmãos Sérgio e Sílvio, pelo apoio inestimável que me concederam.

Ao amigos José Ricardo Rahal, Lélia Marta de Mello e Marcus Aurélio Sitelli pelo amizade e cuidado com que me agraciaram.

A Keilla, pelo amor, estímulo e paciência constantes.

A todos que, direta ou indiretamente, colaboraram para a realização deste trabalho. 


\section{SUMÁRIO}

LISTA DE FIGURAS

$\mathbf{X}$

LISTA DE TABELAS .......................................................................... xiii

NOTAÇÃ

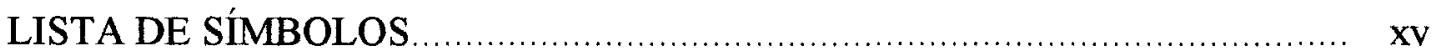

RESUMO

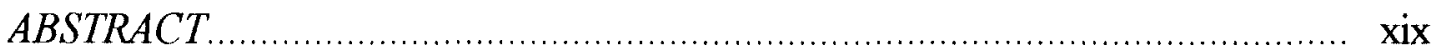

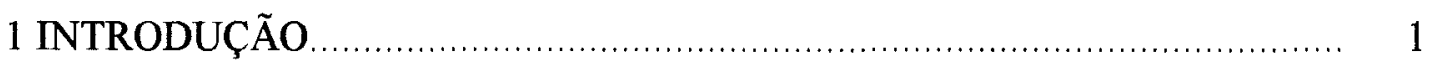

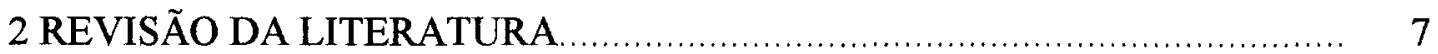

2.1 O Método dos Elementos de Contorno .............................................. 7

2.2 Mecânica do Fraturamento .............................................................. 11

2.3 Aplicação do Método dos Elementos de Contorno à Mecânica do Fraturamento

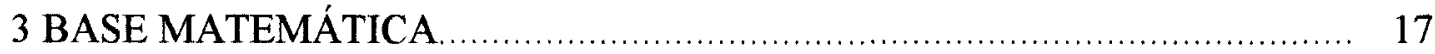

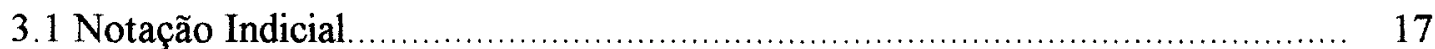

3.1.1 Convenção de Somatório, Índices Mudos......................................... 17

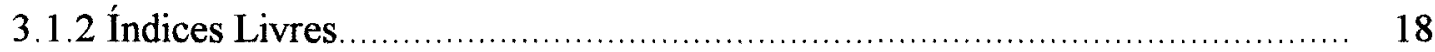


3.1.3 Delta de Kronecker .............................................................. 19

3.1.4 Convenção de Diferenciação .................................................. 20

3.2 Problemas de Valor de Contorno .................................................. 20

3.3 Funções de Green...................................................................... 22

3.4 Equações Integrais e Valor Principal de Cauchy ....................................... 26

3.5 Teoremas de Green ................................................................... 27

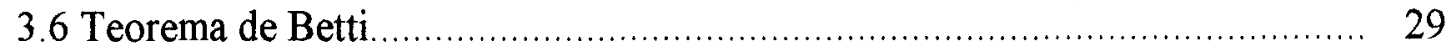

3.7 Funções de Interpolação e Formulação Isoparamétrica ............................ 30

3.8 Integração Numérica................................................................ 32

3.8.1 Coordenadas Naturais ....................................................... 32

3.8.2 Quadratura de Gauss-Legendre ............................................ 33

3.9 Fórmulas de Quadratura de Kutt ...................................................... 34

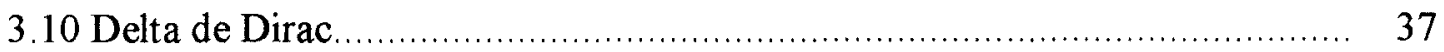

4 FUNDAMENTOS DA MECÂNICA DOS SÓLIDOS ............................. 39

4.10 Estado de Tensões em um Ponto................................................... 39

4.2 Equações de Equilíbrio.................................................................. 41

4.3 Condições de Contorno ............................................................... 42

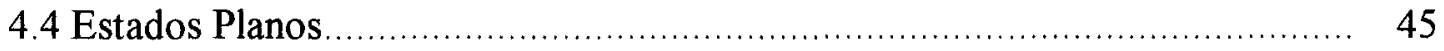

4.4.1 Estado Plano de Tensão ............................................................ 45

4.4.2 Estado Plano de Deformação ........................................................... 46

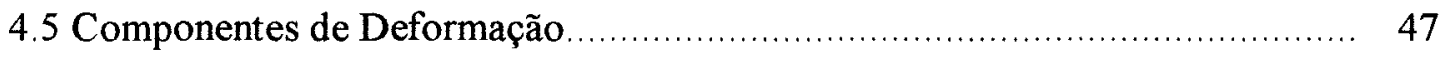

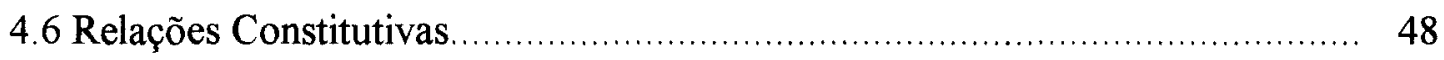

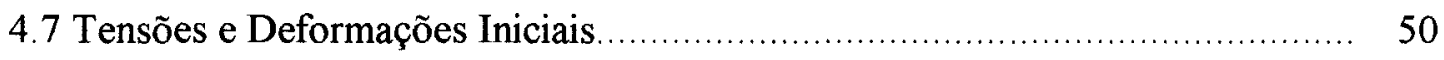

5 INTRODUÇÃO À MECÂNICA DO FRATURAMENTO ......................... 52

5.1 Por que Utilizar a Mecânica do Fraturamento?....................................... 52

5.1.1 Energia Necessária Para a Formação de Fissuras .................................. 52

5.1 .2 Objetividade dos Cálculos .................................................... 53

5.1.3 Falta do Patamar de Escoamento ...................................................... 55

5.1.4 Capacidade de Absorção de Energia e Ductilidade................................ 57

5.1.5 Efeito de Escala .......................................................................... 57 


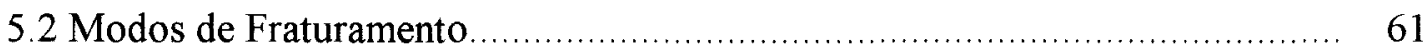

5.3 Mecânica do Fraturamento Elástica Linear (MFEL) .............................. 62

5.3.1 Crack Estacionário Devido a Solicitações Elásticas............................... 64

5.4 O Balanço Energético de Griffith ......................................................... 67

5.5 Conceitos de Fratura e Modelagem Numérica ....................................... 70

5.5.1 O Modelo de Fratura Fictícia (MFF) ........................................... 70

5.5.2 Aplicação do MFF Através do Método dos Elementos Finitos ................. 73

5.6 Modelo Coesivo do Fraturamento....................................................... 78

5.7 Curva de Amolecimento no Modo de Abertura e Parâmetros Relacionados.... 80

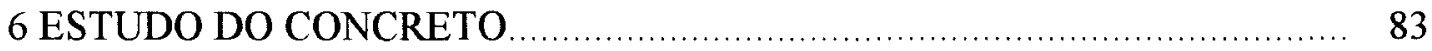

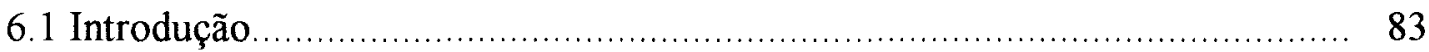

6.1.1 Desenvolvimento Histórico ..................................................... 83

6.1.2 O Concreto Como Material Estrutural................................................ 85

6.2 Formação Prévia de Fissuras............................................................ 87

6.3 Aspectos Fenomenológicos do Fraturamento ....................................... 89

6.4 Abordagem em Três Niveis .................................................................... 97

6.5 Modelos do Material ........................................................................ 97

7 O MÉTODO DOS ELEMENTOS DE CONTORNO ................................ 101

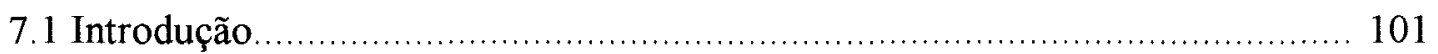

7.1.1 Comparando-se Elementos de Contorno com Elementos Finitos............... 105

7.2 Formulações Integrais de Contorno.................................................... 109

7.3 Formulação do MEC Para Elasticidade Plana........................................ 110

7.3.1 Dedução da Equação Integral de Contorno......................................... 110

7.3.2 Dedução da Equação Integral de Contorno Para Pontos no Contorno.......... 113

7.3.3 Formulação em Elementos de Contorno............................................ 116

7.3.4 Montagem do Sistema de Equações................................................... 119

7.3.5 Imposição das Condições de Contorno ............................................. 120

7.3.6 Resolução do Sistema de Equações................................................. 121

7.3.7 Cálculo de Parâmetros Adicionais.................................................... 121

7.4 Peculiaridades da Implementação do MEC ......................................... 126 


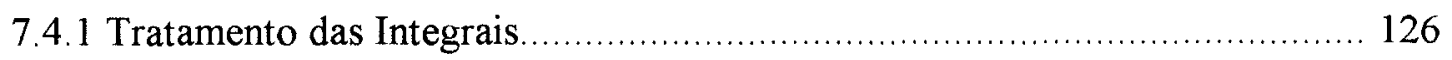

7.4.2 Tratamento de Vértices e Arestas................................................ 137

8 APLICAÇÃO DO MÉTODO DOS ELEMENTOS DE CONTORNO À 139 MECÂNICA DO FRATURAMENTO.

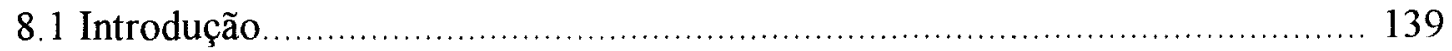

8.2 Formulação do MEC Para o Problema de Tensões Iniciais ........................... 140

8.2.1 Equação Integral de Contorno Para a Aplicação de Solicitações Iniciais em

Pontos do Domínio....................................................................... 140

8.2.2 Equação Integral de Contorno Considerando-se Tensões Iniciais Atuantes em Uma Faixa Estreita................................................................... 141

8.2.3 Formulação em Elementos de Contorno e Elementos de Fratura............... 149

8.3 Contribuição dos Dipolos Para a Abertura de Fratura ................................ 152

8.4 Equação Integral de Contorno Para o Cálculo de Tensões em Pontos Internos 154

8.4.1 Formulação em Elementos de Contorno e Elementos de Fratura................ 155

8.4.2 Tratamento das Integrais Hiper-singulares........................................ 157

9 EXEMPLOS NUMÉRICOS ..................................................... 162

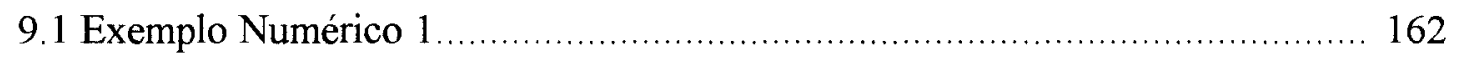

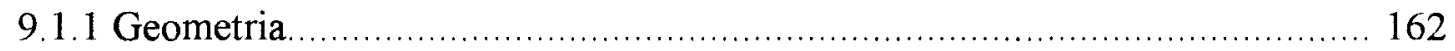

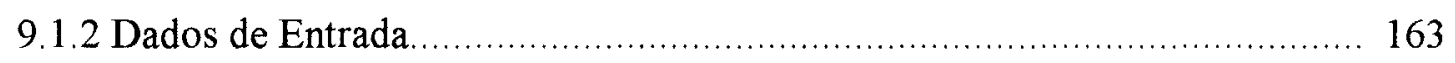

9.1.3 Resultados da Análise ................................................................. 165

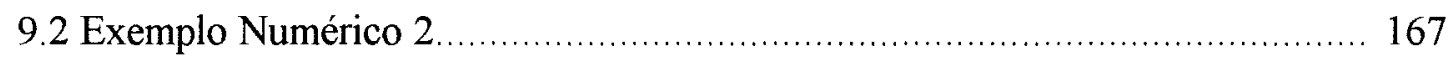

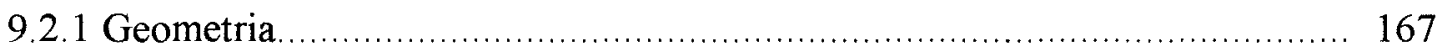

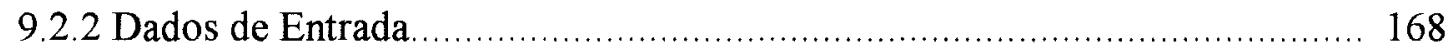

9.2.3 Resultados da Análise ................................................................. 172

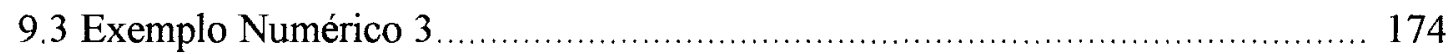

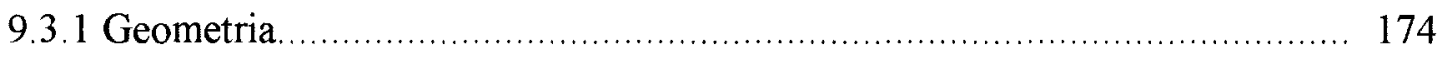

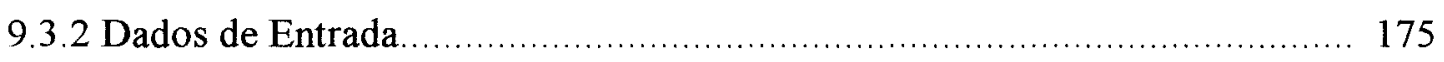

9.3.3 Resultados da Análise ............................................................. 178

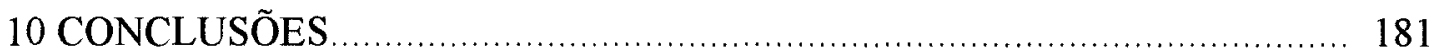




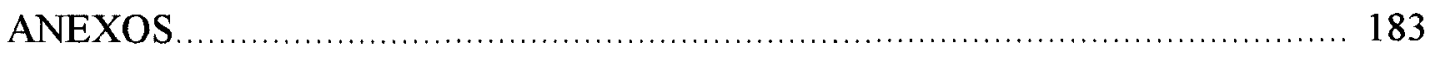

A Formulação Matricial da Análise ........................................................ 184

A. 1 Análise Elástica Linear ................................................................... 184

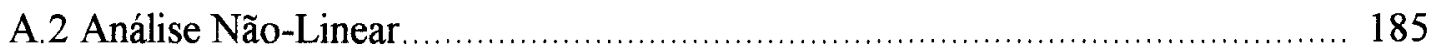

B Algoritmo Utilizado na Análise ........................................................ 187

C Organização do Projeto MEFRECLI ...................................................... 190

D Códigos-Fonte dos Arquivos Constituintes do Projeto MEFRECLI............... 191

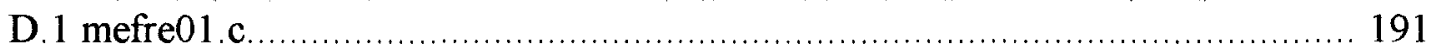

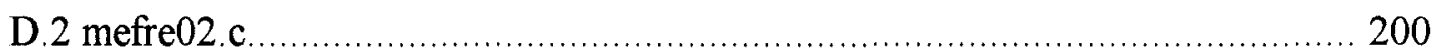

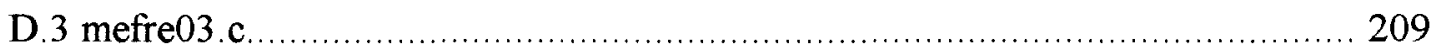

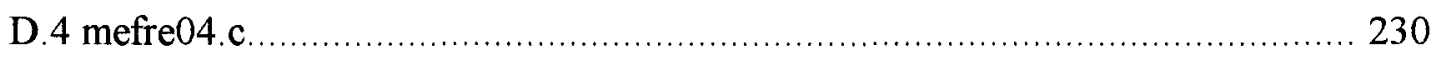

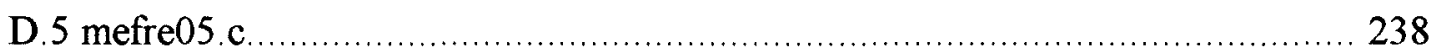

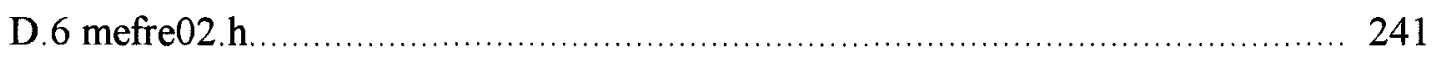

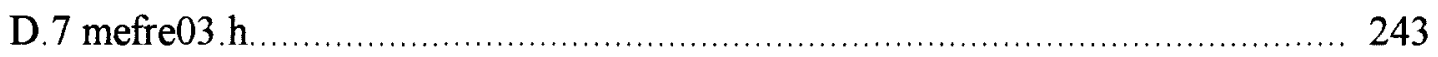

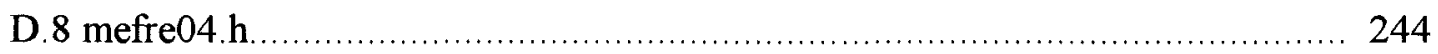

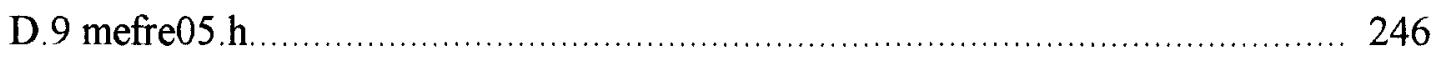

REFERÊNCIAS BIBLIOGRÁFICAS ............................................. 248

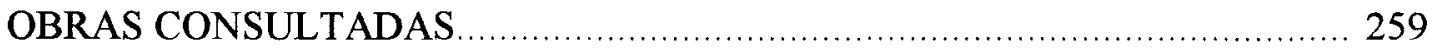

\section{APÊNDICE}

1 Dedução de Algumas Equações do Texto 


\section{LISTA DE FIGURAS}

Figura 3.1 - Um problema de valor de contorno......................................... 21

Figura 3.2 - Classificação dos domínios ................................................. 22

Figura 3.3 - Interpretação geométrica das componentes da solução fundamental... 25

Figura 3.4 - Definição geométrica de integral de Cauchy................................. 26

Figura 3.5 - Definição e utilização da coordenada natural .............................. 32

Figura 3.6 - Definição da função delta de Dirac.......................................... 37

Figura 4.1 - Componentes de tensão referidas às coordenadas cartesianas........... 40

Figura 4.2 - Forças atuando em um tetraedro infinitesimal que representa um elemento de superficie ..................................................... 43

Figura 4.3 - Condições de contorno para um problema bidimensional ................ 44

Figura 4.4 - Exemplos de problemas onde hipóteses simplificadoras podem ser aplicadas.................................................................... 46

Figura 4.5 - Diagramas tensão-deformação............................................... 50

Figura 5.1 - Relações constitutivas...................................................... 53

Figura 5.2 - Exemplos de sensibilidade a malhas grosseiras.......................... 54

Figura 5.3 - Resultados numéricos do exemplo anterior ............................... 55

Figura 5.4 - Diagrama solicitação-deslocamento de estruturas........................ 56

Figura 5.5 - Natureza progressiva da ruína ilustrada pelo puncionamento de uma laje ........................................................................ 57

Figura 5.6 - O efeito de escala da mecânica do fraturamento em estruturas geometricamente semelhantes de portes diferentes. 
Figura 5.7 - Três modos principais de solicitação de um corpo fraturado............. 62

Figura 5.8 - Distribuição de tensões próxima à extremidade de uma fratura......... 65

Figura 5.9 - Coordenadas na extremidade da fratura .................................. 65

Figura 5.10 - Uma fratura central .................................................... 67

Figura 5.11 - Abordagem do balanço de energia de Griffith .......................... 70

Figura 5.12 - Princípios utilizados no MFF................................................ 71

Figura 5.13 - Aplicação da abordagem de fratura discreta ............................. 74

Figura 5.14 - Desenvolvimento de uma zona de fratura de acordo com o modelo de fratura fictícia .......................................................... 74

Figura 5.15 - Dissipação de energia relacionada com os diagramas $\sigma-\varepsilon$ e $\sigma$-w...... 76

Figura 5.16 - Distribuição de tensões, à frente da extremidade de uma fratura ...... 76

Figura 5.17 - Hipóteses aproximadas simples para uso em cálculos numéricos..... 78

Figura 5.18 - Curva de amolecimento ................................................... 80

Figura 5.19 - Propagação de fratura no modo I..................................... 81

Figura 6.1 - Fissuras no concreto descarregado...................................... 89

Figura 6.2 - Teste de tração no concreto ................................................... 90

Figura 6.3 - Curvas tensão-deformação para agregado, cimento e concreto em compressão .................................................................... 91

Figura 6.4 - Algumas características de fissuras....................................... 92

Figura 6.5 - Curva tensão-deformação para o concreto.................................. 93

Figura 6.6 - Uma viga de concreto solicitada.......................................... 96

Figura 6.7 - Esquema de classificação proposto ......................................... 99

Figura 7.1 - Classificação dos métodos numéricos em mecânica do contínuo....... 102

Figura 7.2 - Pontos do contorno no caso bidimensional................................. 114

Figura 7.3 - Diferentes tipos de elementos de contorno ............................... 117

Figura 7.4 - Definição do elemento linear isoparamétrico ............................ 118

Figura 7.5 - Definições geométricas para o cálculo das tensões no contorno........ 125

Figura 7.6-Definições geométricas para o cálculo analítico das integrais singulares ................................................................... 127

Figura 7.7 - Implementação efetiva da integração externa ............................ 134 
Figura 7.8 - Implementação da integração em sub-elementos

Figura 7.9 - Descontinuidades de forças de superficie em vértices

Figura 8.1 - Domínio apresentando região com tensões iniciais.

Figura 8.2 - Sistema de coordenadas.

Figura 8.3 - Definições geométricas para a região de tensão inicial. 143

Figura 8.4 - Definições geométricas para a linha de descontinuidade. 144

Figura 8.5 - Representação dos dipolos constituintes do quadripolo

Figura 8.6 - Representação geométrica do elemento de fratura e caracterização das funções de interpolação para os quadripolos

Figura 8.7 - Ponto de colocação nas proximidade de uma fratura vertical.

Figura 8.8 - Representação geométrica do elemento de fratura e caracterização das funções de interpolação para os quadripolos no caso da integração hiper-singular.

Figura 9.1 - Geometria do exemplo numérico 1.

Figura 9.2 - Gráfico força de superficie-deslocamento para o exemplo numérico 1165

Figura 9.3 - Gráfico tensão-abertura de fratura para o exemplo numérico 1........ 167

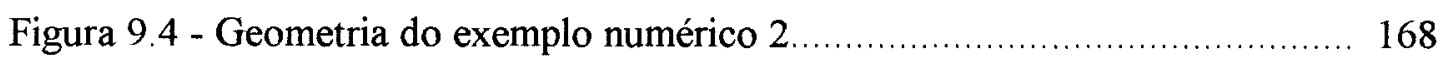

Figura 9.5 - Gráficos força-deslocamento para o exemplo numérico 2 ................. 172

Figura 9.6 - Configuração deformada e padrão de fraturamento para o exemplo numérico 2 .

Figura 9.7 - Geometria do exemplo numérico 3.

Figura 9.8 - Gráfico força-deslocamento para o exemplo numérico 3.

Figura 9.9 - Configuração deformada e padrão de fraturamento para o exemplo numérico 3 


\section{LISTA DE TABELAS}

Tabela 3.1 - Coordenadas naturais e fatores de ponderação para a quadratura de Gauss-Legendre com 12 pontos.

Tabela 6.1 - Períodos característicos na vida útil do concreto e estágios correspondentes de formação de fissuras.

Tabela C.1 - Relacionamento entre os arquivos do projeto computacional desenvolvido. 


\section{NOTAÇÃO}

$\mathrm{x}, \mathrm{y}, \mathrm{z}$ Coordenadas cartesianas (também denominadas 1,2 e 3 , respectivamente).

$\{A\},\left\{A_{i}\right\}, \vec{A} \quad$ Tensor de primeira ordem (vetor).

$\mathrm{b}_{\mathrm{i}} \quad$ Componente $\mathrm{i}$ do vetor.

$\{C\}^{\mathrm{T}} \quad$ Vetor transposto.

$[d],\left[d_{i j}\right] \quad$ Tensor de segunda ordem (matriz).

$\mathrm{E}_{\mathrm{ij}} \quad$ Componente ij da matriz.

$[\mathrm{f}]^{\mathrm{T}},\{\mathrm{f}\}^{\mathrm{T}} \quad$ Tensor transposto.

$\{G\}^{k},[G]^{k} \quad O$ tensor em questão é tomado no ponto ou elemento $\mathrm{k}$.

$\{\mathrm{h}\}_{\mathrm{n}},[\mathrm{h}]_{\mathrm{n}} \quad$ Tensores de valores nodais

$\overrightarrow{\mathrm{a}} \cdot \overrightarrow{\mathrm{b}} \quad$ Indica o produto escalar, ou interno, entre vetores.

(i.ja-c*) Indica as j-ésimas equações do capítulo i, divididas em partes a, b e c. $\mathrm{O}$ asterisco $\left(^{*}\right)$ indica que a dedução da equação é apresentada no apêndice.

[a.b], [a.b.c] Indicam uma seção do texto ('a', 'b' e 'c' são números inteiros).

Termos novos são indicados em negrito e definidos, quando necessário, na primeira vez em que aparecem no texto. 


\section{LISTA DE SÍMBOLOS}

\section{Gregos}

\begin{tabular}{ll}
$\beta$ & Índice de fragilidade. \\
$\gamma$ & Energia especifica de superficie. \\
$\gamma_{\mathrm{xy}}$ & Deformação de cisalhamento. \\
$\delta_{\mathrm{ij}}$ & Delta de Kronecker. \\
$\Delta^{\mathrm{i}}, \delta^{(p)}, \delta(\mathrm{p}, \mathrm{Q})$ & Função Delta de Dirac. \\
$\varepsilon_{\mathrm{ij}}$ & Componente do tensor deformação. \\
$\varepsilon_{\mathrm{x}}$ & Deformação na direção x. \\
$\varepsilon_{\mathrm{y}}$ & Deformação na direção y. \\
{$[\varepsilon]$} & Tensor deformação total. \\
{$\left[\varepsilon^{\mathrm{e}}\right]$} & Tensor deformação elástica. \\
{$\left[\varepsilon^{0}\right]$} & Tensor deformação inicial. \\
$\lambda, \mu$ & Constantes de Lamé. \\
$\nu$ & Coeficiente de Poisson. \\
$\xi$ & Coordenada natural. \\
$\xi_{\mathrm{i}}$ & Coordenada natural do i-ésimo ponto de integração de Gauss. \\
$\sigma_{\mathrm{ij}}$ & Componente do tensor tensão. \\
{$[\sigma]$} & Tensor tensão total. \\
{$\left[\sigma^{\mathrm{e}}\right]$} & Tensor tensão elástica. \\
{$\left[\sigma^{0}\right]$} & Tensor tensão inicial. \\
\hline &
\end{tabular}



$\phi_{\mathrm{i}}$
Função de forma ou de interpolação.
$\omega_{1}$
Fator de ponderação para o ponto correspondente de integração de Gauss.
$\nabla$
Operador gradiente.
$\nabla^{2}$
Operador laplaciano.

\section{Latinos}

a

$a_{c}$

$b_{i}$

$\mathbf{e}_{\mathrm{i}}$

E

$\mathrm{E}_{\mathrm{S}}$

$\mathrm{E}_{\mathrm{C}}$

$f_{t}$

G

$\mathrm{G}_{\mathrm{C}}$

$\mathrm{G}_{\mathrm{F}}$

$\mathrm{G}_{\mathrm{FE}}$

$\mathrm{I}_{\mathrm{CH}}$

$|\mathbf{J}|, \mathbf{J}$

$\mathrm{K}$

$\mathbf{K}_{\mathrm{C}}$

$\mathrm{K}_{\mathrm{I}}, \mathrm{K}_{\mathrm{II}}, \mathrm{K}_{\mathrm{II}}$

Metade do comprimento de uma fratura.

Comprimento crítico de fratura.

Força volumétrica atuante na direção i.

Versor na direção i do sistema cartesiano de coordenadas.

Módulo de elasticidade longitudinal ou módulo de Young.

Módulo de elasticidade longitudinal do aço.

Módulo de elasticidade longitudinal do concreto.

Resistência à tração.

Módulo de elasticidade transversal ou módulo de cisalhamento

Também taxa de liberação de energia.

Taxa crítica de liberação de energia.

Energia de fraturamento.

$\mathrm{G}_{\mathrm{F}}$ experimental.

Comprimento característico de fratura.

Jacobiano.

Fator de intensidade de tensão.

Fator de intensidade de tensão crítico.

Fatores de intensidade de tensão nos modos I, II e III, respectivamente.

$1_{\text {ef }} \quad$ Comprimento de um elemento de fratura.

(n) Normal à superfície.

p Ponto de carga, fonte ou ponto de colocação.

\{p\} Força de superficie ("traction"). 


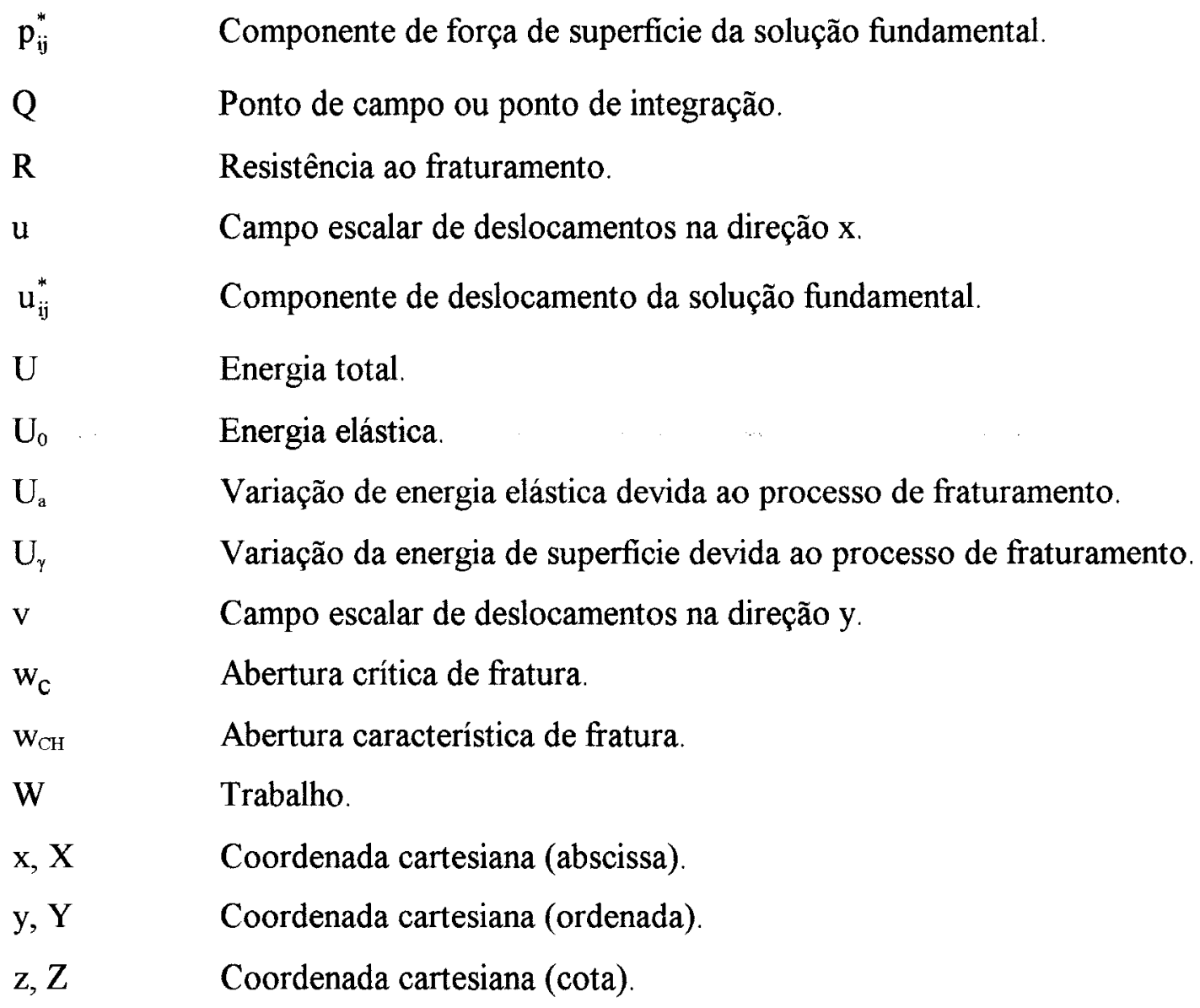




\section{RESUMO}

LOPES JR., M. C. Modelagem numérica do crescimento de fraturas através do método dos elementos de contorno. São Carlos, 1996. 261p. Dissertação (Mestrado) - Escola de Engenharia de São Carlos, Universidade de São Paulo.

Desenvolvem-se a formulação do Método dos Elementos de Contorno e correspondente algoritmo (para implementação em microcomputador) para a análise de propagação de fraturas em domínios bidimensionais. São utilizados elementos lineares isoparamétricos, tanto para discretizar o contorno quanto para simular a fratura. Os elementos de fratura são descontínuos.

A formulação é baseada em equações integrais de tensões e de deslocamentos, onde o termo que considera tensões iniciais concentradas na linha de fratura é formulado a partir da definição de dipolos. $O$ critério adotado é o modelo de fratura coesiva. Os termos singulares e hiper-sigulares da formulação são tratados analiticamente e os termos quase-singulares são calculados através de um esquema numérico baseado na utilização de sub-elementos.

Os valores dos dipolos são estimados ponto a ponto. Ao longo das fraturas, o valor máximo da tensão normal de tração permite definir novos elementos. As tensões de cisalhamento são removidas para manter a direção principal durante o processo.

Palavras-chave: Método dos Elementos de Contorno, Mecânica da Fratura, Concreto (Estruturas). 


\section{ABSTRACT}

LOPES JR., M. C. Numerical modelling of crack growth through boundary elements method. São Carlos, 1996. 261p. Dissertação (Mestrado) - Escola de Engenharia de São Carlos, Universidade de São Paulo.

The Boundary Element Method formulation and corresponding algorithm (for microcomputer implementation) are developed for crack growth analysis in twodimensional domains. Linear isoparametric elements are used to discretize both boundary and crack path. Fracture elements are assumed to be discontinuous.

The formulation is based on stress and displacement integral equations, where the term that takes into account initial stresses concentrated along fracture line is formulated from dipoles definition. The coesive fracture model is the criterium adopted. Singular and hipersingular formulation terms are anallitically treated and quasi-singular terms are computed by a numerical scheme based on element subdivision.

Dipole values are estimated point by point. Along fractures, the maximum normal tensile strenght is used to define new elements. Shear stresses are also removed to maintain the principal direction during the process.

Keywords: Boundary Element Method, Fracture Mechanics, Concrete (Structures). 



\section{INTRODUÇÃ̃O}

Atualmente, o concreto é o material mais utilizado de construção civil, encontrando amplas possibilidades de aplicação em engenharia, seja empregado sozinho (concreto simples), seja em combinação com outros materiais (concreto armado, concreto reforçado com fibras etc.), em barragens, pavimentação, estruturas de edifícios etc. Na opinião de MEHTA \& MONTEIRO (1994), "o futuro do concreto é extremamente promissor, pois é capaz de fornecer durabilidade e propriedades mecânicas excelentes a um baixo custo, além de sua utilização gerar significantes beneficios ecológicos ao incorporar resíduos de outras indústrias em sua produção."

No entanto, apesar de poder ser chamado de material de construção universal, o concreto está longe de ser considerado perfeito, pois as estruturas de concreto também apresentam desvantagens: seu comportamento mecânico, por exemplo, é extremamente complexo e uma das causas dessa complexidade é a existência de um grande número de fissuras.

A preocupação com fissuras se justifica porque as mesmas podem provocar vários problemas. A presença de fissuras descaracteriza a aparência monolítica da construção e pode indicar problemas estruturais mais graves. No caso particular do concreto armado, podem expor a armadura a oxigênio e umidade, tornando o aço mais suscetível à corrosão. Além disso, sua presença aumenta o tempo e o esforço gastos em manutenção e reparo. 
Sabe-se que os agentes responsáveis pelo surgimento de fissuras podem conduzir à fratura de componentes e, conseqüentemente, à ruína estrutural, colocando em risco vidas humanas nos casos extremos. O colapso de estruturas de concreto geralmente é precedido pelo crescimento estável de zonas de fissuração e pela formação de fraturas de grande porte antes que a solicitação máxima seja alcançada.

As causas específicas da fissuração são várias e as fissuras podem surgir como pequenas falhas inerentes ao processo de fabricação do material ou podem ser o resultado de danos à estrutura como um todo. Além de serem normalmente causadas por tensões que surgem devidas à limitação de mudança volumétrica (ou a solicitações aplicadas à estrutura), as fissuras são consideradas, atualmente, as grandes responsáveis pelo comportamento não-linear do material.

Existem técnicas capazes de minimizar o aparecimento de fissuras. Por exemplo, o uso de armadura de pele convenientemente distribuída (nas zonas tracionadas) limita a abertura das fissuras, tornando-as capilares. Obtém-se efeito semelhante com a utilização de protensão. No entanto, já que as fissuras não podem ser completamente eliminadas, faz-se necessário idealizar procedimentos para quantificar e predizer o comportamento de estruturas fissuradas sob condições de serviço. Bem entendido: modelos devem ser definidos para caracterizar as fissuras, bem como seus efeitos, e para predizer se - e quando - elas podem se constituir em um fator de insegurança durante a utilização das estruturas, levando-se em conta as finalidades para que foram projetadas.

A Mecânica do Fraturamento é a teoria utilizada na quantificação e previsão de resistência, durabilidade e segurança de componentes estruturais que contenham fissuras ou defeitos semelhantes.

Atualmente, pode-se dizer que a introdução da mecânica do fraturamento nos critérios de projeto e na análise de ruínas frágeis de estruturas de concreto armado (tais como em cisalhamento diagonal, cisalhamento de punção, torção ou arrancamento) pode produzir beneficios significativos, especialmente no que diz respeito à obtenção de margens de segurança mais uniformes (principalmente quando 
são consideradas estruturas de tamanhos diferentes). Isto, por sua vez, aumentará tanto a economia quanto a confiabilidade estutural.

A mecânica do fraturamento poderá ser particularmente importante para a análise de estruturas de concreto de alto desempenho (alta resistência), estruturas de concreto reforçado com fibras, estruturas de concreto de porte excepcionalmente grande e estruturas protendidas. A aplicação da mecânica da fratura é mais urgente em estruturas tais como barragens de concreto ou estruturas de confinamento de reatores nucleares, onde a preocupação com segurança é particularmente alta e as conseqüências de um desastre potencial, enormes.

Obviamente, a compreensão dos comportamentos de concreto e aço, bem como do contato entre os mesmos, deve preceder um estudo a respeito do concreto armado. Neste sentido, este trabalho apresenta uma formulação desenvolvida com a finalidade de analisar o processo de fraturamento de materiais que exibam comportamento frágil. Em particular, a formulação é aplicada à modelagem do concreto simples.

Cumpre ressaltar que as soluções analíticas existentes para problemas de mecânica do fraturamento limitam-se a um pequeno número de situações idealizadas, onde o domínio é considerado infinito, homogêneo e isotrópico, sendo solicitado de forma relativamente simples. Por outro lado - como é o caso em aplicações práticas — os problemas de mecânica do fraturamento ocorrem em estruturas contendo falhas, de tamanho finito e submetidas a solicitações complexas. Isto conduz, freqüentemente, à utilização de métodos numéricos (neste caso, o Método dos Elementos de Contorno, MEC) para abordar o problema em questão: surgimento e propagação de fraturas em estruturas de concreto.

A implementação do método dos elementos de contorno é feita considerandose o material como elástico linear e corrigindo-se a solução encontrada através da combinação de técnicas de análise não-linear, de modo a levar em conta a existência da não-linearidade física do material. Isto posto, é possível listar os objetivos pretendidos pelo presente trabatho: 


\section{Geral}

- Desenvolvimento de uma formulação do MEC para a modelagem do surgimento de fraturas mecânicas e acompanhamento de sua evolução.

\section{Específicos}

- Desenvolver um programa do MEC para a análise plana elástica linear utilizando elementos lineares contínuos e descontínuos.

- Desenvolver a formulação do MEC para modelagem de fraturamento a partir de um estado inicial de tensões.

- Desenvolver um elemento de fratura linear isoparamétrico.

- Desenvolver um programa para modelagem de propagação de fraturas, considerando-se o modelo coesivo.

Os demais capítulos do trabalho estão organizados da seguinte maneira:

o CAPítulo 2 apresenta uma revisão bibliográfica, descrevendo o desenvolvimento histórico do tema, visando a situar o presente trabalho no contexto do estado da arte dos métodos numéricos aplicados à mecânica do fraturamento.

o CAPítulo 3 contém a base matemática necessária à compreensão do restante do texto. Nele, são encontrados temas como notação indicial, teoremas de Green e esquemas de integração numérica, dentre outros. Optou-se por agrupar estes ítens em um capítulo único em lugar de descrevê-los dentro dos capítulos relevantes.

o CAPÍTULO 4 é dedicado ao estabelecimento das equações fundamentais que regem os comportamentos elástico e elasto-plástico de sólidos. As hipóteses que permitem a simplificação da análise de estruturas tridimensionais são comentadas. 
Também são introduzidos os estados iniciais de tensão e deformação. Além disso, a não-linearidade física é considerada.

O CAPÍTULO 5 oferece razões para a introdução da mecânica do fraturamento em certos aspectos do projeto de estruturas de concreto e apresenta, também, conceitos e hipóteses básicos para a compreensão do fenômeno. Estes incluem: diferentes modos de fraturamento, fundamentos da mecânica do fraturamento elástica linear, conceitos de estabilidade de crescimento de fraturas, fator de intensidade de tensões e balanço de energia de Griffith. Alguns conceitos de modelagem numérica também são tratados, bem como é fornecida uma descrição sucinta dos diferentes métodos de abordagem existentes.

O comportamento mecânico do concreto (sob o enfoque da mecânica do fraturamento) é tratado no CAPÍTULO 6. São feitas algumas considerações sobre o desenvolvimento do material, bem como sobre suas vantagens e desvantagens. Discute-se a aplicabilidade da mecânica do fraturamento elástica linear e apresentamse alguns aspectos relacionando o processo produtivo ao surgimento de fissuras. $\mathrm{O}$ comportamento não-linear do concreto é comentado, ao tempo em que são apresentados alguns modelos correspondentes.

O método dos elementos de contorno é abordado no CAPítuLO 7. Primeiramente, é posicionado em relação a outros métodos numéricos existentes. Em seguida, a formulação para análise elástica linear é desenvolvida em etapas. Atenção especial é dada a aspectos peculiares da implementação do método, dentre eles o cálculo analítico das integrais singulares e quase-singulares e o tratamento de vértices do contorno.

A aplicação do MEC à análise do processo de fraturamento é feita no CAPÍTULO 8. A formulação utilizada para modelar o comportamento não-linear foi desenvolvida considerando-se a técnica de correções sucessivas do comportamento elástico linear através da combinação de algoritmos incrementais e iterativos. A abordagem utilizada consistiu em relacionar a retirada de tensões à aplicação de quadripolos ao longo de elementos fictícios, convenientemente introduzidos onde o 
surgimento ou propagação de fraturas fosse verificado. $O$ algoritmo de Kutt foi utilizado no tratamento das integrais hiper-singulares da formulação.

No CAPÍTULO 9, são mostrados exemplos de aplicação da formulação desenvolvida no capítulo 8 .

O CAPÍTULO 10 é reservado para as conclusões do trabalho.

Em se tratando de um trabalho de domínio público, faz-se mister a inclusão tanto do código fonte do programa computacional desenvolvido (em linguagem $\mathrm{C}$ ) quanto do algoritmo utilizado. Ambos foram incluídos nos ANEXOS, juntamente com uma descrição da formulação matricial empregada e do projeto computacional desenvolvido.

Após as REFERÊNCIAS BIBLIOGRÁfICAS e as OBRAS CONSULTADAS, encontra-se o APÊNDICE, que contém a dedução de algumas das equações do texto. Estas equações foram escolhidas devido à importância que têm para a compreensão do trabalho. Como as demonstrações podem ser longas, optou-se por fazê-las no apêndice, a fim de facilitar a leitura do texto. 


\section{REVISÃO DA LITERATURA}

\subsection{O Método dos Elementos de Contorno}

A década de 60 marcou o início do desenvolvimento de computadores de grande porte, possibilitando a solução dos problemas de engenharia através de métodos numéricos. A coincidência existente entre os avanços no desenvolvimento tanto de computadores digitais quanto de linguagens de programação (ocorridos principalmente nas décadas de 60 e 70) e o surgimento dos métodos numéricos pode não parecer evidente à primeira vista. Porém, sem a existência de recursos adequados de "software" e "hardware", seria extremamente dificil - para não dizer impossível - gerar e resolver os sistemas de equações provenientes das formulações, utilizadas na época, para a resolução dos problemas existentes.

O método dos elementos finitos foi rapidamente adotado por conta de sua versatilidade, aliada à capacidade de descrição mais realista dos problemas de engenharia. COOK et al. (1989) afirmam que o termo foi introduzido por Clough em 1960. A princípio, a utilização do método baseava-se principalmente em intuição e argumentação física. Por volta de 1963, estabeleceu-se a base matemática do método: poderia ser considerado como a resolução de um problema variacional através da minimização de um funcional. Desta forma, poderia ser aplicado a qualquer problema que pudesse ser formulado de forma variacional. 
Entretanto, do ponto de vista prático, o método apresentava dificuldades relacionadas principalmente à quantidade de informação necessária para modelar um problema (cf. [7,1]).

No início da década de 70, segundo MACKERLE \& BREBBIA (1988), começou-se a procurar uma alternativa às dificuldades acima. Basicamente, o que se pretendia era desenvolver técnicas que se adaptassem melhor à resolução de problemas de grande porte - principalmente os tridimensionais. Dentre as opções possíveis, encontravam-se as seguintes:

- Técnicas de Redução, úteis para certas aplicações, porém dificeis de generalizar. Deram origem a métodos tais como a técnica de faixas finitas (para pontes e edificios altos), diferenças finitas arbitrárias, métodos matriciais de transferência etc.

- Princípios Variacionais Mistos, em combinação com elementos finitos (WASHIZU (1975)).

- Técnicas de Equações Integrais de Contorno, até então consideradas como um tipo diferente de método analítico, pouco relacionado às técnicas aproximadas utilizadas em engenharia.

Diversos livros e artigos sobre a aplicação de equações integrais à teoria do potencial e da elasticidade foram escritos. Os assim chamados métodos integrais tornaram-se conhecidos na Europa ocidental através dos trabalhos de uma série de matemáticos russos, tais como KELLOG (1929), MUSKHELISHVILI (1953), MIKHLIN (1957) e KUPRADZE (1965).

Os métodos modernos de equações integrais de contorno estão diretamente relacionados ao trabalho de FREDHOLM (1903) ${ }^{1}$, que utilizou equações integrais 
discretizadas para tratar problemas de potencial, formando a base para a abordagem indireta (cf. [7.2]) do MEC. Essa abordagem é mencionada como indireta porque faz uso de funções de densidade (ou fontes) fictícias, sem significado físico, mas que podem ser utilizadas no cálculo de grandezas físicas como deslocamentos e tensões.

$\mathrm{Na}$ opinião de BECKER (1992), o primeiro a adotar a abordagem direta (cf. [7.2]) de utilizar deslocamentos e forças de superficie em uma equação integral aplicável ao contorno foi RIZZO (1967). Seu trabalho foi o primeiro a explorar a analogia entre as teorias de potencial e da elasticidade clássica e a imaginar uma forma numérica de resolver o problema. Ele usou elementos retilíneos para discretizar o contorno onde as funções (neste caso, deslocamentos e forças de superficie) assumiam valores constantes em cada elemento. A regra de Simpson foi utilizada para as integrais não-singulares.

Entretanto, para MACKERLE \& BREBBIA (1988), KUPRADZE (1965) e CRUSE (1968) estão entre os primeiros pesquisadores a trabalhar com a formulação direta do MEC - este último na aplicação das equações integrais de contorno à resolução de problemas de elastodinâmica.

Em 1963, houve a publicação de dois artigos clássicos por JASWON (1963)² e SYMM (1963) ${ }^{3}$. Estes trabalhos abordavam problemas bidimensionais de potencial regidos pela equação de Laplace e trouxeram uma contribuição notável à resolução de integrais de contorno. A técnica utilizada consistia em discretizar as equações integrais em elementos retilíneos, sobre os quais as funções de potencial eram assumidas constantes. Os elementos foram descritos em termos de pontos nodais e as integrações efetuadas através da regra de Simpson, exceto algumas integrais singulares que o foram analiticamente. Esta abordagem pode ser classificada como semi-direta (cf. [7.2]) porque as funções utilizadas para formular o problema não

${ }^{2}$ JASWON, M. A. Integral equation method in potential theory - I. Proc. Roy. Soc. Lond., v. A275, p. 23-32, 1963 apud BECKER (1992).

${ }^{3}$ SYMM, G. T. Integral equation methods in potential theory - II. Proc. Roy. Soc. Lond., v. A275, p. 33-46, 1963 apud BECKER (1992). 
eram fictícias, podendo ser diferenciadas ou integradas para calcular as quantidades físicas.

JASWON \& PONTER (1963) publicaram um artigo sobre a solução da equação integral do problema da torção. Formularam o problema em termos das funções de torção, utilizando uma equação integral do segundo tipo, e o resolveram numericamente, encontrando a rigidez à torção e as tensões de cisalhamento no contorno. Outras abordagens semelhantes de equações integrais foram adotadas por HESS \& SMITH (1967), para tratar problemas de fluxo de potencial em torno de formas arbitrárias, e HARRIGTON et al. (1969) em problemas bidimensionais de engenharia elétrica.

CRUSE (1969) estendeu a abordagem direta de equações integrais a problemas tridimensionais, seguindo uma formulação muito parecida com o trabalho de Rizzo, exceto pelo fato de a superfície ser discretizada em elementos triangulares planos, com deslocamentos e forças de superficie assumidos constantes em cada elemento. $\mathrm{O}$ trabalho de Cruse foi continuado em duas publicações posteriores: a primeira, para incluir aplicações tridimensionais práticas e comparar com o MEF (CRUSE (1973)) e, a segunda, usando elementos curvos com variáveis lineares em cada elemento (CRUSE (1974)).

Durante o período inicial de desenvolvimento (de 1967 a 1972), as formulações integrais de contorno foram estendidas de forma a tratar problemas nãohomogêneos contendo inclusões (RIZZO \& SHIPPY (1968), problemas de elastodinâmica (CRUSE (1968) e CRUSE \& RIZZO (1968)), elastoplasticidade (SWEDLOW \& CRUSE (1971)), materiais anisotrópicos (CRUSE \& SWEDLOW (1971)) e mecânica do fraturamento tridimensional (CRUSE \& VAN BUREN (1971) e CRUSE (1972)). Essas publicações foram fundamentais por fornecerem uma base sólida para o desenvolvimento posterior do método e por demonstrarem que a abordagem de elementos de contorno constituía-se em uma ferramenta numérica potente e precisa. 
Segundo BECKER (1992), o crédito pela "invenção" das técnicas integrais de contorno deve ser dado a M. A. Jaswom, G. T. Symm, F. J. Rizzo e T. A. Cruse. As publicações de Cruse (1968 - 1973) foram as primeiras a demonstrar a precisão da técnica de elementos de contorno, não apenas em problemas de elastostática tridimensional, mas também de elastodinâmica, anisotropia, plasticidade e mecânica do fraturamento.

Houve um progresso ainda maior durante a década de 70 , onde começou a ficar claro que a abordagem do MEC oferecia uma excelente alternativa, em relação a elementos finitos, para a resolução de muitos problemas práticos. Desde então, a abordagem do MEC continua a se desenvolver a passo rápido e foi estendida de forma a abranger um espectro amplo da mecânica do contínuo, incluindo-se aplicações não-lineares avançadas.

No decorrer do tempo, as formulações de equações integrais têm sido mencionadas como Método da Equação Integral de Contorno ou Método dos Elementos de Contorno.

Na opinião de DOMINGUEZ (1993), o termo Método dos Elementos de Contorno foi utilizado pela primeira vez em 1977, aparecendo em, pelo menos, três publicações: a tese de Ph. D. de DOMINGUEZ (1977), um artigo de BANERJEE \& BUTTERFIELD (1977) e um outro de autoria de BREBBIA \& DOMINGUEZ (1977). Existe alguma dúvida relacionada a quem teria utilizado primeiramente a sigla BEM (Boundary Element Method).

\subsection{Mecânica do Fraturamento}

A mecânica do fraturamento foi primeiramente estudada abordando-se materiais frágeis, como o vidro, por GRIFFITH (1920) (cf. [5.4]). Desde então, tem 
sido aplicada a uma grande faixa de materiais e componentes diferentes, tornando-se um ramo importante da engenharia.

MINDESS fornece uma revisão histórica (1983a) e apresenta uma revisão bibliográfica comentada da aplicação da mecânica do fraturamento a cimento e concreto (1983b). Segundo MINDESS (1983a), o fraturamento de pasta de cimento endurecida e de concreto começou a ser estudado seriamente a partir do trabalho de RICHART et al $(1928)^{4}$, que analisaram o desenvolvimento de fissuras em concreto submetido a compressão.

Para ELFGREN (1989a), as primeiras aplicações para o concreto parecem ter sido feitas por NEVILLE (1959) ${ }^{5}$, com a sugestão de que o efeito de escala (cf. [5.1.5]) sobre a resistência do concreto poderiam estar relacionados à distribuição aleatória de falhas de Griffith. Além disso, o primeiro estudo experimental da aplicabilidade da mecânica do fraturamento ao concreto teria sido conduzido por KAPLAN (1961) ${ }^{6}$, que executou ensaios de flexão em vigas de concreto com entalhe e calculou $\mathrm{G}_{\mathrm{C}}$, a taxa de liberação de energia de deformação crítica (cf. [5.4]). Kaplan concluiu que "o conceito (de Griffith) de uma taxa de liberação de energia de deformação crítica como sendo uma condição para a propagação rápida, $e$ conseqüente fratura, é aplicável ao concreto."

A aplicação da mecânica do fraturamento a estruturas de concreto tem proporcionado novas maneiras de compreender e modelar os fenômenos que, anteriormente, só poderiam ser tratados empiricamente. Existe um interesse internacional crescente nessas questões e que se reflete na literatura publicada recentemente. Alguns trabalhos cobrindo as principais partes do desenvolvimento foram apresentados por WITTMANN $(1983,1986)$, BAZANT $(1985,1986)$, SHAH

\footnotetext{
${ }^{4}$ RICHART, F. E.; BRANDTZAEG, A.; BROWN, R. L. Bulletin no 105. Engineering Experiment Station. University of Illinois, 1928. 104p apud MINDESS (1983a).

${ }^{5}$ NEVILLE, A. M. Some aspects of the strength of concrete. Civil Engineering, v. 54, p. 11531156, 1308-1310, 1435-1439, 1959 apud ELFGREN (1989a).

${ }^{6}$ KAPLAN, F. M. Crack propagation and the fracture of concrete. J. American Concrete Institute, v. 58, p. 591-610, 1961 apud ELFGREN (1989a)
} 
$(1985)^{7}$, CARPINTERI \& INGRAFFEA (1984), SIH \& DI TOMMASO (1985), REINHARDT (1986) ${ }^{8}$ e CARPINTERI (1986).

\subsection{Aplicação do Método dos Elementos de Contorno à Mecânica do Fraturamento}

Problemas tridimensionais de mecânica do fraturamento foram tratados no princípio do desenvolvimento geral do MEC por CRUSE \& VANBUREN (1971), que consideraram uma fratura plana em um bloco retangular. Tratada como um problema simétrico, a geometria da fratura idealizada não apresenta dificuldades, sendo necessário apenas considerar a modelagem do campo singular da extremidade da fratura. Isto é feito através da discretização das superficies de fratura através de uma malha graduada de elementos triangulares constantes, com dimensões reduzindo em direção à extremidade da fratura. Os fatores de intensidade de tensão são calculados por extrapolação de deslocamentos.

Subseqüentemente, em um importante artigo, CRUSE (1973) mostrou a utilização do MEC em problemas bidimensionais e tridimensionais de mecânica do fraturamento, incluindo uma comparação favorável com o método dos elementos finitos e apontando as vantagens da modelagem e discretização do contorno pelo MEC. Um procedimento mais geral foi considerado para modelar a geometria da fratura. Uma vez que, como observado, o MEC usual é incapaz de distinguir entre duas superfícies no mesmo plano, a fratura é modelada como duas superficies

7 SHAH, S. P., ed. Application of fracture mechanics to cementitious composites. Dordrecht, Martinus Nijhoff, 1985. (NATO ASI Series, Serie E, Applied Sciences - n. 94) apud ELFGREN (1989a)

8 REINHARDT, H. W. The role of fracture mechanics in rational rules for concrete design. IABSE Periodica, n. 1, IABSE surveys, S-34/86, 1986 apud ELFGREN (1989a) 
separadas por uma distância pequena - mas finita - e ligadas por uma curva elíptica. Embora este modelo não seja ideal, permite que problemas assimétricos sejam analisados.

Elementos lineares são utilizados para analisar tensões em CRUSE (1974). A dificuldade existente no cálculo de integrais singulares para obter os coeficientes de deslocamento é superada pela introdução do conceito de cálculo dos termos diagonais via somas de linha.

Uma extensão posterior a elementos de ordem superior (cf. [7.3.3]) é descrita por BESUNER \& SNOW (1975), que usam geometria reta ou parcialmente circular, combinada com variações quadráticas de deslocamentos e forças de superficie, para resolver problemas bidimensionais de mecânica do fraturamento. É feita uma comparação entre o método dos elementos finitos e o método dos elementos de contorno, utilizando-se elementos semelhantes aos do tipo CST e um número semelhante de nós no contorno. A precisão obtida no segundo caso, em um tempo computacional menor, é muito maior. A utilização da taxa de liberação de energia de deformação ( $G$, cf. [5.4], a rigor, taxa de liberação de energia potencial) para encontrar os fatores de intensidade de tensão (FIT, cf. [5.3.1]) tem a desvantagem de serem necessários dois cálculos no MEC, mas a vantagem de as funções de ponderação poderem ser calculadas de forma simples.

A utilização de G no cálculo dos FIT's em problemas tridimensionais é feita por CRUSE \& MEYERS (1977), que acham esse método mais preciso que a fórmula de deslocamento de um ponto.

Elementos isoparamétricos padrões, de forma polinomial, não se adaptam bem à modelagem da variação de $V_{r}$ (distância em relação à extremidade de fratura) próximo às extremidades de fratura e taxas de convergência melhoradas não podem ser obtidas simplesmente aumentando-se o grau das funções de interpolação. Elementos isoparamétricos, refletindo a natureza dos campos na extremidade de fraturas, foram desenvolvidos independentemente, no contexto do MEF, por BARSOUM (1974) e HENSHELL \& SHAW (1975). O uso de tais elementos 
empregando a técnica "quarter point", juntamente com as modificações necessárias para incorporar as singularidades de força de superficie no $\mathrm{MEC}$, foi examinado por CRUSE \& WILSON (1977), utilizando o programa de elementos quadráticos tridimensionais de LACHAT \& WATSON (1975) para analisar um problema tridimensional simétrico.

O MEC direto usual para elasticidade baseia-se nas soluções fundamentais (ou funções de Green, cf. [3.3]) $u_{i j}^{*}$ e $p_{i j}^{*}$ da equação de Navier, que fornecem os deslocamentos e forças de superficie provenientes de uma carga concentrada em um ponto arbitrário situado numa região elástica infinita. SNYDER \& CRUSE (1975) mostraram que uma solução fundamental para um sólido bidimensional infinito, contendo uma única fissura reta e livre de forças de superficie, poderia ser desenvolvida - um método implícito de mecânica do fraturamento. Na análise de uma região finita contendo uma fissura desse tipo, apenas o contorno da região precisou ser modelado, sendo os efeitos devidos às superficies de fratura implicitamente considerados na nova solução.

O método implícito de fratura requer o uso de funções de variável complexa para calcular um termo adicional (real) no esquema de integração do MEC usual. A estensão desse método a elementos lineares origina problemas posteriores de análise complexa e aponta erros anteriores (CRUSE (1978)). Esta técnica tanto é elegante quanto precisa, mas a integração é mais custosa do que no MEC convencional, e não pode ser estendida (de modo geral) a problemas de fratura tridimensional ou curva.

MEWS (1987) utilizou o método implícito de mecânica do fraturamento em problemas do modo misto, fraturas ramificadas e fraturas solicitadas (que requerem o cálculo de integrais de superficie de fratura).

A técnica de subtração de singularidade foi introduzida no contexto de equações integrais por SYMM (1973), para a solução de problemas de potencial, e por ALIABADI (1987), para elasticidade. Em uma região linear elástica contendo uma singularidade, as soluções para $u$ e p podem ser separadas (usando-se 
superposição) em duas componentes: uma parte suave e outra singular, devida à extremidade da fratura. Se K (cf. [5.3.1]) for conhecido, as contribuições singulares podem ser subtraídas das condições de contorno aplicadas em cada nó e, então, o MEC fornecerá a parte suave da solução.

Diversas estratégias para a modelagem de corpos fraturados tridimensionais são citadas por RAVEENDRA \& CRUSE (1989).

ROCHA \& VENTURINI (1988) utilizaram uma formulação de elementos de contorno para modelar descontinuidades em domínios bidimensionais. Enfatizou-se como o termo integral - empregado para modelar a redução de tensões ao longo de todas as descontinuidades - poderia ser introduzido nas equações integrais usuais. Foi proposto um algoritmo não-linear para modelar o comportamento do material.

Neste trabalho, a formulação utilizada para modelar o comportamento nãolinear foi desenvolvida considerando-se a técnica de correções sucessivas do comportamento elástico linear através da combinação de algoritmos incrementais e iterativos. A abordagem utilizada consistiu em relacionar a retirada de tensões à aplicação de quadripolos ao longo de elementos fictícios, convenientemente introduzidos onde o surgimento ou propagação de fraturas fosse verificado. 


\section{BASE MATEMÁTICA}

Aqui, faz-se uma discussão breve de alguns tópicos que foram selecionados por sua relevância à compreensão do trabalho. Nos capítulos seguintes, serão feitas referências a algumas das teorias aqui apresentadas, em vez de tentativas de descrevêlas nas seções do texto onde são aplicáveis.

Os conceitos são apresentados da maneira mais informal possível, sem a pretensão de manter um rigor matemático muito elevado. Admite-se que sejam conhecidos os conceitos de álgebra vetorial. Caso haja necessidade de maior aprofundamento nos temas, os textos seguintes poderão ser utilizados: LAI et al. (1986), BREBBIA \& DOMINGUEZ (1989), KREYSZIG (1988), COOK et al. (1989), BAJPAI et al. (1977), CAKMAK et al. (1987) e ZAGOTIS (1984).

\subsection{Notação Indicial}

\subsubsection{Convenção de Somatório, Índices Mudos}

Seja o somatório

$$
\mathrm{s}=\mathrm{a}_{1} \mathrm{x}_{1}+\mathrm{a}_{2} \mathrm{x}_{2}+\cdots+\mathrm{a}_{\mathrm{n}} \mathrm{x}_{\mathrm{n}}=\sum_{\mathrm{i}=1}^{\mathrm{n}} \mathrm{a}_{\mathbf{i}} \mathrm{x}_{\mathrm{i}}
$$


Como a soma independe da letra utilizada como índice, diz-se que o índice $\mathrm{i}$, na eq. (3.1) é um índice mudo. A eq. (3.1) pode ser simplificada e, para tanto, é suficiente adotar-se a seguinte convenção: a repetição de um índice, uma única vez, indica um índice mudo e, portanto, um somatório com o índice assumindo valores inteiros $1,2, \ldots, n$. Esta é conhecida como a convenção de somatório de Einstein. Utilizando-a, a eq. (3.1) reduz-se a

$$
\mathrm{s}=\mathrm{a}_{\mathrm{i}} \mathrm{x}_{\mathrm{i}}
$$

A repetição de um índice mais de uma vez não está definida pela convenção, mas a repetição de mais de um índice, uma única vez, pode representar um somatório múltiplo.

\subsection{2 Índices Livres}

Seja o seguinte sistema de três equações

$$
\begin{aligned}
& y_{1}=a_{11} x_{1}+a_{12} x_{2}+a_{13} x_{3} \\
& y_{2}=a_{21} x_{1}+a_{22} x_{2}+a_{23} x_{3} \\
& y_{3}=a_{31} x_{1}+a_{32} x_{2}+a_{33} x_{3}
\end{aligned}
$$

Utilizando-se a convenção de somatório, obtém-se

$$
\begin{aligned}
& y_{1}=a_{1 n} x_{n} \\
& y_{2}=a_{2 n} x_{n}, \\
& y_{3}=a_{3 n} x_{n}
\end{aligned}
$$

que podem ser simplificadas para

$$
\mathrm{y}_{\mathrm{m}}=\mathrm{a}_{\mathrm{mn}} \mathrm{x}_{\mathrm{n}}, \quad \mathrm{m}=1,2,3
$$


$\mathrm{O}$ índice $\mathrm{m}$, que aparece uma, e somente uma, vez em cada membro da equação, é chamado de índice livre, assumindo valores inteiros, um de cada vez. Uma equação pode ter mais de um índice livre. Neste caso, cada índice livre deve obedecer às definições anteriores. Portanto, as equações seguintes não têm significado

$$
\begin{aligned}
& a_{i}=b_{j}, \\
& a_{i}+k_{i}=c_{i}, \\
& a_{i}+b_{i} c_{j} d_{j}=0 .
\end{aligned}
$$

Uma equação contendo dois índices livres, como a seguinte

$$
\mathrm{T}_{\mathrm{ij}}=\mathrm{A}_{\mathrm{im}} \mathrm{A}_{\mathrm{jm}}, \quad \mathrm{i}=1,2,3 ; \mathrm{j}=1,2,3
$$

representa um conjunto de nove equações.

\subsubsection{Delta de Kronecker}

O delta de Kronecker, representado por $\delta_{\mathrm{ij}}$, é definido como

$$
\delta_{i j}= \begin{cases}1, & \text { se } \mathrm{i}=\mathrm{j} \\ 0, & \text { se } \mathrm{i} \neq \mathrm{j}\end{cases}
$$

Ou seja, a matriz

$$
\left[\delta_{\mathrm{ij}}\right]=\left[\begin{array}{lll}
\delta_{11} & \delta_{12} & \delta_{13} \\
\delta_{21} & \delta_{22} & \delta_{23} \\
\delta_{31} & \delta_{32} & \delta_{33}
\end{array}\right]
$$

equivale à matriz identidade.

Manipulando-se um pouco com a notação indicial, pode-se verificar que 


$$
\begin{aligned}
& \delta_{\mathrm{ii}}=\delta_{11}+\delta_{22}+\delta_{33}=1+1+1=3, \\
& \delta_{\mathrm{ij}} \mathrm{a}_{\mathrm{j}}=\mathrm{a}_{\mathrm{i}}, \\
& \delta_{\mathrm{ij}} \mathrm{T}_{\mathrm{ij}}=\mathrm{T}_{\mathrm{ii}}=\mathrm{T}_{\mathrm{ij}}, \\
& \delta_{\mathrm{im}} \delta_{\mathrm{mj}} \delta_{\mathrm{jn}}=\delta_{\mathrm{in}} .
\end{aligned}
$$

\subsubsection{Convenção de Diferenciação}

Com a finalidade de simplificar as formas de algumas expressões, o símbolo convencional de derivada parcial $(\partial)$ poderá ser substituído pela vírgula, conforme exemplificado a seguir (FUNG (1965)):

$$
\begin{aligned}
& \frac{\partial \phi}{\partial x_{k}}=\phi_{, k} \\
& \frac{\partial g_{j}}{\partial x_{k}}=g_{j, k} . \\
& \frac{\partial \sigma_{i j}}{\partial x_{k}}=\sigma_{i j, k}
\end{aligned}
$$

\subsection{Problemas de Valor de Contorno}

Um Problema de Valor de Contorno envolve a aplicação de uma equação diferencial a um domínio $\Omega$, limitado por um contorno $\Gamma$ (fig. (3.1)). Como exemplo, pode-se citar a equação de Poisson

$$
\nabla^{2} \phi(x, y)=b(x, y) \quad \text { em } \Omega,
$$

onde $\phi(\mathrm{x}, \mathrm{y})$ é a função incógnita (neste caso, um potencial) a ser determinada e b(x,y) é uma função definida no domínio $\Omega$. 


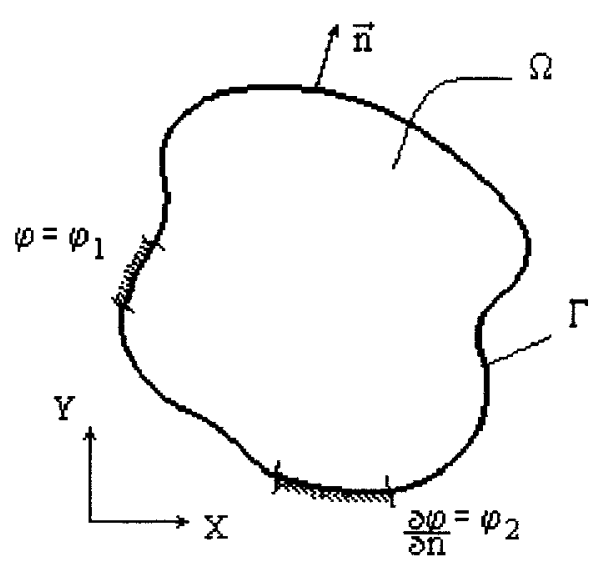

FIGURA 3.1 - Um problema de valor de contorno. BECKER (1992).

A obtenção da solução de uma equação diferencial exige a especificação das condições de contorno, estabelecendo o valor da função incógnita, ou de suas derivadas, em trechos do contorno $\Gamma$. Essas condições de contorno podem ser de dois tipos:

- Valores prescritos da função incógnita $\phi$ :

$$
\phi(\mathrm{x}, \mathrm{y})=\varphi_{1}
$$

também conhecidas como condições essenciais ou condições do tipo Dirichlet.

- Valores prescritos da derivada da função incógnita em relação à normal ao contorno:

$$
\frac{\partial \phi(x, y)}{\partial \mathrm{n}}=\varphi_{2}
$$

também conhecidas como condições naturais ou condições do tipo Neumann. 
O contorno pode ser definido como o lugar geométrico dos pontos em cuja vizinhança existem tanto pontos internos quanto pontos externos em relação ao domínio. Em relação ao domínio, pode ser de dois tipos: externo (fig. (3.2a)) ou interno (fig. (3.2b)). Dependendo do tipo de contorno, o domínio pode ser classificado como fechado (fig. (3.2a)) ou aberto (fig. (3.2b)) e o sentido de numeração dos nós do contorno será, respectivamente, anti-horário ou horário.

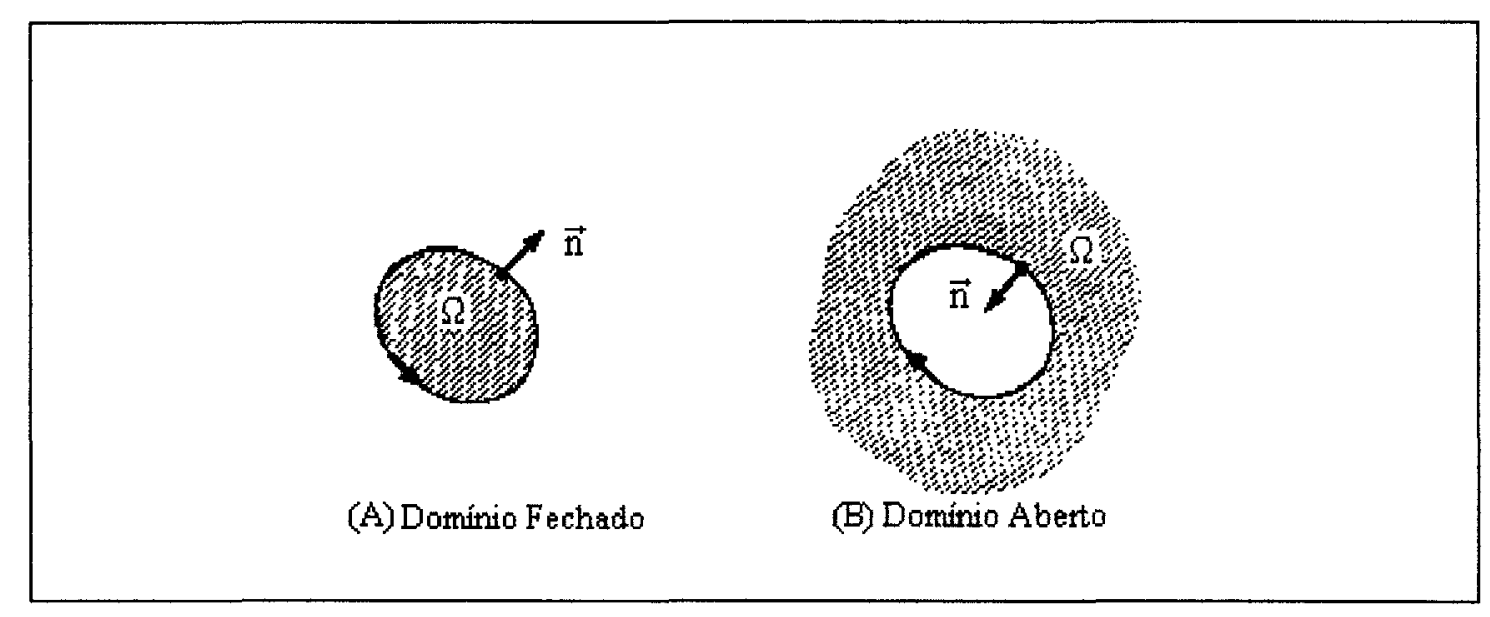

FIGURA 3.2 - Classificação dos domínios. BREBBIA \& DOMINGUEZ (1989).

\subsection{Funções de Green}

Uma Função de Green é definida como a resposta de um sistema a um estímulo padrão de entrada. Alguns exemplos clássicos de funções de Green são (ALIABADI \& ROOKE (1991)):

- A voltagem de saída, como função do tempo, de um circuito elétrico em resposta a um pulso de voltagem de entrada.

- A resposta dinâmica de um sistema mecânico colocado em movimento por um golpe impulsivo. 
- O campo de tensões produzido em um corpo elástico em resposta a uma força concentrada agindo sobre o corpo.

As funções de Green são importantes porque - quando definidas de maneira adequada - contêm toda a informação essencial sobre o sistema. Além disso, permitem a obtenção da resposta do sistema a qualquer entrada - considerada como composta por vários impulsos menores e independentes. A resposta total seria a soma de todas as respostas individuais, devidas, respectivamente, a cada impulso agindo em separado.

O sistema em questão deve possuir as seguintes propriedades, a fim de permitir sua representação através de funções de Green (ALIABADI \& ROOKE (1991))

- Relação de Causa e Efeito: Sem estímulo, não há resposta.

- Invariância: A resposta a um dado estímulo é sempre a mesma.

- Linearidade: Se a resposta ao estímulo $E_{1}$ é $R_{1}$ e a resposta ao estímulo $E_{2}$ é $R_{2}$, então a resposta ao estímulo $I_{1}+I_{2}$ é $R_{1}+R_{2}$.

No Método dos Elementos de Contorno, as Funções de Green aparecem sob a forma de Soluções Fundamentais (talvez um termo mais apropriado fosse Funções de Influência, cf. [7.3.1]). As soluções fundamentais podem ser entendidas como a solução das equações diferenciais de equilíbrio (cf. [4.2] e [4.6]), quando expressas em termos de deslocamentos (equações de Navier):

$$
\left(\frac{1}{1-2 v}\right) \mathrm{u}_{\mathrm{j}, \mathrm{j} \ell}+\mathrm{u}_{\ell, \mathrm{j} j}+\frac{1}{\mathrm{G}} \mathrm{b}_{\ell}=0
$$

Seja um domínio infinito, contínuo e elástico-linear, submetido à ação de uma única força unitária concentrada. Assumindo-se que esta força concentrada esteja aplicada em um ponto interior $\mathrm{p}$ (usualmente chamado de ponto de carga, ou fonte), 
o que se procura encontrar é o efeito desta força em um outro ponto $Q$, situado em qualquer lugar do domínio, satisfazendo as seguinte condições:

- Todas as tensões devem se anular quando a distância entre p e Q tender ao infinito.

- As tensões devem ser singulares em $\mathrm{p}$, isto é, devem tender ao infinito quando a distância entre $p$ e $Q$ tender a zero.

A solução para o problema acima (conhecido como problema de Kelvin), é a solução fundamental de Kelvin'1, utilizada neste trabalho. Em um problema isotrópico bidimensional onde se admite estado plano de deformação (cf. [4.4.2]), pode ser definida deste modo:

$$
\sigma_{\mathrm{kj}, \mathrm{j}}^{*}+\Delta^{\mathrm{p}} \delta_{\mathrm{k} \ell}=0
$$

ou seja, corresponde à distribuição de tensões provocada pela aplicação de uma força unitária concentrada no ponto $\mathrm{p}$, na direção $\ell \cdot \Delta^{\mathrm{p}}$ corresponde à função delta de Dirac $\delta(p, Q)$ (eq. (3.50)) e utilizou-se a convenção de diferenciação (cf. [3.1.4]).

A solução fundamental também pode ser expressa, em termos de deslocamentos e forças de superficie, da seguinte maneira (BREBBIA \& DOMINGUEZ (1989)):

$$
\begin{aligned}
& \mathrm{u}_{\ell \mathrm{k}}^{*}=\frac{1}{8 \pi \mathrm{G}(1-v)}\left[(3-4 v) \ln \left(\frac{1}{\mathrm{r}}\right) \delta_{\ell \mathrm{k}}+\mathrm{r}_{, \ell} \mathrm{r}_{, \mathrm{k}}\right] \\
& \mathrm{p}_{\ell \mathrm{k}}^{*}=-\frac{1}{4 \pi(1-v) \mathrm{r}}\left[\mathrm{r}_{, \mathrm{n}}\left[(1-2 v) \delta_{\ell \mathrm{k}}+2 \mathrm{r}_{, \ell} \mathrm{r}_{, \mathrm{k}}\right]+(1-2 v)\left(\mathrm{n}_{\ell} \mathrm{r}_{, \mathrm{k}}-\mathrm{n}_{\mathrm{k}} \mathrm{r}_{, \ell}\right)\right]
\end{aligned}
$$

onde, considerando-se um ponto qualquer do domínio, $\mathrm{u}_{\ell \mathrm{k}}^{*}\left(\mathrm{p}_{\ell \mathrm{k}}^{*}\right)$ representa o deslocamento (a força de superficie) na direção $k$ quando uma força unitária é

${ }^{1}$ MINDLIN, R. D. Force at a point in the interior of a semi-infinite solid. Physics, v. 7, p. 195 , 1936 apud BREBBIA \& WALKER (1980). 
aplicada, no ponto $\mathrm{p}$, na direção $\ell$ (fig. (3.3)) e $\overrightarrow{\mathrm{e}}_{\mathrm{k}}$ representa o versor na direção $\mathrm{k}$. A função $r=r(p, Q)$ é a distância física entre os pontos $p$ e $Q$ (módulo do vetor posição $\overrightarrow{\mathrm{r}}$ ) e $\mathrm{r}_{\mathrm{n}}$ representa a derivada de $\mathrm{r}$ em relação à direção indicada pelo versor normal ao contorno, $\overrightarrow{\mathrm{n}}$.

Obviamente, os vetores deslocamento e força de superficie são dados por

$$
\begin{aligned}
& \overrightarrow{\mathrm{u}}^{*}=\mathrm{u}_{\mathrm{k}}^{*} \overrightarrow{\mathrm{e}}_{\mathrm{k}}=\mathrm{u}_{\mathrm{jk}}^{*} \delta_{\ell \mathrm{j}} \overrightarrow{\mathrm{e}}_{\mathrm{k}}=\mathrm{u}_{\ell \mathrm{k}}^{*} \overrightarrow{\mathrm{e}}_{\mathrm{k}} \\
& \overrightarrow{\mathrm{p}}^{*}=\mathrm{p}_{\mathrm{k}}^{*} \overrightarrow{\mathrm{e}}_{\mathrm{k}}=\mathrm{p}_{\mathrm{jk}}^{*} \delta_{\ell \mathrm{j}} \overrightarrow{\mathrm{e}}_{\mathrm{k}}=\mathrm{p}_{\ell \mathrm{k}}^{*} \overrightarrow{\mathrm{e}}_{\mathrm{k}}
\end{aligned}
$$

BREBBIA \& WALKER (1980) apresentam a forma explícita da solução fundamental de alguns problemas conhecidos.

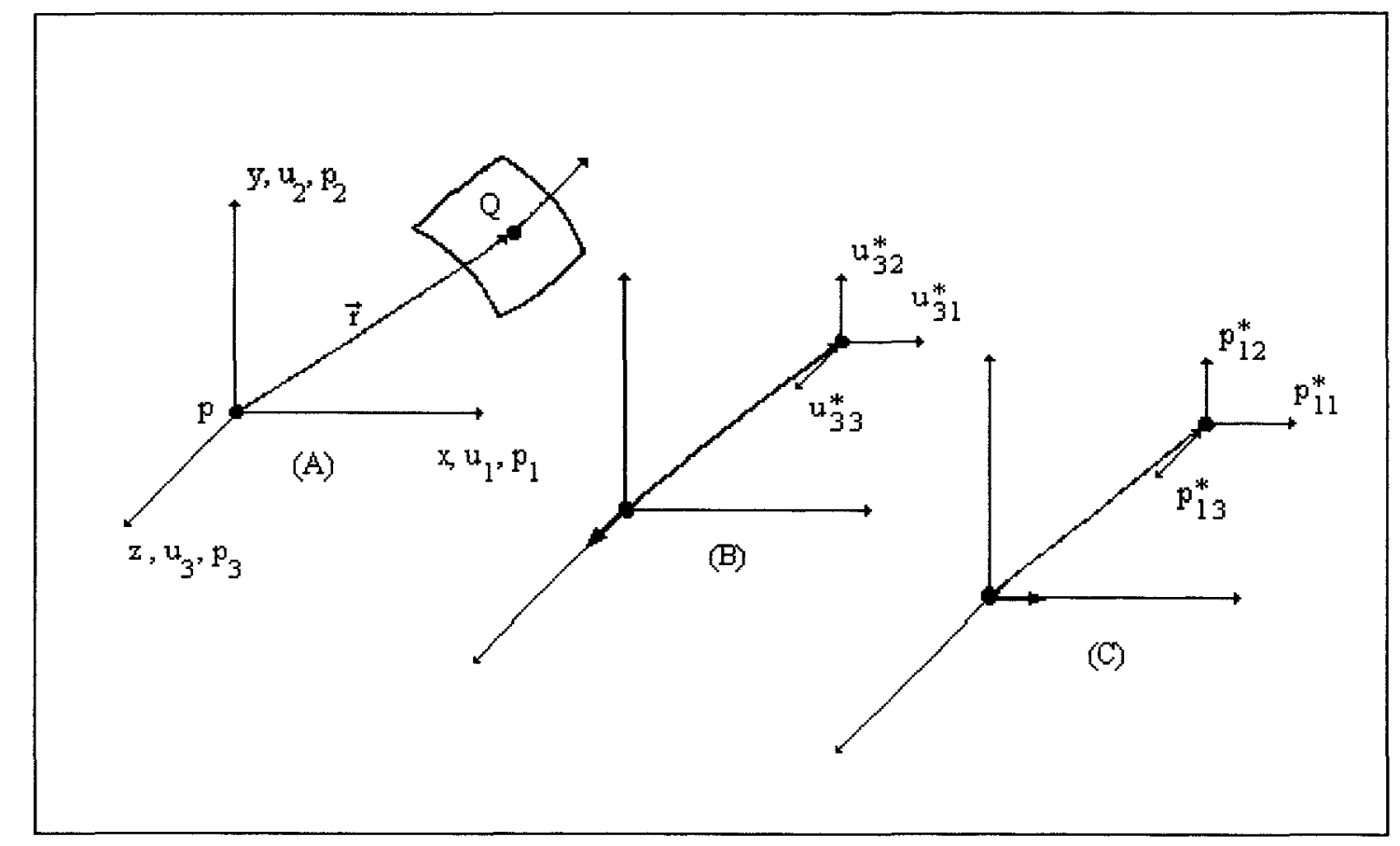

FIGURA 3.3 - Interpretação geométrica das componentes da solução fundamental. BREBBIA \& DOMINGUEZ (1989). 


\subsection{Equações Integrais e Valor Principal de Cauchy}

Em uma equação integral, os integrandos são funções desconhecidas onde as incógnitas desempenham a função de densidades. Quando essas funções estão definidas em um contorno $\Gamma$ são chamadas de funções de contorno.

Seja $\varphi=\varphi(t)$ uma função de contorno não definida em um ponto $t_{0}$ pertencente a $\Gamma$. Para ser possível calcular a integral de $\varphi$ ao longo de $\Gamma$, altera-se o domínio $\Gamma$ para $\Gamma-\bar{\Gamma}$, sendo $\bar{\Gamma}$ um segmento da curva $\Gamma$ delimitado por uma circunferência de raio $\varepsilon$ com centro em $t_{0}$ (fig. (3.4)). Desta forma, poder-se-á calcular

$$
\int_{\Gamma} \varphi(\mathrm{t}) \mathrm{d} \Gamma
$$

quando existir o limite

$$
\lim _{\varepsilon \rightarrow 0} \int_{\Gamma-\bar{\Gamma}} \varphi(t) d \Gamma
$$

conhecido como integral singular da função $\varphi(t)$ ao longo do contorno $\Gamma$.

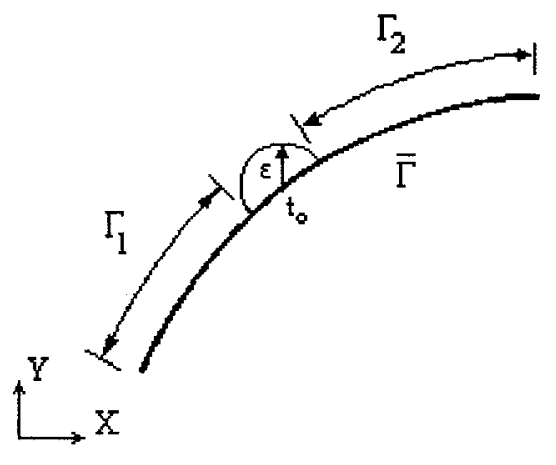

FIGURA 3.4 - Definição geométrica de integral de Cauchy. ROCHA (1988). 
Como o ponto $\mathrm{t}_{0}$ não está situado nas extremidades do segmento de curva, o trecho $\Gamma-\bar{\Gamma}$ fica dividido em dois trechos, $\Gamma_{1}$ e $\Gamma_{2}$ (fig. (3.4)) e a eq. (3.19) torna-se

$$
\lim _{\varepsilon \rightarrow 0} \int_{\Gamma_{1}} \varphi(t) d \Gamma_{1}+\lim _{\varepsilon \rightarrow 0} \int_{\Gamma_{2}} \varphi(t) d \Gamma_{2}
$$

Se os dois limites acima existirem, diz-se que a integral (3.18), apesar de apresentar singularidade, não apresenta uma singularidade especial e seu limite é calculado normalmente. Entretanto, quando os limites não existem isoladamente, pode-se tentar o artificio de cálculá-los em conjunto, da seguinte maneira

$$
\lim _{\varepsilon \rightarrow 0}\left(\int_{\Gamma_{1}} \varphi(t) d \Gamma_{1}+\int_{\Gamma_{2}} \varphi(t) d \Gamma_{2}\right)
$$

Quando os termos integrais se compensam, este limite existe e, portanto, a integral (3.18). Quando os limites (3.20) e (3.21) existem, são chamados de valor principal de Cauchy da integral (3.18). Isto posto, pode-se dizer que

$$
\int_{\Gamma} \varphi(t) d \Gamma=\lim _{s \rightarrow 0} \int_{\Gamma-\bar{\Gamma}} \varphi(t) d \Gamma
$$

Quando a integral (3.18) não apresenta singularidade especial, o ponto $t_{0}$ pode estar situado em uma das extremidades da curva. A existência do limite (3.21) depende, obviamente, do tipo da função $\varphi(t)$ e do tipo de curva $\Gamma$.

\subsection{Teoremas de Green}

Sejam $\nabla$ e $\nabla^{2}$, respectivamente, os operadores gradiente e laplaciano dados, no espaço tridimensional, por: 


$$
\begin{aligned}
& \nabla=\overrightarrow{\mathrm{i}} \frac{\partial}{\partial \mathrm{x}}+\overrightarrow{\mathrm{j}} \frac{\partial}{\partial \mathrm{y}}+\overrightarrow{\mathrm{k}} \frac{\partial}{\partial \mathrm{z}} \\
& \nabla^{2}=\nabla \cdot \nabla=\frac{\partial^{2}}{\partial \mathrm{x}^{2}}+\frac{\partial^{2}}{\partial \mathrm{y}^{2}}+\frac{\partial^{2}}{\partial \mathrm{z}^{2}}
\end{aligned}
$$

onde $\vec{i}, \vec{j}$ e $\vec{k}$ representam os versores ao longo das direções $x, y$ e $z$, repectivamente.

Considere-se, agora, um domínio consistindo de um volume $\Omega$ limitado por um contorno $\Gamma$, suave por partes, onde as funções $F(x, y)$, escalar, e $\vec{G}(x, y)$, vetorial, têm primeira derivada contínua em relação às coordenadas cartesianas. Neste caso, valem os seguintes teoremas:

$$
\int_{\Omega} \operatorname{grad}(\mathrm{F}) \mathrm{d} \Omega=\int_{\Omega} \nabla \mathrm{Fd} \Omega=\oint_{\Gamma} \overrightarrow{\mathrm{n}} \mathrm{F} \mathrm{d} \Gamma
$$

conhecido como o Teorema do Gradiente, e

$$
\int_{\Omega} \operatorname{div}(\overrightarrow{\mathrm{G}}) \mathrm{d} \Omega=\int_{\Omega} \nabla \cdot \overrightarrow{\mathrm{G}} \mathrm{d} \Omega=\oint_{\Gamma} \overrightarrow{\mathrm{n}} \cdot \overrightarrow{\mathrm{G}} \mathrm{d} \Gamma
$$

conhecido como o Teorema da Divergência. Em três dimensões, as equações acima são equivalentes a

$$
\int_{\Omega}\left(\overrightarrow{\mathrm{i}} \frac{\partial \mathrm{F}}{\partial \mathrm{x}}+\overrightarrow{\mathrm{j}} \frac{\partial \mathrm{F}}{\partial \mathrm{y}}+\overrightarrow{\mathrm{k}} \frac{\partial \mathrm{F}}{\partial \mathrm{z}}\right) \mathrm{d} \Omega=\oint_{\Gamma}\left(\overrightarrow{\mathrm{i}} \mathrm{n}_{\mathrm{x}}+\overrightarrow{\mathrm{j}} \mathrm{n}_{\mathrm{y}}+\overrightarrow{\mathrm{k}} \mathrm{n}_{\mathrm{z}}\right) \mathrm{Fd} \Gamma
$$

e

$$
\int_{\Omega}\left(\frac{\partial G_{x}}{\partial x}+\frac{\partial G_{y}}{\partial y}+\frac{\partial G_{z}}{\partial z}\right) d \Omega=\oint_{\Gamma}\left(n_{x} G_{x}+n_{y} G_{y}+n_{z} G_{z}\right) d \Gamma
$$


respectivamente. O ponto, $(\cdot)$, representa o produto escalar de vetores, $\overrightarrow{\mathrm{n}}$ representa o versor normal externo ao contorno $\Gamma$ e $n_{x}, n_{y}$ e $n_{z}\left(G_{x}, G_{y}, G_{z}\right)$ são os componentes cartesianos de $\overrightarrow{\mathrm{n}}(\overrightarrow{\mathrm{G}})$.

As seguintes identidades, que podem ser derivadas a partir dos teoremas anteriores, são utilizadas no desenvolvimento do trabalho (REDDY (1993)):

$$
\begin{gathered}
\int_{\Omega}(\nabla \mathrm{F}) \mathrm{Hd} \Omega=-\int_{\Omega}(\nabla \mathrm{H}) \mathrm{Fd} \Omega+\oint_{\Gamma} \overrightarrow{\mathrm{n}} \mathrm{FH} \mathrm{d} \Gamma, \\
\int_{\Omega} \mathrm{F}(\nabla \cdot \overrightarrow{\mathrm{G}}) \mathrm{d} \Omega=-\int_{\Omega}(\nabla \mathrm{F}) \cdot \overrightarrow{\mathrm{G}} \mathrm{d} \Omega+\oint_{\Gamma} \overrightarrow{\mathrm{n}} \cdot \mathrm{F} \overrightarrow{\mathrm{G}} \mathrm{d} \Gamma, \\
\int_{\Omega}\left(\nabla^{2} \mathrm{~F}\right) \mathrm{Hd} \Omega+\int_{\Omega} \nabla \mathrm{F} \cdot \nabla \mathrm{Hd} \Omega=\oint_{\Gamma} \overrightarrow{\mathrm{n}}(\nabla \mathrm{F}) \mathrm{Hd} \Gamma=\oint_{\Gamma} \frac{\partial \mathrm{F}}{\partial \mathrm{n}} \mathrm{Hd} \Gamma .
\end{gathered}
$$

onde $H(x, y)$ representa uma função escalar com as mesmas propriedades de $F(x, y)$.

O teorema da divergência pode ser utilizado para relacionar duas variáveis no volume $\Omega$. Assumindo-se a existência de duas variáveis, $\phi$ e $\lambda$, com primeiras e segundas derivadas contínuas no volume $\Omega$, e empregando-se as eqs. (3.23b) e (3.24b), é possível demostrar que a seguinte identidade, conhecida como o Teorema de Green, é válida:

$$
\int_{\Omega}\left(\phi \nabla^{2} \lambda-\lambda \nabla^{2} \phi\right) \mathrm{d} \Omega=\oint_{\Gamma}\left(\phi \frac{\partial \lambda}{\partial \mathrm{n}}-\lambda \frac{\partial \phi}{\partial \mathrm{n}}\right) \mathrm{d} \Gamma .
$$

\subsection{Teorema de Betti}

Considere-se um corpo em equilíbrio quando submetido à ação de dois estados de carregamento, cada um deles levando a um dos estados de tensão definidos a seguir: 
- Para um estado de carregamento (a), tensões $\sigma_{\mathrm{ij}}^{(a)}$ que dão origem ao conjunto de deformações $\varepsilon_{\mathrm{ij}}^{(\mathrm{a})}$.

- Para um estado de carregamento (b), diferente do anterior, tensões $\sigma_{\mathrm{ij}}^{(\mathrm{b})}$ que dão origem ao conjunto de deformações $\varepsilon_{\mathrm{ij}}^{(\mathrm{b})}$.

O teorema de Betti (também chamado de teorema do trabalho recíproco) estabelece que o trabalho feito pelas tensões do sistema (a) sobre as deformações do sistema (b) é igual ao trabalho efetuado pelas tensões do sistema (b) sobre as deformações do sistema (a), ou seja

$$
\int_{\Omega} \sigma_{\mathrm{ij}}^{(\mathrm{a})} \varepsilon_{\mathrm{ij}}^{(\mathrm{b})} \mathrm{d} \Omega=\int_{\Omega} \sigma_{\mathrm{ij}}^{(\mathrm{b})} \varepsilon_{\mathrm{ij}}^{(\mathrm{a})} \mathrm{d} \Omega
$$

\subsection{Funções de Interpolação e Formulação Isoparamétrica}

Um campo $f$ pode ser interpolado ao longo de um elemento a partir de $n$ valores nodais $\{f\}_{\mathrm{n}}=\left\{f_{1} f_{2} \cdots f_{\mathrm{n}}\right\}^{\mathrm{T}}$, da seguinte maneira

$$
f=[\Phi]\{f\}_{\mathrm{n}}=\sum_{\mathrm{i}=1}^{\mathrm{n}} \phi_{\mathrm{i}} f_{\mathrm{i}}=\phi_{\mathrm{i}} f_{\mathrm{i}}
$$

onde os $\phi_{i}$ são funções das coordenadas definidas no espaço cartesiano adotado (conhecidas como funções de forma ou funções de interpolação). Uma função de forma $\phi_{\mathrm{i}}$ define a distribuição de $f$ ao longo do elemento quando o i-ésimo grau de liberdade, $f_{\mathrm{i}}$, tem valor unitário e todos os outros $f^{\prime}$ 's são zero. 
As funções $\phi_{i}$ apresentam as seguintes características (COOK et al. (1989)):

- Todas as funções de forma $\phi_{\mathrm{i}}$, e a própria função $f$, são polinômios do mesmo grau.

- $f_{\mathrm{i}}=\delta_{\mathrm{ij}}$ quando $\mathrm{x}=\mathrm{x}_{\mathrm{j}}$ (coordenada ao longo do elemento).

- A soma das funções de forma tem valor unitário.

As funções $\phi_{\mathrm{i}}$ podem ser obtidas a partir da fórmula de interpolação de Lagrange (COOK et al. (1989)), com seguem:

$$
\begin{gathered}
\phi_{1}=\frac{\left(x_{2}-x\right)\left(x_{3}-x\right)\left(x_{4}-x\right) \cdots\left(x_{n}-x\right)}{\left(x_{2}-x_{1}\right)\left(x_{3}-x_{1}\right)\left(x_{4}-x_{1}\right) \cdots\left(x_{n}-x_{1}\right)} \\
\phi_{2}=\frac{\left(x_{1}-x\right)\left(x_{3}-x\right)\left(x_{4}-x\right) \cdots\left(x_{n}-x\right)}{\left(x_{1}-x_{2}\right)\left(x_{3}-x_{2}\right)\left(x_{4}-x_{2}\right) \cdots\left(x_{n}-x_{2}\right)} \\
\vdots \\
\phi_{n}=\frac{\left(x_{1}-x\right)\left(x_{2}-x\right)\left(x_{3}-x\right) \cdots\left(x_{n-1}-x\right)}{\left(x_{1}-x_{n}\right)\left(x_{3}-x_{n}\right)\left(x_{4}-x_{n}\right) \cdots\left(x_{n-1}-x_{n}\right)}
\end{gathered}
$$

A interpolação a partir de valores nodais (eq. (3.29)) tanto pode ser utilizada para aproximar o campo de uma variável dependente (como, por exemplo, os deslocamentos) quanto a geometria de um elemento. Dependendo do relacionamento entre o grau de aproximação utilizado para a geometria (m) e o grau de aproximação utilizado para as variáveis dependentes (n), as formulações podem ser agrupadas em três categorias:

- Formulação Subparamétrica: $\quad \mathrm{m}<\mathrm{n}$;

- Formulação Isoparamétrica: $\quad m=n$;

- Formulação Superparamétrica: $\quad m>n$; 


\subsection{Integração Numérica}

A integração numérica é empregada quando o cálculo analítico de integrais da forma

$$
\int_{a}^{b} F(x) d x
$$

for dificil ou impossível de se obter por meios exatos, muitas vezes devido à complexidade do integrando F. A idéia básica é a de que uma integral com limites arbitrários pode ser transformada através da utilização de coordenadas naturais e, então, calculada numericamente.

\subsubsection{Coordenadas Naturais}

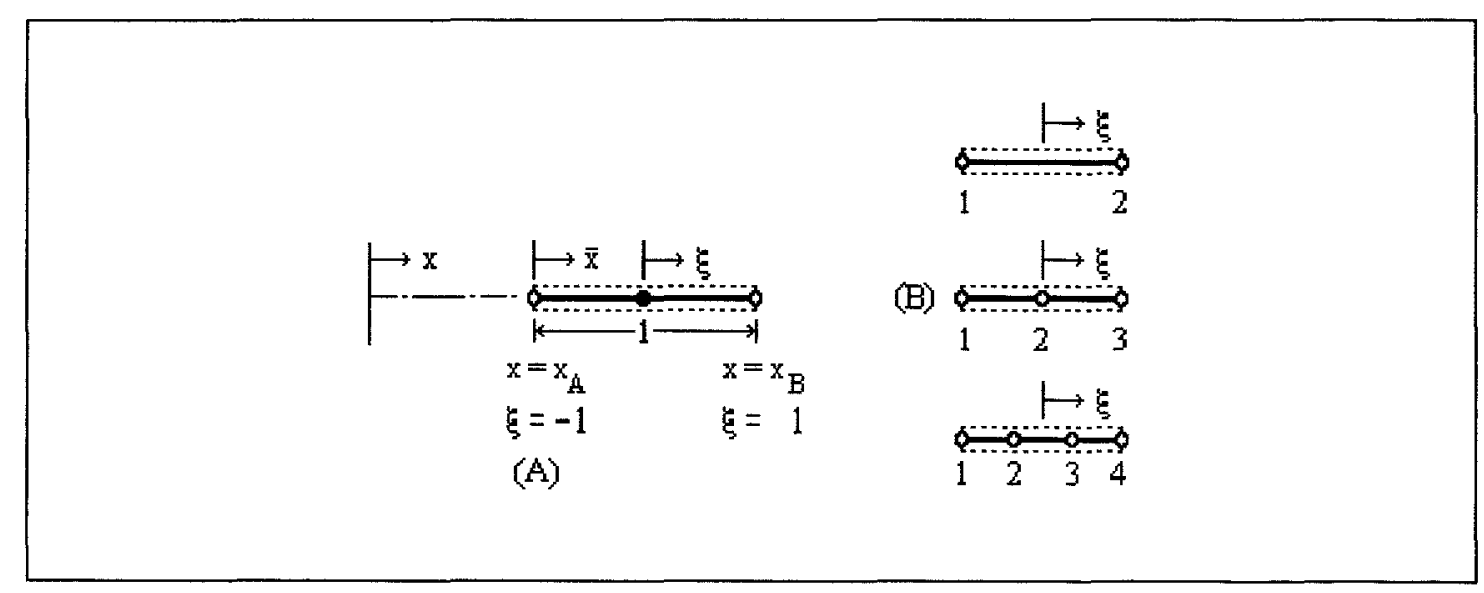

FIGURA 3.5 - Definição e utilização da Coordenada Natural. (a) Coordenada global x, coordenada local $\overline{\mathrm{x}}$ e coordenada local normalizada $\xi$. (b) Interpolações de Lagrange em termos da coordenada natural. REDDY (1993).

Em vários problemas onde se requer integração numérica, é necessário efetuar a transformação da coordenada global do problema (por exemplo, x) para uma coordenada local, $\xi$, de forma que, quando $\mathrm{x}=\mathrm{x}_{\mathrm{A}}, \xi=-1 \mathrm{e}$, quando $\mathrm{x}=\mathrm{x}_{\mathrm{B}}, \xi=1$ (fig. 
3.5a). A coordenada local $\xi$ também é chamada de coordenada normal, natural ou homogênea.

As funções de interpolação de Lagrange (eqs. (3.30)) também podem ser expressas em função da coordenada natural $\xi$. Em particular, para os exemplos mostrados na fig. (3.5b), tem-se, respectivamente,

$$
\begin{aligned}
\phi_{1} & =\frac{1}{2}(1-\xi) \\
\phi_{2} & =\frac{1}{2}(1+\xi) \\
\phi_{1} & =-\frac{1}{2} \xi(1-\xi) \\
\phi_{2} & =(1+\xi)(1-\xi) \\
\phi_{3} & =\frac{1}{2} \xi(1+\xi)
\end{aligned}
$$

e

$$
\begin{aligned}
& \phi_{1}=-\frac{9}{16}(1-\xi)\left(\frac{1}{3}+\xi\right)\left(\frac{1}{3}-\xi\right) \\
& \phi_{2}=\frac{27}{16}(1+\xi)(1-\xi)\left(\frac{1}{3}-\xi\right) \\
& \phi_{3}=\frac{27}{16}(1+\xi)(1-\xi)\left(\frac{1}{3}+\xi\right) \\
& \phi_{4}=-\frac{9}{16}\left(\frac{1}{3}+\xi\right)\left(\frac{1}{3}-\xi\right)(1+\xi)
\end{aligned}
$$

\subsubsection{Quadratura de Gauss-Legendre}

Quadratura é o termo empregado para o cálculo numérico de integrais (em lugar do cálculo analítico através de tabelas). Existem várias regras de quadratura: Newton-Cotes, Gauss-Legendre etc. 
A fórmula de integração de Gauss-Legendre é dada por

$$
\int_{\mathrm{a}}^{\mathrm{b}} \mathrm{F}(\mathrm{x}) \mathrm{dx}=\int_{-1}^{1} \mathrm{~F}(\mathrm{x}(\xi))|\mathrm{J}| \mathrm{d} \xi \approx \sum_{\mathrm{i}=1}^{\mathrm{n}} \mathrm{F}\left(\xi_{\mathrm{i}}\right)|\mathrm{J}|_{\mathrm{i}} \omega_{\mathrm{i}},
$$

onde $\omega_{\mathrm{i}}$ são os fatores de ponderação, $\xi_{\mathrm{i}}$ são os pontos-base e $|\mathrm{J}|_{\mathrm{i}}$ indica o jacobiano da transformação de coordenadas, calculado no i-ésimo ponto de Gauss.

Para REDDY(1993), a quadratura de Gauss-Legendre requer menos pontosbase que a quadratura de Newton-Cotes a fim de obter a mesma precisão. Os fatores de ponderação, bem como os pontos de Gauss, para a quadratura de Gauss-Legendre podem ser encontrados, por exemplo, em BREBBIA \& DOMINGUEZ (1989), COOK et al. (1989) e REDDY(1993). O número, as coordenadas naturais e os fatores de ponderação dos pontos de Gauss utilizados neste trabalho são fornecidos na tabela 3.1 :

\begin{tabular}{|c|c|c|}
\hline $\mathrm{n}$ & $\pm \xi_{\mathrm{i}}$ & $\omega_{1}$ \\
\hline 12 & 0.125233408511469 & 0.249147045813403 \\
& 0.367831498998180 & 0.233492536538355 \\
& 0.587317954286617 & 0.203167426723066 \\
& 0.769902674194305 & 0.160078328543346 \\
& 0.904117256370475 & 0.106939325995318 \\
& 0.981560634246719 & 0.047175336386512 \\
\hline
\end{tabular}

TABELA 3.1 - Coordenadas naturais e fatores de ponderação para a quadratura de Gauss-Legendre com 12 pontos. BREBBIA \& DOMINGUEZ (1989).

\subsection{Fórmulas de Quadratura de Kutt}

KUTT (1975) estudou o problema de calcular a parte finita de integrais do tipo 


$$
\int_{\mathrm{s}}^{\mathrm{r}} \frac{f(\mathrm{x})}{(\mathrm{x}-\mathrm{s})^{\lambda}} \mathrm{dx}, \quad \lambda \text { real } \mathrm{e} \geq 1
$$

onde $f(\mathrm{x})$ é uma função real da variável real x. A eq. (3.37) é aproximada por um produto escalar de pesos e valores da função em certas estações (posições) préestabelecidas - ambos definidos através de tabelas. As estações são igualmente espaçadas no intervalo $[s, r]$, de forma que a primeira coincide com $s$, mas nenhuma com r. Dadas N estações, o grau de precisão da fórmula desenvolvida por Kutt é N-1, isto é, a fórmula é exata para todos os polinômios de grau $\leq \mathrm{N}-1$.

Para aplicar a fórmula numérica, deve-se, primeiramente, efetuar uma mudança de escala (normalização) de $[s, r]$ para $[0,1]$. Ou seja, procura-se transformar a eq. (3.37) em

$$
\int_{0}^{1} \frac{g(x)}{x^{\lambda}} d x \approx \sum_{i=1}^{N} \omega_{i} g\left(x_{i}\right), \quad \lambda \geq 1, i=1,2, \ldots, N
$$

onde os $\omega_{i}$ são os pesos correspondentes às estações $\mathrm{x}_{\mathrm{i}}$.

Sendo estações igualmente espaçadas em $[0,1], x_{i}=(i-1) / N$, para $i=1,2, \ldots$, $\mathrm{N}$. Neste caso, as estações são fixas e apenas os pesos têm que ser computados. A normalização fornece

$$
\int_{\mathrm{s}}^{\mathrm{r}} \frac{f(\mathrm{x})}{(\mathrm{x}-\mathrm{s})^{\lambda}} \mathrm{dx}=(\mathrm{r}-\mathrm{s})^{1-\lambda} \int_{0}^{1} \frac{f[(\mathrm{r}-\mathrm{s}) \mathrm{t}+\mathrm{s}]}{\mathrm{t}^{\lambda}} \mathrm{dt}+f^{(\lambda-1)}(\mathrm{s}) \frac{\ln |\mathrm{r}-\mathrm{s}|}{(\lambda-1) !}
$$

onde

$$
f^{(\lambda-1)}(\mathrm{s})=(\mathrm{r}-\mathrm{s})^{1-\lambda} \mathrm{F}^{(\lambda-1)}(0) \approx(\mathrm{r}-\mathrm{s})^{1-\lambda} \sum_{\mathrm{i}=1}^{\mathrm{N}} \mathrm{c}_{\mathrm{i}} f\left[(\mathrm{r}-\mathrm{s}) \mathrm{x}_{\mathrm{i}}+\mathrm{s}\right]
$$

Se $\lambda$ for racional, a eq. (3.37) é invariante a mudanças de escala, isto é 


$$
\int_{\mathrm{s}}^{\mathrm{r}} \frac{f(\mathrm{x})}{(\mathrm{x}-\mathrm{s})^{\lambda}} \mathrm{dx}=(\mathrm{r}-\mathrm{s})^{1-\lambda} \int_{0}^{1} \frac{f[(\mathrm{r}-\mathrm{s}) \mathrm{t}+\mathrm{s}]}{\mathrm{t}^{\lambda}} \mathrm{dt}
$$

Desta maneira, obtém-se a fórmula de quadratura para $\lambda$ racional:

$$
\int_{\mathrm{s}}^{\mathrm{r}} \frac{f(\mathrm{x})}{(\mathrm{x}-\mathrm{s})^{\lambda}} \mathrm{dx} \approx(\mathrm{r}-\mathrm{s})^{1-\lambda} \sum_{\mathrm{i}=1}^{\mathrm{N}} \omega_{\mathrm{i}} f[(\mathrm{r}-\mathrm{s}) \mathrm{t}+\mathrm{s}]
$$

A abordagem para a fórmula de quadratura da eq. (3.37), $\operatorname{com} \lambda$ inteiro, foi aproximar $f^{(\lambda-1)}(\mathrm{s})$ por um produto escalar utilizando-se as mesmas estações igualmente espaçadas $\mathrm{x}_{\mathrm{i}}$, como em (3.41). Portanto, a fórmula de quadratura para $\lambda$ inteiro é:

$$
\int_{\mathrm{s}}^{\mathrm{r}} \frac{f(\mathrm{x})}{(\mathrm{x}-\mathrm{s})^{\lambda}} \mathrm{dx} \approx(\mathrm{r}-\mathrm{s})^{1-\lambda} \sum_{\mathrm{i}=1}^{\mathrm{N}}\left[\omega_{\mathrm{i}}+\mathrm{c}_{\mathrm{i}} \ln [\mathrm{r}-\mathrm{s}] /(\lambda-1) !\right] f\left[(\mathrm{r}-\mathrm{s}) \mathrm{x}_{\mathrm{i}}+\mathrm{s}\right] .
$$

Neste trabalho, as tabelas de Kutt foram utilizadas para calcular a parte finita de integrais do tipo

$$
\begin{aligned}
\int_{0}^{\mathrm{a}} \frac{1}{\mathrm{r}^{2}} \mathrm{dr} & =\int_{\mathrm{t}}^{\mathrm{a}+\mathrm{t}} \frac{1}{(\mathrm{z}-\mathrm{t})^{2}} \mathrm{dz} \approx \mathrm{a}^{-1} \sum_{\mathrm{i}=1}^{\mathrm{N}}\left[\omega_{\mathrm{i}}+\mathrm{c}_{\mathrm{i}} \ln (\mathrm{a})\right] \underbrace{f\left[\mathrm{ax}_{\mathrm{i}}+\mathrm{t}\right]}_{\mathrm{i}}= \\
& =\frac{1}{\mathrm{a}} \sum_{\mathrm{i}=1}^{\mathrm{N}}\left[\omega_{\mathrm{i}}+\mathrm{c}_{\mathrm{i}} \ln (\mathrm{a})\right]=\frac{1}{\mathrm{a}}\left(\sum_{\mathrm{i}=1}^{\mathrm{N}} \omega_{\mathrm{i}}+\ln (\mathrm{a}) \sum_{\mathrm{i}=1}^{\mathrm{N}} \mathrm{c}_{\mathrm{i}}\right) \approx \\
& \approx \frac{1}{\mathrm{a}}(-0,99999999808-0,00000000029 \ln (\mathrm{a})) \approx-\frac{1}{\mathrm{a}}
\end{aligned}
$$

$\operatorname{para} \mathrm{N}=10$ 


\subsection{Delta de Dirac}

Considere-se a função $\delta^{(\varepsilon)}(\mathrm{x})$, definida por (fig. (3.6)):

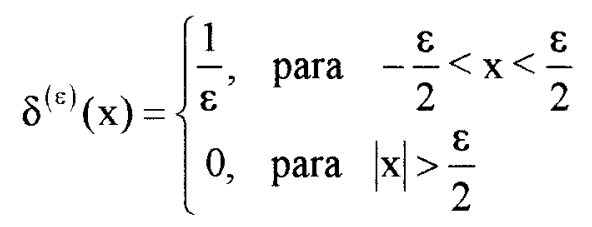

onde $\varepsilon$ é um número positivo, e calcule-se a integral

$$
I=\int_{-\infty}^{+\infty} \delta^{(\varepsilon)}(x) f(x) d x
$$

onde $\mathrm{f}(\mathrm{x})$ é uma função qualquer bem definida em $\mathrm{x}=0$. Se $\varepsilon$ for suficientemente pequeno, a variação de $\mathrm{f}(\mathrm{x})$ no intervalo efetivo de integração $[-\varepsilon / 2, \varepsilon / 2]$ é negligenciável e $f(x)$ permanece praticamente igual a $f(0)$, de forma que:

$$
I \cong f(0) \int_{-\infty}^{+\infty} \delta^{(\varepsilon)}(x) d x=f(0)
$$

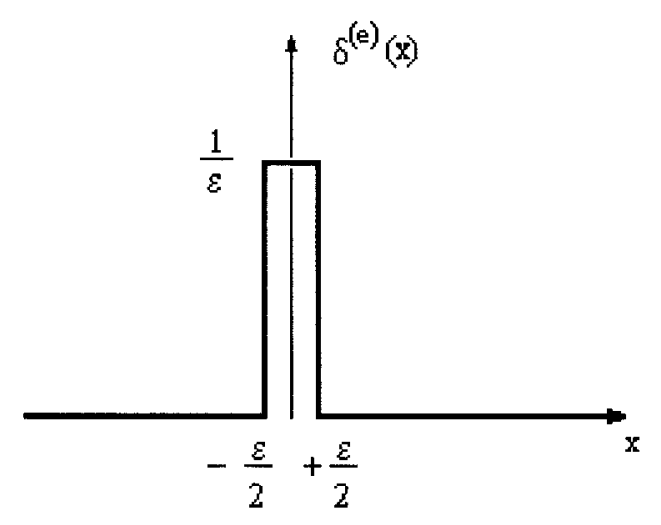

FIGURA 3.6 - Definição da função delta de Dirac. COHEN-TANNOUDJI et al. (1973). 
A aproximação é tanto melhor quanto menor for $\varepsilon$. Na passagem ao limite, quando $\varepsilon \rightarrow 0$, obtém-se a definição da função delta de Dirac pela relação

$$
\int_{-\infty}^{+\infty} \delta(x) f(x) d x=f(0)
$$

válida para qualquer função $\mathrm{f}(\mathrm{x})$ definida na origem. Uma definição mais geral seria

$$
\int_{-\infty}^{+\infty} \delta\left(x-x_{0}\right) f(x) d x=f\left(x_{0}\right)
$$

O conceito da função Delta de Dirac pode ser facilmente estendido a domínios n-dimensionais. Considerando-se uma função f que depende da localização de cada ponto no corpo, define-se $\delta(p, Q)$, como a função Delta de Dirac, quando são válidas as seguintes propriedades:

$$
\begin{aligned}
& \delta(p, Q)=\left\{\begin{array}{ll}
\infty, & \text { se } p=Q \\
0, & \text { se } p \neq Q
\end{array},\right. \\
& \int_{\Omega} g(Q) \delta(p, Q) d \Omega(Q)=g(p) .
\end{aligned}
$$

A função Delta de Dirac também pode ser representada da seguinte maneira

$$
\delta(\mathrm{p}, \mathrm{Q})=\Delta^{\mathrm{p}}
$$




\section{FUNDAMENTOS DA MECÂNICA DOS SÓLIDOS}

A seguir, serão discutidos alguns dos tópicos essenciais das teorias da elasticidade e plasticidade, pertinentes ao tema mecânica do fraturamento. Admite-se que haja familiaridade com os conceitos de tensão e deformação (BEER \& JOHNSTON (1989), MEGUID (1989), TIMOSHENKO \& GOODIER (1980), VALLIAPPAN (1981)).

\subsection{O Estado de Tensões em um Ponto}

Seja um elemento, pertencente a um sólido tridimensional, submetido à ação de um campo de tensões, fig. (4.1a). As tensões mostradas são todas positivas e esta figura define a convenção de sinais utilizada em todo o texto. Utilizando-se a notação indicial (cf. [3.1]), os índices subscritos nas tensões definem tanto a localização quanto a orientação das mesmas; ou seja, $\sigma_{\mathrm{ij}}$ denota uma tensão que, além de atuar na face do elemento perpendicular ao eixo $\mathrm{i}$, está orientada segundo o eixo $\mathrm{j}$. 


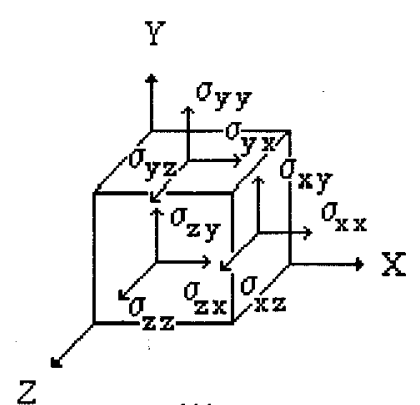

(A)

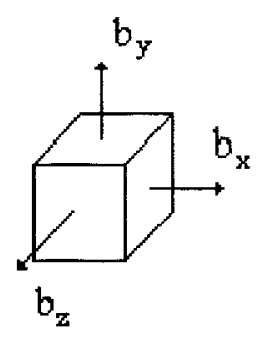

(B)

FIGURA 4.1 - Componentes de tensão referidas às coordenadas cartesianas. BECKER (1992), BREBBIA \& DOMINGUEZ (1989).

Neste texto, as tensões normais são chamadas $\sigma_{\mathrm{xx}}, \sigma_{\mathrm{yy}} \mathrm{e} \sigma_{\mathrm{zz}}$ (ou, simplificadamente, $\sigma_{\mathrm{x}}, \sigma_{\mathrm{y}}$ e $\sigma_{\mathrm{z}}$ ) e as tensões de cisalhamento, $\tau_{\mathrm{xy}}, \tau_{\mathrm{yz}}$ e $\tau_{\mathrm{zx}}-$ ou, de forma geral, $\sigma_{i j}$, com i e j variando de 1 a 3 . Na fig. (4.1b), $b_{x}, b_{y}$ e $b_{z}$ representam as forças volumétricas (ou forças por unidade de volume) ao longo das direções $\mathrm{x}, \mathrm{y}$ e $z$, respectivamente.

Como mostrado na fig. (4.1), o estado de tensões no ponto pode ser definido pelas tensões cartesianas abaixo, representadas em formas equivalentes (TIMOSHENKO \& GOODIER (1980)):

$$
\left[\begin{array}{lll}
\sigma_{\mathrm{xx}} & \tau_{\mathrm{xy}} & \tau_{\mathrm{xz}} \\
\tau_{\mathrm{yx}} & \sigma_{\mathrm{yy}} & \tau_{\mathrm{yz}} \\
\tau_{\mathrm{zx}} & \tau_{\mathrm{zy}} & \sigma_{\mathrm{zz}}
\end{array}\right],\left[\begin{array}{lll}
\sigma_{\mathrm{x}} & \tau_{\mathrm{xy}} & \tau_{\mathrm{xz}} \\
\tau_{\mathrm{yx}} & \sigma_{\mathrm{y}} & \tau_{\mathrm{yz}} \\
\tau_{\mathrm{zx}} & \tau_{\mathrm{zy}} & \sigma_{z}
\end{array}\right],\left[\begin{array}{lll}
\sigma_{11} & \sigma_{12} & \sigma_{13} \\
\sigma_{21} & \sigma_{22} & \sigma_{23} \\
\sigma_{31} & \sigma_{32} & \sigma_{33}
\end{array}\right], \quad(4.1 \mathrm{a}-\mathbf{c})
$$

ou simplesmente pelo tensor tensão [ $\sigma]$ (cf. [3.1]) . 


\subsection{Equações de Equilíbrio}

Se todo o corpo em análise estiver em equilíbrio - sob a ação das tensões atuantes em suas faces e das forças volumétricas - o elemento em consideração também deverá estar. $\mathrm{O}$ equilíbrio das forças, nas direções $\mathrm{x}, \mathrm{y}$ e $\mathrm{z}$, produz as equações diferenciais de equilíbrio ou equações de equilíbrio de forças. Combinando-as e agrupando-se os termos comuns, o equilíbrio ao longo das direções $\mathrm{x}, \mathrm{y}$ e $\mathrm{z}$ reduz-se a (no limite, quando as dimensões do elemento tendem a zero $\mathrm{e}$ infinitésimos de ordem superior podem ser desprezados)

$$
\begin{aligned}
& \frac{\partial \sigma_{x x}}{\partial x}+\frac{\partial \tau_{x y}}{\partial y}+\frac{\partial \tau_{x z}}{\partial z}+b_{x}=0 \\
& \frac{\partial \tau_{y x}}{\partial x}+\frac{\partial \sigma_{y y}}{\partial y}+\frac{\partial \tau_{y z}}{\partial z}+b_{y}=0 \\
& \frac{\partial \tau_{z x}}{\partial x}+\frac{\partial \tau_{x y}}{\partial y}+\frac{\partial \sigma_{z z}}{\partial z}+b_{z}=0
\end{aligned}
$$

ou, simplesmente,

$$
\frac{\partial \sigma_{i j}}{\partial x_{j}}+b_{i}=0
$$

o que é o mesmo que

$$
\boldsymbol{\sigma}_{\mathrm{ij}, \mathrm{j}}+\mathbf{b}_{\mathrm{i}}=0
$$

onde $b_{i}$ representa a força volumétrica atuante na direção $i$.

No caso de um estado bidimensional de tensões, as eqs. (4.2) se reduzem a 


$$
\begin{aligned}
& \frac{\partial \sigma_{x x}}{\partial x}+\frac{\partial \tau_{x y}}{\partial y}+b_{x}=0 \\
& \frac{\partial \tau_{y x}}{\partial x}+\frac{\partial \sigma_{y y}}{\partial y}+b_{y}=0
\end{aligned}
$$

O equilíbrio rotacional do elemento da fig. (4.1) (novamente, no limite, quando as dimensões do elemento tendem a zero e infinitésimos de ordem superior podem ser desprezados) assegura a simetria do tensor tensão, ou seja,

$$
\sigma_{\mathrm{ij}}=\sigma_{\mathrm{ji}},
$$

isto é,

$$
\tau_{\mathrm{xy}}=\tau_{\mathrm{yx}}, \quad \tau_{\mathrm{yz}}=\tau_{\mathrm{zy}}, \quad \tau_{\mathrm{zx}}=\tau_{\mathrm{xz}}
$$

indicando, desta forma, que existem apenas três tensões de cisalhamento independentes. Conseqüentemente, o campo tridimensional de tensões em um ponto fica completamente determinado por apenas seis componentes de tensão.

\subsection{Condições de Contorno}

As eqs. (4.2) devem ser satisfeitas em todos os pontos do corpo considerado Particularmente, as componentes de tensão atuantes no contorno devem estar em equilíbrio com as forças externas.

Projetando-se as componentes de tensão no contorno do corpo em análise (fig. (4.2a)), obtêm-se as componentes das forças de superficie, denominadas $\vec{p}$, tais que (fig. (4.2b)) 


$$
\begin{aligned}
& \mathrm{p}_{1}=\sigma_{11} \mathrm{n}_{1}+\sigma_{12} \mathrm{n}_{2}+\sigma_{13} \mathrm{n}_{3} \\
& \mathrm{p}_{2}=\sigma_{21} \mathrm{n}_{1}+\sigma_{22} \mathrm{n}_{2}+\sigma_{23} \mathrm{n}_{3} . \\
& \mathrm{p}_{3}=\sigma_{31} \mathrm{n}_{1}+\sigma_{32} \mathrm{n}_{2}+\sigma_{33} \mathrm{n}_{3}
\end{aligned}
$$

Utilizando-se notação matricial, as eqs. (4.8) podem ser escritas

$$
\{p\}=[\sigma]\{n\}
$$

onde

$$
\{p\}=\left\{\begin{array}{l}
p_{1} \\
p_{2} \\
p_{3}
\end{array}\right\}, \quad[\sigma]=\left[\begin{array}{lll}
\sigma_{11} & \sigma_{12} & \sigma_{13} \\
\sigma_{21} & \sigma_{22} & \sigma_{23} \\
\sigma_{31} & \sigma_{32} & \sigma_{33}
\end{array}\right], \quad\{n\}=\left\{\begin{array}{l}
n_{1} \\
n_{2} \\
n_{3}
\end{array}\right\} .
$$

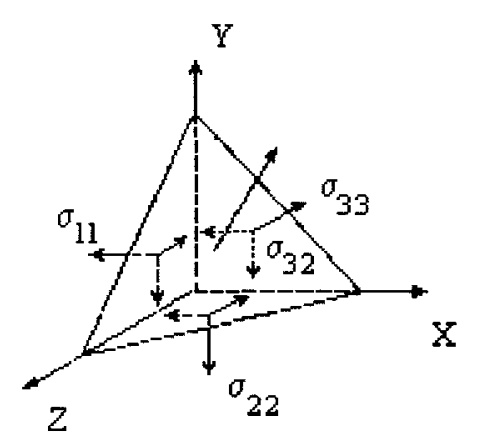

(A)

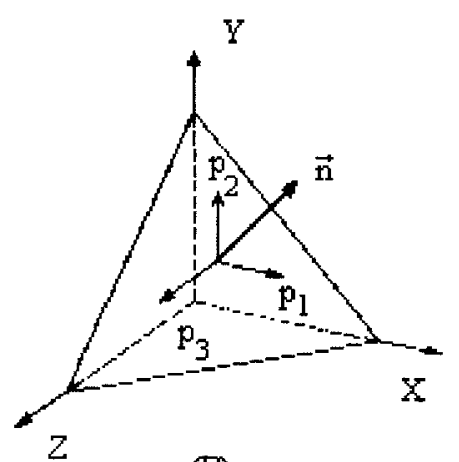

(B)

FIGURA 4.2 - Forças atuando em um tetraedro infinitesimal que representa um elemento de superfície: (a) estado de tensão em um ponto; (b) componentes do vetor força de superfície. MEGUID (1989).

Em notação indicial, as eqs. (4.8) têm a seguinte forma

$$
\mathrm{p}_{\mathrm{i}}=\sigma_{\mathrm{ij}} \mathrm{n}_{\mathrm{j}}
$$

onde $n_{1}, n_{2}$ e $n_{3}$ são os co-senos diretores da normal externa ao contorno (versor normal), em relação aos eixos coordenados $\mathrm{x}, \mathrm{y}$ e $\mathrm{z}$, isto é 


$$
n_{1}=\cos (\vec{n}, \overrightarrow{o x}), \quad n_{2}=\cos (\vec{n}, \overrightarrow{o y}), \quad n_{3}=\cos (\vec{n}, \overrightarrow{o z})
$$

ou

$$
\mathrm{n}_{1}=\overrightarrow{\mathrm{n}} \cdot \overrightarrow{\mathrm{e}}_{1}, \quad \mathrm{n}_{2}=\overrightarrow{\mathrm{n}} \cdot \overrightarrow{\mathrm{e}}_{2}, \quad \mathrm{n}_{3}=\overrightarrow{\mathrm{n}} \cdot \overrightarrow{\mathrm{e}}_{3},
$$

onde $\overrightarrow{\mathrm{e}}_{\mathrm{i}}$ representa um versor na direção i do sistema cartesiano de coordenadas.

As eqs. (4.2), (4.7) e (4.8) são atribuídas a Cauchy por TIMOSHENKO (1953).

No caso particular de um problema elástico bidimensional (cf. [4.4]), as condições de contorno típicas são (fig. (4.3), cf. [3.2]):

- Condições essenciais, geométricas ou de deslocamentos:

$$
\mathrm{u}_{\mathrm{k}}=\overline{\mathrm{u}}_{\mathrm{k}}, \text { em } \Gamma_{1}
$$

- Condições naturais, mecânicas, ou de forças de superfície:

$$
\mathrm{p}_{\mathrm{k}}=\sigma_{\mathrm{kj}} \mathrm{n}_{\mathrm{j}}=\overline{\mathrm{p}}_{\mathrm{k}}, \mathrm{em} \Gamma_{2}
$$

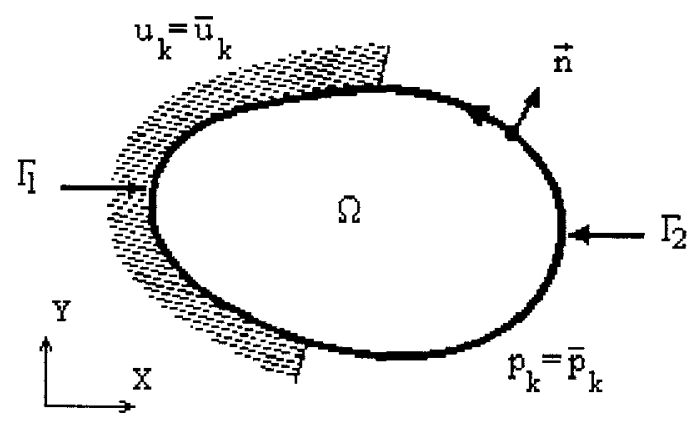

FIGURA 4.3 - Condições de contorno para um problema bidimensional. BREBBIA \& DOMINGUEZ (1989). 
onde $\Gamma=\Gamma_{1}+\Gamma_{2}$ e as barras indicam valores conhecidos

\subsection{Estados Planos}

Parece óbvio que a análise de um corpo tridimensional seja feita também no espaço tridimensional. Em determinadas situações, contudo, é possível abordar o problema tratando-o como bidimensional - desde que sejam assumidas certas aproximações. Os problemas elásticos bidimensionais, assim definidos, podem ser divididos em tensão plana ou deformação plana, dependendo de como o sólido em estudo é restringido na direção perpendicular ao plano em questão.

A seguir, esboçam-se as hipóteses básicas de cada um deles.

\subsubsection{Estado Plano de Tensão}

Considere-se, por exemplo, a fig. (4.4a), que mostra uma chapa solicitada por forças aplicadas em seu contorno, sendo estas paralelas ao plano da chapa e distribuídas uniformemente ao longo da espessura da mesma.

As hipóteses básicas aplicáveis a este problema são:

- A espessura da chapa (isto é, o comprimento na direção perpendicular ao plano) é pequena, quando comparada com as dimensões representativas da mesma no plano.

- Não há forças atuando nas faces perpendiculares ao eixo z.

- As forças volumétricas - quando houver - atuam apenas em planos paralelos a xy e são independentes de $z$, isto é, $b_{3}=0$ e $b_{1}, b_{2}$ são funções apenas de x e y. 
- As forças externas atuantes na chapa situam-se no plano e são independentes de $z$, isto é, $p_{3}=0$ e $p_{1}, p_{2}$ são funções apenas de $\mathrm{x}$ e $\mathrm{y}$.

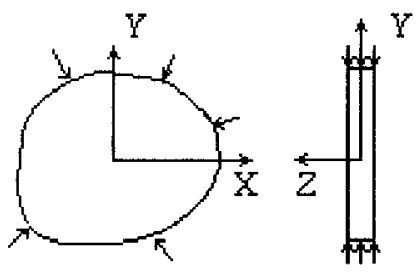

(A)

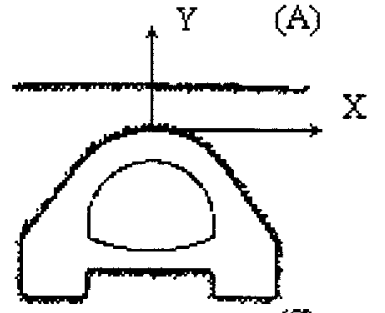

(C)

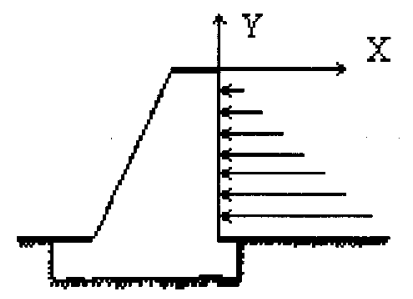

(B)

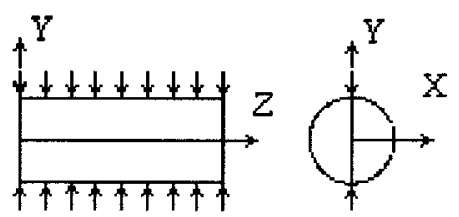

(D)

FIGURA 4.4 - Exemplos de problemas onde hipóteses simplificadoras podem ser aplicadas: (a) chapa (estado plano de tensão); (b) muro de arrimo com pressão lateral, (c) túnel e (d) cilindro comprimido por forças diametrais (estados planos de deformação). TIMOSHENKO \& GOODIER (1980).

Partindo-se destas hipóteses, é razoável supor que existam deslocamentos somente em planos paralelos ao plano xy e independentes da coordenada $z$. Vale a pena salientar, como lembram BREBBIA \& DOMINGUEZ (1989), que tais hipóteses violam a equação de compatibilidade (cf. [4.5]), apesar de sua utilização ser razoável na prática de engenharia.

\subsubsection{Estado Plano de Deformação}

Quando a dimensão do sólido em estudo, em uma direção (por exemplo, na direção z) é muito maior que as dimensões nas outras direções, é possível adotar simplificações semelhantes às anteriores. Isto é o que acontece em estruturas como muros de arrimo submetidos a pressão lateral (fig. 4.4b), túneis (fig. 4.4c) e cilindros comprimidos no plano diametral (fig. 4.4d), como é o caso em rolamentos. 
Se as forças atuantes em um corpo longo cilíndrico ou prismático são transversais e não variam ao longo do comprimento do mesmo, pode-se admitir que as seções extremas estão confinadas entre planos rígidos fixos, sem atrito, de tal forma que o deslocamento na direção axial fica impedido. Neste caso, não havendo deslocamento axial nas extremidades e, por simetria, na seção do meio, é possível assumir que todas a seções transversais estejam nas mesmas condições e assumir as seguintes hipóteses:

- Os deslocamentos $u_{3}$ nas seções extremas são nulos, uma vez que as mesmas estão impedidas de efetuar qualquer movimento (pois a espessura, na direção $z$, é muito maior que as dimensões representativas nas direções $\mathrm{x} e \mathrm{y}$ ).

- As forças volumétricas e de superficie atuando na superficie cilíndrica não têm componentes na direção $z$ e são independentes de $z$.

\subsection{Componentes de Deformação}

$\mathrm{Na}$ resolução de um problema bidimensional, a distribuição de tensões procurada deve satisfazer tanto as equações diferenciais de equilíbrio (eqs. (4.2a-c)) quanto as condições de contorno (eqs. (4.8a-c)). Estes dois conjuntos de equações, entretanto, são insuficientes para a determinação das componentes de tensão, tornando o problema estaticamente indeterminado.

A solução para o problema bidimensional é obtida considerando-se as componentes de deformação

$$
\varepsilon_{x}=\frac{\partial u}{\partial x}, \quad \varepsilon_{y}=\frac{\partial v}{\partial y}, \quad \gamma_{x y}=\frac{\partial u}{\partial y}+\frac{\partial v}{\partial x}
$$


onde $\mathrm{u}$ e $\mathrm{v}$ definem os campos de deslocamentos, respectivamente, nas direções $\mathrm{x}$ e $\mathrm{y}$. Essas expressões podem ser generalizadas e escritas em notação indicial:

$$
\varepsilon_{i j}=\frac{1}{2}\left(\frac{\partial u_{i}}{\partial x_{j}}+\frac{\partial u_{j}}{\partial x_{i}}\right)=\frac{1}{2}\left(u_{i, j}+u_{j, i}\right)
$$

onde

$$
\gamma_{\mathrm{xy}}=2 \varepsilon_{\mathrm{xy}}
$$

A partir das equações acima, é possível obter uma relação entre as componentes de deformação, a chamada condição ou equação de compatibilidade, a saber

$$
\frac{\partial^{2} \varepsilon_{x}}{\partial y^{2}}+\frac{\partial^{2} \varepsilon_{y}}{\partial x^{2}}=\frac{\partial^{2} \gamma_{x y}}{\partial x \partial y}
$$

A eq. (4.18) pode ser transformada em uma relação entre componentes de tensão através da Lei de Hooke. Em geral, a distribuição de tensões, em um problema bidimensional, pode ser determinada a partir do conjunto de equações formado pelas equações de equilibrio, condições de contorno e pela equação de compatibilidade.

\subsection{Relações Constitutivas}

Os estados de tensão e deformação existentes em um corpo relacionam-se através das equações tensão-deformação ou relações constitutivas do material Para um material elástico linear, é possível definir duas constantes (as constantes de Lamé, $\lambda$ e $\mu$ ), a partir das quais é possivel escrever (BREBBIA \& DOMINGUEZ (1989)) 


$$
\sigma_{\mathrm{ij}}=\lambda \delta_{\mathrm{ij}} \varepsilon_{\mathrm{kk}}+2 \mu \varepsilon_{\mathrm{ij}}
$$

onde $\delta_{\mathrm{ij}}$ é o delta de Kronecker (cf. [3.1.3]) e a convenção de somatório vale para $\varepsilon_{\mathrm{kk}}$, a deformação volumétrica.

Invertendo-se a eq. (4.19), obtém-se

$$
\varepsilon_{\mathrm{ij}}=-\frac{\lambda}{2 \mu(3 \lambda+2 \mu)} \delta_{\mathrm{ij}} \sigma_{\mathrm{kk}}+\frac{1}{2 \mu} \sigma_{\mathrm{ij}}
$$

As constantes de Lamé podem ser escritas em função de outras mais usuais, tais como o módulo de cisalhamento (ou módulo de elasticidade transversal), $G$, o módulo de elasticidade (ou módulo de elasticidade longitudinal ou módulo de Young), E, e o coeficiente de Poisson, $v$, da seguinte maneira

$$
\mu=\mathrm{G}=\frac{\mathrm{E}}{2(1+v)}, \quad \lambda=\frac{v \mathrm{E}}{(1+v)(1-2 v)}, \quad \frac{\lambda}{\mu}=\frac{2 v}{1-2 v} .
$$

Escrevendo-se as componentes de tensão e deformação (eqs. (4.19) e (4.20), respectivamente) em função de $\mathrm{E}$ e $v$, obtêm-se

$$
\sigma_{\mathrm{ij}}=\frac{E}{(1+v)}\left[\frac{v}{(1-2 v)} \delta_{\mathrm{ij}} \varepsilon_{\mathrm{kk}}+\varepsilon_{\mathrm{ij}}\right]
$$

$$
\varepsilon_{\mathrm{ij}}=-\frac{v}{E} \delta_{\mathrm{ij}} \sigma_{\mathrm{kk}}+\frac{1+v}{E} \sigma_{\mathrm{ij}}
$$

No MEC, trabalha-se com a formulação para o estado plano de deformação (cf. [4.4.2]), já que a solução fundamental é conhecida para este tipo de problema. Equações equivalentes às duas últimas podem ser obtidas pela modificação das constantes elásticas da seguinte maneira: 


$$
\mathrm{E}^{\prime}=\frac{(1+2 v)}{(1+v)^{2}} \mathrm{E}, \quad v^{\prime}=\frac{v}{(1+v)}
$$

Deste modo, a formulação também pode ser utilizada para a resolução de problemas do estado plano de tensão.

\subsection{Tensões e Deformações Iniciais}

Em muitos problemas, pode-se ter um estado inicial de tensões ou deformações provocado por variações térmicas ou por outras causas quaisquer. A consideração de tais estados permite analisar, por exemplo, o comportamento plástico dos materiais, considerado como um desvio do comportamento linear (fig. (4.5)).
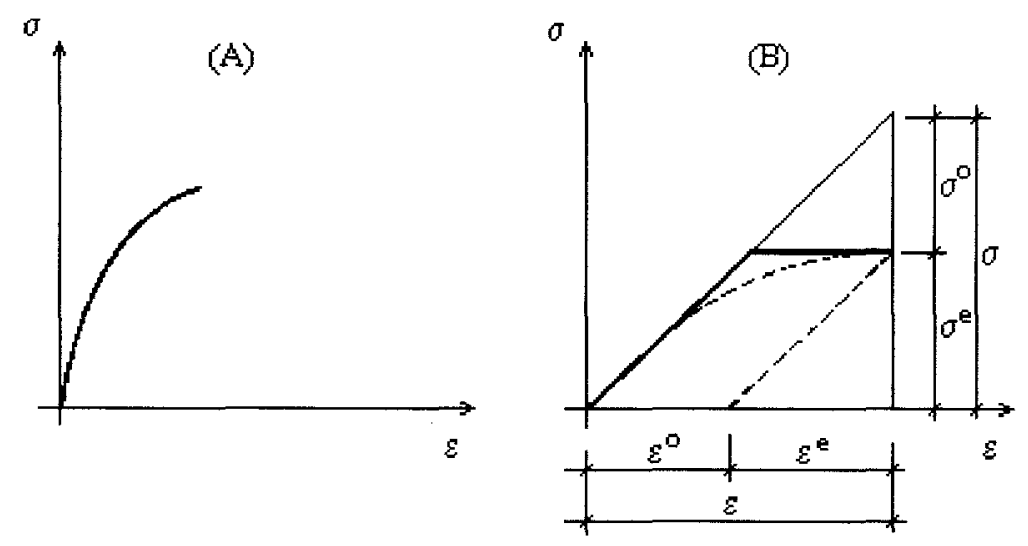

FIGURA 4.5 - Diagramas tensão-deformação: (a) material não-linear; (b) material elasto-plástico perfeito.

Considere-se um estado inicial de deformações, a título de exemplo. Neste caso, as componentes elásticas de deformação (fig. (4.5b)) são obtidas subtraindo-se, das deformações totais, a parcela devida às deformações iniciais, isto é 


$$
\varepsilon_{\mathrm{ij}}^{\mathrm{e}}=\varepsilon_{\mathrm{ij}}-\varepsilon_{\mathrm{ij}}^{0}
$$

onde $\varepsilon_{\mathrm{ij}}^{e}$ indica as componentes elásticas do tensor deformação (deformação elástica), $\varepsilon_{\mathrm{ij}}$ as componentes totais (deformação total) e $\varepsilon_{\mathrm{ij}}^{0}$ as componentes iniciais do mesmo (deformação inicial).

É possível definir as tensões (elásticas) a partir das deformações elásticas. Considerando-se a fig. (4.5b) e substituindo-se a eq. (4.25) na eq. (4.19), tem-se (explicitando-se que se tratam de componentes elásticas pelo índice sobrescrito ${ }^{\mathrm{e}}$ ):

$$
\begin{aligned}
\sigma_{\mathrm{ij}}^{e} & =\lambda \delta_{\mathrm{ij}} \varepsilon_{\mathrm{kk}}^{\mathrm{e}}+2 \mu \varepsilon_{\mathrm{ij}}^{\mathrm{e}}= \\
& =\lambda \delta_{\mathrm{ij}}\left(\varepsilon_{\mathrm{kk}}-\varepsilon_{\mathrm{kk}}^{0}\right)+2 \mu\left(\varepsilon_{\mathrm{ij}}-\varepsilon_{\mathrm{ij}}^{0}\right)= \\
& =\left(\lambda \delta_{\mathrm{ij}} \varepsilon_{\mathrm{kk}}+2 \mu \varepsilon_{\mathrm{ij}}\right)-\left(\lambda \delta_{\mathrm{ij}} \varepsilon_{\mathrm{kk}}^{0}+2 \mu \varepsilon_{\mathrm{ij}}^{0}\right)= \\
& =\sigma_{\mathrm{ij}}-\sigma_{\mathrm{ij}}^{0}
\end{aligned}
$$

onde as componentes $\sigma_{\mathrm{ij}}$ representam as tensões totais e as componentes $\sigma_{\mathrm{ij}}^{0}$ representam as tensões iniciais, estas definidas por

$$
\sigma_{\mathrm{ij}}^{0}=\lambda \delta_{\mathrm{ij}} \varepsilon_{\mathrm{kk}}^{0}+2 \mu \varepsilon_{\mathrm{ij}}^{0}
$$

CRISFIELD (1991) e ZIENKIEWICZ \& TAYLOR (1991) apresentam descrições dos diversos métodos (incrementais, iterativos ou combinados) de análise utilizados em problemas que envolvem não-linearidade física. 


\section{INTRODUÇÃO FRATURAMENTO}

\subsection{Por que Utilizar a Mecânica do Fraturamento?}

Considerando-se que as estruturas - em particular as estruturas de concreto — têm sido projetadas e construídas com sucesso, pode parecer desnecessário alterar a prática corrente com a inclusão da mecânica do fraturamento nos atuais critérios de projeto. Contudo, o ACI (1989) apresenta pelo menos cinco razões convincentes para se estudar como fazê-lo:

\subsubsection{Energia Necessária Para a Formação de Fissuras}

O surgimento de fissuras depende da tensão atuante, enquanto que a propagação real das mesmas requer uma certa energia (a energia de fraturamento), que representa a energia de superficie de um sólido (cf. [5.7]). Seria de se esperar, portanto, que um critério de resistência para previsão de fraturamento levasse em conta o balanço energético envolvido. 


\subsubsection{Objetividade dos Cálculos}

Uma teoria é considerada objetiva quando os resultados de cálculos efetuados com a utilização da mesma não dependem de aspectos subjetivos, como a escolha de coordenadas, da malha utilizada para discretizar o domínio em questão etc. Uma teoria que se apresenta como subjetiva deve ser rejeitada sem sequer haver necessidade de verificação experimental.

Para ilustrar o problema, considere-se a abordagem de fraturamento difuso, introduzida por RASHID (1968) na análise do fraturamento de concreto utilizando-se elementos finitos.

De acordo com essa abordagem, a tensão em um elemento finito é limitada pela resistência à tração do material, $\mathrm{f}$, e, após este limite ser alcançado, a tensão no elemento deve decrescer. Inicialmente, foi adotado que a tensão decrescia repentinamente até zero (fig. (5.1a)); mas, como logo se percebeu, resultados melhores e mais realistas seriam obtidos se a tensão fosse reduzida gradualmente, isto é, se o material exibisse amolecimento (fig. (5.1b), (SCANLON (1971), LIN \& SCORDELIS (1975)).

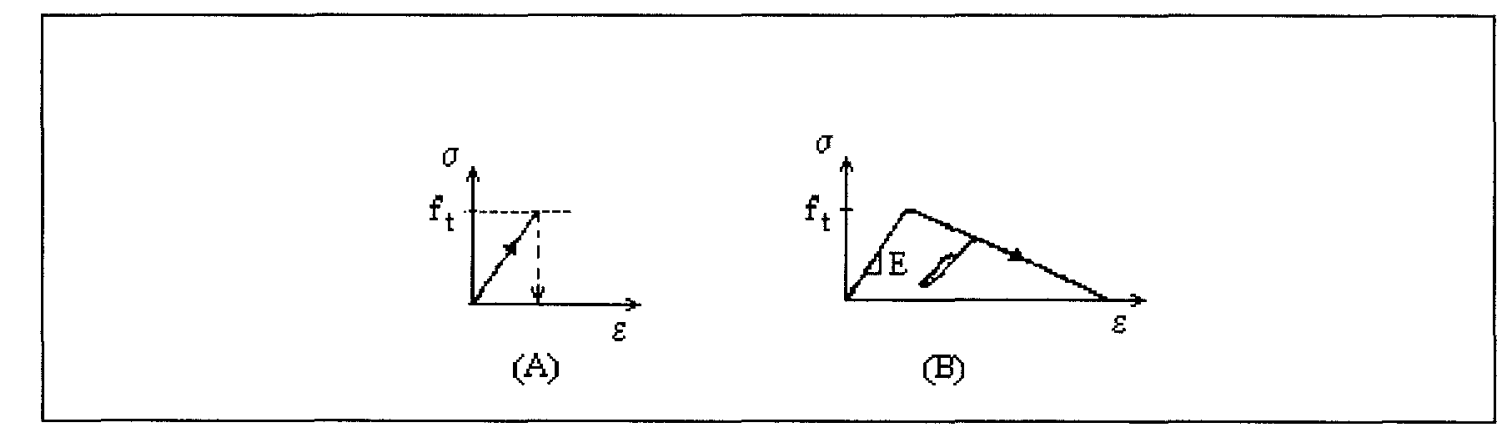

FIGURA 5.1 - Relações constitutivas. (a) Fraturamento difuso, (b) amolecimento de deformações. ACI (1989).

Após essa hipótese ter sido largamente utilizada, com implementação em programas de elementos finitos de grande porte, descobriu-se que as propriedades de convergência estavam incorretas e o resultado dos cálculos não eram objetivos em 
relação à escolha da malha utilizada (BAZANT (1976), BAZANT \& CEDOLIN $(1979,1980,1983))$. Problemas semelhantes são encontrados quando a análise do processo de fraturamento é feita utilizando-se critérios de resistência.

O problema de sensibilidade a malhas grosseiras pode ser ilustrado pelos painéis retangulares da fig. (5.2), submetidos a um deslocamento vertical uniforme no topo. Admite-se que a região próxima ao centro, do lado esquerdo, possua uma resistência menor que as demais. Como conseqüência, uma banda de fratura difusa (cf. [5.5.2]) começa a crescer da esquerda para a direita.

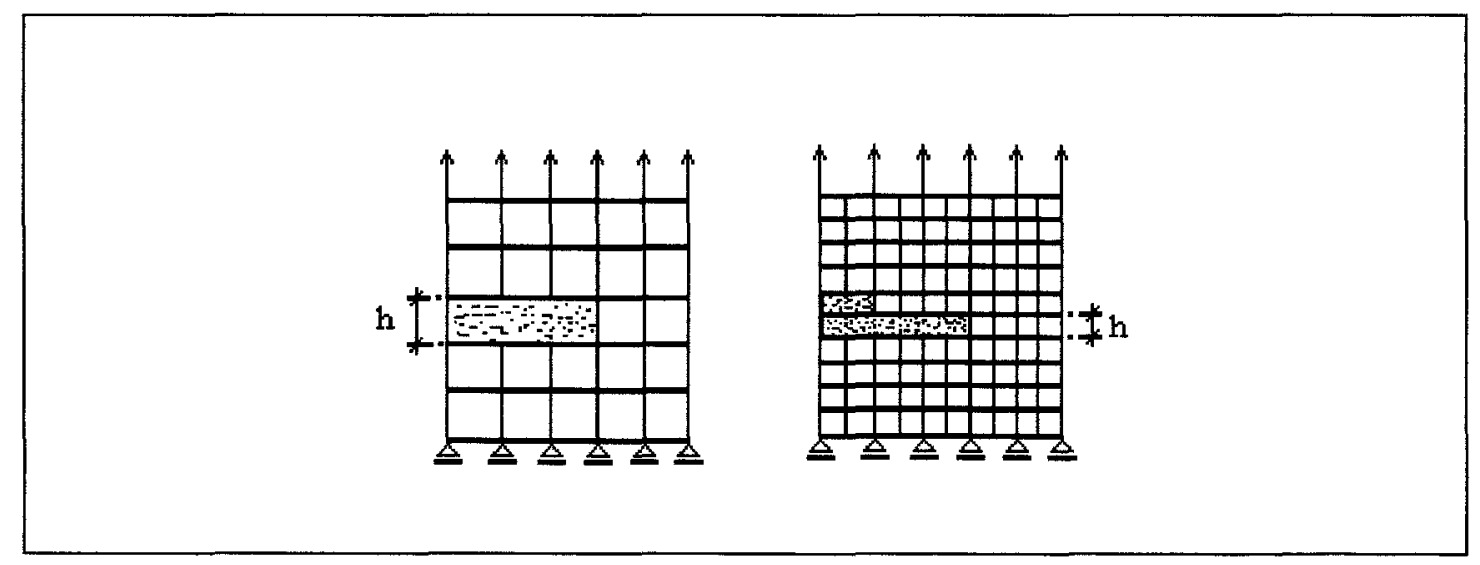

FIGURA 5.2 - Exemplo de sensibilidade a malhas grosseiras. ACI (1989).

A aplicação da solicitação foi feita de forma incremental e duas redes de elementos finitos com malhas de tamanhos diferentes foram utilizadas. Os resultados numéricos típicos são mostrados na fig. (5.3).

No diagrama carga-deslocamento, fig. (5.3a), vê-se que tanto a carga última quanto o amolecimento pós-pico são fortemente dependentes do tamanho da malha, sendo aproximadamente proporcionais a $\mathrm{h}^{-1 / 2}$, onde $\mathrm{h}$ é o tamanho do elemento. Traçando-se o diagrama carga (reação) x comprimento da banda de fratura, encontram-se novas diferenças (fig. (5.3b)). A energia dissipada, devida ao fraturamento, diminui com o refinamento da malha de elementos finitos (fig. (5.3c)) e converge para 0 quando $\mathrm{h}$ tende a zero. 
(A)
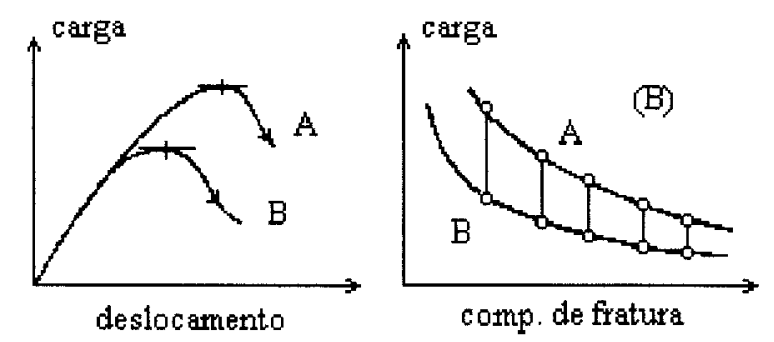

deslocamento

comp. de fratura

(C)

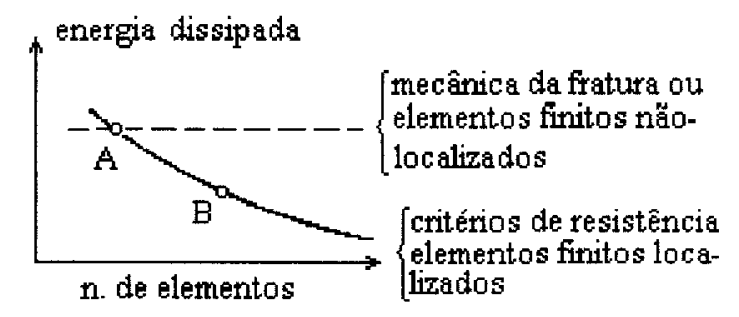

FIGURA 5.3 - Resultados numéricos do exemplo anterior. (a) Diagramas carga-deslocamento, (b) diagramas carga-comprimento da banda de fratura e (c) relação entre energia dissipada devido ao fraturamento e refinamento da malha de elementos finitos. ACI (1989).

A falta de objetividade acima descrita é fisicamente inaceitável. Um modo de evitá-la é através da adoção de algum modelo de mecânica do fraturamento. Especificando-se a energia dissipada no processo de fraturamento (por unidade de comprimento da fratura ou da banda de fratura), força-se a dissipação total de energia a ser independente da subdivisão dos elementos (linha pontilhada na fig. (5.3c)) e, da mesma forma, a carga última.

\subsubsection{Falta do Patamar de Escoamento}

Existem, basicamente, dois tipos de ruína local: plástica (dúctil) e frágil, o que pode ser observado a partir dos diagramas solicitação-deslocamento (ou, alternativamente, dos diagramas tensão-deformação) de diversos materiais.

A característica típica da ruína dúctil é o desenvolvimento seqüencial de mecanismos, com um único grau de liberdade, em várias partes da estrutura. As 
evidências deste tipo de ruína podem ser observadas pela existência de um patamar de escoamento no diagrama solicitação-deslocamento (fig. (5.4a)). A inexistência desse patamar indica que a ruína não é plástica, mas sim frágil (fig. 5.4b).

(A)

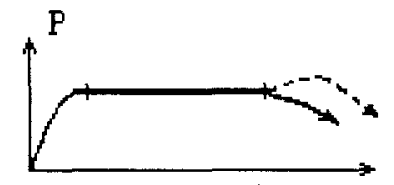

(B)

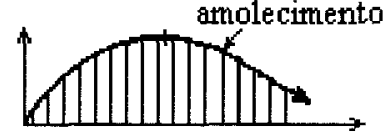

deslocamento

FIGURA 5.4 - Diagrama solicitação-deslocamento de estruturas (a) dúcteis e (b) frágeis. ACI (1989).

Não havendo efeitos geométricos significantes - como o efeito P- $\Delta$ na flambagem - a ausência do patamar de escoamento implica na existência de amolecimento do material devido a fissuramento ou outra espécie de dano; implica que o processo de ruína não pode desenvolver um mecanismo com um grau de liberdade único, mas consiste na propagação da zona de fratura (cf. [5.5.1]) através da estrutura. Deste modo, a ruína não é simultânea e se propaga.

Para ilustrar este comportamento, considere-se a ruína por cisalhamento de uma laje submetida a punção (fig. 5.5). As distribuições típicas (aproximadas) de tensões de tração, ao longo da superficie de ruína, são mostradas na figura. Se o material for plástico, a seção transversal plastifica-se gradualmente, até que todos os seus pontos estejam submetidos à tensão de escoamento. Entretanto, se o material exibe amolecimento, o pico de tensão desloca-se ao longo da superficie de falha deixando uma tensão reduzida (amolecimento) por onde passa.

Se a estrutura for de pequeno porte, a redução de tensão é suave e o comportamento não difere muito do encontrado na análise limite plástica. Em caso 
contrário, quando a estrutura é de grande porte, as soluções fornecidas pela análise limite superestimam de forma grosseira a carga de ruptura.

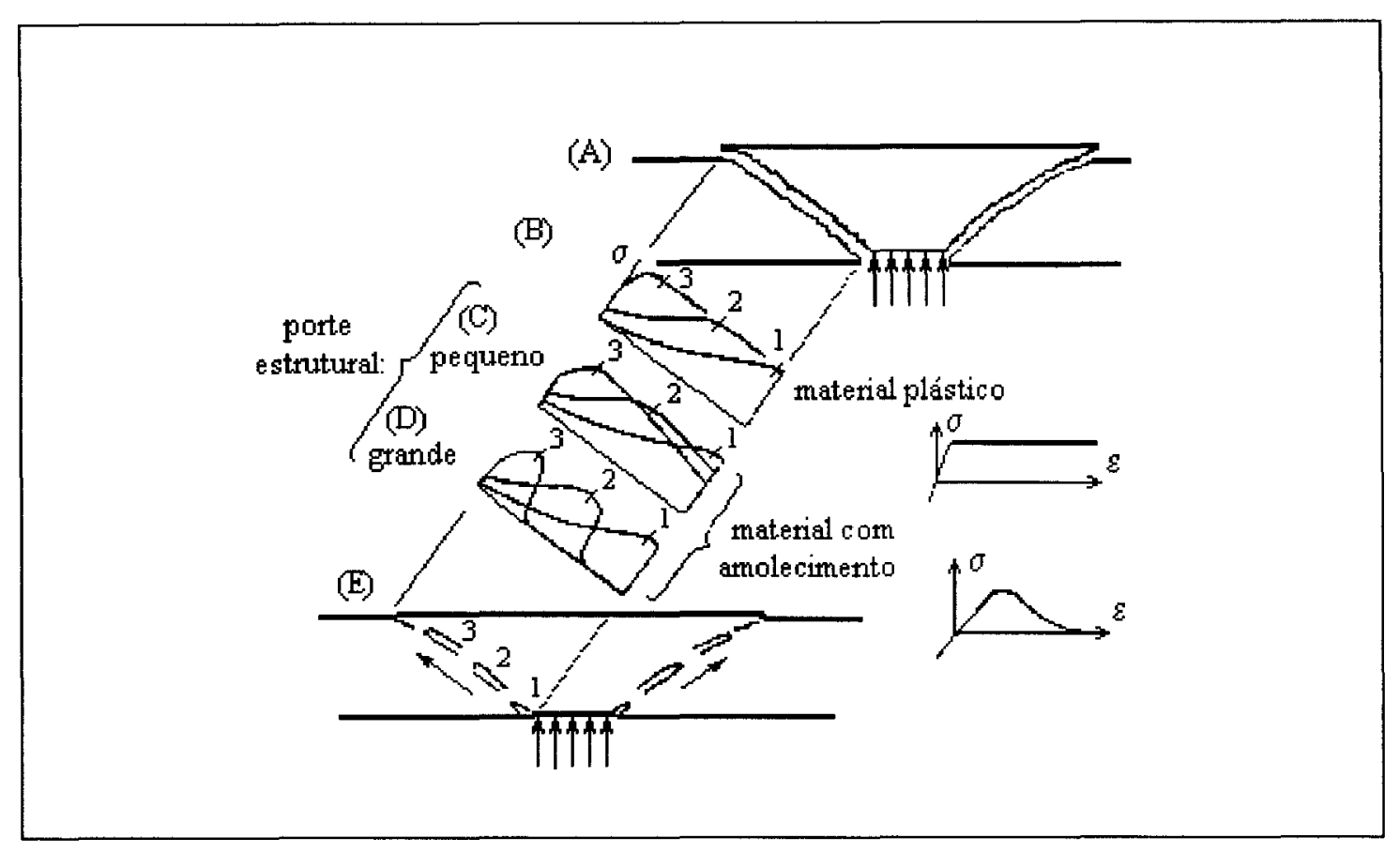

FIGURA 5.5 - Natureza progressiva da ruína ilustrada pelo puncionamento de uma laje. ACI (1989).

\subsubsection{Capacidade de Absorção de Energia e Ductilidade}

A análise limite plástica não é capaz de fornecer informações sobre o comportamento pós-pico da solicitação, bem como sobre a energia dissipada nesse processo. Algum modelo de mecânica do fraturamento é necessário.

\subsubsection{Efeito de Escala}

$O$ efeito de escala é definido através da comparação entre estruturas geometricamente semelhantes de tamanhos (dimensões, portes) diferentes, sendo convenientemente caracterizado em termos da tensão nominal máxima $\sigma_{\mathrm{n}}$ na carga última, $P_{u}$. Quando $\sigma_{n}$, para estruturas geometricamente semelhantes de tamanhos 
diferentes, tem o mesmo valor, diz-se que não há efeito de escala. A dependência de $\sigma_{\mathrm{n}}$ em relação ao tamanho da estrutura é chamada de efeito de escala.

Um critério de fraturamento pode ser definido como uma condição matemática para a determinação do fraturamento de uma estrutura quando submetida a solicitação monotônica. Uma das condições essenciais que deve satisfazer é prever adequadamente o efeito de escala em sua faixa de aplicabilidade, isto é, deve descrever adequadamente a influência do tamanho na solicitação última, quando um conjunto de corpos geometricamente semelhantes são considerados sujeitos à mesma solicitação.

De acordo com as teorias clássicas, tais como a análise elástica com tensões admissíveis, a análise limite plástica (bem como quaisquer outras teorias que utilizem algum tipo de critério de resistência em termos de tensões), $\sigma_{\mathrm{n}}$ é constante, isto é, independe do tamanho da estrutura.

Por contraste, as ruínas regidas pela mecânica do fraturamento elástica linear exibem um efeito de escala acentuado, ilustrado na fig. (5.6) pela linha pontilhada com inclinação $-1 / 2$.
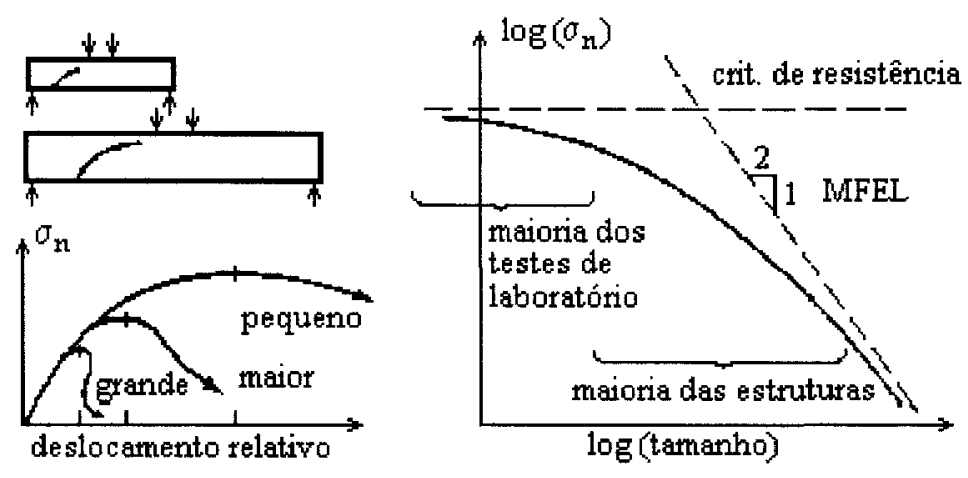

FIGURA 5.6 - O efeito de escala da mecânica do fraturamento em estruturas geometricamente semelhantes de portes diferentes ACI (1989). 
As estruturas reais de concreto exibem um efeito de escala intermediário, ilustrado pela linha sólida na figura. Esta curva aproxima a linha horizontal dos critérios de resistência se a estrutura for de pequeno porte, e a linha inclinada da mecânica do fraturamento elástica linear se a estrutura for de grande porte. Este efeito de escala, que é geralmente ignorado pelas normas atuais, é (obviamente) importante no projeto de estruturas de concreto e, portanto, existe a necessidade de um critério não-linear de fraturamento.

"O efeito de escala no fraturamento de rochas é análogo ao de concreto, por conta das semelhanças no mecanismo de fraturamento. Em metais, (...) o mecanismo de arredondamento da frente de fratura (crack blunt) é diferente; contudo, o efeito de escala é semelhante. (...) O efeito de escala verdadeiro em estruturas de concreto representa uma transição gradual da linha horizontal para a linha inclinada." (BAZANT (1984), p. 519-520, cf. fig. (5.6)).

BAZANT (1984) equacionou o efeito de escala (em função dos parâmetros relacionados ao fraturamento) em concreto, rocha e metais. Sua análise baseou-se na hipótese de que a liberação de energia, causada pelo fraturamento, depende tanto do comprimento quanto da área da banda de fratura (cf. [5.5.2]). Também demonstrou que o efeito de escala consiste em uma transição suave dos critérios de resistência (aplicados a estruturas de pequeno porte) para a MFEL (aplicada a estruturas de grande porte, cf. [5.3]) e que a tensão nominal na ruína, $\sigma_{n}$, diminui (com o porte estrutural) da seguinte maneira:

$$
\sigma_{\mathrm{n}}=\frac{\sqrt{1-\frac{\mathrm{E}_{\mathrm{c}}}{\mathrm{E}_{\mathrm{t}}}} f_{\mathrm{t}}}{\sqrt{1+\frac{\lambda}{\lambda_{0}}}}=\frac{\mathrm{B} f_{\mathrm{t}}}{\sqrt{1+\beta}}
$$

onde $E_{c}$ é o módulo de elasticidade tangente do concreto; $E_{t}$ é o módulo de elasticidade durante o amolecimento; $\lambda_{0}$ é uma constante e $\lambda$ é um comprimento estrutural característico relativo. $O$ parâmetro $\beta$ é chamado de índice de fragilidade. 
Bazant verificou que, se houver armadura presente à frente da fratura, e esta se comportar elasticamente, a diminuição de $\sigma_{\mathrm{n}}$ é do mesmo tipo, mas acontece em tamanhos estruturais maiores; entretanto, se a armadura escoar, a diminuição de $\sigma_{n}$ termina. Explorando o fato de que, em metais, o tamanho da zona de escoamento à frente da fratura é aproximadamente constante, mostrou (utilizando análise dimensional) que o fraturamento elasto-plástico provoca um efeito de escala semelhante.

O ACI (1989, p. 62-63) e DI TOMMASO (1989) apresentam definições propostas por vários autores para o índice de fragilidade. ELFGREN (1989b) definiu o índice de fragilidade como a relação entre a energia elástica armazenada em uma estrutura e a energia necessária para a propagação de uma fratura através da mesma, ou seja,

$$
\beta=\frac{\text { energia ela'stica }}{\text { energia de fraturamento }}=\frac{\mathrm{L}^{3}\left(f_{\mathrm{t}}\right)^{2} / \mathrm{E}}{\mathrm{L}^{2} \mathrm{G}_{\mathrm{F}}}=\frac{\mathrm{L}\left(f_{\mathrm{t}}\right)^{2}}{\mathrm{EG}_{\mathrm{F}}}
$$

onde L caracteriza o tamanho (comprimento, porte) da estrutura, $\left(f^{t}\right)^{2} /$ E é a energia elástica armazenada, na ruína, em um volume unitário, enquanto que $G_{F}$ é a energia de fraturamento (cf. [5.7]).

Analizando-se a eq. (5.2), é possível definir o índice de fragilidade para vigas biapoiadas. Neste caso, L é o comprimento do vão. Aproximando-se a curva de amolecimento por uma reta, chega-se a

$$
\beta=\frac{2 \mathrm{~L} f_{\mathrm{t}}}{\mathrm{Ew}_{\mathrm{c}}}
$$

O ACI (1989) esclarece que valor $\beta=1$ corresponde, no gráfico do efeito de escala (fig. (5.6)), ao ponto onde a assíntota horizontal do critério de resistência e a assíntota inclinada da mecânica da fratura elástica linear se interceptam. Para $\beta<1$, o comportamento aproxima-se da análise limite plástica e, para $\beta>1$, é mais próximo da 
mecânica do fraturamento elástica linear. Se $\beta<1$ ou $\beta>1$, a mecânica do fraturamento não-linear não é necessária. $\mathrm{O}$ método de análise, portanto, pode ser escolhido como segue:

\section{- Análise Limite Plástica: $\quad \beta<0.1$}

- Mecânica do Fraturamento Não-Linear: $\quad 0.1 \leq \beta \leq 10$

- Mecânica do Fraturamento Elástica Linear: $\beta>10$

Segundo o ACI (1989), diversos experimentos foram efetuados com a finalidade de verificar a lei do efeito de escala e sua influência na ruína de estruturas de concreto. Os resultados experimentais apresentaram boa concordância com a teoria e podem ser considerados como a verificação experimental da aplicabilidade da mecânica do fraturamento à análise da ruína frágil de estruturas de concreto.

\subsection{Modos de Fraturamento}

Segundo RAVEENDRA \& CRUSE (1989), a modelagem elástica do comportamento do ponto na extremidade da fratura faz uso da deformação devida a três modos primários de solicitação, como ilustrado na fig. (5.7). Os três modos são: modo de abertura (Modo I ou modo de tração), devido a tensões normais; modo de deslizamento (Modo II ou modo de cisalhamento no plano), devido a tensões de cisalhamento atuantes no plano de fraturamento; e o modo de rasgamento (Modo III, modo de fendilhamento ou modo de cisalhamento anti-plano), devido a tensões de cisalhamento atuando fora do plano de fraturamento. 


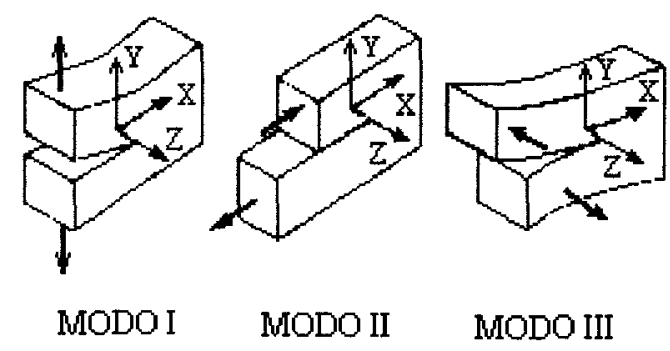

FIGURA 5.7 - Três modos principais de solicitação de um corpo fraturado. RAVEENDRA \& CRUSE (1989).

\subsection{Mecânica do Fraturamento Elástica Linear (MFEL)}

Quando a resistência à tração de um material frágil é alcançada, começam a surgir fissuras. A mecânica do fraturamento estuda as condições existentes em volta e adiante da extremidade de uma fissura. Em particular, as idealizações baseadas na hipótese de desprezar a plasticidade na extremidade da fissura é conhecida como Mecânica do Fraturamento Elástica Linear (MFEL).

Em materiais reais, sempre haverá algum comportamento plástico perto da extremidade da fratura, comportamento este motivado pela concentração de tensões induzida pela existência da própria fratura. Entretanto, na grande maioria dos problemas práticos, esta região é tão pequena que pode ser negligenciada, ou corrigida, a fim de que os resultados lineares possam ser utilizados. Essa é a hipótese básica da MFEL, ou seja, a deformação inelástica na vizinhança da extremidade da fratura, devida à concentração de tensões, é considerada pequena em comparação com o tamanho da fratura e outros comprimentos característicos. 
A aplicação da MFEL significa que uma singularidade de tensões é admitida na extremidade da fratura e que a propagação da mesma depende da intensidade dessa singularidade, por exemplo, expressa como um fator de intensidade de tensões $\mathrm{K}_{\mathrm{I}}$. A fratura propaga-se quando a intensidade das tensões atinge um valor crítico, isto é, quando $\mathrm{K}_{\mathrm{I}}$ atinge $\mathrm{K}_{\mathrm{IC}}$, por exemplo.

"Embora a mecânica do fraturamento pareça apropriada para analisar o concreto quando a ruína acontecer devido a fissuramento, já se mostrou claramente que a mecânica do fraturamento elástica linear (clássica) não se aplica ao concreto (...), excetuando-se, possivelmente, no caso de estruturas excepcionalmente grandes. Por esta razão, e talvez também por razões de simplicidade, as normas atuais para estruturas de concreto (...) aderem universalmente aos critérios baseados em resistência. Entretanto, esses critérios não concordam com os dados de testes de fraturamento de forma melhor que a mecânica do fraturamento clássica. Mais ainda, são inconsistentes quando aplicados em análises via elementos finitos, já que conduzem a dependências grosseiras dos resultados em relação ao tamanho dos elementos (...) e em relação à consideração de queda repentina de tensões ou amolecimento (...).

Recentemente, entretanto, demonstrou-se (...) que o concreto obedece à mecânica do fraturamento, desde que se utilize uma forma adequada de mecânica do fraturamento não-linear, onde o arredondamento da extremidade de fratura (crack blunt) pelo grande tamanho da zona microfissurada é levado em consideração." (BAZANT (1984), p. 518-519).

Ou seja, a MFEL, em regra, não é aplicável a estruturas de concreto de tamanho moderado ou pequeno (cf. [5.1.5]). Sua aplicabilidade, entretanto, também pode ser estendida através da introdução de um comprimento de fratura "efetivo" (HILLERBORG (1983)), adicionado ao comprimento de fratura real (cf. [5.5.2]). Este modo simples de modificar a MFEL fornece resultados melhores, porém ainda insatisfatórios. 
Outros métodos também foram propostos. Um deles é a combinação de uma pressão de fechamento dentro da zona de processo de fratura com o cálculo de um fator de intensidade de tensões na extremidade desta zona. Isto pode ser chamado de combinação do modelo de fratura fictícia (cf. [5.5.1]) com a MFEL, onde parte da energia de fratura é absorvida pelas forças de fechamento e parte na extremidade da fratura. Um outro modo de modificar a MFEL foi proposto por JENQ \& SHAH (1985).

Todas as análises baseadas na MFEL apresentam o inconveniente de serem, em princípio, aplicáveis apenas a estruturas já fraturadas, enquanto que as aplicações práticas mais interessantes dizem respeito a estruturas que não apresentam fraturas.

Para o ACI (1989), as divergências existentes no concreto em relação à teoria clássica da MFEL (cf. [5.1]) são causadas pela existência de fissuração (ou dano) distribuída ao longo de uma zona de processo de fraturamento, com amolecimento progressivo, em torno da extremidade de uma fratura progressiva.

\subsubsection{Crack Estacionário Devido a Solicitações Elásticas}

Uma fratura pode ser idealizada como um par de linhas (ou superficies) interceptando-se em alguma região - a extremidade da fratura — segundo um ângulo agudo. As tensões na extremidade de uma fratura podem ser expressas como uma série infinita com termo principal inversamente proporcional à raiz quadrada da distância à extremidade da fratura (WILLIAMS (1957)). A tensão, portanto, é teoricamente infinita na extremidade. O coeficiente do primeiro termo está relacionado ao fator de intensidade de tensão, usualmente considerado como o único parâmetro importante a ser determinado em problemas de mecânica do fraturamento. Entretanto, vários estudos mostraram que os termos de segunda ordem podem ser importantes na caracterização do comportamento próximo à extremidade da fratura. 


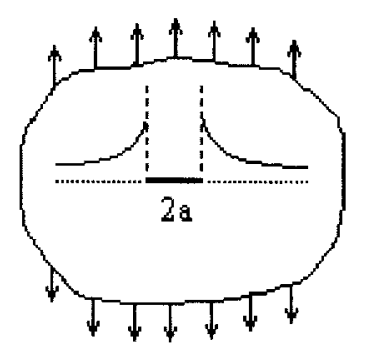

FIGURA 5.8 - Distribuição de tensões próxima à extremidade de uma fratura. REINHARDT (1989).

IRWIN (1957) mostrou que as tensões na vizinhança da extremidade da fratura (fig. (5.8)) tinham a forma

$$
\sigma_{\mathrm{ij}}=\frac{\mathrm{K}}{\sqrt{2 \pi \mathrm{r}}} \mathrm{f}_{\mathrm{ij}}(\theta)+\cdots
$$

onde $\mathrm{i}$ e $\mathrm{j}$ referem-se às coordenadas cartesianas e $\mathrm{r}$ e $\theta$ são as coordenadas polares; $\mathrm{f}_{\mathrm{ij}}$ é uma função trigonométrica; $K$ determina a grandeza das tensões elásticas e é chamado de fator de intensidade de tensão (FIT).

Definindo as coordenadas na extremidade de uma fratura pela fig. (5.9), IRWIN (1958)1 descreveu as expressões das tensões e dos deslocamentos:

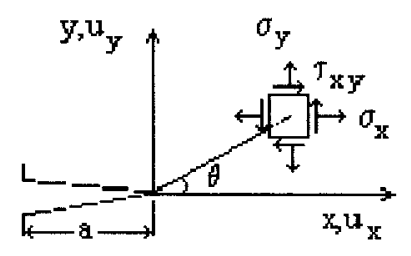

FIGURA 5.9 - Coordenadas na extremidade da fratura. SMITH (1988).

${ }^{1}$ IRWIN, G. R. Fracture. In: Handbuch der Physik. Heildelberg, Springer-Verlag, 1958, v6, p. 551-590 apud SMITH (1988). 


$$
\begin{aligned}
& \sigma_{y}=\frac{K_{I}}{\sqrt{2 \pi r}} \cos \left(\frac{\theta}{2}\right)\left[1+\operatorname{sen}\left(\frac{\theta}{2}\right) \operatorname{sen}\left(\frac{3 \theta}{2}\right)\right] \\
& +\frac{\mathrm{K}_{\mathrm{I}}}{\sqrt{2 \pi \mathrm{r}}} \operatorname{sen}\left(\frac{\theta}{2}\right) \cos \left(\frac{\theta}{2}\right) \cos \left(\frac{3 \theta}{2}\right)+\mathrm{O}\left(\mathrm{r}^{0}\right)+\mathrm{O}\left(\mathrm{r}^{\frac{1}{2}}\right) \\
& \sigma_{\mathrm{x}}=\frac{\mathrm{K}_{\mathrm{I}}}{\sqrt{2 \pi \mathrm{r}}} \cos \left(\frac{\theta}{2}\right)\left[1-\operatorname{sen}\left(\frac{\theta}{2}\right) \operatorname{sen}\left(\frac{3 \theta}{2}\right)\right] \\
& -\frac{\mathrm{K}_{\mathrm{II}}}{\sqrt{2 \pi \mathrm{r}}} \operatorname{sen}\left(\frac{\theta}{2}\right)\left[2+\cos \left(\frac{\theta}{2}\right) \cos \left(\frac{3 \theta}{2}\right)\right]+\mathrm{O}\left(\mathrm{r}^{0}\right)+\mathrm{O}\left(\mathrm{r}^{\frac{1}{2}}\right) \\
& \tau_{\mathrm{xy}}=\frac{\mathrm{K}_{\mathrm{I}}}{\sqrt{2 \pi \mathrm{r}}} \operatorname{sen}\left(\frac{\theta}{2}\right) \cos \left(\frac{\theta}{2}\right) \cos \left(\frac{3 \theta}{2}\right) \\
& +\frac{\mathrm{K}_{\mathrm{II}}}{\sqrt{2 \pi \mathrm{r}}} \cos \left(\frac{\theta}{2}\right)\left[1-\operatorname{sen}\left(\frac{\theta}{2}\right) \operatorname{sen}\left(\frac{3 \theta}{2}\right)\right]+\mathrm{O}\left(\mathrm{r}^{0}\right)+\mathrm{O}\left(\mathrm{r}^{\frac{1}{2}}\right) \\
& \mathrm{u}_{\mathrm{x}}=\frac{\mathrm{K}_{\mathrm{I}}}{\mu} \sqrt{\frac{\mathrm{r}}{2 \pi}} \cos \left(\frac{\theta}{2}\right)\left[\frac{1}{2}(\kappa-1)+\operatorname{sen}^{2}\left(\frac{\theta}{2}\right)\right] \\
& +\frac{\mathrm{K}_{\text {II }}}{\mu} \sqrt{\frac{\mathrm{r}}{2 \pi}} \operatorname{sen}\left(\frac{\theta}{2}\right)\left[\frac{1}{2}(\kappa+1)+\cos ^{2}\left(\frac{\theta}{2}\right)\right]+\mathrm{O}(\mathrm{r}) \\
& u_{y}=\frac{K_{I}}{\mu} \sqrt{\frac{r}{2 \pi}} \operatorname{sen}\left(\frac{\theta}{2}\right)\left[\frac{1}{2}(\kappa+1)-\cos ^{2}\left(\frac{\theta}{2}\right)\right] \\
& +\frac{\mathrm{K}_{\mathrm{II}}}{\mu} \sqrt{\frac{\mathrm{r}}{2 \pi}} \cos \left(\frac{\theta}{2}\right)\left[\frac{1}{2}(1-\kappa)+\operatorname{sen}^{2}\left(\frac{\theta}{2}\right)\right]+\mathrm{O}(\mathrm{r})
\end{aligned}
$$

onde $K_{I}$ e $K_{I I}$ são os fatores de intensidade de tensão dos modos de abertura e de deslizamento; $\mu$ é o módulo de elasticidade transversal; $\kappa$ vale $(3-4 v)$ para deformação plana e $(3-4 v) /(1+v)$ para tensão plana; $v$ é o coeficiente de Poisson.

O fator de intensidade de tensão é dado por

$$
\mathrm{K}=\sigma_{0}(\pi \mathrm{a})^{\frac{1}{2}} \mathrm{~g}(\text { geometria })
$$

onde g é uma função que depende da geometria do corpo de prova ou da estrutura e da configuração da fratura. A tensão local aumenta com a tensão $\sigma_{0}$ até que um valor crítico $\sigma_{c}$ é atingido, levando a 


$$
\mathrm{K}_{\mathrm{c}}=\sigma_{\mathrm{c}}(\pi \mathrm{a})^{\frac{1}{2}} \mathrm{~g}(\text { geometria })
$$

$\mathrm{K}_{\mathrm{c}}$ é chamado fator de intensidade de tensão crítico e é uma propriedade material. Quando $K_{c}$ e g(geometria) são conhecidos, um critério de fratura fica estabelecido para um certo tamanho 'a' da fratura.

\subsection{O Balanço Energético de Griffith}

GRIFFITH $(1920)^{2}$ considerou uma fratura de comprimento ' $2 \mathrm{a}^{\prime}$ em uma chapa submetida à tensão de tração $\sigma_{0}$ (fig. (5.10)):

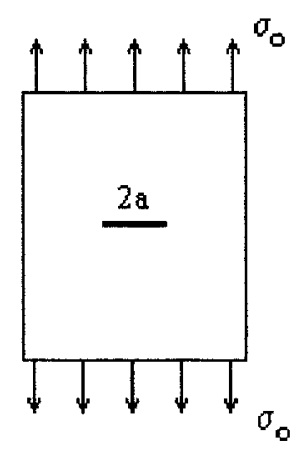

FIGURA 5.10 - Uma fratura central. REINHARDT (1989).

A conclusão dos seus experimentos foi que as fissuras pequenas tinham um efeito danoso muito menor, nas propriedades dos materiais, que grandes fissuras.

Entretanto, parecia razoável supor - de acordo com os critérios de resistência da época - que, em um corpo contendo fissuras geometricamente

${ }^{2}$ GRIFFITH, A. A. The phenomena of rupture and flow in solids. Philosophical Transations A, Royal Society of London, v. 22, p. 163-198, 1920 apud REINHARDT (1989). 
semelhantes, as concentrações de tensão causadas pelas mesmas seriam equivalentes, de modo que o efeito sobre a resistência seria o mesmo, não dependendo do tamanho da fissura.

Desta forma, foi preciso desenvolver um critério de resistência capaz de considerar o balanço de energia envolvido. Para tanto, ele levou em conta não apenas a contribuição de solicitações externas, mas também a energia de deformação elástica acumulada e a energia de superficie do corpo em questão.

A energia total $\mathrm{U}$ da chapa fraturada pode ser definida como

$$
\mathrm{U}=\mathrm{U}_{0}+\mathrm{U}_{\mathrm{a}}+\mathrm{U}_{\gamma}-\mathrm{W}
$$

onde $U_{0}$ é a energia elástica da chapa carregada, sem fraturar, (que é constante), $U_{a}$ é a mudança na energia elástica devida à fratura, $\mathrm{U}_{\gamma}$ é a mudança na energia de superficie causada pela formação de novas superficies de fratura e W é o trabalho efetuado pelas forças externas.

$\mathrm{O}$ equilíbrio é possível na medida em que a energia total aumenta com o crescimento da fratura. $\mathrm{O}$ crescimento instável da fratura começa quando $\mathrm{U}$ diminui. O ponto de instabilidade é dado por $\mathrm{dU} / \mathrm{da}=0$. Com $\mathrm{U}_{\mathrm{a}}=-\pi\left(\sigma_{0}\right)^{2} \mathrm{a}^{2} / \mathrm{E}$ (INGLIS $\left.(1913)^{3}\right)$ e $U_{\gamma}=2(2 a \gamma)$, esta condição pode ser descrita como

$$
\frac{d}{d a}\left(U_{0}-\frac{\pi \sigma_{0}^{2} a^{2}}{E}+4 a \gamma-W\right)=0
$$

onde $\mathrm{E}$ é o módulo de elasticidade e $\gamma$ é a energia específica de superfície. Já que $\mathrm{U}_{0}$ é constante e admitindo-se $\mathrm{W}=0^{(*)}$, a condição torna-se (MEGUID (1989))

\footnotetext{
3 INGLIS, C. E. Stress ins a plate due to the presence of cracks and sharp corners. Trans. Inst. Naval Architects, p. 219-241, 1913 apud REINHARDT (1989).

${ }^{*}$ Imagina-se que os apoios (contornos) superior e inferior sejam fixos durante o fraturamento, de forma que o trabalho da carga $\sigma_{0}$ aplicada nos extremos seja nulo (BAZANT (1984)).
} 


$$
\sigma_{0} \sqrt{\mathrm{a}}=\sqrt{\frac{2 \mathrm{E} \gamma}{\pi}} ; \quad \sigma_{0} \sqrt{\mathrm{a}}=\sqrt{\frac{2 \mathrm{E} \gamma}{\pi\left(1-v^{2}\right)}}
$$

respectivamente, para tensão e deformação plana. $\mathrm{O}$ valor correspondente da abertura de fratura chama-se comprimento crítico de fratura, $a_{c}$. As eqs. (5.11) são importantes porque relacionam a dimensão da imperfeição (2a) à resistência à tração do material.

O termo $\mathrm{dU}_{\mathfrak{a}} / \mathrm{da}$, na eq. (5.10) é chamado de taxa de liberação de energia $\mathbf{G}$; no estado crítico, esta taxa $\left(G_{c}\right.$, também mencionada como a taxa crítica de liberação de energia) é igual a $2 \gamma$, que é a chamada resistência à fratura, $\mathbf{R}$.

O primeiro membro das eqs. (5.11) é o produto entre a tensão remota $\sigma_{0}$ e a raiz quadrada da metade do comprimento da fratura, isto é, um termo mecânico e outro geométrico, enquanto que o segundo membro é uma propriedade do material elástico linear. Para utilizar esta relação em aplicações práticas, a energia de superficie deve ser conhecida e, de acordo com a teoria, uma fratura de formato ideal deve estar presente ali. Por outro lado, se duas solicitações e geometrias semelhantes tiverem de ser comparadas, as eqs. (5.11) estabelecem que a tensão $\sigma_{0}$ é inversamente proporcional à raiz quadrada da grandeza absoluta do comprimento da fratura. A abordagem da resistência dos materiais não teria predito uma influência do tamanho (comprimento da fratura) sobre $\sigma_{0}$.

É evidente que, para aumentar o comprimento da fratura na região $0 \leq \mathrm{a} \leq \mathrm{a}_{\mathrm{c}}$, é necessário fornecer energia para o sistema, esta é a condição chamada crescimento estável de fratura. Entretanto, para $a>a_{c}$, a energia de deformação liberada numa extensão incremental da fratura excede a energia que é absorvida na criação de novas superficies de fratura, conduzindo ao crescimento instável de fratura. Claramente, a instabilidade da fratura está associada com o valor estacionário da curva de energia total, fig. (5.11) 


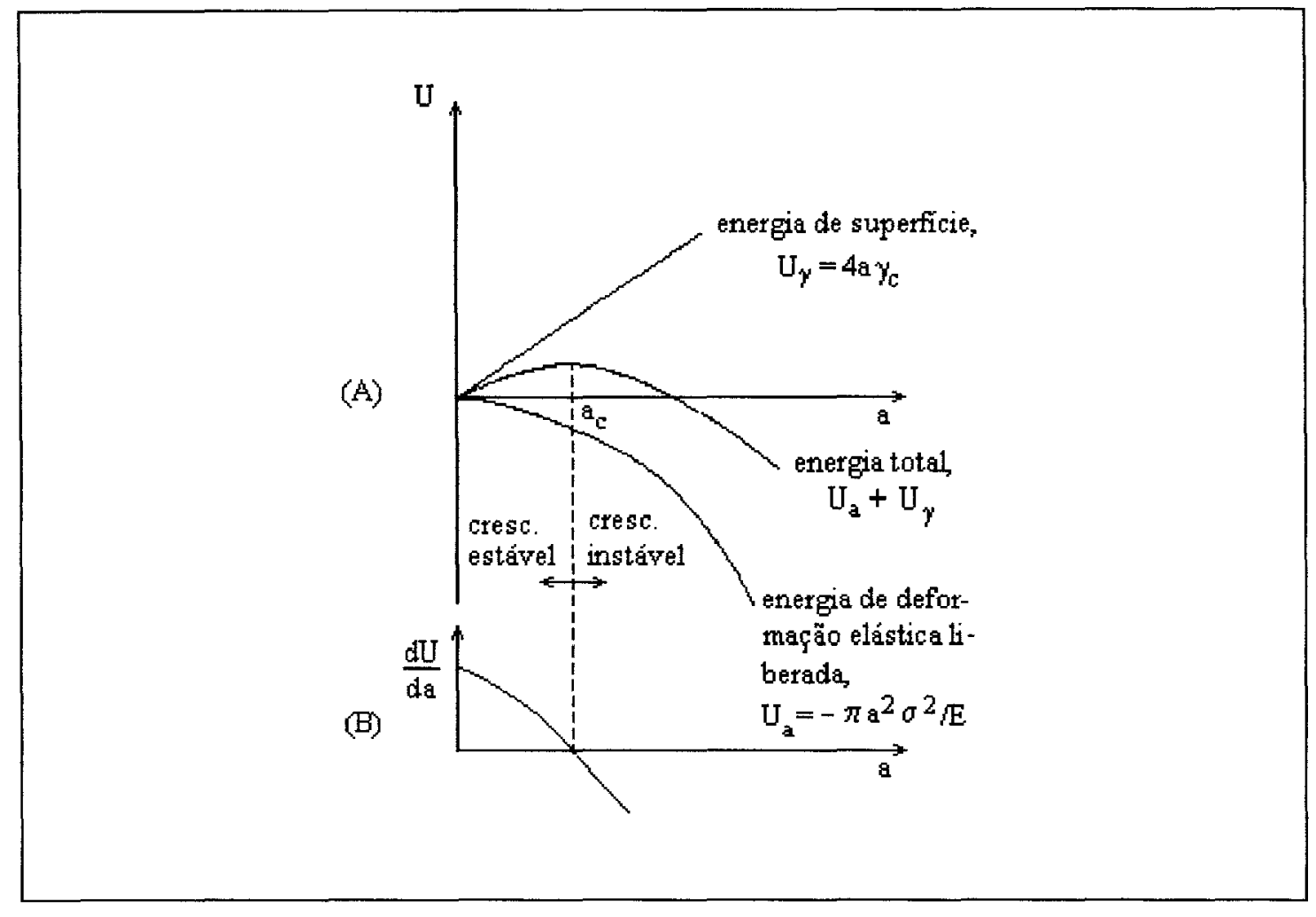

FIGURA 5.11 - Abordagem do balanço de energia de Griffith. (a) Variação da liberação de energia de deformação elástica, $U_{a}$, e da energia de superfície, $U_{\gamma}$, versus comprimento de fratura. (b) Mudança na energia total por extensão unitária de fratura contra o comprimento de fratura. MEGUID (1989).

\subsection{Conceitos de Fratura e Modelagem Numérica}

\subsubsection{O Modelo de Fratura Fictícia (MFF)}

O Modelo de Fratura Fictícia (MFF) foi proposto por HILLERBORG et al. (1976). Sua idéia fundamental pode ser demonstrada através de um teste estável de tração, ilustrado na fig. (5.12), onde se fez controle de deformação para possibilitar o acompanhamento completo do ramo descendente da curva força-alongamento Assume-se que a deformação seja medida ao longo de dois trechos A e B de mesmo comprimento. 
Sendo o espécime homogêneo e de área constante, as curvas A e B coincidem até que a carga de ruptura seja alcançada. A partir deste ponto, uma zona de fratura (ou zona de processo) forma-se em algum lugar no espécime. Esta zona de fratura tem largura limitada na direção da tensão e, à medida que a mesma se desenvolve, a solicitação diminuirá devido à formação de microfissuras e ao correspondente enfraquecimento do material. $\mathrm{O}$ decréscimo de solicitação resulta em uma diminuição da deformação existente fora da zona de fratura e corresponde à curva de descarregamento no diagrama força-alongamento. Não é possível formar outra zona de fratura enquanto a solicitação diminui.

$\mathrm{Na}$ fig. (5.12), assume-se que a zona de fratura esteja situada no trecho A. Desta forma, a deformação no trecho B pode ser descrita por meio de uma curva tensão-deformação, incluindo um ramo de descarregamento.
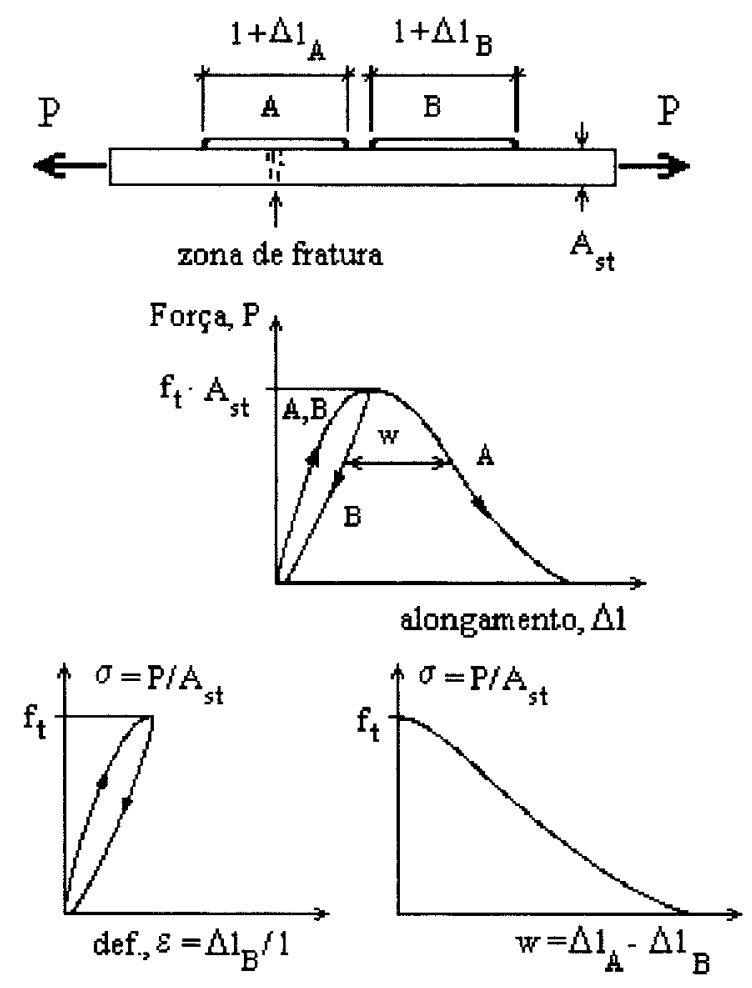

FIGURA 5.12 - Princípios utilizados no MFF para a divisão das propriedades de deformação em um diagrama $\sigma$ - $\varepsilon$ e outro $\sigma$-w, onde w é o alongamento adicional devido à formação de uma zona de fratura. HILLERBORG (1983). 
A deformação do trecho A também inclui a deformação da zona de fratura. Essa deformação adicional equivale à diferença $w$, entre os ramos descendentes das curvas A e B, dividida pelo comprimento inicial 1. Pode-se, portanto, definir

$$
\mathrm{w}=\text { alongamento adicional devido à zona de fratura. }
$$

Deste modo, é possível descrever as propriedades do espécime testado por meio de dois diagramas:

- O diagrama tensão-deformação $(\sigma-\varepsilon)$, incluindo-se o ramo descendente.

- O diagrama tensão-abertura de fratura $(\sigma-w)$, para a zona de fratura.

Por meio desses dois diagramas, pode-se calcular o alongamento $\Delta 1$ de qualquer comprimento $1_{0}$, desde que sua extremidade não esteja situada na zona de fratura:

$$
\Delta \mathrm{l}=\varepsilon_{0}+\mathrm{W}
$$

Obviamente, se não houver zona de fratura, $w=0$. Vale salientar que $w$ é um comprimento, ao contrário de $\varepsilon$, que é uma deformação.

A zona de fratura pode ser descrita como uma fratura localizada, de abertura $\mathrm{w}$, isto é, uma fratura que pode transferir uma tensão $\sigma$ quando sua abertura for $w$ (de acordo com a curva $\sigma-w$ ). Este comportamento é descrito como coesivo (cf. [5.6]). Como a zona de fratura, na realidade, tem uma certa extensão, a fratura localizada, que é introduzida como uma descrição simplificada, não é uma fratura real. É chamada, portanto, de fratura fictícia e este termo foi utilizado para caracterizar o modelo. 


\subsubsection{Aplicação do MFF Através do Método dos Elementos Finitos}

Quando a propagação da fratura é analizada sob a hipótese de existência de forças coesivas na zona de processo, geralmente algum tipo de método numérico é utilizado, embora o uso de métodos analíticos também seja possível.

A complexidade da análise por elementos finitos depende muito do fato de o percurso da fratura ser previamente assumido ou não. Em caso afirmativo, a malha de elementos finitos é gerada de modo que a fratura siga o contorno dos elementos ou por dentro dos elementos, paralelamente a seus contornos. No primeiro caso, a zona de fratura é modelada como uma separação dos elementos ao longo da via de fraturamento. Este é um modelo de fratura puro, freqüentemente mencionado como modelo de fratura fictícia (MFF) (HILLERBORG et al. (1976), MODÉER (1979) ${ }^{4}$, PETERSSON $\left.(1981)^{5}\right)$. No último caso, a zona de fratura é modelada como uma mudança na rigidez de uma coluna de elementos. Isto é mencionado como o modelo de banda de fratura (BAZANT \& OH (1983), BAZANT (1984)).

Esses modelos estão ilustrados por meio de uma viga que apresenta uma zona de fratura no lado tracionado, fig. (5.13). Diferem na formulação de elementos finitos utilizada, mas os resultados numéricos são praticamente idênticos.

\footnotetext{
${ }^{4}$ MODÉER, M. A fracture mechanics approach to failure analysis of concrete materials. Sweden, Division of Building Materials, Univ, of Lund, 1979. Report TVBM-1001 apud HILLERBORG \& ROTS (1989)

5 PETERSSON, P.-E. Crack growth and development of fracture zones in plain concrete and similar materials. Sweden, Division of Building Materials, Univ. of Lund, 1981. Report TVBM1006 apud HILLERBORG \& ROTS (1989).
} 


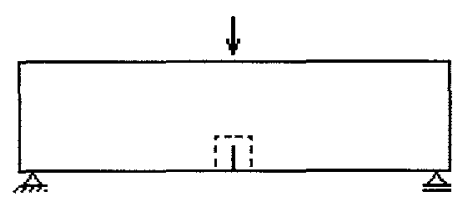

(A)
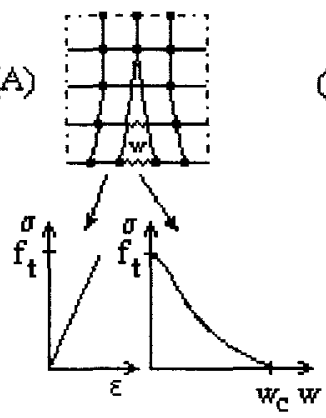

(B)
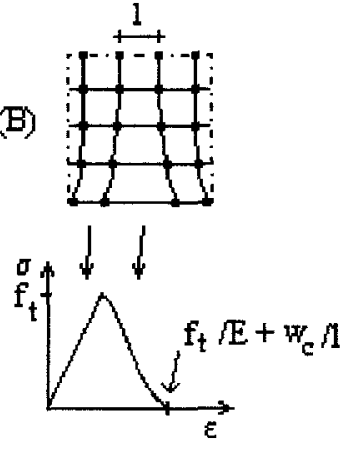

FIGURA 5.13 - Aplicação da abordagem de fratura discreta através de análise por elementos finitos e (a) modelo de fratura fictícia; (b) modelo de banda de fratura. HILLERBORG \& ROTS (1989).

A análise da formação e propagação de uma zona de fratura pelo modelo de fratura fictícia é ilustrada na fig. (5.14), que mostra o desenvolvimento da zona de fratura através da malha de elementos finitos da viga da fig. (5.13)

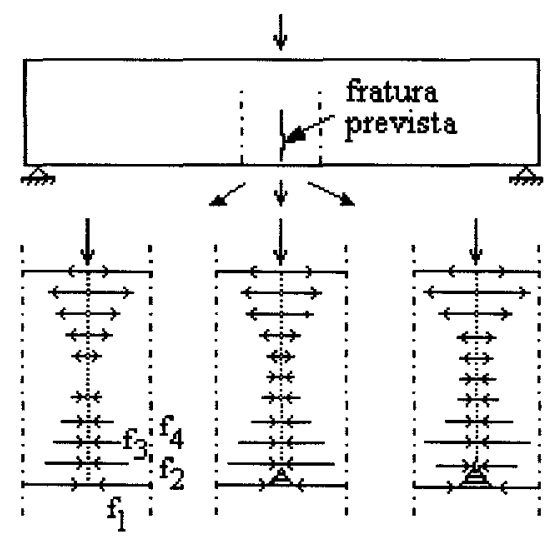

FIGURA 5.14 - Desenvolvimento de uma zona de fratura de acordo com o modelo de fratura fictícia. Apenas os pontos nodais ao longo da via prevista de fratura são mostrados, juntamente com as forças de fechamento. HILLERBORG \& ROTS (1989). 
O primeiro passo na análise é calcular a solicitação que torna a força entre um par de pontos nodais equivalente à resistência à tração do material. Neste ponto, surge uma zona de processo, o que significa que os dois pontos nodais são separados, mas uma força de fechamento $F_{1}$, correspondente à tensão coesiva, atua entre eles. A relação entre a distância de separação e a força de fechamento é dada pela curva de amolecimento do material.

O próximo passo é encontrar a condição para a propagação da zona de processo, isto é, a solicitação que faz a força $\mathrm{F}_{2}$ alcançar um valor correspondente à resistência à tração.

Através dessa análise passo a passo, o comportamento da viga pode ser completamente seguido à medida que a zona de fratura se propaga. Se a curva tensãodeformação é não-linear, a solução em cada passo é obtida através de iterações. $\mathrm{Na}$ maioria das aplicações práticas, a curva tensão-deformação é assumida como linear. Se for assumida n-linear, a análise pode ser efetuada em incrementos, sem iterações.

Se a via de fraturamento não é previamente conhecida, o problema é muito mais complicado e duas estratégias diferentes podem ser seguidas quando a abordagem de fratura discreta for aplicada.

Uma delas é assumir diferentes caminhos de fratura fixos e fazer uma análise para cada via - cada vez com a malha arranjada de acordo com a via escolhida. É possível checar se um caminho está próximo do correto comparando a direção de propagação da fratura com as direções principais.

A outra estratégia é estudar uma fratura que não segue a malha original, mas que percorre seu próprio caminho pela estrutura. Isto pode ser conseguido de dois modos diferentes: por redefinições sucessivas da malha na vizinhança da extremidade da fratura ou projetando-se as propriedades da fratura oblíqua em elementos distintos do contorno quando o modelo de fratura fictícia for aplicado. 
De acordo com HILLERBORG (1983), a absorção de energia fora da fratura fictícia é determinada de maneira usual como o volume do espécime vezes a área abaixo da curva $\sigma-\varepsilon$, fig. (5.15). Em um material puramente elástico, obviamente, essa energia de absorção é zero.
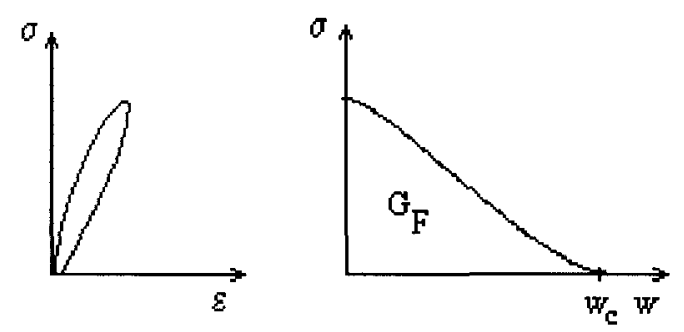

FIGURA 5.15 - Dissipação de energia relacionada com os diagramas $\sigma-\varepsilon$ e $\sigma-w$. As áreas dos gráficos representam a dissipação de energia por unidade de volume do material e por área unitária de fratura, respectivamente. HILLERBORG (1983).

A fig. (5.16) mostra a distribuição de tensões à frente de um entalhe ou de uma extremidade de fratura em uma viga submetida a uma deformação imposta crescente. Uma zona de fratura se desenvolveu e essa zona de fratura é descrita como uma fratura fictícia.

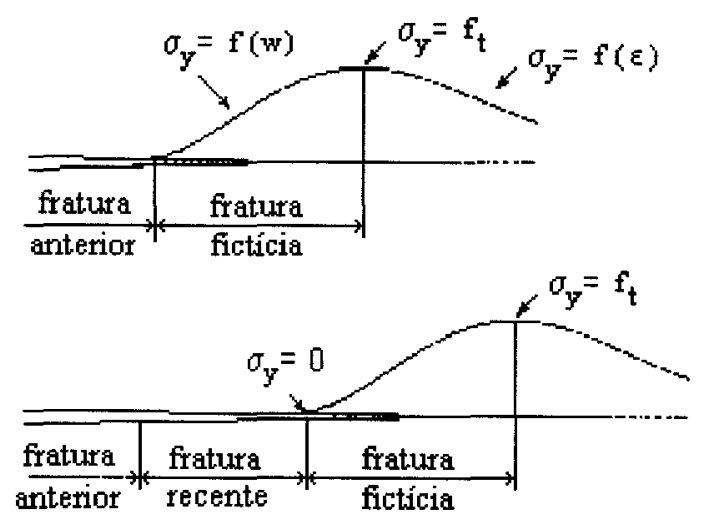

FIGURA 5.16 - Distribuição de tensões, à frente da extremidade de uma fratura, antes e depois do crescimento da fratura real. HILLERBORG (1983), corrigida. 
Dentro da fratura fictícia, a relação entre tensão, $\sigma$, e abertura de fratura, w, é dada pela curva $\sigma-w$ (fig. (5.12), cf. [5.7])). Em qualquer lugar fora da fratura fictícia, a curva $\sigma-\varepsilon$ para o material é válida. À medida que a deformação aumenta, as tensões à frente da extremidade da fratura também aumentam. Nenhuma tensão é assumida como maior que a resistência à tração $f_{t}$. Tão logo alguma tensão tenha atingido $f_{t}$, qualquer aumento adicional na deformação provoca o desenvolvimento de uma fratura fictícia no ponto em questão. Desta forma, a tensão na extremidade da fratura fictícia é $\mathrm{f}_{\mathrm{t}}$ assim que a mesma começa a se propagar.

O modelo de fratura fictícia é de aplicabilidade geral. Pode ser utilizado para analisar a formação e a propagação de zonas de fraturas e de fraturas, independentemente de a fratura ter início em uma fissura, um entalhe, uma irregularidade ou uma superficie plana. Também pode ser utilizado onde atuam deformações provenientes de retração ou gradientes de temperatura e em materiais anisotrópicos. Por outro lado, é dificil encontrar soluções analíticas baseadas no MFF. Por conta disto, é preciso utilizar métodos numéricos.

Nos cálculos, a utilização de curvas $\sigma-\varepsilon$ não-lineares toma muito tempo. Entretanto, é relativamente simples utilizar curvas $\sigma$-w $n$-lineares. Desta forma, uma curva $\sigma$-w não-linear pode ser levada em consideração mais facilmente que uma curva $\sigma-\varepsilon$ não-linear.

Segundo HILLERBORG (1983), as hipóteses mais simples possíveis em relação a curvas $\sigma-\varepsilon$ e $\sigma-w$, a serem utilizadas nos cálculos, são de acordo com a fig. (5.17), isto é, aproximações de linha reta para ambas as curvas. A maioria dos cálculos já efetuados tem se baseado nessas hipóteses.

Com as formas das curvas $\sigma-\varepsilon$ e $\sigma$-w dadas na fig. $(5.17)$, as propriedades do material ficam completamente definidas por $f_{t}$, a resistência à tração, $E$, o módulo de elasticidade $\mathrm{G}_{\mathrm{F}}$, a energia de fraturamento. A curva $\sigma$-w pode ser determinada por meio de um ensaio de tração, que fornece um ramo descendente completo estável, 
enquanto que $\mathrm{G}_{\mathrm{F}}$ pode ser facilmente determinada em um ensaio de flexão de uma viga com entalhe.
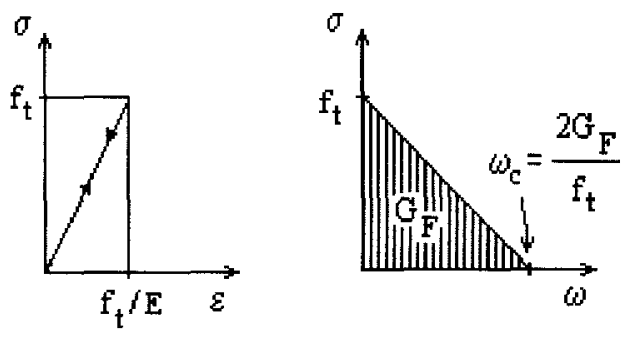

FIGURA 5.17 - Hipóteses aproximadas simples para uso em cálculos numéricos. HILLERBORG (1983).

O processo de propagação de fraturas também foi modelado por ZAITSEV \& WITTMANN $(1981)^{6}$, através de simulação computacional

\subsection{Modelo Coesivo do Fraturamento}

Segundo ELICES \& PLANAS (1989), a definição completa de um modelo coesivo do fraturamento inclui a definição do comportamento do volume, a especificação da condição para a formação de fratura e a formulação das equações para a evolução da fratura. Essas três condições são como segue (cf. [6.5]):

\section{Comportamento do Volume}

Materiais sem dissipação de energia no volume devem exibir comportamento elástico. Geralmente, o comportamento é admitido como elástico linear. Para o concreto, o comportamento do volume é usualmente assumido como isotrópico

\footnotetext{
${ }^{6}$ ZAITSEV, Y. B.; WITTMANN, F. H. Mater. Constr., v. 14, p. 357-365, 1981 apud HILLERBORG (1983).
} 
elástico linear, definido, portanto, por um módulo de elasticidade, E, e um coeficiente de Poisson, $v$

\section{Início de Fraturamento}

Em materiais isotrópicos, o comportamento em um ponto é geralmente assumido como elástico até o momento em que a tensão principal máxima atinge a resistência à tração, $\mathrm{f}_{\mathrm{t}}$. Neste momento, a fratura começa, perpendicular à direção da tensão de tração máxima, como uma fratura coesiva (transferindo tensão) - daqui a condição para início da fratura ser tomada como independente da triaxialidade (cf. [6.3]). Esta suposição pode - obviamente - ser modificada para levar em conta a influência das tensões transversais sobre a resistência, mas tal refinamento não foi introduzido na prática. Uma generalização para materiais anisotrópicos ainda está em falta.

\section{Evolução do Fraturamento}

Uma vez que a fratura coesiva tenha sido formada, assume-se que a tensão transferida através das faces da mesma depende do deslocamento relativo de suas faces. No caso de abertura pura, a tensão transferida, $\sigma$, é normal às faces da fratura e geralmente assumida como dependente apenas da evolução da abertura de fratura (normal), w. No caso de abertura monotônica de fratura, a tensão transferida é freqüentemente considerada como unicamente definida pela abertura da fratura, ou seja:

$$
\sigma=f(\mathrm{w})
$$

onde $f(\mathrm{w})$ descreve o comportamento de amolecimento do material, sendo chamada função de amolecimento ou curva de amolecimento. A função $f(w)$ depende do material em questão, mas não de condições externas. É uma função do material. 


\subsection{Curva de Amolecimento no Modo de Abertura e Parâmetros Relacionados}

A curva de amolecimento é geralmente admitida como sendo uma função positiva e monotonicamente decrescente da abertura da fratura, como mostrado na fig. (5.18). Para ser consistente com a condição de formação da fratura, o valor de tensão correspondente à abertura de fratura zero deve ser igual à resistência à tração $\mathrm{f}_{\mathrm{t}}$. À medida que a abertura da fratura aumenta, a tensão diminui e, eventualmente, anula-se para a abertura crítica de fratura, $w_{\mathrm{c}}$.

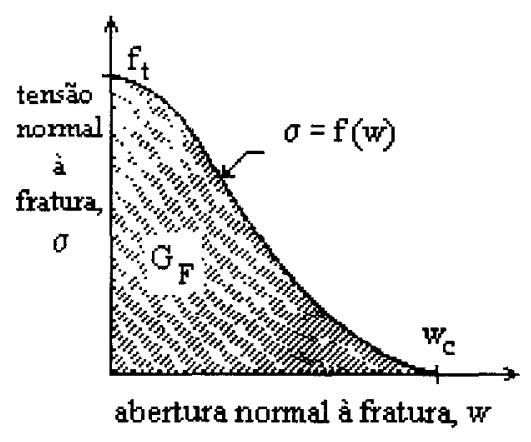

FIGURA 5.18 - Curva de amolecimento. ELICES \& PLANAS (1989).

A área sob a curva de amolecimento representa a energia absorvida por uma unidade fixa de área quando a fratura a alcança, monotonicamente, até o fraturamento completo da mesma. É chamada energia de fraturamento e referenciada como $\mathrm{G}_{\mathrm{F}}$. Obviamente, $G_{F}$ é um parâmetro material na mesma medida em que a curva de amolecimento é considerada uma função material.

A partir de parâmetros elásticos e de fraturamento, duas grandezas com dimensão de comprimento podem ser definidas. São chamadas abertura característica de fratura, $W_{\mathrm{CH}}$, e comprimento característico de fratura, $I_{\mathrm{CH}}$, (HILLERBORG et al. (1976)) e são definidas como 


$$
w_{c h}=\frac{G_{F}}{f_{t}} ; \quad I_{c h}=\frac{E G_{F}}{f_{t}^{2}}
$$

Se a função de amolecimento for definida, a análise da propagação de fraturas pode ser levada à efeito diretamente. A fig. (5.19) apresenta uma amostra sendo solicitada simetricamente, de forma que a fratura se propaga em modo de abertura puro

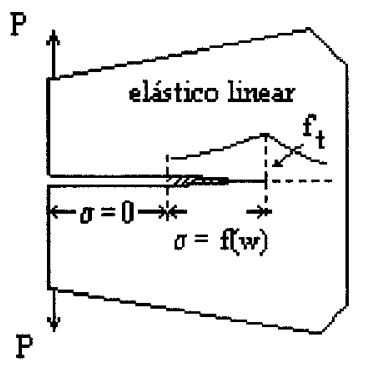

FIGURA 5.19 - Propagação de fratura no modo I. ELICES \& PLANAS (1989).

Quando a amostra é solicitada de tal modo que uma única fratura se desenvolve, e sem que haja formas de dissipação de energia além da fratura tênsil, é óbvio que a energia total fornecida necessária para romper a amostra, de forma quase estática, é, simplesmente, $\mathrm{G}_{\mathrm{F}}$ vezes a superficie da fratura formada. Contudo, a fim de evitar incertezas na interpretação de dados experimentais, ELICES \& PLANAS (1989) sugeriram uma definição experimental para $G_{F}$ :

$$
\mathrm{G}_{\mathrm{FE}}=\frac{\text { energia externa fornecida }}{\text { superficie da fratura }}
$$

Apenas quando eventuais fontes de dissipação de energia forem eliminadas e quando $G_{F}$ for uma propriedade do material é que se tem

$$
\mathrm{G}_{\mathrm{FE}}=\mathrm{G}_{\mathrm{F}}
$$


A taxa crítica de liberação de energia de deformação, $\mathrm{G}_{\mathrm{C}}$ (cf. [5.4]), representa o consumo de energia por unidade de área de extensão da fratura, isto é, a quantidade de energia dissipada no sistema inteiro quando a extremidade da fratura alcança uma área unitária. É definida estritamente para materiais de comportamento elástico

A energia de fraturamento $\left(G_{F}\right)$ é conceitualmente diferente de $G_{\mathcal{C}}$. Repetindose, é a energia dissipada em uma área unitária de localização fixa quando a fratura a atravessa, até a abertura completa. $\mathrm{G}_{\mathrm{F}}$ é igual à área sob a curva $\sigma-\mathrm{w}$ nos modelos $(c, x, c)($ cf. [6.5])

Ambos os conceitos coincidem apenas para materiais elásticos, onde a dissipação de energia acontece em uma região infinitesimalmente pequena em torno da extremidade da fratura. Por este motivo, a relação $G_{C} / G_{F}$ deve ser útil como uma medida de quão bem a mecânica do fraturamento elástica linear descreve o fraturamento de uma estrutura. 


\section{ESTUDO DO CONCRETO}

Não é pretensão esgotar o tema concreto neste capítulo. Longe disto, buscouse justificar o interesse pela escolha do material, bem como caracterizar os parâmetros relevantes à modelagem numérica.

O objetivo básico é descrever como o fraturamento do concreto é influenciado por dimensões (efeito de escala, cf. [5.1.5]) e propriedades materiais, tais como resistência à tração, rigidez (módulo de elasticidade) e energia de fraturamento. Para tanto, faz-se uso dos modelos da mecânica do fraturamento.

O concreto foi escolhido como exemplo por se tratar de um material onde a formulação pode ser aplicada, já que exibe comportamento coesivo durante o fraturamento.

\subsection{Introdução}

\subsubsection{Desenvolvimento Histórico}

Segundo ELFGREN (1989a), as estruturas de concreto, construídas atualmente, são o resultado de uma longa cadeia de desenvolvimentos sucessivos, 
começando com o uso antigo de emplastro de gesso e limo. Outros importantes elos da cadeia são:

- O desenvolvimento de cimentos hidráulicos por gregos e romanos.

- O desenvolvimento de cimento Portland (Joseph Aspdin, Isaac Charles Johnson, por volta de 1845).

- A introdução de armadura de aço (Joseph Monier, 1870).

- O pré-tensionamento da armadura a fim de prevenir a formação de fissuras (Eugène Freysinnet, 1928).

- O uso de dispersantes e micro-sílica para aumentar a densidade e a resistência (à compressão) do concreto (por volta de 1970).

À medida que os processos construtivos evoluíam, acontecia o aperfeiçoamento dos métodos de projeto de estruturas. À princípio, todas as decisões ficavam por conta dos artesãos envolvidos com o trabalho.

Mais tarde, engenheiros estruturais, utilizando regras empíricas, engajaram-se no processo. Por volta de 1900 a 1930, aconteceu o primeiro avanço significativo: a introdução da teoria elástica linear. Aplicou-se o conceito de tensões admissíveis, assumindo-se uma proporção constante entre os módulos de elasticidade do aço e do concreto $\left(\mathrm{n}=\mathrm{E}_{\mathrm{s}} / \mathrm{E}_{\mathrm{c}}=10\right.$ ou 15$)$.

A segunda revolução, baseada principalmente numa teoria concebida durante a década de 30, foi a introdução da análise limite plástica, o que ocorreu no período de 1940-1970. Com o aumento na eficiência da utilização dos materiais, a teoria da plasticidade foi aplicada na análise dos estados limites últimos. 
Atualmente, o diagrama tensão-deformação não-linear real pode ser aplicado ao concreto submetido à compressão, inclusive quando se admite o escoamento da armadura.

Há boas razões para se acreditar que a introdução da mecânica do fraturamento, nos critérios de projeto, pode se constituir na terceira revolução.

\subsubsection{O Concreto Como Material Estrutural}

O concreto é um material compósito poroso, consistindo principalmente de pasta de cimento endurecida, agregados e água. Quando barras de aço são colocadas nas peças, tem-se o concreto armado.

"No caso do concreto armado, a armadura tem por finalidade resistir aos esforços de tração decorrentes das solicitações da estrutura. A armadura resiste passivamente a esses esforços, não sendo ela responsável pela introdução de esforços suplementares na própria estrutura, como é o caso do concreto protendido. Por esse motivo, a armadura das peças de concreto armado é chamada de armadura passiva. A solidariedade entre a armadura e o concreto é o que caracteriza a existência do concreto armado. (...) A solidariedade existe desde que a deformação relativa $\varepsilon_{\mathrm{S}} \mathrm{da}$ armadura seja igual à deformação relativa $\varepsilon_{\mathrm{C}}$ do concreto adjacente que a envolve." (FUSCO (1976), p. 5-6)

O concreto é empregado em virtualmente todos os tipos de estruturas e, dado seu custo mais baixo, tem ocupado cada vez mais os lugares antes exclusivos de outros materiais estruturais. Como exemplos de aplicação, têm-se estruturas de edificios residenciais e industriais, pontes, túneis, barragens, abóbadas, silos, reservatórios, cais, fundações, obras de contenção, galerias de metrôs etc.

Segundo SÜSSEKIND (1989), o concreto armado pode ser considerado uma alternativa viável por, pelo menos, três motivos básicos: 
- Trabalho conjunto do concreto e do aço, assegurado pela aderência entre os dois materiais.

- Os coeficientes de dilatação térmica do aço e do concreto são praticamente iguais.

- O concreto protege da oxidação o aço da armadura, garantindo a durabilidade da estrutura.

Apresenta, ainda, as seguintes vantagens e desvantagens:

\section{Vantagens:}

- Economia

- Adaptação a qualquer tipo de forma e facilidade de execução.

- Excelente solução para se obter uma estrutura monolítica hiperestática

- Manutenção e conservação praticamente nulas, em associação a grande durabilidade.

- Resistência considerável a efeitos atmosféricos e a desgastes mecânicos.

\section{Desvantagens:}

- Peso próprio elevado.

- Dificuldades para reformas ou demolições.

- Baixo grau de proteção térmica.

- Fissuração da região tracionada. 


\subsection{Formação Prévia de Fissuras}

É bem conhecido o fato de que, sob condições climáticas usuais, existem numerosas fissuras na pasta de cimento endurecida (pce), argamassa e concreto antes de qualquer solicitação ser aplicada. Há várias causas para o desenvolvimento dessas fissuras, que devem ser observadas como uma característica estrutural importante do concreto com relação ao comportamento sob solicitação e com respeito à ruína estrutural.

Na tabela 1, são listados - e, em seguida, comentados — os diferentes estágios de desenvolvimento de resistência e de formação de fissuras no concreto.

\begin{tabular}{|c|c|}
\hline $\begin{array}{c}\text { Estágio de desenvolvimento do } \\
\text { concreto }\end{array}$ & Descontinuidade Típica \\
\hline
\end{tabular}

\begin{tabular}{|l|l|}
\hline Lançamento e compactação & Poros de compactação \\
\hline Concreto fresco & Cavidades de sedimentação \\
\hline Concreto em endurecimento & $\begin{array}{l}\text { Fissuras térmicas } \\
\text { Fissuras de retração química } \\
\text { Fissuras de retração por capilaridade }\end{array}$ \\
\hline Concreto secando & Fissuras de retração higroscópica \\
\hline Concreto solicitado & Fissuras interfaciais \\
& Crescimento de fissuras \\
\hline
\end{tabular}

TABELA 6.1 - Períodos característicos na vida útil do concreto e estágios correspondentes de formação de fissuras. WITTMANN (1983).

De acordo com WITTMANN (1983), e considerando-se a vida útil de um membro estrutural de concreto, as primeiras fissuras são formadas por compactação incompleta. A compactação insuficiente conduz ao surgimento de zonas locais de alta porosidade, que agem como áreas pré-fissuradas quando sob solicitação. 
Imediatamente após o lançamento, e antes do endurecimento, ocorre sedimentação. Este processo dá origem a cavidades preenchidas com água sobre os agregados graúdos. Como conseqüência, fissuras horizontais são formadas. Este efeito, obviamente, causa um certo grau de anisotropia. Esta explicação é sustentada pelo trabalho experimental de DHIR \& SANGHA (1974) ${ }^{1}$, os quais observaram que a densidade de fissuras é maior na direção horizontal, em todos os níveis de tensão.

À medida que a hidratação continua, é liberado calor de hidratação. Sob condições normais, isto introduz um gradiente de temperatura dependente do tempo. Segundo WITTMANN (1983), pode ser mostrado que, em muitos elementos de concreto, o fissuramento térmico ocorre nas zonas externas, mais frias. A orientação dessas fissuras depende da geometria dos mesmos. As tensões térmicas são, usualmente, responsáveis pela fissuração em estruturas com mais de um metro de espessura (MEHTA \& MONTEIRO (1994)).

Após o desmolde, a superfície do concreto começa a secar e alcança o equilíbrio com a umidade ambiental muito rapidamente, enquanto que o centro de um dado espécime pode permanecer saturado por muitos anos. Este gradiente higroscópico induz fissuras de retração, caso em que as fissuras emanam radialmente a partir dos agregados (ZIEGELDORF et al. $(1981)^{2}$ ). Novamente, a orientação dessas fissuras depende da geometria.

A cura do concreto tem o efeito de inchar a pasta de cimento endurecida e dá origem a fissuras tangenciais de interface (L'HERMITE $(1961)^{3}$ ).

No concreto endurecido, a interface entre a pce e agregado graúdo permanece fraca por um longo tempo. Portanto, solicitações moderadas, bem abaixo da carga de projeto, podem causar fissuramento interfacial. Desta forma, o padrão de fissuramento que deve ser esperado no concreto é semelhante ao da fig. (6.1).

\footnotetext{
${ }^{1}$ DHIR, R. K.; SANGHA, C. M. Mat. Constr., v. 7, p. 17-23, 1974 apud ZIEGELDORF (1983). ${ }^{2}$ ZIEGELDORF, S.; MÜlleR, H. S.; HILSDORF, H. K. 5th Int. Conf. on Fracture. Cannes, 1981. p. 2243-2252 apud ZIEGELDORF (1983).

${ }^{3}$ L'HERMITE, R. Cahiers de la Recherchet. Constr., n. 12. Paris, Eyrolles, 1961 apud ZIEGELDORF (1983).
} 


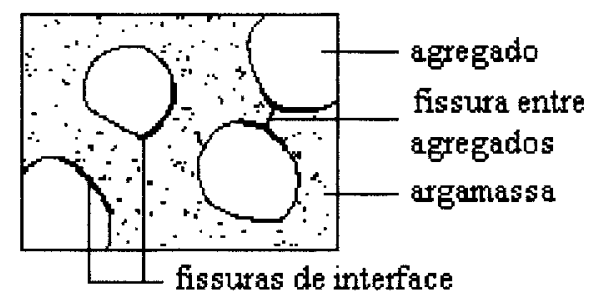

FIGURA 6.1 - Fissuras no concreto descarregado. ZIEGELDORF (1983)

Em resumo, pode-se concluir que, num espécime de concreto, algumas das causas mencionadas nesta seção e listadas na tabela (6.1) — ou combinações das mesmas - introduzirão, em condições normais, fissuras na estrutura. Algumas dessas fissuras serão orientadas aleatoriamente e outras iniciarão um certo grau de anisotropia. Logo, a resistência observada depende não somente da composição do concreto, mas também das condições de produção do mesmo.

\subsection{Aspectos Fenomenológicos do Fraturamento}

Geralmente, a resistência à tração do concreto é negligenciada. Nesse caso, é totalmente desconsiderada ou admite-se que o concreto sofra ruptura frágil quando submetido mesmo a tensões de baixo valor (fig. (6.2a)). Para ELFGREN (1989a), esta hipótese funciona a contento em estruturas de concreto submetidas a tensões baixas. Entretanto, em muitos tipos de ruína onde a capacidade tênsil governa, observa-se um efeito de escala estranho (cf. [5.1.5]) de dificil entendimento. Tal é o caso em:

- Ruína à flexão de vigas sem armadura.

- Ruína de cisalhamento e ligação. 
- Fraturamento em estruturas de concreto-massa.

Para explicar esses tipos de ruína, deve-se levar em consideração a curva força-deslocamento completa (fig. (6.2b)), onde o ramo descendente da mesma pode ser visto (amolecimento de tensões).

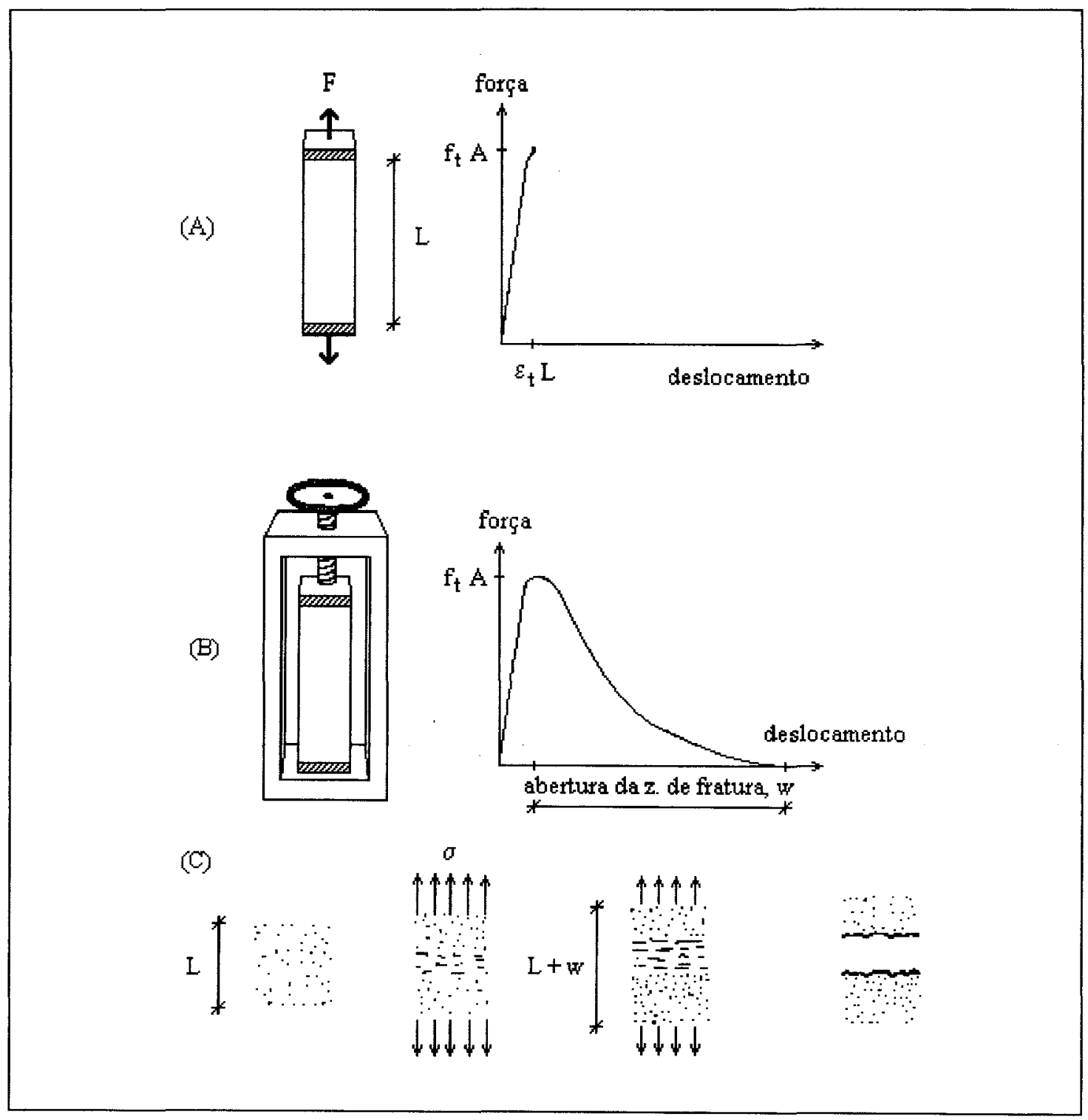

FIGURA 6.2 - Teste de tração no concreto. (a) Teste com controle de carga, que fornece fratura frágil. (b) Teste com controle de deformação. Aqui, o ramo descendente do diagrama força-deslocamento pode ser registrado. (c) Formação de uma fratura no concreto. ELFGREN (1989). 
$\mathrm{Na}$ fig. (6.3), são mostradas as curvas tensão-deformação $(\sigma-\varepsilon)$ para o agregado, para a pasta de cimento endurecida e para o concreto (MINDESS (1983a)). A curva tensão-deformação para o agregado, submetido a compressão, é essencialmente linear até o ponto de ruína. Semelhantemente, para a pce, o comportamento linear é observado até cerca de $90-95 \%$ da resistência última. Entretanto, a curva $\sigma-\varepsilon$ para o concreto é altamente não-linear. Esta não-linearidade é devida em parte à ação compósita do concreto, já que existe uma ligação altamente imperfeita entre o agregado e a pce. Além disso, uma quantidade considerável de fissuramento ocorre à medida que a solicitação aumenta.

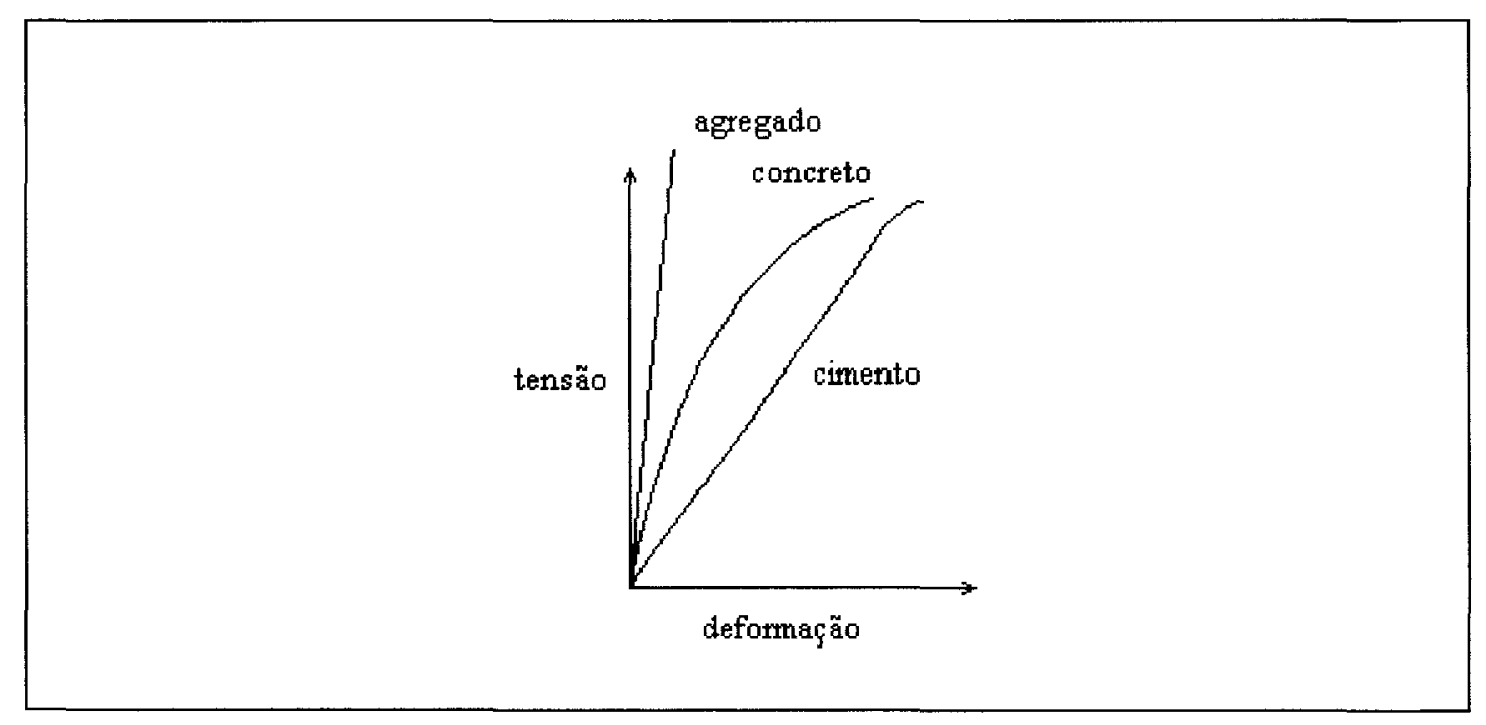

FIGURA 6.3 - Curvas tensão-deformação para agregado, cimento e concreto em compressão. MINDESS (1983a).

Segundo ZIEGELDORF (1983), esta diferença notável entre a deformação do concreto e a deformação de seus constituintes deve-se principalmente à formação de fissuras, embora parte da não-linearidade observada pode ser atribuída ao comportamento viscoso da pasta de cimento endurecida, como proposto por SPOONER et al. (1976) ${ }^{4}$. Além disso, o distanciamento da linearidade do diagrama tensão-deformação está ligado à ampliação das fissuras de ligação pré-existentes. Em grandes solicitações, são formadas fissuras contínuas que, sob solicitação constante,

\footnotetext{
${ }^{4}$ SPOONER, D. C.; POMEROY, C. D.; DOUGILL, J. W. Mag. Concr. Res., v. 28, p. 21-29, 1976 apud ZIEGELDORF (1983).
} 
podem conduzir à ruína do material. Após a solicitação máxima, mesmo um decréscimo na solicitação conduz à formação de fissuras adicionais.

A propagação de fissuras, no concreto, pode ser relacionada à heterogeneidade do material em diferentes níveis. Em escala microscópica, a ruptura do concreto por tensão é caracterizada pela formação de uma superficie perpendicular à direção da tensão atuante. Até mesmo em espécimes feitos de pasta de cimento endurecida, as fissuras seguem um caminho tortuoso, como mostrado na fig. (6.4a).

BAZANT (1984) afirma que no concreto - tanto quanto em argamassa, rochas e certas cerâmicas - o fraturamento é precedido por uma microfissuração, dispersa gradualmente, que ocorre dentro de uma zona de processo relativamente extensa, à frente da extremidade de fratura (fig. (6.4b)). Além disso, as fissuras em propagação são atraídas pelas partículas de agregado, resultando na ramificação das mesmas (fig. (6.4c)). Desta forma, a superficie de fratura verdadeira, existente no concreto, é consideravelmente maior que a superficie de fratura aparente.

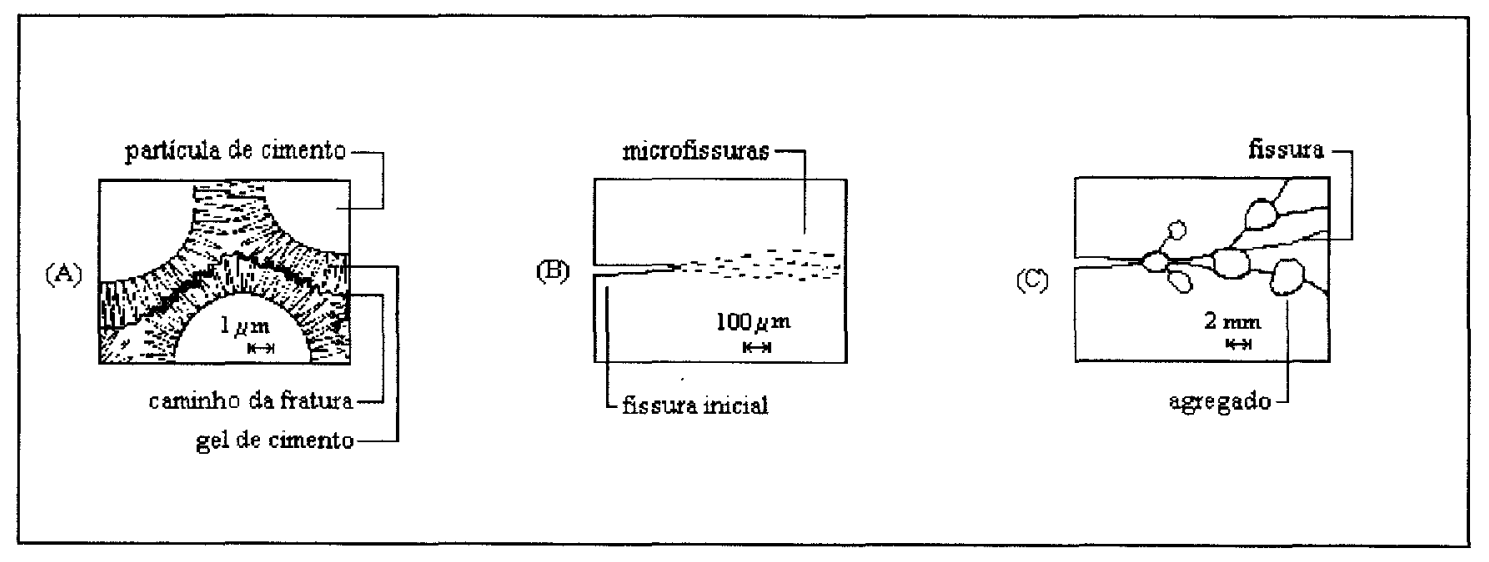

FIGURA 6.4 - Algumas caracteristicas de fissuras. (a) Tortuosidade de uma fissura em pce. (b) Formação de microfissuras em pce. (c) Atração e ramificação de fissuras nos agregados. ZIEGELDORF (1983).

Para LIANG \& LI (1991), a existência de uma zona de processo (cf. [5.5.1]) em volta da extremidade de fratura, no concreto, é reconhecida como a principal causa da não-linearidade física do material. O comportamento característico do 
concreto é controlado, em grande parte, pelo tamanho e pela forma dessa zona de processo

A curva $\sigma-\varepsilon$ para o concreto pode ser dividida nas quatro regiões mostradas na fig. (6.5) (GLUCKLICH $\left.(1965)^{5}\right)$.

Abaixo de cerca de $30 \%$ da tensão última $\left(\sigma_{\text {ult }}\right)$, há muito pouco prolongamento das fissuras pré-existentes em taxas normais de solicitação e a curva $\sigma-\varepsilon$ é essencialmente linear. Além deste ponto, a curva $\sigma-\varepsilon$ torna-se cada vez mais não-linear à medida em que as fissuras interfaciais começam a crescer sob carregamento, parcialmente devido às diferenças de constantes elásticas entre pce $\mathrm{e}$ agregado, parcialmente devido às altas concentrações de tensão existentes nessas regiões.

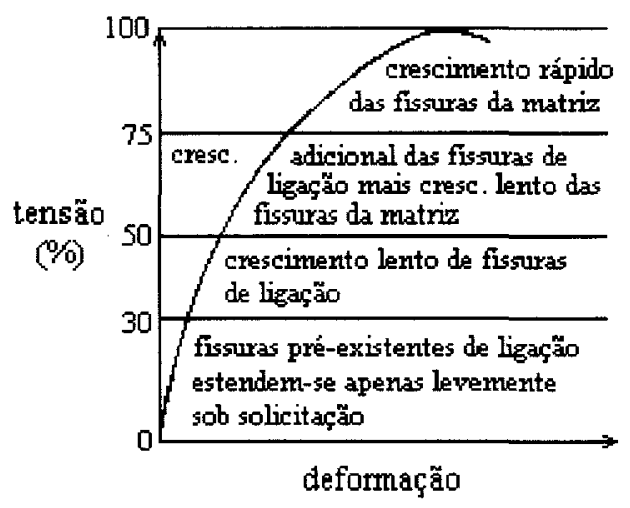

FIGURA 6.5 - Curva tensão-deformação, para o concreto, mostrando diferentes regiões de crescimento de fissuras. GLUCKLICH (1965).

Por volta de $0.5 \sigma_{\text {ult }}$, além do crescimento adicional das fissuras interfaciais, as fissuras começam a se estender através da matriz de cimento, ligando as partículas de agregado graúdo, paralelamente ao eixo de solicitação, mas ainda de modo estável.

\footnotetext{
${ }^{5}$ GLUCKLICH, J. In: BROOKS, A. E.; NEWMAN, K., eds. Proc. Int. Conf. The Structure of concrete, London 1965. London, Cement and Concrete Association, 1968, p. 176-189 apud MINDESS(1983a).
} 
Finalmente, em torno de $0.75 \sigma_{\text {ult }}$, as fissuras da matriz começam a formar uma rede muito mais estensa, eventualmente provocando a ocorrência de ruína.

Na medida em que a propagação instável das fissuras é macroscopicamente impedida, o diagrama tensão-deformação exibe um ramo descendente pronunciado.

MOAVENZADEH \& BREMNER $(1969)^{6}$ observaram que as características estruturais mais propensas à iniciação de fraturas eram, em ordem decrescente de importância:

- Fissuras nos agregados situadas a $45^{\circ}$ das tensões aplicadas.

- Agregados graúdos com fissuras de ligação.

- Vazios.

- Segregação local de agregados graúdos.

Para WITTMANN (1983), os parâmetros da mecânica da fratura do concreto não são independentes da história do fissuramento. Enquanto este ocorre, uma zona danificada (a chamada zona de processo, cf. [5.5.1]) é criada em frente à extremidade da fissura. Como conseqüência, os parâmetros da mecânica do fraturamento aumentam com o comprimento até que a zona danificada tenha se desenvolvido completamente.

De acordo com ZIEGELDORF (1983), o tipo de superficie de fratura depende principalmente do tipo de carregamento e - no caso de concretos de alta resistência - a curva tensão-deformação é mais inclinada e linear até uma proporção tensãoresistência maior que em concretos normais, por conta do decréscimo na quantidade e extensão das fissuras de ligação. A densidade de fissuras, no fraturamento, é maior no caso de solicitações repetidas ou constantes do que no caso de solicitação

\footnotetext{
${ }^{6}$ MOAVEnZADEH, F.; BREMNER, T. W. Int. Conf. on Structure, Solid Mechanics and Engineering Design. In: Civil Engineering, Southampton University, 1969 apud MINDESS (1983a).
} 
monotônica. Essa densidade de fissuras aumenta com a diminuição da tensão máxima na ruína.

Segundo HILLERBORG (1983), o comportamento do concreto no fraturamento é muito diferente do de metais. Isto acontece porque o fissuramento do concreto é precedido por microfissuramento em vez de escoamento. Esse microfissuramento não é acompanhado por qualquer contração substancial correspondente à que ocorre quando os metais escoam. Por esta razão, não existe diferença essencial entre os estados de deformação plana e tensão plana para o concreto. A conseqüência disso é que a largura (profundidade) do espécime não deve ser esperada como de importância majoritária para a análise do concreto.

Outra conseqüência disto é que as tensões diminuem com o aumento da microfissuração e, desta forma, com o aumento das deformações. Algumas das microfissuras crescem até formarem fissuras visíveis enquanto o espécime ainda suporta uma solicitação substancial. $\mathrm{O}$ fato de uma fissura ser visível não é prova de que a tensão caiu a zero.

Devido ao microfissuramento, as tensões na frente de uma extremidade de fratura podem ter uma distribuição típica, de acordo com a fig. (6.6). Neste caso, não há uma extremidade de fratura bem definida, mas sim uma zona de fraturamento ou zona de processo (cf. [5.5.1]), dentro da qual o fissuramento aumenta. Mesmo que não seja possível identificar uma extremidade de fratura bem definida, alguns pontos de interesse podem ser notados: 


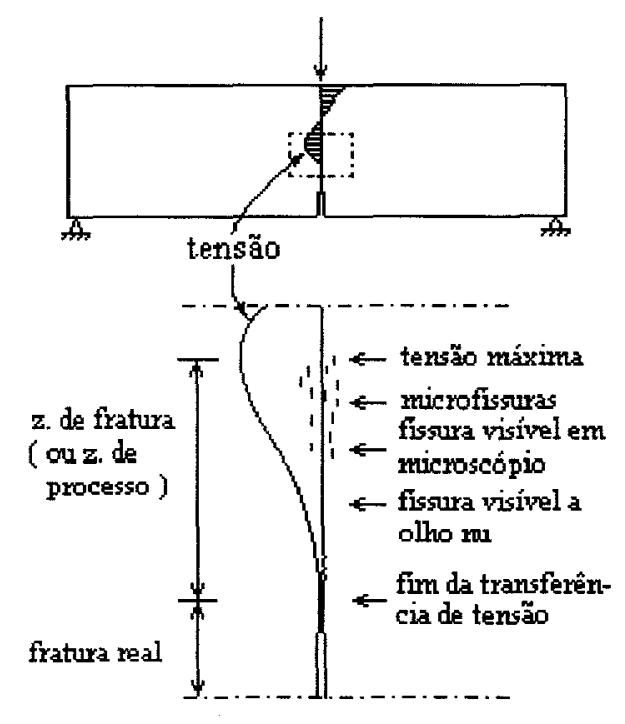

FIGURA 6.6 - Uma viga de concreto solicitada, apresentando fratura e zona de fraturamento. Não há extremidade de fratura bem definida. HILLERBORG (1983).

1. O ponto onde a tensão apresenta o valor máximo. Aumentando-se a solicitação, a tensão diminui com o aumento correspondente da microfissuração. Isto pode ser visto como o primeiro sinal de fraturamento e este ponto pode servir como um limite para a zona de fraturamento.

2. Os pontos onde a fratura começa a ficar visível, com ou sem microscópio.

3. O ponto onde a transferência de tensão termina. Este ponto pode servir como um limite entre a zona de fratura e o que pode ser chamado de fratura real, isto é, a parte da fratura onde não há mais transferência de tensão. Este ponto pode ser considerado como a definição mais natural da extremidade de fratura, embora não seja possivel observá-lo em um teste de concreto.

Do acima exposto, é evidente que não existe extremidade de fratura bem definida para o concreto (como ocorre nos metais), devido ao rompimento gradual com o aumento da deformação e ao microfissuramento dentro da zona de fratura. 


\subsection{Abordagem em Três Níveis}

WITTMANN (1983) introduziu a idéia de três níveis de observação e modelagem - a então chamada "3L-approach" (abordagem de três níveis) — que torna claro e eficiente o trato com concreto

No nível microscópico, o concreto consiste de cristais de silicato de Cálcio, hidratados com ligações primárias e secundárias. As camadas de água adsorvidas em torno dos cristais também desempenham um papel importante. Este nível não é adequado para as aplicações de mecânica do fraturamento.

O nível médio considera a natureza compósita do concreto e distingue entre pasta de cimento endurecida, agregado e a camada de ligação entre esses constituintes. Se as propriedades de todos os três forem conhecidas, a mecânica do fraturamento elástica linear pode ser aplicada através de métodos numéricos. Entretanto, este ainda não é o nível de aplicação prática.

Apenas o terceiro nível, que é o nível macroscópico, é adequado para este propósito. Neste nível, o concreto é modelado como um material homogêneo isotrópico contendo falhas, podendo, portanto, ser tratado pela mecânica do fraturamento.

\subsection{Modelos do Material}

O problema central da mecânica do fraturamento, nas abordagens clássicas, foi a obtenção de condições para a propagação de uma fratura única, modelada como uma descontinuidade simples de superficie. Tal problema foi essencialmente tratado por meio de um critério de fraturamento acrescentado às equações clássicas de campo 
da mecânica do contínuo. Este tratamento levou a uma nítida distinção conceitual e computacional entre mecânica da fratura e os métodos derivados da análise limite, que podem ser aplicados, respectivamente, quando o modo de falha dominante é propagação de fratura ou escoamento.

$\mathrm{Na}$ maioria das situações práticas, o comportamento estrutural real não era dominado por esses modos extremos e novos modelos de fratura foram desenvolvidos para que se obtivesse uma descrição melhorada do comportamento real. Foram chamados, genericamente, de modelos não-lineares de fraturamento e alguns deles não incluíam um critério de fratura global, sendo aptos a descrever o fraturamento progressivo do material sem singularidades de tensão. Tais modelos, denominados modelos de fraturamento progressivo, permitem a descrição de uma transição suave do meio contínuo ao descontínuo (completamente fraturado) e contam com dois conceitos básicos: amolecimento de tensões e localização de deformações.

A idéia essencial a manter para fins de classificação é a de que o amolecimento do material ocorre dentro de uma região de fraturamento (cujas forma e tamanho são especificados por um critério de localização) enquanto a solicitação do material fora da zona de fratura (o material do volume) diminui. Um modelo de fraturamento completo deve estabelecer, portanto, comportamento do volume, comportamento dentro da zona de fraturamento e critério de localização.

ELICES \& PLANAS (1989) definiram uma classificação através de um código de três letras $(\mathrm{ABC})$, onde:

- A está associado ao comportamento do volume.

- B está associado ao comportamento dentro da zona de fraturamento

- C está associado ao critério de localização.

Três possíveis opções de cada código estão esboçadas na fig. (6.7) e explicadas a seguir. 


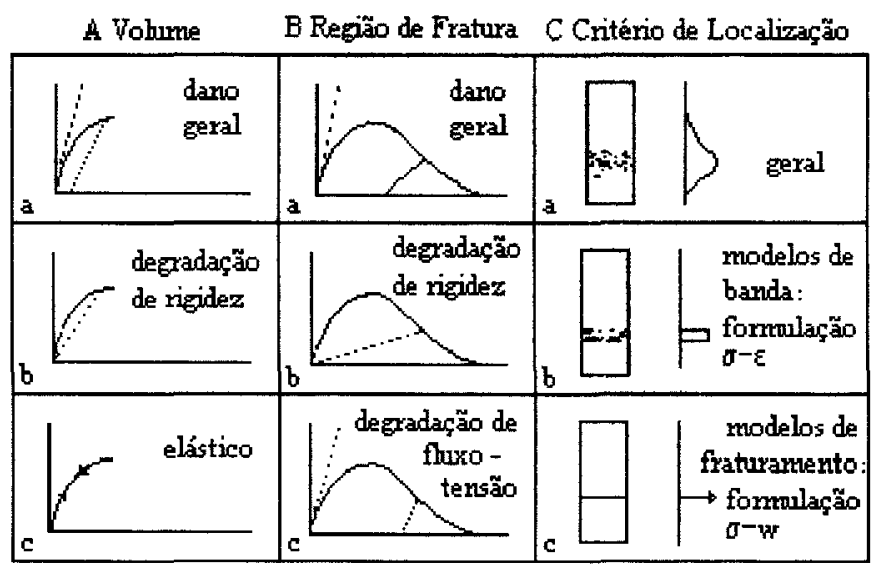

FIGURA 6.7 - Esquema de classificação proposto. ELICES \& PLANAS (1989).

\section{A: Comportamento de Volume do Concreto.}

Em geral, dissipação de energia e irreversibilidade de deformações estarão presentes, como mostrado na fig. (6.7A-a). Este comportamento é chamado dano geral e inclui amolecimento plástico (degradação de fluxo-tensão sem perda de rigidez) como caso limite. Um grande número de modelos de amolecimento apresentam descarregamento até a origem, como na fig. (6.7A-b). Isto é chamado degradação de rigidez. Um conjunto de modelos particulares, mas amplamente utilizados, assume que não há dissipação fora da zona de fratura, de forma que o terceiro comportamento a considerar é o elástico, fig. (6.7A-c). Deve-se perceber que, como sempre ocorre descarregamento em alguma região do volume após a localização de deformação, estabelecer o comportamento do mesmo é essencial.

\section{B: Comportamento do Concreto na Zona de Fraturamento.}

Este comportamento pode ser classificado como dano geral, fig. (6.7B-a), degradação de rigidez, fig. (6.7B-b) e degradação de fluxo-tensão, fig. (6.7B-c). Deve-se notar que, para deslocamentos monotônicos dentro da zona de fratura, os três tipos de comportamento são indistinguiveis, de forma que uma grande proporção 
dos modelos utilizados na prática são formulações monotônicas particulares de ambos os comportamentos.

\section{C: Critério de Localização.}

Enquanto um critério de localização geral é deixado em aberto, como indicado na fig. (6.7C-a), os critérios mais usuais são ou de localização em banda modelos de banda, fig. (6.7C-b) — ou de localização em linha - modelos de fraturamento, fig. (6.7C-c).

Com relação à localização de deformação e ao critério de localização, parece razoável que as deformações estejam localizadas de forma gradual, como mostrado na fig. (6.7C-a). Dificuldades de implementação desta hipótese geral levaram a critérios mais simples (figs. (6.7C-b), BAZANT (1976) e (6.7C-c), HILLERBORG et al. (1976)). 


\section{O MÉTODO DOS ELEMENTOS DE CONTORNO}

\subsection{Introdução}

O grau de complexidade existente nos problemas práticos de engenharia torna praticamente inviável a utilização de um processo analítico para a resolucão dos mesmos. Se for desejável um grau razoável de precisão, a resolução, sem que se utilizem métodos numéricos, é quase impossível. A maioria das técnicas numéricas existentes baseia-se no princípio de que é possível derivar equações e relações capazes de descrever uma pequena parte do sistema em estudo. Partindo-se deste ponto, os métodos clássicos de resolução do problema do meio contínuo geralmente utilizam alguma forma de discretização do domínio ou do contorno do mesmo. Desta forma, os métodos numéricos mais comuns (em mecânica do contínuo) podem ser classificados em três abordagens: diferenças finitas, elementos finitos e elementos de contorno (fig. (7.1))

A idéia básica desses métodos consiste em dividir o sistema inteiro em um grande número de "partes" menores, utilizando equações adicionais para garantir a montagem ou o agrupamento das mesmas. Deste modo, é possível prever — com tão melhor precisão quanto maior for o número de "partes" — os valores de variáveis como tensão e deslocamento em vários pontos do sistema. 


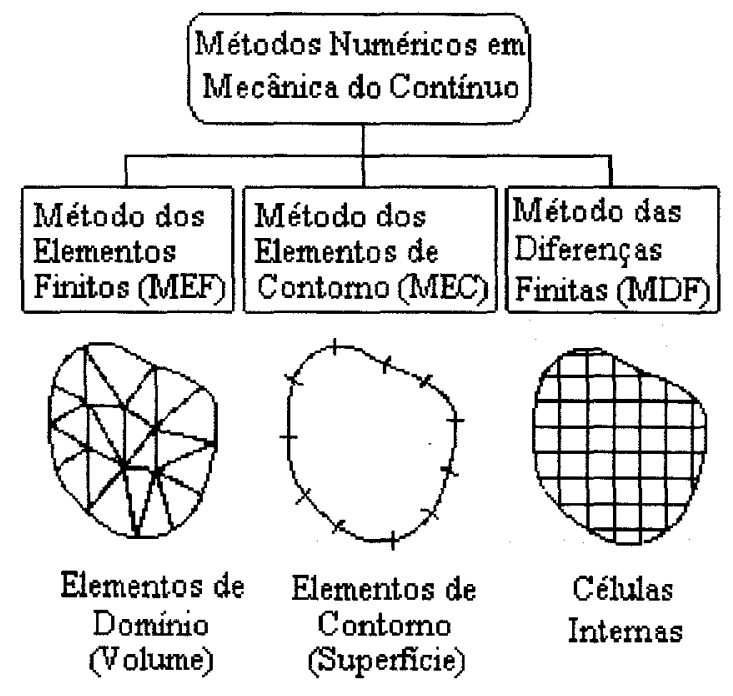

FIGURA 7.1 - Classificação dos métodos numéricos em mecânica do contínuo. BECKER (1992).

\section{O MÉTODO DAS DIFERENÇAS FINITAS, MDF (finite differences}

method, FDM) trata a equação diferencial que rege um determinado problema aproximando suas derivadas. Para tanto, utiliza algum tipo de expansão de Taylor truncada, exprimindo as derivadas em termos de valores num certo número de pontos discretos (obtidos pela divisão do domínio em células internas). Isto resulta em uma série de equações algébricas (equações de diferenças), às quais condições de contorno são aplicadas para resolver o problema.

Embora o esquema de discretização interna seja comparativamente direto, as principais dificuldades da técnica situam-se na consideração de geometrias curvas e na aplicação de condições de contorno. No caso de contornos gerais, a malha regular de diferenças finitas é incapaz de reproduzir precisamente a geometria do problema, por conta da dificuldade de variar o tamanho das células em regiões particulares. Isso faz com que o método não se adapte bem a problemas onde existam variáveis que mudem rapidamente, como é o caso de problemas de concentração de tensões. Além disso, a introdução de condições de contorno envolvendo derivadas requer o uso de pontos externos fictícios ou a definição de uma expansão de ordem superior, o que diminui a precisão dos resultados. 
Em contrapartida, os códigos computacionais de diferenças finitas são relativamente menores (quando comparados aos de outras técnicas) e de funcionamento mais simples, devido à simplicidade de geração e manipulação matriciais. Por conta disto, são ainda amplamente utilizados em aplicações tais como transferência de calor e dinâmica dos fluidos, onde são necessárias malhas muito refinadas e um grande número de operações repetitivas.

\section{O MÉTODO DOS ELEMENTOS FINITOS, MEF (finite elements} method, FEM) foi desenvolvido originalmente para ser aplicado em mecânica dos sólidos, num esforço para se obter uma melhor representação dos problemas existentes e também simplificar a introdução de condições de contorno. O método envolve a aproximação das variáveis sobre pequenas partes finitas do domínio — daí o nome elementos finitos - através de funções de interpolação polinomiais. Uma equação de resíduos ponderados pode ser escrita a fim de distribuir o erro introduzido por esta aproximação sobre cada elemento ou, alternativamente, esta operação pode ser vista como a minimização de um funcional de energia.

Esta operação resulta em matrizes de influência que expressam as propriedades de cada elemento em função de um número discreto de valores nodais. A montagem de todas estas, juntas, produz uma matriz global que representa as propriedades do contínuo. A aplicação das condições de contorno pode, então, ser efetuada de modo relativamente simples. Tanto geometrias gerais de contorno podem ser representadas por elementos curvos como qualquer derivada pode ser expressa em termos das funções de interpolação mencionadas. $O$ método é muito mais versátil que o método das diferenças finitas.

As desvantagens do método dos elementos finitos são a grande quantidade de dados necessária para discretizar o domínio inteiro - particularmente em problemas tridimensionais - e a imprecisão por vezes existente nos resultados. Isto geralmente ocorre no caso de funções descontínuas, singularidades ou funções que variam rapidamente. Também existem dificuldades na modelagem de regiões infinitas e em problemas com contornos móveis. 
O MÉTODO DOS ELEMENTOS DE CONTORNO, MEC (boundary elements method, BEM), também conhecido como o MÉTODO DAS EQUAÇÕES INTEGRAIS DE CONTORNO (boundary integral equation (BIE) method) foi desenvolvido como uma resposta às dificuldades acima. Sua idéia básica consiste em transformar as equações diferenciais que regem o domínio (onde um determinado problema é analisado (cf. [4.2])) em equações integrais (cf. [3.4]), aplicáveis à superfície ou contorno (cf. [3.2]) do mesmo. Em seguida, é possível discretizar o contorno da região considerada, dividindo-o em elementos - daí o nome elementos de contorno - como também relacionar as variáveis em pontos do contorno pelo uso de funções de Green (cf. [3.3]), ou seja, a solução fundamental.

Como resultado, obtêm-se uma série de coeficientes de influência que podem ser arranjados de forma matricial. As condições de contorno são, então, aplicadas de modo semelhante ao realizado em elementos finitos. A redução da dimensionalidade do problema responde por grande parte do interesse pelo método. Isto significa que, comparada a uma análise de domínio do MEF, uma análise pelo MEC reduz a quantidade de dados necessária para resolver um determinado problema, já que o método requer apenas a discretização do contorno.

Os elementos de contorno podem ser de vários tipos e possibilitam a modelagem de contornos curvos, mesmo tendo reduzido a dimensionalidade do problema em um (1) (repetindo, somente o contorno do sistema é discretizado). Por conta da solução do problema em termos de soluções fundamentais, as descontinuidades e as singularidades podem ser modeladas sem dificuldades especiais. Como a solução é necessária apenas sobre o contorno, a técnica adequa-se bem a problemas de superficies móveis e livres. Uma outra vantagem importante do método é a satisfação automática das condições de contorno em domínios infinitos e semiinfinitos, evitando-se a necessidade de discretização numérica de contornos remotos ou o truncamento do domínio numa distância finita. Isso é possível mediante a introdução de soluções fundamentais apropriadas que satisfazem, de forma exata, as condições de contorno dessas geometrias características. 
Além disso, outra característica importante da formulação empregada no MEC é a modelagem contínua (e exata) do domínio (a discretização do interior não é necessária). Como conseqüência, tanto tensões quanto deslocamentos, em pontos internos, podem ser calculados com uma resolução elevada.

É interessante notar que, enquanto diferenças finitas envolvem apenas a aproximação das equações diferenciais governando o problema, elementos finitos requerem a integração por partes dos termos de domínio resultantes da representação das variáveis utilizando-se funções polinomiais. Em elementos de contorno, por outro lado, embora o problema seja expresso utilizando-se apenas integrais de contorno, essas são mais complexas que aquelas apresentadas em elementos finitos. Por conta disso, técnicas especiais de integração são necessárias para obter resultados precisos e muito do trabalho efetuado no desenvolvimento do método concentrou-se no cálculo das integrais através de técnicas de integração numérica. Incluem-se, aqui, as integrais quase-singulares, singulares e hiper-singulares.

\subsubsection{Comparando-se Elementos de Contorno com Elementos Finitos}

De acordo com BECKER (1992), as vantagens e desvantagens do método dos elementos de contorno, em relação ao método dos elementos finitos, podem ser sintetizadas da seguinte maneira:

\section{Vantagens:}

- Menor tempo de preparação de dados.

Isto é conseqüência direta da modelagem apenas do contorno. Redefinições de malha, portanto, são mais simples, o que é particularmente importante no estudo preliminar de projetos, em problemas de propagação de fraturas e de contato. 
- Alta resolução para as tensões.

As tensões são precisas porque a modelagem do domínio é contínua e exata. Desta forma, problemas envolvendo tensões com gradiente forte (concentração elevada de tensões e problemas de contato e fratura) podem ser convenientemente tratados.

- Menores tempos computacionais de armazenamento e processamento.

Para manter o mesmo nível de precisão no cálculo de tensões, o MEC utiliza menos nós e elementos que o MEF, inclusive no contorno. As malhas de elementos de contorno não devem ser comparadas a malhas de elementos finitos sem os pontos internos, pois a aproximação do MEC é feita apenas no contorno. $\mathrm{O}$ processo de discretização fica ainda mais simples se forem utilizados, nos vértices, elementos que, às vezes, não se ligam — os chamados elementos descontínuos (cf. [7.4.2]), inadmissíveis em elementos finitos. Ademais, a utilização de elementos nos planos de simetria é desnecessária.

- Menos informação desnecessária.

A abordagem utilizada em elementos finitos (de discretizar todo o domínio e calcular as tensões em cada ponto nodal) é bastante ineficiente. Primeiramente, porque - na maioria dos problemas da prática de engenharia - as piores condições (fraturamento, concentração de tensões, choque térmico etc.) encontram-se justamente no contorno do domínio em análise. Além disso, como os pontos internos são opcionais (na resolução de um problema através do MEC), o analista pode concentrar a atenção numa região interna particular e não em todo o domínio.

- Facilmente aplicável a materiais incompressíveis.

A formulação de deformação plana de elementos finitos, baseada em deslocamentos, falha quando o coeficiente de Poisson vale 0.5 (como é o caso em materiais incompressíveis). A formulação do MEC trata esses materiais sem dificuldade. Portanto, para analisar materiais incompressíveis, o MEC é muito mais adequado que o MEF. 


\section{Desvantagens:}

- Matemática não-usual.

Como já mencionado, a maioria das vantagens do MEC estão relacionadas à sua base matemática mais complexa. Hoje em dia, entretanto, não é mais necessário um profundo conhecimento matemático a fim de provar tanto a existência quanto a unicidade de cada solução

Se, por um lado, esta formulação matemática significa versatilidade e precisão elevadas em programas bem escritos, por outro lado pode ter conseqüências desastrosas no caso de códigos ineficientes. BREBBIA \& DOMINGUEZ (1989) chamam a atenção para o fato de o MEC estar sujeito a erros quando se utilizam técnicas numéricas inadequadas. Pode-se dizer, aqui, que as palavras de COOK et al. (1989): "Embora o método dos elementos finitos possa tornar um bom engenheiro melhor, também pode tornar um mau engenheiro mais perigoso." encontram um respaldo BEM maior na utilização do MEC. Vale salientar que uma boa parte dos procedimentos numéricos utilizados no MEF aplicam-se diretamente ao MEC (integração numérica, aplicação das condições de contorno etc.).

O capítulo 3 contém, em grande parte, a base matemática acima citada, que diga-se de passagem - embora não seja completamente usual, é de fácil aprendizado. Exceção feita à consideração de funções de Green e ao tratamento de integrais singulares ou hiper-singulares, os demais tópicos são comuns ao currículo normal de engenharia.

- $\mathrm{O}$ interior deve ser modelado em problemas não-lineares.

Em geral, quando o material em análise exibe não-linearidade física ou está sujeito à ação de forças volumétricas ou térmicas, a modelagem do domínio é necessária. Bem entendido: a formulação passa a conter integrais de domínio que embora não possuam incógnitas - exigem a discretização de todo o domínio (em regiões de integração denominadas células) a fim de serem calculadas numericamente. Isso representa um dificuldade considerável e diminui tanto a elegância quanto a eficiência computacionais do método (a redução de dimensionalidade deixa de existir), embora as soluções continuem precisas. 
Em muitos casos práticos, felizmente, as integrais de domínio podem ser tratadas por técnicas capazes de transferi-las para o contorno (TANG (1988)). No caso particular de elastoplasticidade, a modelagem do domínio pode se restringir a àreas selecionadas - como a região em volta da extremidade de uma fratura. Em outros casos, a não-linearidade é simulada a partir de técnicas incrementais, iterativas ou de uma combinação de ambas, como neste trabalho.

- O desenvolvimento de aplicativos é mais dificil.

Via de regra, e do ponto de vista do usuário final, a análise pelo MEC é mais simples do que pelo MEF, pelas várias razões acima expostas. Justiça seja feita, do ponto de vista do projetista de "software", a tarefa é bem mais complexa do que se fosse feita com o MEF. Isto acontece devido à necessidade do tratamento das integrais singulares e quase-singulares (cf. [7.4.1]) ou das integrais hiper-singulares (cf. [8.3.2]), que surgem como consequêencia das soluções fundamentais utilizadas (cf. [3.3]). Além disso, considerando-se que as condições de contorno são baseadas em valores prescritos nos elementos - e não nos nós - é necessário um tratamento especial para manusear descontinuidades de tração que possa haver nos nós situados em vértices (cf. [7.4.2])

- Pobre para análise de cascas.

As cascas apresentam uma relação superficie / volume elevada, fazendo com que a redução de dimensionalidade do MEC não traga vantagens adicionais. Os pontos nodais situados em lados opostos (quando muito próximos) provocam imprecisão nas integrações numéricas ou mal-condicionamento do sistema de equações resultante.

- Matriz de solução cheia e não-simétrica.

O MEF apresenta a vantagem de utilizar matrizes com formato característico (simétricas e em banda), o que não ocorre no MEC, cujas matrizes são cheias e sem simetria. No entanto, esta não é uma desvantagem séria porque, para obter o mesmo nível de precisão que o MEF, o MEC utiliza menos nós e elementos, resultando em um sistema de ordem bem menor. 
Portanto, para decidir qual solução, seja MEF ou MEC, é a mais adequada para um problema em particular, três fatores devem ser levados em consideração:

- O tipo do problema (linear, não-linear, análise de cascas etc.).

- O grau de precisão necessário.

- A quantidade de tempo a ser gasta na preparação e interpretação dos dados.

\subsection{Formulações Integrais de Contorno}

Existem diversas maneiras de derivar as formulações do MEC: CRUSE \& RIZZO (1968) utilizaram o teorema recíproco de Betti (cf. [3.6]), BREBBIA \& DOMINGUEZ (1977) introduziram o conceito de resíduos ponderados na derivação e JENG \& WEXLER (1977) utilizaram uma formulação variacional semelhante à utilizada no MEF. Neste trabalho, seguir-se-á a primeira, cujo desenvolvimento é ilustrado na seção [7.3].

É possível dividir as formulações do MEC em três categorias (cf. [2.1], BECKER (1992) e ALIABADI \& ROOKE (1991)):

\section{- Método Indireto}

Baseia-se na utilização de funções-densidade fictícias para formular o problema. Embora essas funções não tenham significado fisico definido, podem ser integradas para obtenção de deslocamentos e tensões. Esta abordagem é indireta porque os deslocamentos e tensões reais não são utilizados em toda a formulação. 


\section{- Método Semi-direto}

Neste caso, as funções utilizadas para formular o problema estão relacionadas às funções de tensão, que possuem maior significado físico que as funções-densidade fictícias. As funções de tensão podem ser diferenciadas ou integradas, possibilitando o cálculo de deslocamentos e tensões.

\section{- Método Direto}

As grandezas físicas reais, tais como deslocamentos e forças de superficie, são utilizadas desde o início do desenvolvimento das equações integrais. As equações regentes do problema (obtidas através de equações de equilíbrio (cf. [4.2]), relações constitutivas (cf. [4.6]) e equações de compatibilidade (cf. [4.5])) são tranformadas em equações integrais válidas no contorno (cf. [3.4]) através dos teoremas de Green (cf. [3.5]) e do teorema recíproco de Betti (cf. [3.6]).

\subsection{Formulação do MEC Para Elasticidade Plana}

\subsubsection{Dedução da Equação Integral de Contorno}

Seja um domínio $\Omega$, limitado por um contorno $\Gamma$, submetido a dois estados de carregamento: o primeiro correspondente ao problema em estudo e o segundo ao problema de Kelvin (cf. [3.3]). A partir do teorema de Betti (eq. (3.28)),

$$
\int_{\Omega} \sigma_{\mathrm{kj}} \varepsilon_{\mathrm{kj}}^{*} \mathrm{~d} \Omega=\int_{\Omega} \sigma_{\mathrm{kj}}^{*} \varepsilon_{\mathrm{kj}} \mathrm{d} \Omega
$$

onde $\sigma_{\mathrm{kj}}$ e $\varepsilon_{\mathrm{kj}}$ indicam as componentes de tensão e deformação do problema em estudo e $\sigma_{\mathrm{kj}}^{*}$ e $\varepsilon_{\mathrm{kj}}^{*}$ indicam as componentes correspondetes do problema de Kelvin Considerando-se que 


$$
\sigma_{\mathrm{kj}} \varepsilon_{\mathrm{kj}}^{*}=\sigma_{\mathrm{kj}} \mathrm{u}_{\mathrm{k}, \mathrm{j}}^{*}
$$

chega-se a

$$
\int_{\Omega} \sigma_{\mathrm{kj}} \mathrm{u}_{\mathrm{k}, \mathrm{j}}^{*} \mathrm{~d} \Omega=\int_{\Omega} \sigma_{\mathrm{kj}}^{*} \mathrm{u}_{\mathrm{k}, \mathrm{j}} \mathrm{d} \Omega
$$

Integrando-se ambos os membros por partes, obtêm-se:

$$
\int_{\Omega} \sigma_{\mathrm{kj}} \mathrm{u}_{\mathrm{k}, \mathrm{j}}^{*} \mathrm{~d} \Omega=-\int_{\Omega} \sigma_{\mathrm{k}, \mathrm{j}} \mathrm{u}_{\mathrm{k}}^{*} \mathrm{~d} \Omega+\int_{\Gamma} \mathrm{p}_{\mathrm{k}} \mathrm{u}_{\mathrm{k}}^{*} \mathrm{~d} \Gamma
$$

e

$$
\int_{\Omega} \sigma_{\mathrm{kj}}^{*} \mathrm{u}_{\mathrm{k}, \mathrm{j}} \mathrm{d} \Omega=-\int_{\Omega} \sigma_{\mathrm{kj}, \mathrm{j}}^{*} \mathrm{u}_{\mathrm{k}} \mathrm{d} \Omega+\int_{\Gamma} \mathrm{p}_{\mathrm{k}}^{*} \mathrm{u}_{\mathrm{k}} \mathrm{d} \Gamma
$$

Substituindo-se (7.4) e (7.5) em (7.3), chega-se a:

$$
-\int_{\Omega} \sigma_{\mathrm{kj}, \mathrm{j}} \mathrm{u}_{\mathrm{k}}^{*} \mathrm{~d} \Omega+\int_{\Gamma} \mathrm{u}_{\mathrm{k}}^{*} \mathrm{p}_{\mathrm{k}} \mathrm{d} \Gamma=-\int_{\Omega} \sigma_{\mathrm{kj}, \mathrm{j}}^{*} \mathrm{u}_{\mathrm{k}} \mathrm{d} \Omega+\int_{\Gamma} \mathrm{p}_{\mathrm{k}}^{*} \mathrm{u}_{\mathrm{k}} \mathrm{d} \Gamma
$$

A partir da equação de equilíbrio (eq. (4.4)):

$$
\int_{\Omega} \sigma_{\mathrm{kj}, \mathrm{j}} \mathrm{u}_{\mathrm{k}}^{*} \mathrm{~d} \Omega=\int_{\Omega}\left(-\mathrm{b}_{\mathrm{k}}\right) \mathrm{u}_{\mathrm{k}}^{*} \mathrm{~d} \Omega=-\int_{\Omega} \mathrm{b}_{\mathrm{k}} \mathrm{u}_{\mathrm{k}}^{*} \mathrm{~d} \Omega .
$$

A partir da solução fundamental (eq. (3.15)):

$$
\int_{\Omega} \sigma_{\mathrm{kj}, \mathrm{j}}^{*} \mathrm{u}_{\mathrm{k}} \mathrm{d} \Omega=\int_{\Omega}\left(-\Delta^{\mathrm{p}} \delta_{\mathrm{k} \ell}\right) \mathrm{u}_{\mathrm{k}} \mathrm{d} \Omega=-\int_{\Gamma} \Delta^{\mathrm{p}} \mathrm{u}_{\ell} \mathrm{d} \Omega=-\mathrm{u}_{\ell}^{\mathrm{p}},
$$

onde o último termo representa o deslocamento, na direção $\ell$, do ponto $\mathrm{p}$.

Logo, a eq. (7.6) torna-se: 


$$
\int_{\Omega} u_{k}^{*} b_{k} d \Omega+\int_{\Gamma} u_{k}^{*} p_{k} d \Gamma=u_{\ell}^{p}+\int_{\Gamma} p_{k}^{*} u_{k} d \Gamma
$$

Interpretando-se geometricamente os componentes da solução fundamental (cf. [3.3]), têm-se:

$$
\mathrm{u}_{\mathrm{k}}^{*}=\mathrm{u}_{\mathrm{wk}}^{*} \delta_{\ell \mathrm{w}}=\mathrm{u}_{\ell \mathrm{k}}^{*} ; \quad \mathrm{p}_{\mathrm{k}}^{*}=\mathrm{p}_{\mathrm{wk}}^{*} \delta_{\ell \mathrm{w}}=\mathrm{p}_{\ell \mathrm{k}}^{*}
$$

Substituindo-se as eqs. (7.10) na eq. (7.9):

$$
\mathrm{u}_{\ell}^{\mathrm{p}}=-\int_{\Gamma} \mathrm{p}_{\ell \mathrm{k}}^{*} \mathrm{u}_{\mathrm{k}} \mathrm{d} \Gamma+\int_{\Gamma} \mathrm{u}_{\ell \mathrm{k}}^{*} \mathrm{p}_{\mathrm{k}} \mathrm{d} \Gamma+\int_{\Omega} \mathrm{u}_{\ell \mathrm{k}}^{*} \mathrm{~b}_{\mathrm{k}} \mathrm{d} \Omega
$$

que é conhecida como a Equação de Somigliana e que fornece os valores dos deslocamentos de pontos internos em função dos valores de força de superfície e deslocamento no contorno, $\mathrm{p}_{\mathrm{k}} \mathrm{e} \mathrm{u}_{\mathrm{k}}$, das forças volumétricas e da solução fundamental. A eq. (7.11) é válida para qualquer ponto do domínio e também pode ser escrita de forma matricial, desde que sejam definidos os arranjos seguintes. Os componentes da solução fundamental podem ser escritos como matrizes $2 \times 2$ cujos elementos são $\mathrm{u}_{\ell \mathrm{k}}^{*}$ e $\mathrm{p}_{\ell \mathrm{k}}^{*}$, isto é:

$$
\left[p^{*}\right]=\left[\begin{array}{ll}
p_{11}^{*} & p_{12}^{*} \\
p_{21}^{*} & p_{22}^{*}
\end{array}\right], \quad\left[u^{*}\right]=\left[\begin{array}{ll}
u_{11}^{*} & u_{12}^{*} \\
u_{21}^{*} & u_{22}^{*}
\end{array}\right]
$$

Os vetores de deslocamentos e forças de superficie (em um ponto qualquer do contorno) e de forças volumétricas (em um ponto qualquer do domínio) são:

$$
\{u\}=\left\{\begin{array}{l}
u_{1} \\
u_{2}
\end{array}\right\},\{p\}=\left\{\begin{array}{l}
p_{1} \\
p_{2}
\end{array}\right\},\{b\}=\left\{\begin{array}{l}
b_{1} \\
b_{2}
\end{array}\right\} .
$$

Portanto, a equação de Somigliana torna-se: 


$$
\{\mathrm{u}\}^{\mathrm{p}}=-\int_{\Gamma}\left[\mathrm{p}^{*}\right]\{\mathrm{u}\} \mathrm{d} \Gamma+\int_{\Gamma}\left[\mathrm{u}^{*}\right]\{\mathrm{p}\} \mathrm{d} \Gamma+\int_{\Omega}\left[\mathrm{u}^{*}\right]\{\mathrm{b}\} \mathrm{d} \Omega
$$

onde $\{\mathrm{u}\}^{\mathrm{p}}$ representa o vetor de deslocamentos no ponto $\mathrm{p}$.

\subsubsection{Dedução da Equação Integral de Contorno Para Pontos no Contorno}

A equação de Somigliana fornece os deslocamentos em qualquer ponto interno desde que os valores de $p_{k}$ e $u_{k}$ sejam conhecidos em todos os pontos do contorno (ou seja, os deslocamentos só poderão ser calculados quando o problema de valor de contorno tiver sido previamente resolvido). Como a equação de Somigliana é válida para qualquer ponto em $\Omega$, incluindo-se $\Gamma$, é possível encontrar uma equação integral levando-se o ponto de colocação para o contorno. Esta expressão, quando aplicada em vários pontos, produz um sistema de equações que, uma vez solucionado, fornece as incógnitas do contorno.

Entretanto, quando o ponto de colocação (onde a eq. é gerada) pertence ao contorno, as integrais de contorno apresentam singularidade (cf. [3.4]), sendo necessário efetuar uma análise cuidadosa das condições na vizinhança do ponto.

Uma maneira simples de fazê-lo é considerar, incicialmente, que o ponto $p$ pertence a um trecho suave do contorno. Neste caso, é possível suplementar o domínio com um hemisfério de raio $\varepsilon$, centrado em p (fig. (7.2a)). Fazendo-se o raio $\varepsilon$ tender a zero, o ponto $\mathrm{p}$ tornar-se-á um ponto do contorno e a expressão resultante será a particularização da eq. (7.11) para pontos de colocação situados no contorno. 


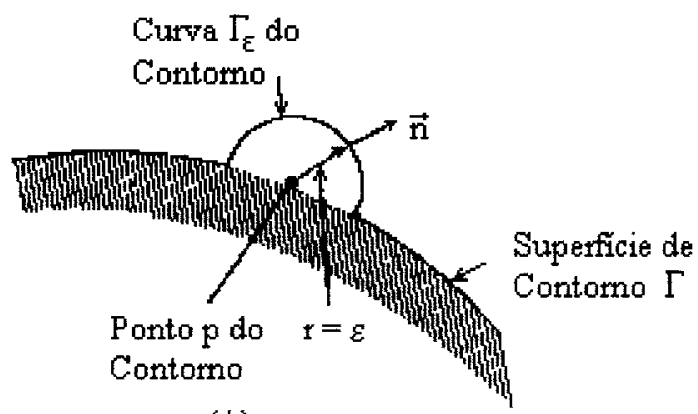

(A)

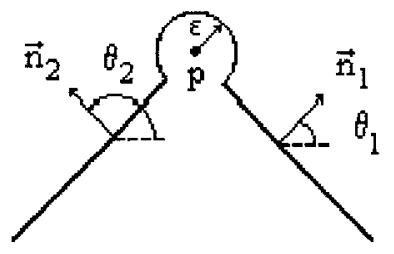

(B)

FIGURA 7.2 - Pontos do contorno no caso bidimensional. (a) Contorno suave; (b) vértice. BREBBIA \& DOMINGUEZ (1989)

A eq. de Somigliana torna-se

$u_{\ell}^{p}=-\lim _{\varepsilon \rightarrow 0}\left\{\int_{\Gamma-\Gamma_{\varepsilon}} p_{\ell k}^{*} u_{k} d \Gamma+\int_{\Gamma_{\varepsilon}} p_{\ell k}^{*} u_{k} d \Gamma_{\varepsilon}\right\}+\lim _{\varepsilon \rightarrow 0}\left\{\int_{\Gamma-\Gamma_{\varepsilon}} u_{\ell k}^{*} p_{k} d \Gamma+\int_{\Gamma_{\varepsilon}} u_{\ell k}^{*} p_{k} d \Gamma_{\varepsilon}\right\}+\int_{\Omega} u_{\ell k}^{*} b_{k} d \Omega$.

A primeira e a terceira integrais na eq. (7.15) tornar-se-ão integrais no contorno inteiro quando $\varepsilon \rightarrow 0$. Para as integrais restantes, é possível demonstrar que valem os limites:

$$
\lim _{\varepsilon \rightarrow 0}\left\{\int_{\Gamma_{\varepsilon}} p_{\ell \mathrm{k}}^{*} \mathrm{u}_{\mathrm{k}} \mathrm{d} \Gamma_{\varepsilon}\right\}=\lim _{\varepsilon \rightarrow 0}\left\{\int_{\Gamma_{\varepsilon}} \mathrm{p}_{\ell \mathrm{k}}^{*} \mathrm{~d} \Gamma_{\varepsilon}\right\} \mathrm{u}_{\mathrm{k}}^{\mathrm{p}}=-\frac{1}{2} \delta_{\ell \mathrm{k}} \mathrm{u}_{\mathrm{k}}^{\mathrm{p}}=-\frac{1}{2} \mathrm{u}_{\ell}^{\mathrm{p}}
$$

e

$$
\lim _{\varepsilon \rightarrow 0}\left\{\int_{\Gamma_{\varepsilon}} u_{\ell \mathbf{k}}^{*} p_{\mathbf{k}} \mathrm{d} \Gamma_{\varepsilon}\right\}=\lim _{\varepsilon \rightarrow 0}\left\{\int_{\Gamma_{\varepsilon}} \mathrm{u}_{\ell \mathrm{k}}^{*} \mathrm{~d} \Gamma_{\varepsilon}\right\} \mathrm{p}_{\mathrm{k}}^{\mathrm{p}}=0
$$

Portanto, no caso de pontos de colocação situados em uma parte suave do contorno, a equação de Somigliana torna-se 


$$
\frac{1}{2} \mathrm{u}_{\ell}^{\mathrm{p}}=-\int_{\Gamma} \mathrm{p}_{\ell \mathrm{k}}^{*} \mathrm{u}_{\mathrm{k}} \mathrm{d} \Gamma+\int_{\Gamma} \mathrm{u}_{\ell \mathrm{k}}^{*} \mathrm{p}_{\mathrm{k}} \mathrm{d} \Gamma+\int_{\Omega} \mathrm{u}_{\ell \mathrm{k}}^{*} \mathrm{~b}_{\mathrm{k}} \mathrm{d} \Omega,
$$

ou

$$
c_{\ell k} u_{k}^{p}=-\int_{\Gamma} p_{\ell k}^{*} u_{k} d \Gamma+\int_{\Gamma} u_{\ell k}^{*} p_{k} d \Gamma+\int_{\Omega} u_{\ell k}^{*} b_{k} d \Omega
$$

onde as integrais incluem o valor principal de Cauchy (cf. [3.4]), $\Gamma$ é suave em p e

$$
\mathrm{c}_{\ell \mathbf{k}}=\frac{1}{2} \delta_{\ell \mathbf{k}}
$$

Em forma matricial, a eq. (7.19) torna-se

$$
[c]\{u\}^{p}=-\int_{\Gamma}\left[p^{*}\right]\{u\} d \Gamma+\int_{\Gamma}\left[u^{*}\right]\{p\} d \Gamma+\int_{\Omega}\left[u^{*}\right]\{b\} d \Omega .
$$

Entretanto, quando o ponto de colocação estiver situado em um vértice (fig. (7.2b)), o limite das forças de superfície da solução fundamental, ou seja,

$$
\mathrm{I}=\lim _{\varepsilon \rightarrow 0}\left\{\int_{\Gamma_{\varepsilon}} \mathrm{p}_{\ell \mathrm{k}}^{*} \mathrm{~d} \Gamma_{\varepsilon}\right\}
$$

fornece um resultado diferente (BREBBIA \& DOMINGUEZ (1989)):

$$
\begin{aligned}
& I=\frac{-1}{8 \pi(1-v)} \\
& {\left[\begin{array}{cc}
4(1-v)\left(\pi+\theta_{2}-\theta_{1}\right)+\operatorname{Sen}\left(2 \theta_{1}\right)-\operatorname{Sen}\left(2 \theta_{2}\right) & \operatorname{Cos}\left(2 \theta_{2}\right)-\operatorname{Cos}\left(2 \theta_{1}\right) \\
\operatorname{Cos}\left(2 \theta_{2}\right)-\operatorname{Cos}\left(2 \theta_{1}\right) & 4(1-v)\left(\pi+\theta_{2}-\theta_{1}\right)+\operatorname{Sen}\left(2 \theta_{2}\right)-\operatorname{Sen}\left(2 \theta_{1}\right)
\end{array}\right]}
\end{aligned}
$$

de forma que 


$$
\mathrm{c}_{\ell \mathrm{k}}=\delta_{\ell \mathrm{k}}+\mathrm{I}_{\ell \mathrm{k}}
$$

\subsubsection{Formulação em Elementos de Contorno}

Para que as equações integrais sejam calculadas numericamente, o contorno deve ser discretizado em uma série de elementos, conforme observado na fig. (7.3). Nestes elementos, tanto a geometria quanto a variação (campo) das incógnitas (deslocamentos e forças de superficie, neste trabalho) devem ser interpoladas a partir de uma série de pontos onde os valores incógnitos são considerados (cf. [3.7]). Estes pontos são denominados nós e os valores que as incógnitas assumem nos mesmos são os valores nodais.

De acordo com o grau de aproximação da geometria, os elementos podem ser classificados em constantes (grau zero, fig. (7.3a)), lineares ( $1^{\circ}$ grau, fig. (7.3b)), quadráticos ( $2^{\circ}$ grau, fig. (7.3c)), cúbicos $\left(3^{\circ}\right.$ grau) ou de ordem superior (grau $\geq$ 4). Além disso, é possível admitir que os graus de aproximação de geometria e variáveis sejam diferentes, caracterizando os elementos subparamétricos, isoparamétricos ou superparamétricos (cf. [3.4]).

Os elementos quadráticos isoparamétricos apresentam a melhor relação precisão/eficiência na maioria das aplicações envolvendo análise de tensões (BECKER (1992)). Para os objetivos deste trabalho, a utilização de elementos lineares isoparamétricos foi suficiente.

Desconsiderando-se as forças de volume e discretizando-se a eq. (7.21):

$$
[c]\{u\}^{p}+\sum_{j=1}^{\mathrm{ne}}\left(\iint_{\Gamma_{\mathrm{j}}}\left[\mathrm{p}^{*}\right]\{\mathrm{u}\} \mathrm{d} \Gamma_{\mathrm{j}}\right)=\sum_{\mathrm{j}=1}^{\mathrm{ne}}\left(\int\left[\mathrm{r}_{\Gamma_{\mathrm{j}}} \mathrm{u}^{*}\right]\{\mathrm{p}\} \mathrm{d} \Gamma_{\mathrm{j}}\right),
$$

onde ne representa o número de elementos de contorno. 

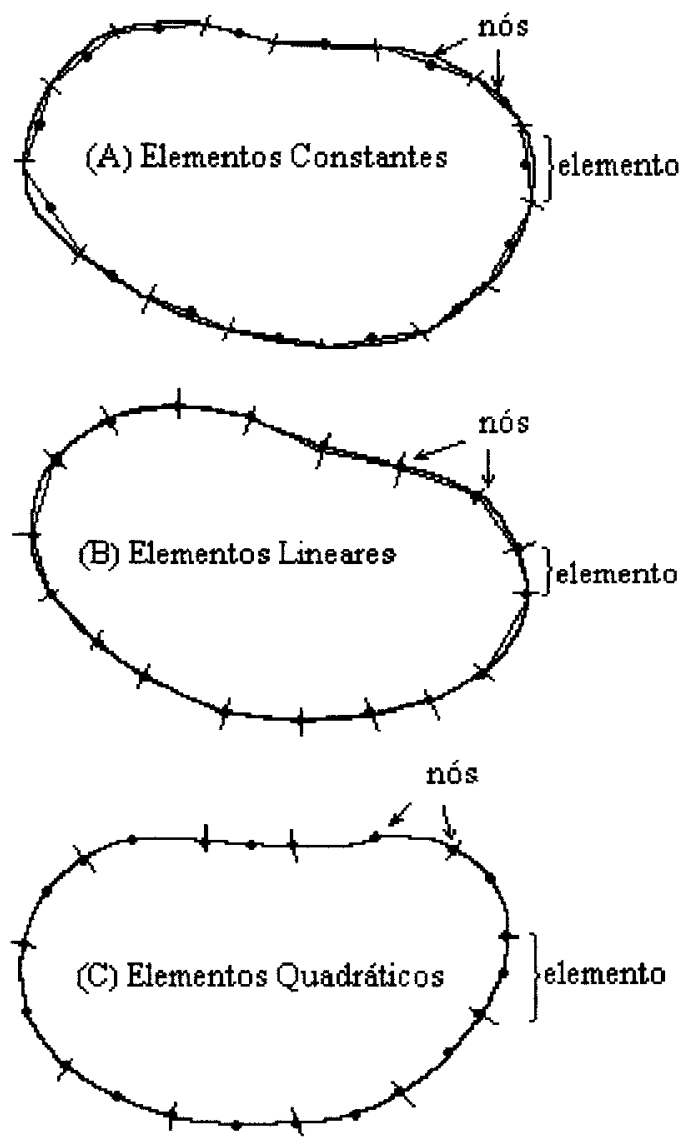

FIGURA 7.3 - Diferentes tipos de elementos de contorno. (a) Constantes. (b) Lineares. (c) Quadráticos. BREBBIA \& DOMINGUEZ (1989).

A aproximação das variáveis pode ser feita utilizando-se duas funções de interpolação $\phi_{1}$ e $\phi_{2}$, definidas em termos da coordenada homogênea $\varepsilon$ (cf. [3.8.1]), como mostrado na fig. (7.4), isto é,

$$
\begin{aligned}
& \{u\}=\left\{\begin{array}{l}
u_{1} \\
u_{2}
\end{array}\right\}=\left[\begin{array}{llll}
\phi_{1} & 0 & \phi_{2} & 0 \\
0 & \phi_{1} & 0 & \phi_{2}
\end{array}\right]\left\{\begin{array}{l}
u_{1}^{1} \\
u_{2}^{1} \\
u_{1}^{2} \\
u_{2}^{2}
\end{array}\right\}=[\Phi]\{u\}_{n}^{j} \\
& \{p\}=\left\{\begin{array}{l}
p_{1} \\
p_{2}
\end{array}\right\}=\left[\begin{array}{llll}
\phi_{1} & 0 & \phi_{2} & 0 \\
0 & \phi_{1} & 0 & \phi_{2}
\end{array}\right]\left\{\begin{array}{l}
p_{1}^{1} \\
p_{2}^{1} \\
p_{1}^{2} \\
p_{2}^{2}
\end{array}\right\}=[\Phi]\{p\}_{n}^{j}
\end{aligned}
$$


onde $u_{w}^{k}\left(p_{w}^{k}\right)$ representa o deslocamento (força de superficie), na direção ' $w$ ', do nó ' $\mathrm{k}$ ' do elemento e $\{\mathrm{u}\}_{\mathrm{n}}^{\mathrm{j}}\left(\{\mathrm{p}\}_{\mathrm{n}}^{\mathrm{j}}\right)$ representa os deslocamentos (forças de superficie) nodais do elemento ' $\mathrm{j}$ '.

A aproximação da geometria também pode ser feita de maneira análoga:

$$
\left\{\begin{array}{l}
x \\
y
\end{array}\right\}=\left[\begin{array}{cccc}
\phi_{1} & 0 & \phi_{2} & 0 \\
0 & \phi_{1} & 0 & \phi_{2}
\end{array}\right]\left\{\begin{array}{l}
x^{1} \\
y^{1} \\
x^{2} \\
y^{2}
\end{array}\right\}
$$

onde valem as considerações anteriores para a notação.

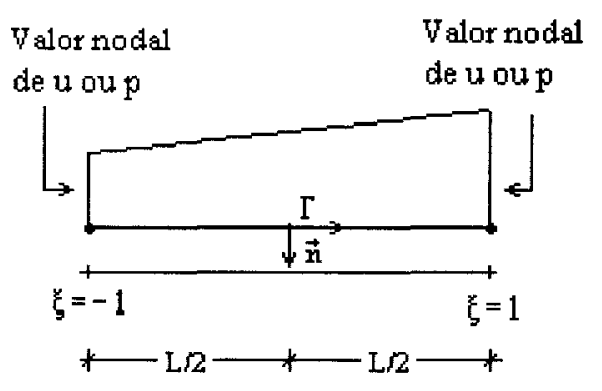

FIGURA 7.4 - Definição do elemento linear isoparamétrico. BREBBIA \& DOMINGUEZ (1989).

Substituindo-se as eqs. (7.26) na eq. (7.25):

$$
[\mathrm{c}][\Phi]^{p}\{\mathrm{u}\}_{\mathrm{n}}^{\mathrm{p}}+\sum_{\mathrm{j}=1}^{\mathrm{ne}}\left(\int_{\Gamma_{\mathrm{j}}}\left[\mathrm{p}^{*}\right][\Phi] \mathrm{d} \Gamma_{\mathrm{j}}\right)\{\mathrm{u}\}_{\mathrm{n}}^{\mathrm{j}}=\sum_{\mathrm{j}=1}^{\mathrm{ne}}\left(\iint_{\Gamma_{\mathrm{j}}}\left[\mathrm{u}^{*}\right][\Phi] \mathrm{d} \Gamma_{\mathrm{j}}\right)\{\mathrm{p}\}_{\mathrm{n}}^{\mathrm{j}},
$$

onde $\{\mathrm{u}\}_{\mathrm{n}}^{\mathrm{p}}$ representa os deslocamentos nodais do elemento onde o ponto de colocação está situado. As integrais que aparecem na eq. (7.28) relacionam os 
deslocamentos do ponto de colocação (em particular, os deslocamentos nodais do elemento onde o ponto de colocação estiver situado) a forças de superfície e deslocamentos nodais em qualquer elemento ' $\mathrm{j}$ '. Por isso, são denominadas matrizes de influência e seus valores resultantes podem ser representados por

$$
\left[H{ }^{\wedge}\right]^{p j}=\int_{\Gamma_{j}}\left[p^{*}\right][\Phi] d \Gamma_{j} \quad \text { e } \quad[G W]^{p j}=\int_{\Gamma_{j}}\left[u^{*}\right][\Phi] d \Gamma_{j}
$$

\subsubsection{Montagem do Sistema de Equações}

Substituindo-se as eqs. (7.29) na eq. (7.28) e considerando-se

$$
[H W]=\left\{\begin{array}{cc}
\hat{H W}]^{p j} & \text { se j } \not \subset p \\
\hat{H W}]^{p j}+[c][\Phi]^{p} & \text { se j } \subset p
\end{array},\right.
$$

chega-se a

$$
\sum_{j=1}^{n e}[H W]^{p j}\{u\}_{n}^{j}=\sum_{j=1}^{n e}[G W]^{p j}\{p\}_{n}^{j}
$$

A eq. (7.31) foi obtida a partir de um determinado ponto de colocação p. Vale salientar que, a princípio, $\mathrm{p}$ pode ser qualquer ponto do contorno, o que significa a possibilidade de obtenção de infinitas equações, cada uma delas relacionando as incógnitas nodais. As limitações para a escolha da posição de p serão tratadas na seção [7.4.2].

No problema elástico bidimensional, existem $4 *$ nn graus de liberdade (onde nn é o número de nós). Destes, $2 *$ nn são incógnitas e $2 *$ nn são obtidos através das condições de contorno. São necessárias, portanto, $2 *$ nn equações (relacionando os $4 *$ nn graus de liberdade) para a resolução do problema. Fazendo-se $\mathrm{p}$ assumir nn 
posições diferentes, obtém-se um sistema de equações lineares, de ordem $2^{*} \mathrm{nn}$, cuja resolução fornece as incógnitas restantes:

$$
[\mathrm{H}]\{\mathrm{U}\}=[\mathrm{G}]\{\mathrm{P}\}
$$

\subsubsection{Imposição das Condições de Contorno}

Em um problema elastostático típico, é possível encontrar três tipos de condições de contorno:

- Deslocamentos prescritos.

- Forças de superficie prescritas.

- Relação linear entre forças de superficie e deslocamentos (como acontece, por exemplo, no caso de um apoio de mola ou inclinado).

Como existem $2^{*}$ nn equações (para $4 *$ nn graus de liberdade), são necessários $2 * n n$ valores prescritos. Em outras palavras, cada nó deve ter duas variáveis (das quatro existentes) prescritas. Para introduzir as condições de contorno em (7.32), as matrizes $[\mathrm{H}]$ e $[\mathrm{G}]$ devem ser rearranjadas de tal forma que todas as variáveis conhecidas estejam no primeiro membro e todas as incógnitas, no segundo. Isto é feito mediante troca de colunas entre as matrizes $[\mathrm{H}]$ e $[\mathrm{G}]$, obtendo-se o sistema

$$
[\mathrm{B}]\{\mathrm{VP}\}=[\mathrm{A}]\{\mathrm{M}\} \quad \text { ou } \quad\{\mathrm{F}\}=[\mathrm{A}]\{\mathrm{M}\}
$$

onde $[\mathrm{B}]$ e $[\mathrm{A}]$ são as formas modificadas das matrizes $[\mathrm{H}]$ e $[\mathrm{G}]$, respectivamente; $\{\mathrm{VP}\}$ é um vetor que reúne todos os valores prescritos; $\{\mathrm{F}\}=[\mathrm{B}]\{\mathrm{VP}\}$ e $\{\mathrm{M}\}$ é o vetor das incógnitas no contorno. De forma semelhante, qualquer relacionamento linear entre forças de superfície e deslocamentos pode ser implementado. 
Como bem lembrado por BECKER (1992), os deslocamentos são diversas ordens de grandeza menores que as forças de superficie por conta do valor elevado do módulo de elasticidade. Portanto, sugere a utilização de um fator de escala, antes do rearranjamento e depois da resolução do sistema de equações, para minimizar os erros provenientes da existência de coeficientes com diferença de diversas ordens de grandeza na matriz [A]. Alternativamente, como neste trabalho, pode-se utilizar uma estratégia de pivoteamento durante a resolução do sistema.

\subsubsection{Resolução do Sistema de Equações}

Em geral, utiliza-se o Método de Eliminação de Gauss. A escolha justifica-se pelo fato de a matriz dos coeficientes ser cheia e não-simétrica. Desta forma, obtémse a solução elástica do problema:

$$
\{\mathrm{M}\}=[\mathrm{A}]^{-1}\{\mathrm{~F}\}
$$

É interessante enfatizar que o vetor das incógnitas é misto (deslocamentos e forças de superficie), ao contrário do que acontece no MEF, onde todas as incógnitas são deslocamentos. Isto é consequeência da formulação mista utilizada no MEC e se constitui em uma vantagem importante sobre o MEF. Por isso, após a resolução do sistema de equações lineares, as variáveis contidas no vetor das incógnitas, $\{M\}$, devem ser reorganizadas em deslocamentos e forças de superficies, antes de serem utilizadas computacionalmente.

\subsubsection{Cálculo de Parâmetros Adicionais}

Após a resolução do sistema de equações, os valores de força de superficie e deslocamento são conhecidos em todos os pontos nodais do contorno. A partir deste instante, determinar os parâmetros adicionais necessários à análise do sistema é um procedimento relativamente simples, como descrito a seguir. 


\section{Deslocamentos em Pontos Internos}

A eq. de Somigliana na forma matricial (eq. (7.14)) pode ser discretizada do mesmo modo que a eq. (7.21) (agora, sem a consideração das forças de volume), fornecendo uma equação análoga à eq. (7.28):

$$
\left.\{u\}^{p}+\sum_{j=1}^{n e}\left(\iint_{\Gamma_{j}}\left[p^{*}\right][\Phi] d \Gamma_{j}\right)\{u\}_{n}^{j}=\sum_{j=1}^{n e}\left(\int\left[u_{\Gamma_{j}}^{*}\right] \Phi\right] d \Gamma_{j}\right)\{p\}_{n}^{j},
$$

onde $\{u\}^{p}$ representa os deslocamentos em um ponto interno ' $p$ ' qualquer. Substituindo-se as eqs. (7.29) na eq. (7.35), obtém-se

$$
\{u\}^{p}=-\sum_{j=1}^{n e}[H W]^{p j}\{u\}_{n}^{j}+\sum_{j=1}^{n e}[G W]^{p j}\{p\}_{n}^{j} .
$$

que fornece os deslocamentos no ponto ' $\mathrm{p}$ ' em função dos deslocamentos e forças de superficie nodais.

\section{Tensões em Pontos Internos}

As tensões em pontos internos podem ser calculadas através das relações constitutivas (eq. (4.19)). Se o meio for isotrópico, as deformações podem ser obtidas pela diferenciação dos deslocamentos correspondentes (eqs. (4.16) e (7.11)). Desta forma, substitutindo-se (4.16) em (4.19), tem-se:

$$
\sigma_{\mathrm{ij}}^{\mathrm{p}}=\frac{2 \mu \nu}{(1-2 v)} \delta_{\mathrm{ij}} \mathrm{u}_{\ell, \ell}+\mu\left(\mathrm{u}_{\mathrm{i}, \mathrm{j}}+\mathrm{u}_{\mathrm{j}, \mathrm{i}}\right)
$$

Substituindo-se os deslocamentos fornecidos pela equação de Somigliana (eq. (7.11)), sem a consideração de forças volumétricas, na eq. (7.37): 


$$
\begin{aligned}
\sigma_{\mathrm{ij}}^{\mathrm{p}} & =\int_{\Gamma}\left\{\frac{2 \mu \nu}{(1-2 v)} \delta_{\mathrm{ij}} \frac{\partial \mathrm{u}_{\ell \mathrm{k}}^{*}}{\partial \mathrm{x}_{\ell}}+\mu\left(\frac{\partial \mathrm{u}_{\mathrm{ik}}^{*}}{\partial \mathrm{x}_{\mathrm{j}}}+\frac{\partial \mathrm{u}_{\mathrm{jk}}^{*}}{\partial \mathrm{x}_{\mathrm{i}}}\right)\right\} \mathrm{p}_{\mathrm{k}} \mathrm{d} \Gamma- \\
& -\int_{\Gamma}\left\{\frac{2 \mu v}{(1-2 v)} \delta_{\mathrm{ij}} \frac{\partial \mathrm{p}_{\ell \mathrm{k}}^{*}}{\partial \mathrm{x}_{\ell}}+\mu\left(\frac{\partial \mathrm{p}_{\mathrm{ik}}^{*}}{\partial \mathrm{x}_{\mathrm{j}}}+\frac{\partial \mathrm{p}_{\mathrm{jk}}^{*}}{\partial \mathrm{x}_{\mathrm{i}}}\right)\right\} \mathrm{u}_{\mathrm{k}} \mathrm{d} \Gamma
\end{aligned}
$$

Interpolando-se trações e deslocamentos e escrevendo-se em notação matricial, a eq. (7.38) fica:

$$
\begin{aligned}
\{\sigma\}^{\mathrm{p}} & =\left\{\begin{array}{l}
\sigma_{11} \\
\sigma_{12} \\
\sigma_{22}
\end{array}\right\}^{\mathrm{p}}= \\
& =\sum_{j=1}^{\mathrm{ne}}\left(\int[\mathrm{D}]^{\mathrm{kij}}[\Phi] \mathrm{d} \Gamma_{\mathrm{j}}\right)\{\mathrm{p}\}_{\mathrm{n}}^{\mathrm{j}}-\sum_{\mathrm{j}=1}^{\mathrm{ne}}\left(\int_{\Gamma_{\mathrm{j}}}[\mathrm{S}]^{\mathrm{kij}}[\Phi] \mathrm{d} \Gamma_{\mathrm{j}}\right)\{\mathrm{u}\}_{\mathrm{n}}^{\mathrm{j}}=,(\mathbf{7 . 3 9}) \\
& =\sum_{\mathrm{j}=1}^{\mathrm{ne}}[\mathrm{DFI}]^{\mathrm{kij}}\{\mathrm{p}\}_{\mathrm{n}}^{\mathrm{j}}-\sum_{\mathrm{j}=1}^{\mathrm{ne}}[\mathrm{SFI}]^{\mathrm{kij}}\{\mathrm{u}\}_{\mathrm{n}}^{\mathrm{j}}= \\
& =-\left[\mathrm{H}^{\prime}\right]\{\mathrm{U}\}+\left[\mathrm{G}^{\prime}\right]\{\mathrm{P}\}
\end{aligned}
$$

onde os tensores $[\mathrm{D}]^{\mathrm{kij}}$ e $[\mathrm{S}]^{\mathrm{kij}}$ são dados por (BREBBIA \& DOMINGUEZ (1989)):

$$
\begin{aligned}
& {[D]^{\mathrm{kij}}=\left[\begin{array}{ll}
\mathrm{D}_{111} & \mathrm{D}_{211} \\
\mathrm{D}_{112} & \mathrm{D}_{212} \\
\mathrm{D}_{122} & \mathrm{D}_{222}
\end{array}\right]=\frac{1}{4 \pi(1-v) \mathrm{r}}\left\{(1-2 v)\left[\delta_{\mathbf{k i}} \mathrm{r}_{, \mathbf{j}}+\delta_{\mathrm{kj}} \mathrm{r}_{, \mathbf{i}}-\delta_{\mathrm{ij}} \mathrm{r}_{\mathrm{k}}\right]+2 \mathrm{r}_{, \mathrm{i}} \mathrm{r}_{\mathrm{j}} \mathrm{r}_{, \mathbf{k}}\right\}}
\end{aligned}
$$

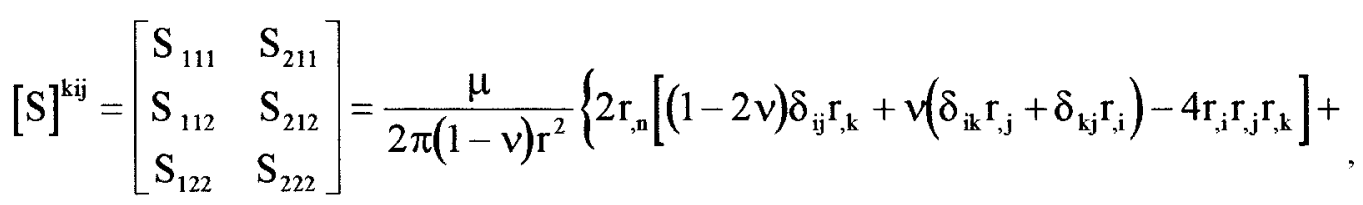

$$
\begin{aligned}
& \left.+2 v\left[n_{i} r_{, j} r_{, k}+n_{j} r_{, i} r_{, k}\right]+(1-2 v)\left[2 n_{k} r_{, i} r_{, j}+n_{j} \delta_{i k}+n_{i} \delta_{j k}\right]-(1-4 v) n_{k} \delta_{i j}\right\}
\end{aligned}
$$

e onde 


$$
\mathrm{r}_{, \mathrm{n}}=\frac{\partial \mathrm{r}}{\partial \mathrm{n}}=\nabla \mathrm{r} \cdot \overrightarrow{\mathrm{n}}=\left(\frac{1}{\mathrm{r}}\right) \overrightarrow{\mathrm{r}} \cdot \overrightarrow{\mathrm{n}}=\left\langle\frac{\partial \mathrm{r}}{\partial \mathrm{x}}, \frac{\partial \mathrm{r}}{\partial \mathrm{y}}\right\rangle\left\langle\mathrm{n}_{\mathrm{x}}, \mathrm{n}_{\mathrm{y}}\right\rangle=\frac{\partial \mathrm{r}}{\partial \mathrm{x}} \mathrm{n}_{\mathrm{x}}+\frac{\partial \mathrm{r}}{\partial \mathrm{y}} \mathrm{n}_{\mathrm{y}}
$$

indica a derivada do raio (módulo do vetor posição) na direção do versor normal ao elemento.

\section{Deslocamentos e Forças de Superfície em Pontos do Contorno}

Podem ser facilmente interpolados a partir dos valores nodais, utilizando-se as eqs. (7.26)

\section{Tensões em Pontos do Contorno}

Podem ser calculadas de duas maneiras. Na primeira, utiliza-se a eq. (7.39). $\mathrm{Na}$ segunda, as tensões são calculadas a partir dos deslocamentos e forças de superficie obtidos no contorno, utilizando-se diferenciação das funções de forma. Embora o primeiro método seja mais preciso, é também mais complicado, pois exige um tratamento especial para a integração dos núcleos hiper-singulares (eqs. (7.40), cf. [7.4.1], [8.3.2]). Portanto, será utilizado o segundo método, que é descrito a seguir.

Seja um ponto suave do contorno, conforme ilustrado pela fig. (7.5a), pertencente a um elemento cujos deslocamentos e coordenadas nodais estão representados na fig. (7.5b).

É possivel demonstrar que a deformação na direção tangencial é dada por

$$
\varepsilon_{22}=\frac{\left(u_{x}^{2}-u_{x}^{1}\right)\left(x^{2}-x^{1}\right)+\left(u_{y}^{2}-u_{y}^{1}\right)\left(y^{2}-y^{1}\right)}{\ell^{2}},
$$

onde $\ell$ é o comprimento do elemento. 

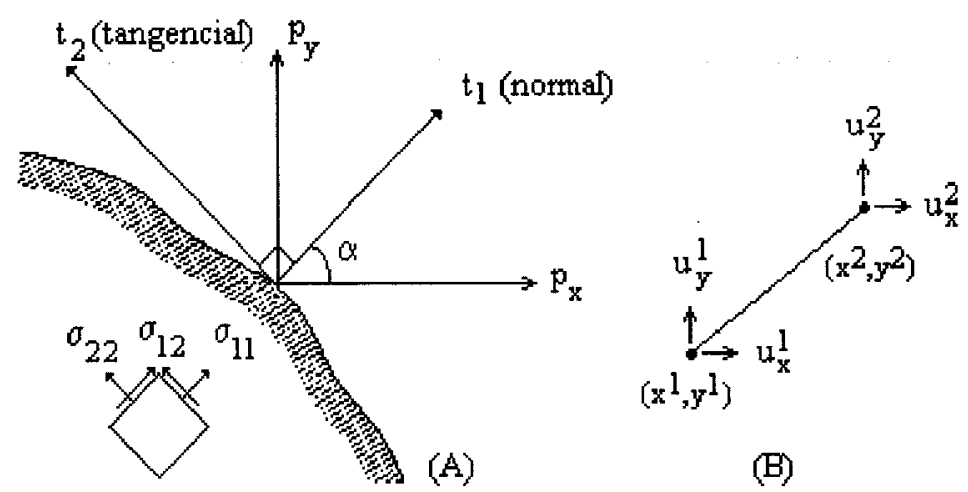

(B)

FIGURA 7.5 - Definições geométricas para o cálculo das tensões no contorno. (a) Componentes locais e cartesianas do vetor de forças de superfície. (b) Deslocamentos e coordenadas nodais de um elemento. BECKER (1992) (modificada).

Escrevendo-se as forças de superficie locais em função das globais, tem-se:

$$
\left\{\begin{array}{l}
t_{1} \\
t_{2}
\end{array}\right\}=\left[\begin{array}{cc}
\operatorname{Cos}(\alpha) & \operatorname{Sen}(\alpha) \\
-\operatorname{Sen}(\alpha) & \operatorname{Cos}(\alpha)
\end{array}\right]\left\{\begin{array}{l}
p_{x} \\
p_{y}
\end{array}\right\}
$$

Utilizando-se a Lei de Hooke (eq. (4.25)), é possível escrever as tensões nas direções locais em função das forças de superfície locais e da deformação tangencial:

$$
\begin{aligned}
& \left\{\begin{array}{l}
\sigma_{11} \\
\sigma_{12}
\end{array}\right\}=\left\{\begin{array}{l}
\mathrm{t}_{1} \\
\mathrm{t}_{2}
\end{array}\right\}=\left[\begin{array}{cc}
\operatorname{Cos}(\alpha) & \operatorname{Sen}(\alpha) \\
-\operatorname{Sen}(\alpha) & \operatorname{Cos}(\alpha)
\end{array}\right]\left\{\begin{array}{l}
\mathrm{p}_{\mathrm{x}} \\
\mathrm{p}_{\mathrm{y}}
\end{array}\right\} \\
& \left\{\sigma_{22}\right\}=\left(\frac{v}{1-v}\right) \sigma_{11}+\left(\frac{\mathrm{E}}{1-v^{2}}\right) \varepsilon_{22}
\end{aligned}
$$

As tensões nas direções globais podem ser encontradas, a partir das tensões nas direções locais, através de rotação (horária) de coordenadas:

$$
\left\{\begin{array}{l}
\sigma_{x} \\
\tau_{x y} \\
\sigma_{y}
\end{array}\right\}=\left[\begin{array}{ccc}
\operatorname{Cos}^{2}(\alpha) & -\operatorname{Sen}(2 \alpha) & \operatorname{Sen}^{2}(\alpha) \\
\operatorname{Sen}(2 \alpha) & \operatorname{Cos}(2 \alpha) & -\frac{\operatorname{Sen}(2 \alpha)}{2} \\
\operatorname{Sen}^{2}(\alpha) & \operatorname{Sen}(2 \alpha) & \operatorname{Cos}^{2}(\alpha)
\end{array}\right]\left\{\begin{array}{l}
\sigma_{11} \\
\tau_{12} \\
\sigma_{22}
\end{array}\right\}
$$




\subsection{Peculiaridades da Implementação do MEC}

\subsubsection{Tratamento das Integrais}

\section{Integração Externa}

Em geral, a quadratura de Gauss-Legendre (cf. [3.8.2]) é um método eficiente de realizar a integração necessária ao MEC quando o ponto de colocação não pertence ao elemento de integração. Este caso, onde $r$ nunca assume o valor nulo, é conhecido como integração externa (KANE (1994)). Portanto, é suficiente utilizar a fórmula de integração de Gauss-Legendre (eq. (3.36)) para calcular as integrais numericamente.

Por exemplo, a eq. (7.29) ficaria

$$
[\mathrm{HW}]^{\mathrm{pj}}=\int_{-1}^{1}\left[\mathrm{p}^{*}\right][\Phi]|\mathrm{J}| \mathrm{d} \xi=\left.\frac{\ell}{2} \sum_{\mathrm{i}=1}^{\mathrm{npg}}\left(\left[\mathrm{p}^{*}\right][\Phi]\right)\right|_{\xi_{\mathrm{i}}} \omega_{\mathrm{i}}
$$

\section{Integração Singular}

Quando o ponto de colocação pertencer ao elemento de integração, o integrando no cálculo das matrizes de influência apresentará uma singularidade devido à solução fundamental. Há várias maneiras de tratar este caso: quadraturas de ordem superior, mudança para coordenadas logarítmicas ou integração analítica são algumas das possibilidades.

Neste trabalho, o cálculo singular das matrizes de influência foi feito analiticamente e os coeficientes calculados são listados a seguir. Entenda-se, por cálculo singular, a obtenção do valor principal de Cauchy, o que foi possível pelo fato de as integrais não apresentarem singularidade especial (cf. [3.4]). 
Três casos foram considerados, dependendo da posição do ponto de colocação ao longo do elemento de integração (fig. (7.6)): no início (fig. (7.6a), em alguma posição intermediária (fig. (7.6b)) ou no final (fig. (7.6c)). Obviamente, tanto o primeiro quanto o terceiro caso podem ser considerados como particularizações do segundo. A consideração dos três individualmente foi utilizada como meio de verificação dos cálculos.

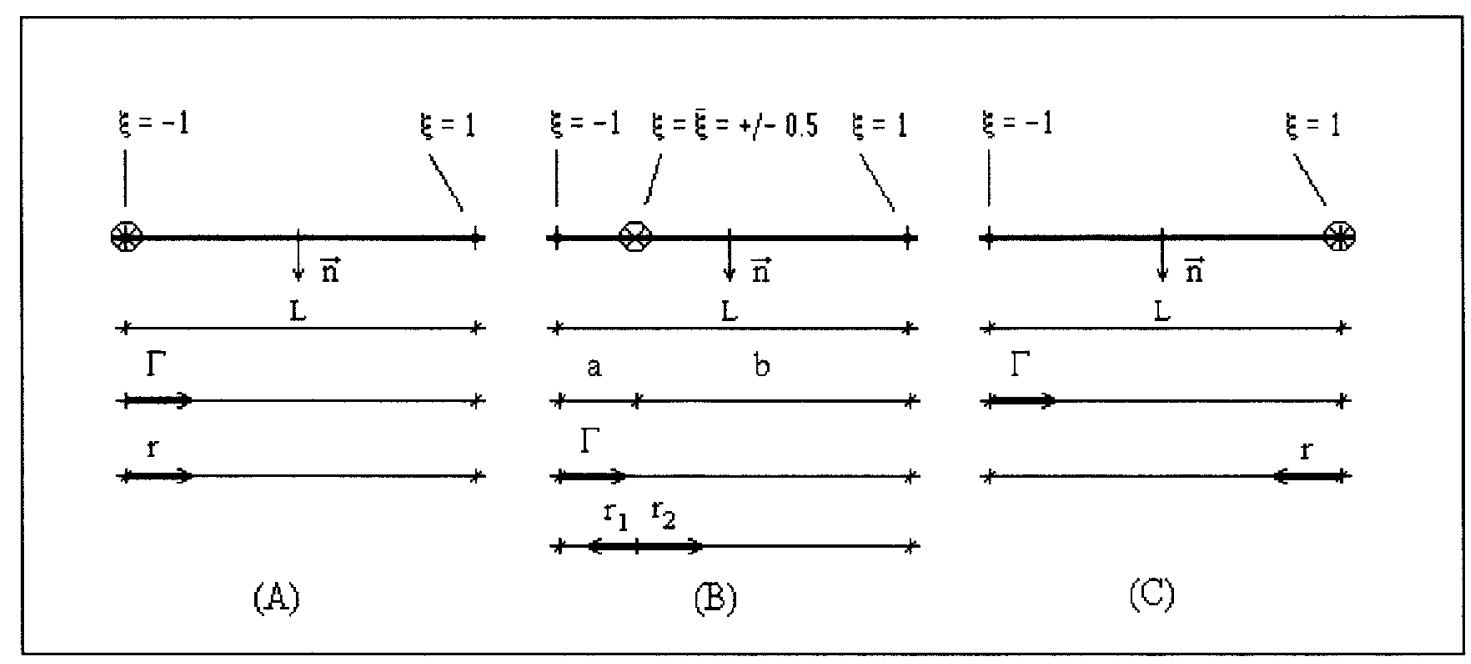

FIGURA 7.6 - Definições geométricas para o cálculo analítico das integrais singulares. (a) Ponto de colocação no início do elemento. (b) Ponto de Colocação em um ponto intermediário (c) Ponto de colocação no final do elemento.

Como se pôde observar, a parcela singular dos coeficientes da matriz [HW] se anula quando são considerados elementos adjacentes $\left(1^{\circ}\right.$ e $3^{\circ}$ casos $)$ ou os dois trechos de integração ( $2^{\circ}$ caso). Isto acontece porque a constante de proporcionalidade é a mesma em ambos. Este termo, portanto, não aparece nos coeficientes a seguir, embora tenha sido calculado.

$1^{\circ}$ Caso: Ponto de colocação coincidindo com o $1^{\circ}$ nó do elemento de integração

Matriz [GW]:

$$
\mathrm{GW}_{11}=\frac{\ell}{16 \pi \mathrm{G}(1-v)}\left((3-4 v)\left(\frac{3}{2}-\ln (\ell)\right)+\left(\frac{\mathrm{dr}}{\mathrm{dx}}\right)^{2}\right)
$$




$$
\begin{aligned}
& \mathrm{GW}_{12}=\frac{\ell}{16 \pi \mathrm{G}(1-v)}\left(\left(\frac{\mathrm{dr}}{\mathrm{dx}}\right)\left(\frac{\mathrm{dr}}{\mathrm{dy}}\right)\right) \\
& \mathrm{GW}_{21}=\frac{\ell}{16 \pi \mathrm{G}(1-v)}\left(\left(\frac{\mathrm{dr}}{\mathrm{dx}}\right)\left(\frac{\mathrm{dr}}{\mathrm{dy}}\right)\right)=\mathrm{GW}_{12} \\
& \mathrm{GW}_{22}=\frac{\ell}{16 \pi \mathrm{G}(1-v)}\left((3-4 v)\left(\frac{3}{2}-\ln (\ell)\right)+\left(\frac{\mathrm{dr}}{\mathrm{dy}}\right)^{2}\right) \\
& \mathrm{GW}_{13}=\frac{\ell}{16 \pi \mathrm{G}(1-v)}\left((3-4 v)\left(\frac{1}{2}-\ln (\ell)\right)+\left(\frac{\mathrm{dr}}{\mathrm{dx}}\right)^{2}\right) \\
& \mathrm{GW}_{14}=\frac{\ell}{16 \pi \mathrm{G}(1-v)}\left(\left(\frac{\mathrm{dr}}{\mathrm{dx}}\right)\left(\frac{\mathrm{dr}}{\mathrm{dy}}\right)\right) \\
& \mathrm{GW}_{23}=\frac{\ell}{16 \pi \mathrm{G}(1-v)}\left(\left(\frac{\mathrm{dr}}{\mathrm{dx}}\right)\left(\frac{\mathrm{dr}}{\mathrm{dy}}\right)\right)=\mathrm{GW}_{14} \\
& \mathrm{GW}_{22}=\frac{\ell}{16 \pi \mathrm{G}(1-v)}\left((3-4 v)\left(\frac{1}{2}-\ln (\ell)\right)+\left(\frac{\mathrm{dr}}{\mathrm{dy}}\right)^{2}\right)
\end{aligned}
$$

Matriz [HW]:

$$
\begin{aligned}
& \mathrm{HW}_{11}=0 \\
& \mathrm{HW}_{12}=\frac{(1-2 v)}{4 \pi(1-v)}(1-\ln (\ell)) \\
& \mathrm{HW}_{21}=-\frac{(1-2 v)}{4 \pi(1-v)}(1-\ln (\ell))=-\mathrm{HW}_{12} \\
& \mathrm{HW}_{22}=0 \\
& \mathrm{HW}_{13}=0 \\
& \mathrm{HW}_{14}=-\frac{(1-2 v)}{4 \pi(1-v)} \\
& \mathrm{HW}_{23}=\frac{(1-2 v)}{4 \pi(1-v)}=-\mathrm{HW}_{14} \\
& \mathrm{HW}_{24}=0
\end{aligned}
$$


$2^{\circ}$ Caso: Ponto de colocação interno ao elemento de integração

Matriz [GW]

$$
\begin{aligned}
& \mathrm{GW}_{11}=\frac{1}{8 \pi \ell \mathrm{G}(1-\mathrm{v})} \cdot \\
&\left\{-(3-4 v)\left[\ln (\mathrm{a})\left(\frac{\mathrm{a}^{2}}{2}+\mathrm{ab}\right)+\ln (\mathrm{b})\left(\frac{\mathrm{b}^{2}}{2}\right)-\left(\frac{\mathrm{a}^{2}}{4}+\mathrm{ab}+\frac{3}{4} \mathrm{~b}^{2}\right)\right]+\frac{\ell^{2}}{2}\left(\frac{\mathrm{dr}}{\mathrm{dx}}\right)^{2}\right\} \\
& \mathrm{GW}_{12}=\frac{\ell}{16 \pi \mathrm{G}(1-\mathrm{v})}\left(\left(\frac{\mathrm{dr}}{\mathrm{dx}}\right)\left(\frac{\mathrm{dr}}{\mathrm{dy}}\right)\right) \\
& \mathrm{GW}_{21}=\frac{\ell}{16 \pi \mathrm{G}(1-v)}\left(\left(\frac{\mathrm{dr}}{\mathrm{dx}}\right)\left(\frac{\mathrm{dr}}{\mathrm{dy}}\right)\right)=\mathrm{GW}_{12}
\end{aligned}
$$

$\mathrm{GW}_{22}=\frac{1}{8 \pi \ell \mathrm{G}(1-v)}$.

$\left\{-(3-4 v)\left[\ln (a)\left(\frac{a^{2}}{2}+a b\right)+\ln (b)\left(\frac{b^{2}}{2}\right)-\left(\frac{a^{2}}{4}+a b+\frac{3}{4} b^{2}\right)\right]+\frac{\ell^{2}}{2}\left(\frac{d r}{d y}\right)^{2}\right\}$

$\mathrm{GW}_{13}=\frac{1}{8 \pi \ell \mathrm{G}(1-v)}$.

$\left\{-(3-4 v)\left[\ln (a)\left(\frac{a^{2}}{2}\right)+\ln (b)\left(\frac{b^{2}}{2}+a b\right)-\left(\frac{3}{4} a^{2}+a b+\frac{b^{2}}{4}\right)\right]+\frac{\ell^{2}}{2}\left(\frac{d r}{d x}\right)^{2}\right\}$

$$
\mathrm{GW}_{14}=\frac{\ell}{16 \pi \mathrm{G}(1-v)}\left(\left(\frac{\mathrm{dr}}{\mathrm{dx}}\right)\left(\frac{\mathrm{dr}}{\mathrm{dy}}\right)\right)
$$$$
\mathrm{GW}_{23}=\frac{\ell}{16 \pi \mathrm{G}(1-v)}\left(\left(\frac{\mathrm{dr}}{\mathrm{dx}}\right)\left(\frac{\mathrm{dr}}{\mathrm{dy}}\right)\right)=\mathrm{GW}_{14}
$$

$\mathrm{GW}_{24}=\frac{1}{8 \pi \ell \mathrm{G}(1-v)}$.

$\left\{-(3-4 v)\left[\ln (a)\left(\frac{a^{2}}{2}\right)+\ln (b)\left(\frac{b^{2}}{2}+a b\right)-\left(\frac{3}{4} a^{2}+a b+\frac{b^{2}}{4}\right)\right]+\frac{\ell^{2}}{2}\left(\frac{d r}{d y}\right)^{2}\right\}$

Matriz [HW]

$$
\mathrm{HW}_{11}=0
$$




$$
\begin{aligned}
& \mathrm{HW}_{12}=\frac{(1-2 v)}{4 \pi \ell(1-v)}\left(\ell-\mathrm{b} \cdot \ln \left(\frac{\mathrm{b}}{\mathrm{a}}\right)\right) \\
& \mathrm{HW}_{21}=-\frac{(1-2 v)}{4 \pi \ell(1-v)}\left(\ell-\mathrm{b} \cdot \ln \left(\frac{\mathrm{b}}{\mathrm{a}}\right)\right)=-\mathrm{HW}_{12} \\
& \mathrm{HW}_{22}=0 \\
& \mathrm{HW}_{13}=0 \\
& \mathrm{HW}_{14}=-\frac{(1-2 v)}{4 \pi \ell(1-v)}\left(\ell+\mathrm{a} \cdot \ln \left(\frac{\mathrm{b}}{\mathrm{a}}\right)\right) \\
& \mathrm{HW}_{23}=\frac{(1-2 v)}{4 \pi \ell(1-v)}\left(\ell+\mathrm{a} \cdot \ln \left(\frac{\mathrm{b}}{\mathrm{a}}\right)\right)=-\mathrm{HW}_{14} \\
& \mathrm{HW}_{24}=0
\end{aligned}
$$

Os coeficientes do $2^{\circ}$ caso podem ser simplificados fazendo-se

$$
\mathrm{a}=(1+\bar{\xi}) \frac{\ell}{2} \quad \text { e } \quad \mathrm{b}=(1-\bar{\xi}) \frac{\ell}{2}
$$

e substituindo-se nas eqs. (7.49) e (7.50), o que fornece:

\section{Matriz [GW]:}

$$
\begin{gathered}
\mathrm{GW}_{11}=\frac{\ell}{64 \pi \mathrm{G}(1-v)} \cdot \\
\left\{4\left(\frac{\mathrm{dr}}{\mathrm{dx}}\right)^{2}-(3-4 v)\left[4 \ln \left(\frac{\ell}{2}\right)+2(\bar{\xi}-2)+\left(3+2 \bar{\xi}-\bar{\xi}^{2}\right) \ln (1+\bar{\xi})+(1-\bar{\xi})^{2} \ln (1-\bar{\xi})\right]\right\} \\
\mathrm{GW}_{12}=\frac{\ell}{64 \pi \mathrm{G}(1-v)}\left(4\left(\frac{\mathrm{dr}}{\mathrm{dx}}\right)\left(\frac{\mathrm{dr}}{\mathrm{dy}}\right)\right) \\
\mathrm{GW}_{21}=\frac{\ell}{64 \pi \mathrm{G}(1-v)}\left(4\left(\frac{\mathrm{dr}}{\mathrm{dx}}\right)\left(\frac{\mathrm{dr}}{\mathrm{dy}}\right)\right)=\mathrm{GW}_{12}
\end{gathered}
$$




$$
\begin{aligned}
& \mathrm{GW}_{22}=\frac{\ell}{64 \pi \mathrm{G}(1-v)} . \\
& \left\{4\left(\frac{\mathrm{dr}}{\mathrm{dy}}\right)^{2}-(3-4 v)\left[4 \ln \left(\frac{\ell}{2}\right)+2(\bar{\xi}-2)+\left(3+2 \bar{\xi}-\bar{\xi}^{2}\right) \ln (1+\bar{\xi})+(1-\bar{\xi})^{2} \ln (1-\bar{\xi})\right]\right\}
\end{aligned}
$$

$$
\begin{aligned}
& \mathrm{GW}_{13}=\frac{\ell}{64 \pi \mathrm{G}(1-v)} . \\
& \left\{4\left(\frac{\mathrm{dr}}{\mathrm{dx}}\right)^{2}-(3-4 v)\left[4 \ln \left(\frac{\ell}{2}\right)-2(\bar{\xi}+2)+\left(3-2 \bar{\xi}-\bar{\xi}^{2}\right) \ln (1-\bar{\xi})+(1+\bar{\xi})^{2} \ln (1+\bar{\xi})\right]\right\}
\end{aligned}
$$

$$
\begin{aligned}
& \mathrm{GW}_{14}=\frac{\ell}{64 \pi \mathrm{G}(1-v)}\left(4\left(\frac{\mathrm{dr}}{\mathrm{dx}}\right)\left(\frac{\mathrm{dr}}{\mathrm{dy}}\right)\right) \\
& \mathrm{GW}_{23}=\frac{\ell}{64 \pi \mathrm{G}(1-v)}\left(4\left(\frac{\mathrm{dr}}{\mathrm{dx}}\right)\left(\frac{\mathrm{dr}}{\mathrm{dy}}\right)\right)=\mathrm{GW}_{14}
\end{aligned}
$$

$$
\begin{aligned}
& \mathrm{GW}_{24}=\frac{\ell}{64 \pi \mathrm{G}(1-v)} . \\
& \left\{4\left(\frac{\mathrm{dr}}{\mathrm{dy}}\right)^{2}-(3-4 v)\left[4 \ln \left(\frac{\ell}{2}\right)-2(\bar{\xi}+2)+\left(3-2 \bar{\xi}-\bar{\xi}^{2}\right) \ln (1-\bar{\xi})+(1+\bar{\xi})^{2} \ln (1+\bar{\xi})\right]\right\}
\end{aligned}
$$

Matriz [HW]:

$$
\begin{aligned}
& \mathrm{HW}_{11}=0 \\
& \mathrm{HW}_{12}=\frac{(1-2 v)}{4 \pi(1-v)}\left(1-\frac{(1-\bar{\xi})}{2} \ln \left(\frac{1-\bar{\xi}}{1+\bar{\xi}}\right)\right) \\
& \mathrm{HW}_{21}=-\frac{(1-2 v)}{4 \pi(1-v)}\left(1-\frac{(1-\bar{\xi})}{2} \ln \left(\frac{1-\bar{\xi}}{1+\bar{\xi}}\right)\right)=-\mathrm{HW}_{12} \\
& \mathrm{HW}_{22}=0 \\
& \mathrm{HW}_{13}=0
\end{aligned}
$$




$$
\begin{aligned}
& \mathrm{HW}_{14}=-\frac{(1-2 v)}{4 \pi(1-v)}\left(1+\frac{(1+\bar{\xi})}{2} \ln \left(\frac{1-\bar{\xi}}{1+\bar{\xi}}\right)\right) \\
& \mathrm{HW}_{23}=\frac{(1-2 v)}{4 \pi(1-v)}\left(1+\frac{(1+\bar{\xi})}{2} \ln \left(\frac{1-\bar{\xi}}{1+\bar{\xi}}\right)\right)=-\mathrm{HW}_{14} \\
& \mathrm{HW}_{24}=0
\end{aligned}
$$

$\underline{3^{\circ} \text { Caso: Ponto de colocação coincidindo com o } 2^{\circ} \text { nó do elemento de integração }}$

Matriz [GW]:

$$
\begin{aligned}
& \mathrm{GW}_{11}=\frac{\ell}{16 \pi \mathrm{G}(1-v)}\left((3-4 v)\left(\frac{1}{2}-\ln (\ell)\right)+\left(\frac{\mathrm{dr}}{\mathrm{dx}}\right)^{2}\right) \\
& \mathrm{GW}_{12}=\frac{\ell}{16 \pi \mathrm{G}(1-v)}\left(\left(\frac{\mathrm{dr}}{\mathrm{dx}}\right)\left(\frac{\mathrm{dr}}{\mathrm{dy}}\right)\right) \\
& \mathrm{GW}_{21}=\frac{\ell}{16 \pi \mathrm{G}(1-v)}\left(\left(\frac{\mathrm{dr}}{\mathrm{dx}}\right)\left(\frac{\mathrm{dr}}{\mathrm{dy}}\right)\right)=\mathrm{GW}_{12} \\
& \mathrm{GW}_{22}=\frac{\ell}{16 \pi \mathrm{G}(1-v)}\left((3-4 v)\left(\frac{1}{2}-\ln (\ell)\right)+\left(\frac{\mathrm{dr}}{\mathrm{dy}}\right)^{2}\right) \\
& \mathrm{GW}_{13}=\frac{\ell}{16 \pi \mathrm{G}(1-v)}\left((3-4 v)\left(\frac{3}{2}-\ln (\ell)\right)+\left(\frac{\mathrm{dr}}{\mathrm{dx}}\right)^{2}\right) \\
& \mathrm{GW}_{14}=\frac{\ell}{16 \pi \mathrm{G}(1-v)}\left(\left(\frac{\mathrm{dr}}{\mathrm{dx}}\right)\left(\frac{\mathrm{dr}}{\mathrm{dy}}\right)\right) \\
& \mathrm{GW}_{23}=\frac{\ell}{16 \pi \mathrm{G}(1-\mathrm{v})}\left(\left(\frac{\mathrm{dr}}{\mathrm{dx}}\right)\left(\frac{\mathrm{dr}}{\mathrm{dy}}\right)\right)=\mathrm{GW} 14 \\
& \mathrm{GW}_{24}=\frac{\ell}{16 \pi \mathrm{G}(1-v)}\left((3-4 v)\left(\frac{3}{2}-\ln (\ell)\right)+\left(\frac{\mathrm{dr}}{\mathrm{dy}}\right)^{2}\right)
\end{aligned}
$$

Matriz [HW]:

$$
\mathrm{HW}_{11}=0
$$




$$
\begin{aligned}
& \mathrm{HW}_{12}=\frac{(1-2 v)}{4 \pi(1-v)} \\
& \mathrm{HW}_{21}=-\frac{(1-2 v)}{4 \pi(1-v)}=-\mathrm{HW}_{12} \\
& \mathrm{HW}_{22}=0 \\
& \mathrm{HW}_{13}=0 \\
& \mathrm{HW}_{14}=\frac{(1-2 v)}{4 \pi(1-v)}(\ln (\ell)-1) \\
& \mathrm{HW}_{23}=\frac{(1-2 v)}{4 \pi(1-v)}(1-\ln (\ell))=-\mathrm{HW}_{14} \\
& \mathrm{HW}_{24}=0
\end{aligned}
$$

\section{Integração Quase-singular}

Mesmo no caso de integração externa, a eficiência da quadratura empregada pode depender de outros fatores além do número de pontos de integração. A distância do ponto de colocação ao elemento de integração é um desses fatores.

Considere-se, por exemplo, a fig. (7.7a). Nesta figura, existem três grupos de pontos de colocação classificados de acordo com sua proximidade do elemento de integração. Os pontos a-c pertencem ao grupo de pontos de colocação que estão próximos ao elemento; os pontos $d$-h estão situados a distância moderada e os pontos i- 1 encontram-se longe do elemento. A fim de caracterizar o comportamento de integrandos associados com estes três grupos, a fig. (7.7b) contém os gráficos de $1 / \mathrm{r}$ como função da coordenada isoparamétrica em um ponto representativo de cada um dos três grupos. 


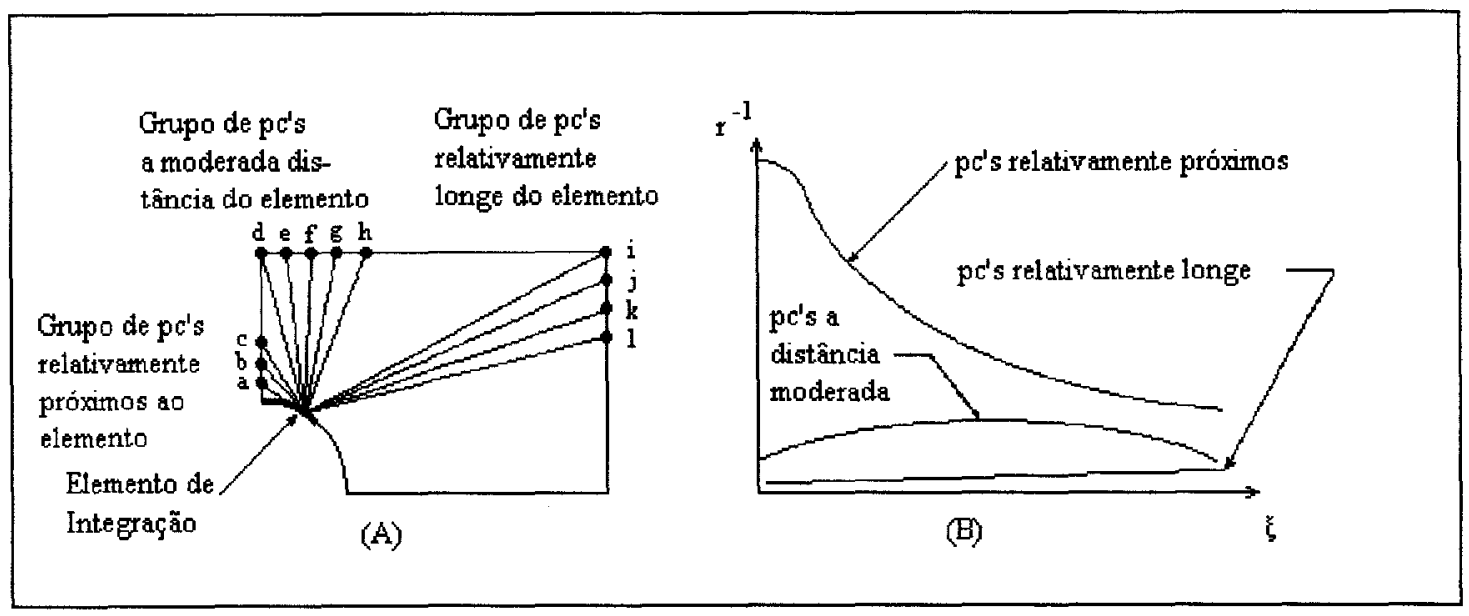

FIGURA 7.7 - Implementação efetiva da integração externa. (a) Grupos de pontos de colocação a pequena, média e longa distância do elemento de integração. (b) Comportamento geral dos integrandos para diferentes distâncias. KANE (1994).

É possível observar que o comportamento dos integrandos associados com os grupos de pontos de colocação próximo e distante é completamente diferente, sendo que o grupo situado a distância moderada apresenta um comportamento intermediário. Apesar de haver outros fatores na integração do MEC (como, por exemplo, as componentes do versor normal e as funções de interpolação), o comportamento de $1 / \mathrm{r}$ caracteriza o comportamento geral destes integrandos.

Parece razoável, então, supor que o número mínimo de pontos de integração para que se obtenha precisão numérica deve ser diferente nos três casos ou que devem ser utilizadas diferentes quadraturas, de acordo com o grupo de pontos em consideração. As duas opções representam um custo computacional elevado. Neste trabalho, utilizou-se a técnica de subdivisão de elementos (ou integração em subelementos) que consiste basicamente em dividir o elemento de integração em subelementos menores (de comprimento padronizado ou progressivo) e aplicar, em cada um destes, a mesma quadratura que seria utilizada em condições normais. Utilizou-se o critério de comparar a distância do ponto de colocação ao início ou ao final do elemento de integração com o comprimento do elemento onde o ponto de colocação estiver situado. Caso aquela seja menor que esta, utiliza-se a estratégia de divisão em sub-elementos, que é demonstrada a seguir. 
Seja o cálculo numérico da integral

$$
I=\int_{\Gamma_{j}} f(\Gamma) d \Gamma_{j}=\frac{\ell}{2} \int_{-1}^{1} f(\xi) d \xi
$$

onde $\ell / 2$ é o jacobiano (elemento linear). Fazendo-se a divisão em sub-elementos (fig. (7.8)) e normalizando-se a coordenada ao longo do sub-elemento:

$$
\left.\begin{array}{l}
\xi=c \eta+d \\
\xi(-1)=a_{i} \\
\xi(1)=b_{i}
\end{array}\right\} \Leftrightarrow\left\{\begin{array}{c}
\xi=\left(\frac{b_{i}-a_{i}}{2}\right) \eta+\left(\frac{b_{i}+a_{i}}{2}\right) . \\
\frac{d \xi}{d \eta}=\frac{b_{i}-a_{i}}{2}
\end{array}\right.
$$

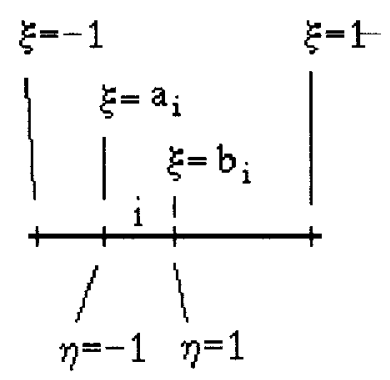

FIGURA 7.8 - Implementação da integração em sub-elementos

A eq. (7.56) torna-se

$$
I=\int_{\Gamma_{j}} f(\Gamma) \mathrm{d} \Gamma_{j}=\frac{\ell}{2} \int_{-1}^{1} f(\xi) \mathrm{d} \xi=\frac{\ell}{2} \sum_{i=1}^{\text {nsubel }} \int_{\mathbf{a}_{i}}^{\mathbf{b}_{\mathrm{i}}} \mathrm{f}(\xi) \mathrm{d} \xi,
$$

onde nsubel representa o número de sub-elementos. Mas 


$$
\int_{a_{i}}^{b_{i}} f(\xi) d \xi=\frac{b_{i}-a_{i}}{2} \int_{-1}^{1} f\left(\frac{b_{i}-a_{i}}{2} \eta+\frac{b_{i}+a_{i}}{2}\right) d \eta
$$

onde $\left(b_{i}-a_{i}\right) / 2$ representa o jacobiano do sub-elemento (no caso linear). No caso de serem utilizados sub-elementos de mesmo comprimento, tem-se:

$$
\begin{array}{ll}
\mathrm{a}_{\mathrm{i}}=-1+\frac{2}{\text { nsubel }}(\mathrm{i}-1) & \mathrm{b}_{\mathrm{i}}=\mathrm{a}_{\mathrm{i}}+\frac{2}{\text { nsubel }} \\
\frac{\mathrm{b}_{\mathrm{i}}-\mathrm{a}_{\mathrm{i}}}{2}=\frac{1}{\text { nsubel }} & \frac{\mathrm{b}_{\mathrm{i}}+\mathrm{a}_{\mathrm{i}}}{2}=\frac{(2 \mathrm{i}-1)}{\text { nsubel }}-1 .
\end{array}
$$

Portanto, a eq. (7.56) fica

$$
I=\frac{\ell}{2 \text { nsubel }} \sum_{i=1}^{\text {nsubel }} \sum_{k=1}^{\text {npg }} f\left(\xi_{k_{i}}\right) \omega_{k_{i}} \text {, }
$$

onde npg representa o número de pontos de Gauss,

$$
\xi_{k_{i}}=\frac{1}{\text { nsubel }} \eta_{k}+\frac{(2 i-1)}{\text { nsubel }}-1=\frac{1}{\text { nsubel }}\left(\eta_{k}+2 i-1-\text { nsubel }\right),
$$

e $\eta_{k}$ é a coordenada do k-ésimo ponto de Gauss e nsubel é o número de subelementos.

Uma condição necessária - mas não suficiente - ao perfeito funcionamento de um programa de elementos de contorno é a verificação, em cada linha da matriz $[\mathrm{H}]$, da condição de somatório nulo, tanto para as colunas ímpares quanto para as colunas pares. Este teste serve tanto para verificar a correção quanto a exatidão dos cálculos, esta última afetada pela propagação de erros. A utilização da técnica da divisão em sub-elementos, neste caso, possibilitou que o zero numérico fosse melhorado por um fator de $10^{10}$. 


\subsubsection{Tratamento de Vértices e Arestas}

Um vértice ou uma aresta podem ser definidos como os lugares geométricos onde o vetor normal muda bruscamente na passagem de um elemento de contorno para outro que lhe seja adjacente. Um vértice pode ter dois conjuntos de valores de força de superficie, um para cada lado do vértice. Quando isto acontecer, ou seja, quando um nó estiver situado em um ponto onde o contorno não seja suave (como é o caso de vértices em problemas bidimensionais ou vértices e arestas em problemas tridimensionais), uma descontinuidade de forças de superficie poderá ocorrer neste nó (fig. (7.9a)). Os problemas da prática de engenharia geralmente envolvem a modelagem de geometrias nestas condições.
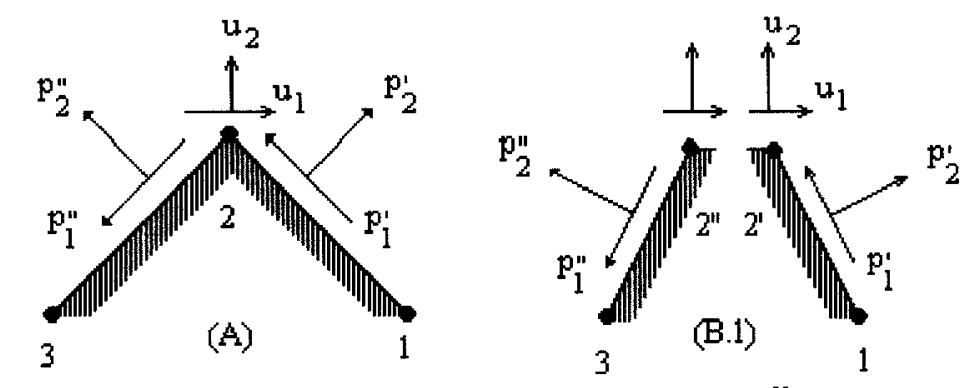

(B)

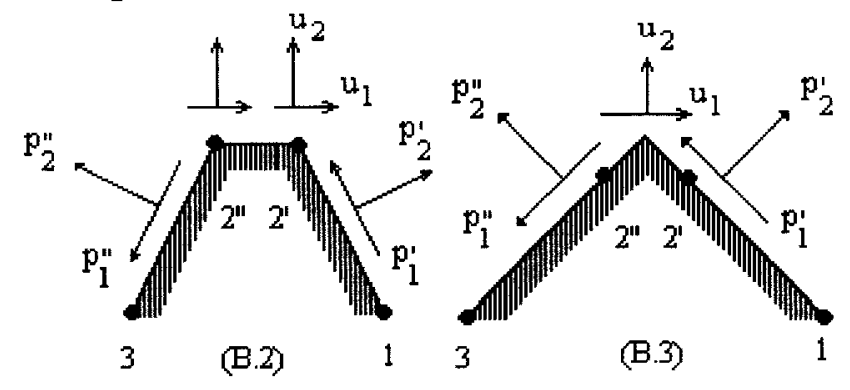

FIGURA 7.9 - Descontinuidades de força de superfície em vértices. (a) Nó continuo em vértice. (b) Modelagem de forças de superfície em vértices e de deslocamentos. BREBBIA \& DOMINGUEZ (1989)

Quando as forças de superficie são conhecidas em ambos os lados do vértice, ou quando (para qualquer das componentes) o deslocamento e uma das trações são conhecidos, não é necessário qualquer tratamento especial para o nó. O mesmo não se 
pode dizer quando dois valores diferentes de qualquer das componentes de força de superficie são desconhecidos e apenas o deslocamento é conhecido. Neste caso, é secessário um tratamento especial para o nó.

A maneira mais simples de fazê-lo é duplicar o nó de canto, definindo-se o que se chama de nó duplo (fig. 7.9b) e atribuir duas componentes de força de superficie a cada nó. Obviamente, a distância entre os nós não deve ser muito grande - a ponto de descaracterizar a geometria do problema - nem muito pequena - o que poderia provocar mal-condicionamento no sistema de equações. Quando um nó de vértice é duplicado, pode-se deixar um pequeno intervalo entre os dois nós (fig. (7.9b1)) ou pode-se assumir a existência de um pequeno elemento entre ambos (fig. (7.9b2)).

Uma outra maneira de utilizar os nós duplos é através de elementos descontínuos (fig. (7.9b3)). Esta abordagem consiste em deslocar os dois nós para o interior dos elementos. Além de simples, apresenta a vantagem de modelar melhor os vértices com concentrações de tensão elevadas. Pode-se conseguir o mesmo resultado mantendo-se os dois nós no vértice, mas deslocando-se os pontos de colocação para o interior dos elementos, o que é feito neste trabalho. 


\section{APLICAÇÃO DO MÉTODO DOS ELEMENTOS DE CONTORNO À MECÂNICA DO FRATURAMENTO}

\subsection{Introdução}

Neste capitulo, será apresentada a formulação do MEC para a análise de problemas de fraturamento mecânico de sólidos bidimensionais.

Como o modelo de fraturamento escolhido é o coesivo - onde deve ser considerada uma região de efeitos não-lineares (zona dissipativa) — optou-se por desenvolver a formulação a partir da representação integral que considera uma região onde tensões iniciais são aplicadas.

O modelo algébrico a ser obtido será similar aos desenvolvidos para análise elastoplástica de sólidos bi ou tridimensionais. Portanto, a equação integral (equação de Somigliana, cf. [7.3]) deve ser novamente obtida considerando-se um campo de tensões iniciais aplicadas ao domínio. Nesse caso, esse campo será considerado apenas em uma região estreita ao longo da fratura. 


\subsection{Formulação do MEC Para o Problema de Tensões Iniciais}

A formulação do MEC para problemas que envolvem a aplicação de campos de tensão ou deformação iniciais é bastante conhecida atualmente. Uma descrição mais detalhada do tema pode ser encontrada em BREBBIA et al. (1984).

Para essa formulação, são necessários os passos: formulação da representação dos deslocamentos, das tensões e suas transformações em equações algébricas decorrentes das discretizações do contorno e do domínio. Esse procedimento, como apresentado a seguir, será alterado convenientemente para a representação das descontinuidades do domínio.

Em linhas gerais, inicia-se admitindo a existência de tensões e deformações iniciais em uma região do domínio e encontra-se a influência dessa região nos campos de deslocamentos e tensões. Utilizando-se os procedimentos matemáticos análogos aos da formulação elástica, a integração é transferida para o contorno da região de tensões iniciais. No limite, quando a largura da região tende a zero, tem-se a influência correspondente ao amolecimento e à abertura do material ao longo da linha de fraturamento.

\subsubsection{Equação Integral de Contorno Para a Aplicação de Solicitações Iniciais em Pontos do Domínio}

Considerando-se as expressões das componentes de tensão e deformação fornecidas no capítulo 4 (eqs. (4.25) e (4.26)), é possível refazer os cálculos apresentados na seção [7.3.1], chegando-se a uma expresssão equivalente à equação de Somigliana, porém considerando-se o termo de domínio relativo a solicitações iniciais: 


$$
u_{\ell}^{p}=-\int_{\Gamma} p_{\ell \mathbf{k}}^{*} u_{k} d \Gamma+\int_{\Gamma} u_{\ell k}^{*} p_{k} d \Gamma+\int_{\Omega} u_{\ell \mathbf{k}}^{*} b_{\mathbf{k}} d \Omega+\int_{\Omega} \varepsilon_{\ell j \mathbf{k}}^{*} \sigma_{j \mathbf{k}}^{0} d \Omega
$$

onde

$$
\varepsilon_{\ell \mathrm{jk}}^{*}=-\frac{1}{8 \pi(1-v) \mathrm{Gr}}\left[(1-2 v)\left(\mathrm{r}_{, \mathrm{k}} \delta_{\ell \mathrm{j}}+\mathrm{r}_{, \mathrm{j}} \delta_{\ell \mathrm{k}}\right)-\mathrm{r}_{\ell} \delta_{\mathrm{jk}}+2 \mathrm{r}_{\ell} \mathrm{r}_{, \mathrm{j}} \mathrm{r}_{\mathrm{k}}\right]\left(\mathbf{8 . 2} \mathbf{2}^{*}\right)
$$

\subsubsection{Equação Integral de Contorno Considerando-se Tensões Iniciais Atuantes em Uma Faixa Estreita}

Seguindo-se um raciocínio análogo ao da seção [7.3.2], é possível deduzir uma expressão equivalente à eq. (8.1) para pontos de colocação no contorno. Isto posto, para um campo de tensões iniciais $\sigma^{\circ}(\mathrm{S})$ (fig. (8.1), tem-se (desconsiderando-se as forças de volume):

$$
c_{\ell k}^{p} u_{k}^{p}=-\int_{\Gamma} p_{\ell k}^{*} u_{\mathrm{k}} d \Gamma+\int_{\Gamma} u_{\ell k}^{*} p_{k} d \Gamma+\int_{\Omega} \varepsilon_{\ell j \mathrm{k}}^{*} \sigma_{j \mathrm{k}}^{0} \mathrm{~d} \Omega
$$

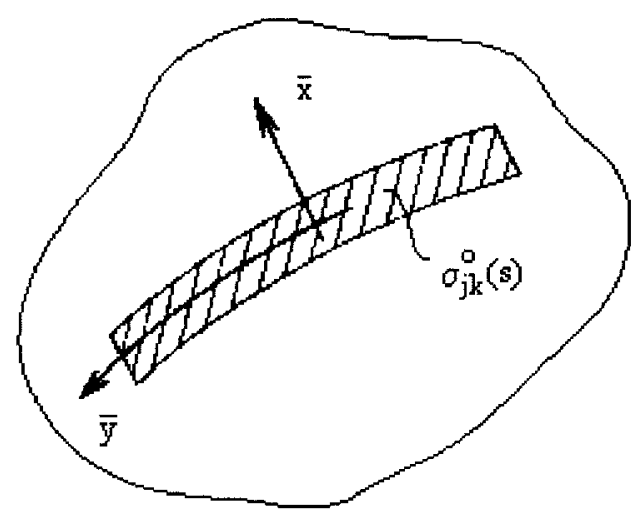

FIGURA 8.1 - Domínio apresentando região com tensões iniciais. VENTURINI (1993).

onde 


$$
\sigma_{\mathrm{jk}}^{0}(\mathrm{~S})=\sigma_{\mathrm{jk}}^{0}(\overline{\mathrm{x}}, \overline{\mathrm{y}})=\sigma_{\mathrm{jk}}^{0}(\overline{\mathrm{y}})
$$

é constante em $\bar{x}$

É possível, agora, examinar o último termo da eq. (8.3) (termo de domínio) e, por simplicidade, considerar que $\sigma_{\mathrm{jk}}^{0}$ não varia ao longo da espessura. Primeiramente, define-se um novo sistema de coordenadas (fig. (8.2)):

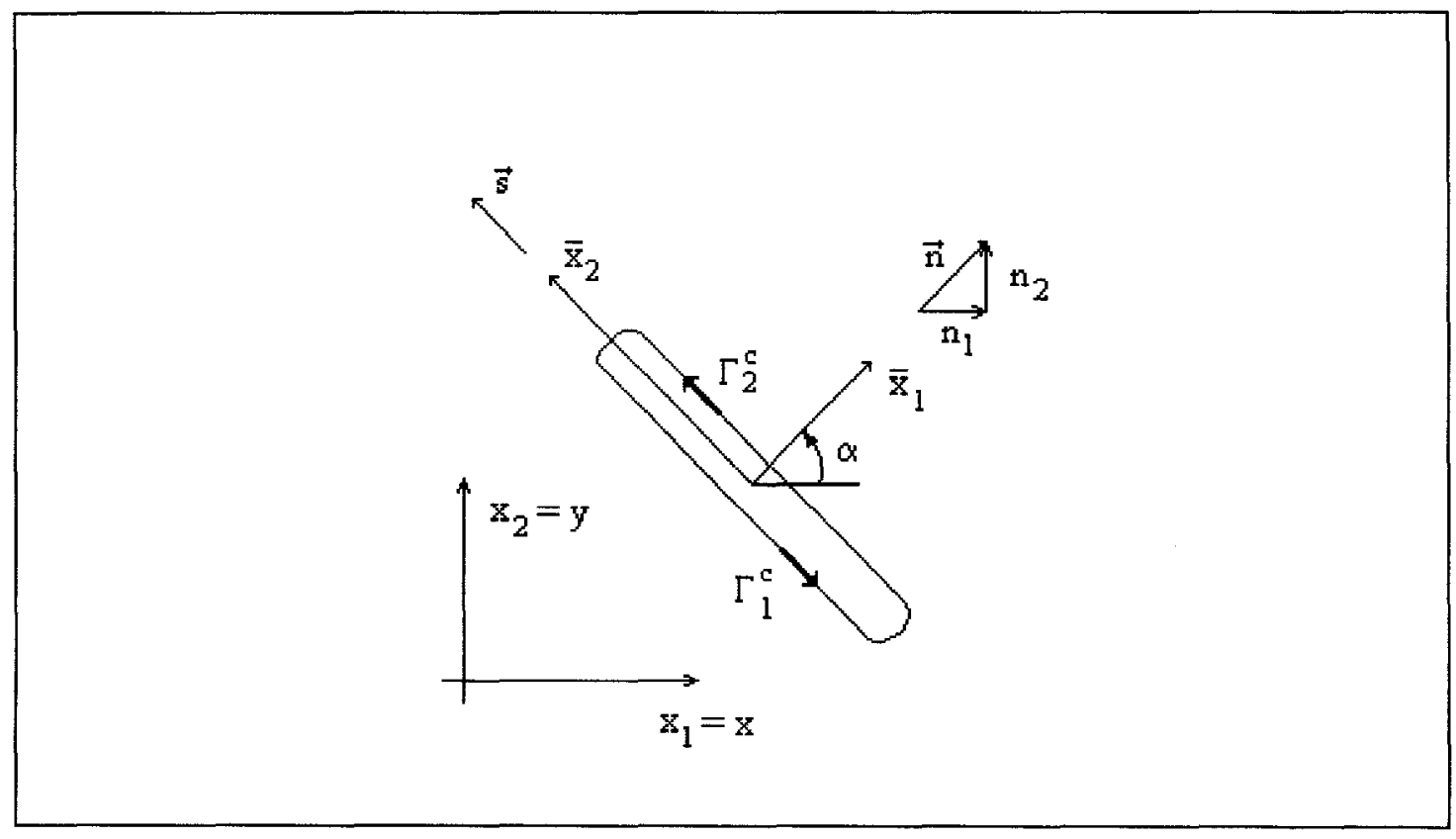

FIGURA 8.2 - Sistema de coordenadas. VENTURINI (1993),

Nesta figura, valem as relações:

$$
\begin{array}{ll}
\mathbf{n}_{1}=\operatorname{Cos}(\alpha) ; & \mathbf{s}_{1}=\operatorname{Cos}(\alpha+\pi / 2)=-\operatorname{Sen}(\pi)=-\mathbf{n}_{2} \\
\mathbf{n}_{2}=\operatorname{Sen}(\alpha) ; & \mathbf{s}_{2}=\operatorname{Sen}(\alpha+\pi / 2)=\operatorname{Cos}(\alpha)=\mathbf{n}_{1} .
\end{array}
$$

Considerando-se que, por analogia com a eq. (7.2):

$$
\varepsilon_{\ell \mathrm{jk}}^{*} \sigma_{\mathrm{jk}}^{0}=u_{\ell \mathrm{j}, \mathrm{k}}^{*} \sigma_{\mathrm{jk}}^{0}
$$

o último termo da eq. (8.3) fica: 


$$
\begin{aligned}
\int_{\Omega} \varepsilon_{\ell \mathbf{j} \mathbf{k}}^{*} \sigma_{j \mathbf{k}}^{0} \mathrm{~d} \Omega & =\int_{\Omega} \mathrm{u}_{\ell \mathrm{j}, \mathbf{k}}^{*} \sigma_{\mathrm{jk}}^{0} \mathrm{~d} \Omega=\int_{\Omega} \nabla \mathrm{u}_{\ell \mathbf{j}}^{*} \cdot \vec{\sigma}_{j}^{0} \mathrm{~d} \Omega=-\int_{\Omega} \mathrm{u}_{\ell \mathrm{j}}^{*} \sigma_{\mathrm{j} \mathbf{k}, \mathbf{k}}^{0} \mathrm{~d} \Omega+ \\
& +\int_{\Gamma_{\mathrm{C}}} \mathrm{u}_{\ell \mathbf{j}}^{*} \vec{\sigma}_{\mathrm{j}}^{0} \cdot \overrightarrow{\mathrm{n}} \mathrm{d} \Gamma_{\mathrm{C}}=-\int_{\Omega} \mathrm{u}_{\ell \mathrm{j}}^{*} \sigma_{\mathrm{j} \mathbf{k}, \mathbf{k}}^{0} \mathrm{~d} \Omega+\int_{\Gamma_{\mathrm{C}}} \mathrm{u}_{\ell \mathrm{j}}^{*} \sigma_{\mathrm{jk}}^{0} \mathrm{n}_{\mathbf{k}} \mathrm{d} \Gamma_{\mathrm{C}}=, \\
& =\int_{\Gamma_{\mathrm{C}}} \mathrm{u}_{\ell \mathrm{j}}^{*} \mathrm{p}_{\mathrm{j}}^{1} \mathrm{~d} \Gamma_{\mathrm{C}}-\int_{\Omega} \mathrm{u}_{\ell \mathrm{j}}^{*} \sigma_{\mathrm{j} \mathbf{k}, \mathbf{k}}^{0} \mathrm{~d} \Omega
\end{aligned}
$$

onde $\Gamma_{c}$ representa o contorno da região de tensão inicial (fig. (8.3)), $\mathrm{p}_{\mathrm{j}}^{1}$ representa a força de superficie atuante na superficie paralela à descontinuidade (com normal $\vec{n}$ ) e $\vec{\sigma}_{j}^{0}=\left\langle\sigma_{j 1}^{0}, \sigma_{\mathrm{j} 2}^{0}, \sigma_{\mathrm{j} 3}^{0}\right\rangle$.

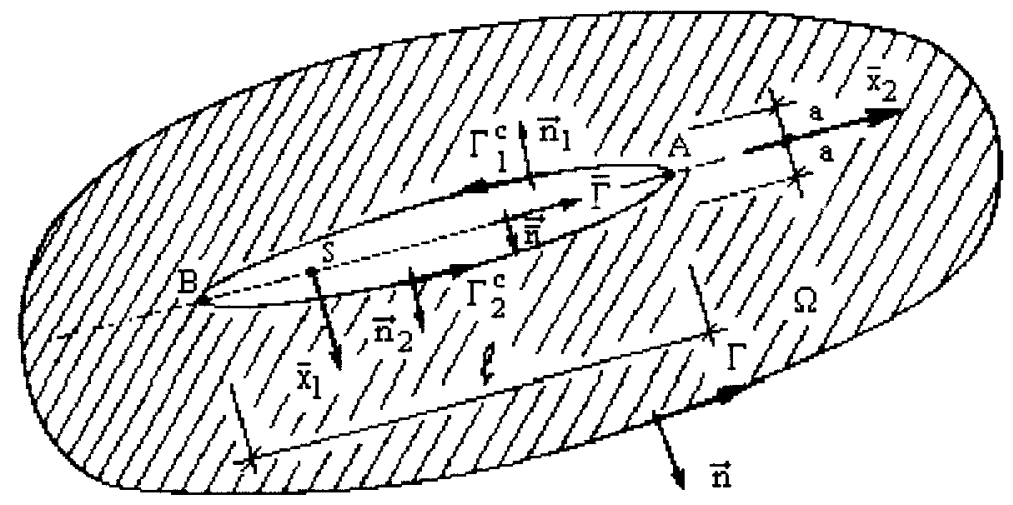

FIGURA 8.3 - Definições geométricas para a região de tensão inicial. VENTURINI (1993).

Portanto, a eq. (8.3) torna-se:

$$
c_{\ell k}^{p} u_{k}^{p}=-\int_{\Gamma} p_{\ell k}^{*} u_{k} d \Gamma+\int_{\Gamma} u_{\ell k}^{*} p_{k} d \Gamma+\int_{\Gamma_{\mathrm{c}}} u_{\ell j}^{*} p_{j}^{1} d \Gamma_{c}-\int_{\Omega} u_{\ell \mathbf{j}}^{*} \sigma_{j \mathbf{k}, \mathbf{k}}^{0} d \Omega
$$

Deve ser enfatizado que $\Gamma_{C}$ é composto pelos trechos $\Gamma_{\mathrm{c}}^{1}$ e $\Gamma_{\mathrm{c}}^{2}$, cujas coordenadas, no eixo $\bar{x}_{1}$, podem ser indicadas, respectivamente, por (S-a) e $(S+a)$. Desta forma, desenvolvendo-se o penúltimo termo da eq. (8.8): 


$$
\int_{\Gamma_{\mathrm{c}}} u_{f j}^{*} p_{j}^{1} d \Gamma_{c}=\int_{\Gamma_{c}^{1}} u_{f j}^{*}(p, S-a) p_{j}^{1}(S-a) d \Gamma_{c}^{1}+\int_{\Gamma_{c}^{2}} u_{f j}^{*}(p, S+a) p_{j}^{1}(S+a) d \Gamma_{c}^{2}
$$

Admitindo-se que o domínio seja infinito, e sendo os contornos $\Gamma_{\mathrm{o}}^{1}$ e $\Gamma_{\mathrm{o}}^{2}$ muito próximos, os efeitos de cargas unitárias aplicadas em lados opostos ficam dados por:

$$
\begin{aligned}
& \mathrm{u}_{\ell \mathrm{j}}^{*}(\mathrm{p}, \mathrm{S}+\mathrm{a})=\mathrm{u}_{\ell \mathrm{j}}^{*}(\mathrm{p}, \mathrm{S})+\frac{\partial \mathrm{u}_{\ell \mathrm{j}}^{*}(\mathrm{p}, \mathrm{S})}{\partial \overline{\mathrm{x}}_{1}} \mathrm{a} \\
& \mathrm{u}_{\ell \mathrm{j}}^{*}(\mathrm{p}, \mathrm{S}-\mathrm{a})=\mathrm{u}_{\ell \mathrm{j}}^{*}(\mathrm{p}, \mathrm{S})-\frac{\partial \mathrm{u}_{\ell_{\mathrm{j}}}^{*}(\mathrm{p}, \mathrm{S})}{\partial \overline{\mathrm{x}}_{1}} \mathrm{a}^{\prime}
\end{aligned}
$$

onde, para a linha de descontinuidade, foram consideradas as orientações definidas pela fig. (8.4):

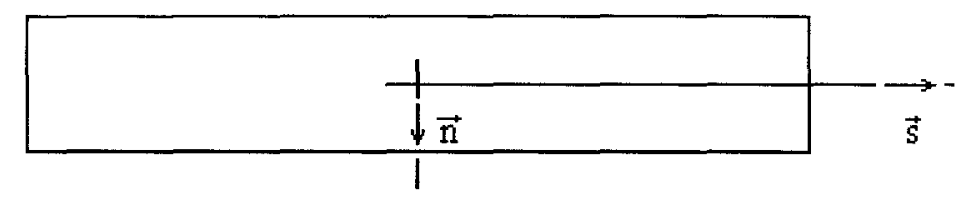

(A)

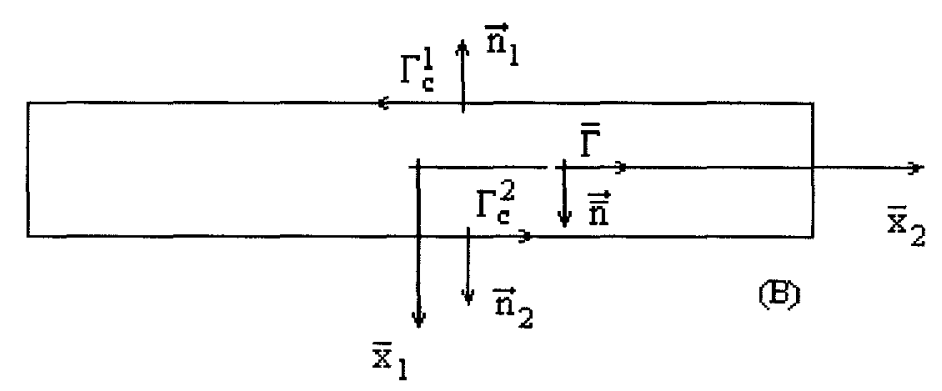

FIGURA 8.4 - Definições geométricas para a linha de descontinuidade. VENTURINI (1993).

Substituindo-se as eqs. (8.10) na eq. (8.9): 


$$
\begin{aligned}
& \int_{\Gamma_{\mathrm{c}}} \mathrm{u}_{\ell \mathrm{j}}^{*} \mathrm{p}_{\mathrm{j}}^{1} \mathrm{~d} \Gamma_{\mathrm{c}}=\int_{\Gamma_{\mathrm{c}}^{1}=\mathrm{A}}^{\Gamma_{\mathrm{c}}^{1}=\mathrm{B}}\left(\mathrm{u}_{\ell \mathrm{j}}^{*}(\mathrm{p}, \mathrm{S})-\frac{\partial \mathrm{u}_{\ell \mathrm{j}}^{*}(\mathrm{p}, \mathrm{S})}{\partial \overline{\mathrm{x}}_{1}} \mathrm{a}\right)\left(-\mathrm{p}_{\mathrm{j}}^{1}(\mathrm{p}, \mathrm{S})\right) \mathrm{d} \Gamma_{\mathrm{c}}^{1}+ \\
& +\int_{\Gamma_{\mathrm{c}}^{2}=\mathrm{B}}^{\Gamma_{\mathrm{c}}^{2}=\mathrm{A}}\left(\mathrm{u}_{\ell \mathrm{j}}^{*}(\mathrm{p}, \mathrm{S})+\frac{\partial \mathrm{u}_{\ell \mathrm{j}}^{*}(\mathrm{p}, \mathrm{S})}{\partial \overline{\mathrm{x}}_{1}} \mathrm{a}\right) \mathrm{p}_{\mathrm{j}}^{1}(\mathrm{p}, \mathrm{S}) \mathrm{d} \Gamma_{\mathrm{c}}^{2}= \\
& =\int_{\bar{\Gamma}=\mathrm{A}}^{\bar{\Gamma}=\mathrm{B}}\left(\mathbf{u}_{\ell \mathrm{j}}^{*}(\mathrm{p}, \mathrm{S})-\frac{\partial \mathrm{u}_{\ell \mathrm{j}}^{*}(\mathrm{p}, \mathrm{S})}{\partial \overline{\mathrm{x}}_{1}} \mathrm{a}\right)\left(-\mathrm{p}_{\mathrm{j}}^{1}(\mathrm{p}, \mathrm{S})\right)(-\mathrm{d} \bar{\Gamma})+ \\
& +\int_{\bar{\Gamma}=\mathrm{B}}^{\bar{\Gamma}=\mathrm{A}}\left(\mathrm{u}_{\ell \mathrm{j}}^{*}(\mathrm{p}, \mathrm{S})+\frac{\partial \mathrm{u}_{\ell \mathrm{j}}^{*}(\mathrm{p}, \mathrm{S})}{\partial \overline{\mathrm{x}}_{1}} \mathrm{a}\right) \mathrm{p}_{\mathrm{j}}^{\mathrm{i}}(\mathrm{p}, \mathrm{S})(\mathrm{d} \bar{\Gamma})= \\
& =\int_{\bar{\Gamma}=\mathrm{B}}^{\bar{\Gamma}=\mathrm{A}}\left(-\mathrm{u}_{\ell \mathrm{j}}^{*}(\mathrm{p}, \mathrm{S})+\frac{\partial \mathrm{u}_{\ell \mathrm{j}}^{*}(\mathrm{p}, \mathrm{S})}{\partial \overline{\mathrm{x}}_{1}} \mathrm{a}\right)\left(\mathrm{p}_{\mathrm{j}}^{1}(\mathrm{p}, \mathrm{S})\right)(\mathrm{d} \bar{\Gamma})+ \\
& +\int_{\bar{\Gamma}=\mathbf{B}}^{\bar{\Gamma}=\mathrm{A}}\left(\mathrm{u}_{\ell \mathrm{j}}^{*}(\mathrm{p}, \mathrm{S})+\frac{\partial \mathrm{u}_{\ell \mathrm{j}}^{*}(\mathrm{p}, \mathrm{S})}{\partial \mathrm{x}_{1}} \mathrm{a}\right) \mathrm{p}_{\mathrm{j}}^{\mathrm{l}}(\mathrm{p}, \mathrm{S})(\mathrm{d} \bar{\Gamma})
\end{aligned}
$$

de onde:

$$
\int_{\Gamma_{\mathrm{c}}} \mathrm{u}_{\ell \mathrm{j}}^{*} \mathrm{p}_{\mathrm{j}}^{1} \mathrm{~d} \Gamma_{\mathrm{c}}=\int_{\Gamma} \frac{\partial \mathrm{u}_{\ell \mathrm{j}}^{*}}{\partial \overline{\mathrm{x}}_{1}} 2 \mathrm{ap}_{\mathrm{j}}^{1} \mathrm{~d} \bar{\Gamma} .
$$

A grandeza $2 a p_{j}^{1}$, da eq. (8.12), representa um dipolo de forças. A característica dessa grandeza é que não apresenta resultante de forças, porém introduz um campo de tensões no meio contínuo. Para analisar o último termo da eq. (8.8), utilizar-se-á a fig. (8.2), onde valem as seguintes transformações de coordenadas:

$$
\begin{aligned}
& \left\{\begin{array}{l}
x \\
y
\end{array}\right\}=\left[\begin{array}{cc}
\operatorname{Cos}(\alpha) & -\operatorname{Sen}(\alpha) \\
\operatorname{Sen}(\alpha) & \operatorname{Cos}(\alpha)
\end{array}\right]\left\{\begin{array}{l}
\bar{x}_{1} \\
\bar{x}_{2}
\end{array}\right\} \\
& \left\{\begin{array}{l}
\bar{x}_{1} \\
\bar{x}_{2}
\end{array}\right\}=\left[\begin{array}{cc}
\operatorname{Cos}(\alpha) & \operatorname{Sen}(\alpha) \\
-\operatorname{Sen}(\alpha) & \operatorname{Cos}(\alpha)
\end{array}\right]\left\{\begin{array}{l}
x \\
y
\end{array}\right\}
\end{aligned}
$$




$$
\begin{aligned}
& \sigma_{\mathrm{jk}, \mathrm{k}}^{0}=\frac{\partial \sigma_{\mathrm{jk}}^{0}}{\partial \mathrm{x}_{\mathrm{k}}}=\frac{\partial \sigma_{\mathrm{j} 1}^{0}}{\partial \mathrm{x}_{1}}+\frac{\partial \sigma_{\mathrm{j} 2}^{0}}{\partial \mathrm{x}_{2}}= \\
& =\frac{\partial \sigma_{\mathrm{j} 1}^{0}}{\underbrace{\partial \overline{\mathrm{x}}_{1}}_{\rightarrow 0}} \frac{\partial \overline{\mathrm{x}}_{1}}{\partial \mathrm{x}_{1}}+\frac{\partial \sigma_{\mathrm{j} 1}^{0}}{\partial \overline{\mathrm{x}}_{2}} \frac{\partial \overline{\mathrm{x}}_{2}}{\partial \mathrm{x}_{1}}+\underbrace{\frac{\partial \sigma_{\mathrm{j} 2}^{0}}{\partial \overline{\mathrm{x}}_{1}}}_{\rightarrow 0} \frac{\partial \overline{\mathrm{x}}_{1}}{\partial \mathrm{x}_{2}}+\frac{\partial \sigma_{\mathrm{j} 2}^{0}}{\partial \overline{\mathrm{x}}_{2}} \frac{\partial \overline{\mathrm{x}}_{2}}{\partial \mathrm{x}_{2}}=, \\
& =\frac{\partial \sigma_{\mathrm{j} 1}^{0}}{\partial \overline{\mathrm{x}}_{2}} \mathrm{~s}_{1}+\frac{\partial \sigma_{\mathrm{j} 2}^{0}}{\partial \overline{\mathrm{x}}_{2}} \mathrm{~s}_{2}=\frac{\partial}{\partial \overline{\mathrm{x}}_{2}}\left(\sigma_{\mathrm{jk}}^{0} \mathrm{~s}_{\mathrm{k}}\right)
\end{aligned}
$$

e onde se considerou que todas as derivadas na direção $\bar{x}_{1}$ são nulas $\left(\sigma_{\mathrm{jk}}^{0}\right.$ é constante neste caso) e não se utilizou notação indicial por clareza.

Portanto, o último termo da eq. (8.8) torna-se, se não for considerada a variação em $\overline{\mathrm{x}}_{1}$ :

$$
-\int_{\Omega} \mathrm{u}_{\ell \mathrm{j}}^{*} \sigma_{\mathrm{jk}, \mathrm{k}}^{0} \mathrm{~d} \Omega=-\int_{\Omega} \mathrm{u}_{\ell \mathrm{j}}^{*} \frac{\partial\left(\sigma_{\mathrm{jk}}^{0} \mathrm{~s}_{\mathrm{k}}\right)}{\partial \mathrm{x}_{2}} \mathrm{d \overline {x } _ { 1 }} d \overline{\mathrm{x}}_{2}=-\int_{\overline{\mathrm{x}}_{2}} \mathrm{u}_{\ell \mathrm{j}}^{*} \frac{\partial\left(\sigma_{\mathrm{jk}}^{0} \mathrm{~s}_{\mathrm{k}}\right)}{\partial \overline{\mathrm{x}}_{2}} 2 \mathrm{ad} \overline{\mathrm{x}}_{2}
$$

Integrando-se por partes:

$$
-\int_{\Omega} \mathrm{u}_{\ell \mathrm{j}}^{*} \sigma_{\mathrm{jk}, \mathbf{k}}^{0} \mathrm{~d} \Omega=-\left[\sigma_{\mathrm{jk}}^{0} \mathrm{~s}_{\mathbf{k}} \mathrm{u}_{\ell \mathrm{j}}^{*} 2 \mathrm{a}\right]_{\overline{\mathrm{x}}_{2}^{1}}^{\overline{\mathrm{x}}_{2}^{2}}+\int_{\overline{\mathrm{x}}_{2}} \frac{\partial \mathrm{u}_{\ell \mathrm{j}}^{*}}{\partial \overline{\mathrm{x}}_{2}} \sigma_{\mathrm{jk}}^{0} \mathrm{~s}_{\mathbf{k}} 2 \mathrm{ad} \overline{\mathrm{x}}_{2} .
$$

$\mathrm{O}$ termo independente anula-se (no limite, quando $\mathrm{a} \rightarrow 0$ e a região tende a uma linha, $\bar{\Gamma}$ ). Lembrando-se que

$$
\sigma_{j \mathbf{k}}^{0} s_{k}=p_{j}^{2}
$$

representa a força de superfície atuante na superficie perpendicular à descontinuidade (com normal $\overrightarrow{\mathrm{s}}$ ), o último termo da eq. (8.8) torna-se: 


$$
-\int_{\Omega} \mathrm{u}_{\ell \mathrm{j}}^{*} \sigma_{\mathrm{j} \mathbf{k}, \mathbf{k}}^{0} \mathrm{~d} \Omega=\int_{\overline{\mathrm{x}}_{2}} \frac{\partial \mathrm{u}_{\ell \mathrm{j}}^{*}}{\partial \overline{\mathrm{x}}_{2}} 2 \mathrm{ap}_{\mathrm{j}}^{2} \mathrm{~d} \overline{\mathrm{x}}_{2}=\int_{\bar{\Gamma}} \frac{\partial \mathrm{u}_{\ell_{\mathrm{j}}}^{*}}{\partial \overline{\mathrm{x}}_{2}} 2 \mathrm{ap}_{\mathrm{j}}^{2} \mathrm{~d} \bar{\Gamma}
$$

A grandeza $2 \mathrm{ap}_{\mathrm{j}}^{2}$, da eq. (8.18), também representa um dipolo de forças e as eqs. (8.12) e (8.18) definem os dois dipolos utilizados na formulação. No limite, quando $\mathrm{a} \rightarrow 0$, as grandezas dipolo ainda podem ser definidas considerando-se os valores dos dipolos finitos e equivalentes a um campo de tensões (forças de superfície) infinitas. Nesse caso:

$$
2 a p_{j}^{1}=q_{j}^{1} \quad \text { e } \quad 2 a p_{j}^{2}=q_{j}^{2} .
$$

Estes dipolos estão representados nas figs. (8.5a) e (8.5b), respectivamente.

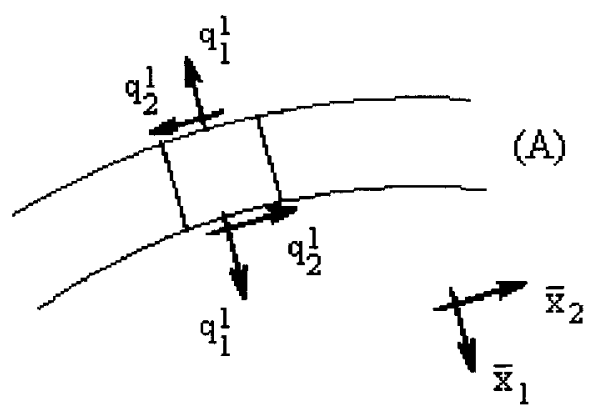

(B)

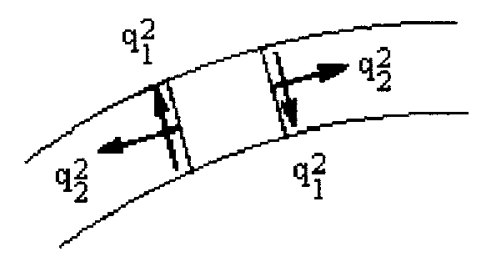

FIGURA 8.5 - Representação dos dipolos constituintes do quadripolo. (a) $q_{j}^{1}$. (b) $q_{j}^{2}$. VENTURINI (1993).

A aplicação de um dipolo equivale à introdução (no ponto de aplicação) de uma descontinuidade de deslocamentos, conforme será mostrado em [8.3]. Contudo, 
por considerações de equilíbrio, os dipolos devem ser aplicados em conjunto, formando um quadripolo, e satisfazendo (ROCHA (1988)):

$$
\mathrm{q}_{2}^{2}=\frac{v}{(1-v)} \mathrm{q}_{1}^{1}
$$

Fazendo-se $\alpha=0$ (fratura vertical ascendente $\Rightarrow \bar{x}_{1}=x_{1}$ e $\bar{x}_{2}=x_{2}$ ), a eq (8.8) torna-se

$$
\mathrm{c}_{\ell \mathrm{k}}^{\mathrm{p}} \mathrm{u}_{\mathrm{k}}^{\mathrm{p}}=-\int_{\Gamma} \mathrm{p}_{\ell \mathrm{k}}^{*} \mathrm{u}_{\mathrm{k}} \mathrm{d} \Gamma+\int_{\Gamma} \mathrm{u}_{\ell \mathrm{k}}^{*} \mathrm{p}_{\mathrm{k}} \mathrm{d} \Gamma+\int_{\Gamma} \frac{\partial \mathrm{u}_{\ell \mathrm{j}}^{*}}{\partial \mathrm{x}_{1}} \mathrm{q}_{\mathrm{j}}^{1} \mathrm{~d} \bar{\Gamma}+\int_{\Gamma} \frac{\partial \mathrm{u}_{\ell \mathrm{j}}^{*}}{\partial \mathrm{x}_{2}} \mathrm{q}_{\mathrm{j}}^{2} \mathrm{~d} \bar{\Gamma}
$$

e pode ser simplificada para

$$
\mathrm{c}_{\ell \mathrm{k}}^{\mathrm{p}} \mathrm{u}_{\mathbf{k}}^{\mathrm{p}}=-\int_{\Gamma} \mathrm{p}_{\ell \mathrm{k}}^{*} \mathrm{u}_{\mathrm{k}} \mathrm{d} \Gamma+\int_{\Gamma} \mathrm{u}_{\ell \mathbf{k}}^{*} \mathrm{p}_{\mathrm{k}} \mathrm{d} \Gamma+\int_{\Gamma} \mathrm{G}_{\ell \mathrm{j}}^{\mathrm{k}} \mathrm{q}_{\mathrm{j}}^{\mathrm{k}} \mathrm{d} \bar{\Gamma}
$$

onde

$$
\begin{aligned}
& \mathrm{G}_{\ell \mathrm{j}}^{\mathbf{k}}=\mathrm{u}_{\ell \mathrm{j}, \mathrm{k}}^{*}=\frac{\partial \mathrm{u}_{\ell \mathrm{j}}^{*}}{\partial \mathrm{x}_{\mathrm{k}}}=\frac{\partial}{\partial \mathrm{x}_{\mathrm{k}}}\left\{\frac{1}{8 \pi \mathrm{G}(1-v)}\left[\mathrm{r}_{, \ell} \mathrm{r}_{, \mathrm{j}}-(3-4 \mathrm{v}) \ln (\mathrm{r}) \delta_{\ell \mathrm{j}}\right]\right\}= \\
& =-\frac{1}{8 \pi \mathrm{G}(1-v)}\left\{\frac{(3-4 v)}{\mathrm{r}} \mathrm{r}_{, \mathbf{k}} \delta_{\ell \mathrm{j}}-\mathrm{r}_{, \ell \mathrm{k}} \mathrm{r}_{, \mathrm{j}}-\mathrm{r}_{\mathrm{j} \mathbf{k}, \ell} \mathrm{r}_{, \ell}\right\}= \\
& =-\frac{1}{8 \pi \mathrm{G}(1-v)}\left\{\frac{(3-4 v)}{\mathrm{r}} \mathrm{r}_{, \mathrm{k}} \delta_{\ell \mathrm{j}}-\frac{1}{\mathrm{r}}\left[\delta_{\ell \mathrm{k}}-\mathrm{r}_{, \ell} \mathrm{r}_{, \mathrm{k}}\right] \mathrm{r}_{, \mathrm{j}}-\frac{1}{\mathrm{r}}\left[\delta_{\mathrm{jk}}-\mathrm{r}_{, \mathrm{j}, \mathrm{k}} \mathrm{r}_{, \ell}\right\}=\right. \\
& =-\frac{1}{8 \pi \mathrm{G}(1-v) \mathrm{r}}\left\{(3-4 v) \mathrm{r}_{, \mathrm{k}} \delta_{\ell \mathrm{j}}-\mathrm{r}_{, \mathrm{j}} \delta_{\ell \mathbf{k}}-\mathrm{r}_{\ell} \delta_{\mathrm{jk}}+2 \mathrm{r}_{\ell} \mathrm{r}_{, \mathrm{j}} \mathrm{r}_{\mathrm{,k}}\right\}
\end{aligned}
$$

Fazendo-se uma analogia com o desenvolvimento da formulação elástica (cf. [7.3.1] e [7.3.2]), a eq. (8.22) pode ser reescrita utilizando-se notação matricial. Antes, porém, é necessário reorganizar seu último termo, levando-se em conta o equilíbrio rotacional $\left(\mathrm{q}_{2}^{1}=\mathrm{q}_{1}^{2}\right.$, cf. [4.2]): 


$$
\begin{aligned}
G_{\ell j}^{\mathrm{k}} \mathrm{q}_{\mathrm{j}}^{\mathrm{k}} & =\mathrm{G}_{\ell 1}^{1} \mathrm{q}_{1}^{1}+\mathrm{G}_{\ell 2}^{1} \mathrm{q}_{2}^{1}+\mathrm{G}_{\ell 1}^{2} \mathrm{q}_{1}^{2}+\mathrm{G}_{\ell 2}^{2} \mathrm{q}_{2}^{2}= \\
& =\mathrm{G}_{\ell 1}^{1} \mathrm{q}_{1}^{1}+\left(\mathrm{G}_{\ell 2}^{1}+\mathrm{G}_{\ell 1}^{2}\right) \mathrm{q}_{2}^{1}+\mathrm{G}_{\ell 2}^{2} \mathrm{q}_{2}^{2}= \\
& =\left[\begin{array}{lll}
\mathrm{G}_{\ell 1}^{1} & \left(\mathrm{G}_{\ell 2}^{1}+\mathrm{G}_{\ell 1}^{2}\right) & \mathrm{G}_{\ell 2}^{2}
\end{array}\right]\left\{\begin{array}{l}
\mathrm{q}_{1}^{1} \\
\mathrm{q}_{2}^{1} \\
\mathrm{q}_{2}^{2}
\end{array}\right\}=[\overline{\mathrm{K}}]\{\mathrm{q}\}
\end{aligned}
$$

e a eq. (8.22) torna-se

$$
[\mathrm{c}]\{\mathrm{u}\}^{\mathrm{p}}=-\int_{\Gamma}\left[\mathrm{p}^{*}\right]\{\mathrm{u}\} \mathrm{d} \Gamma+\int_{\Gamma}\left[\mathrm{u}^{*}\right]\{\mathrm{p}\} \mathrm{d} \Gamma+\int_{\bar{\Gamma}}[\overline{\mathrm{K}}]\{\mathrm{q}\} \mathrm{d} \bar{\Gamma}
$$

onde $\bar{\Gamma}$ representa as descontinuidades existentes.

\subsubsection{Formulação em Elementos de Contorno e Elementos de Fratura}

Para o cálculo da eq. (8.25), é necessário discretizar tanto o contorno (através dos elementos já descritos na seção [7.3.3]) quanto as descontinuidades existentes (através de elementos de fratura).

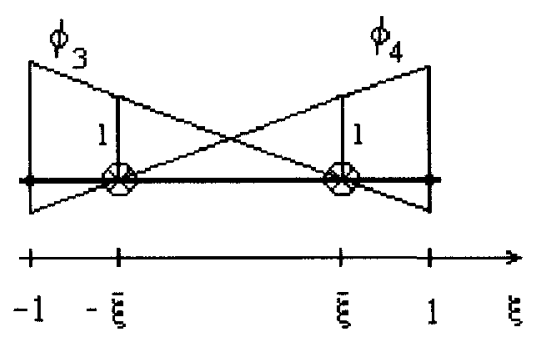

FIGURA 8.6 - Representação geométrica do elemento de fratura e caracterização das funções de interpolação para os quadripolos. 
Os elementos de fratura adotados (fig. (8.6)) são lineares isoparamétricos, a exemplo dos elementos de contorno, porém com duas diferenças significativas. Em primeiro lugar, são fictícios, ou seja, servem para simular, no domínio elástico e contínuo, a existência de fraturas que não são incorporadas ao contorno. A outra diferença é o fato de serem descontínuos (cf. [7.4.2]), ou seja, os nós foram deslocados das extremidades para o interior do elemento.

Semelhantemente ao que foi feito com deslocamentos e forças de superfície (eqs. (7.26)), os quadripolos também podem ser interpolados ao longo dos elementos de fratura. No entanto, em virtude de os elementos de fratura serem descontínuos, estas funções de interpolação, ainda que lineares, não terão as mesmas expressões que as mostradas nas eqs. (3.44), mas as seguintes:

$$
\phi_{3}=\frac{1}{2}\left(1-\frac{\xi}{\bar{\xi}}\right) . \quad \text { e } \quad \phi_{4}=\frac{1}{2}\left(1+\frac{\xi}{\bar{\xi}}\right)
$$

e a aproximação dos quadripolos pode ser feita da seguinte maneira:

$$
\left.\left.\{q\}=\left\{\begin{array}{l}
q_{1}^{1} \\
q_{2}^{1} \\
q_{2}^{2}
\end{array}\right\}=\left[\begin{array}{cccccc}
\phi_{3} & 0 & 0 & \phi_{4} & 0 & 0 \\
0 & \phi_{3} & 0 & 0 & \phi_{4} & 0 \\
0 & 0 & \phi_{3} & 0 & 0 & \phi_{4}
\end{array}\right]\left\{\begin{array}{l}
q_{1}^{1} \\
q_{2}^{1} \\
q_{2}^{2}
\end{array}\right\}^{1}\right\}\left\{\begin{array}{l}
q_{1}^{1} \\
q_{2}^{1} \\
q_{2}^{2}
\end{array}\right\}\right\}=[\Phi 2]\{q\}_{n}^{j}
$$

Para este caso particular, onde $\bar{\xi}=0.65$ :

$$
\phi_{3}=\frac{1}{26}(13-20 \xi) \quad \text { e } \quad \phi_{4}=\frac{1}{26}(13+20 \xi) .
$$

Analisando-se o último termo da eq. 8.25: 


$$
\int_{\bar{\Gamma}}[\overline{\mathrm{K}}]\{\mathrm{q}\} \mathrm{d} \bar{\Gamma}=\sum_{\mathrm{j}=1}^{\mathrm{nef}}\left(\int_{\bar{\Gamma}_{\mathrm{j}}}[\overline{\mathrm{K}}][\Phi 2] \mathrm{d} \bar{\Gamma}_{\mathrm{j}}\right)\{\mathrm{q}\}_{\mathrm{n}}^{\mathrm{j}}=\sum_{\mathrm{j}=1}^{\mathrm{nef}}[\mathrm{KW}]^{\mathrm{pj}}\{\mathrm{q}\}_{\mathrm{n}}^{\mathrm{j}}
$$

onde

$$
[\mathrm{KW}]^{\mathrm{pj}}=\int_{\bar{\Gamma}_{\mathrm{j}}}[\overline{\mathrm{K}}][\Phi 2] \mathrm{d} \bar{\Gamma}_{\mathrm{j}}
$$

e nef representa o número de elementos de fratura. Os coeficientes da matriz $[\overline{\mathrm{K}}]$ são dados por:

$$
\begin{aligned}
& \overline{\mathrm{K}}_{11}=-\frac{1}{8 \pi \mathrm{G}(1-v) \mathrm{r}} \mathrm{r}_{, 1}\left\{1-4 v+2\left(\mathrm{r}_{,}\right)^{2}\right\} \\
& \overline{\mathrm{K}}_{12}=-\frac{1}{8 \pi \mathrm{G}(1-v) \mathrm{r}} \mathrm{r}_{, 2}\left\{2-4 v+4\left(\mathrm{r}_{, 1}\right)^{2}\right\} \\
& \overline{\mathrm{K}}_{13}=-\frac{1}{8 \pi \mathrm{G}(1-v) \mathrm{r}} \mathrm{r}_{, 1}\left\{-1+2\left(\mathrm{r}_{, 2}\right)^{2}\right\} \\
& \overline{\mathrm{K}}_{21}=-\frac{1}{8 \pi \mathrm{G}(1-v) \mathrm{r}} \mathrm{r}_{2}\left\{-1+2\left(\mathrm{r}_{, 1}\right)^{2}\right\} \\
& \overline{\mathrm{K}}_{22}=-\frac{1}{8 \pi \mathrm{G}(1-v) \mathrm{r}} \mathrm{r}_{, 1}\left\{2-4 v+4\left(\mathrm{r}_{, 2}\right)^{2}\right\} \\
& \overline{\mathrm{K}}_{23}=-\frac{1}{8 \pi \mathrm{G}(1-v) \mathrm{r}} \mathrm{r}_{, 2}\left\{1-4 v+2\left(\mathrm{r}_{, 2}\right)^{2}\right\} .
\end{aligned}
$$

Logo, a eq. (8.25) torna-se:

$$
[\mathrm{H}]\{\mathrm{U}\}=[\mathrm{G}]\{\mathrm{P}\}+[\mathrm{K}]\{\mathrm{Q}\}
$$

que é a primeira equação utilizada para a análise não-linear e leva em conta o efeito dos quadripolos sobre deslocamentos e forças de superficie nodais. 


\subsection{Contribuição dos Dipolos Para a Abertura de Fratura}

O objetivo desta seção é encontrar o efeito da aplicação dos quadripolos na abertura de uma fratura. Esta abertura é tratada como uma diferença de deslocamentos entre dois pontos situados em faces opostas, porém pertencentes a uma mesma linha perpendicular à fratura. Seja, por exemplo, um ponto de colocação p' situado próximo e à esquerda de uma fratura vertical (fig. (8.7a)). Nesta figura, valem as relações:

$$
\begin{aligned}
& \mathrm{ds}=\mathrm{rd} \theta ; \quad \operatorname{Cos}(\theta)=\frac{\delta}{\mathrm{r}} ; \quad \mathrm{r}_{\mathrm{n}}=\frac{\mathrm{dr}}{\mathrm{dn}}=\frac{1}{\mathrm{r}} \overrightarrow{\mathrm{r}} \cdot \overrightarrow{\mathrm{n}}=\operatorname{Cos}(\theta) \\
& \mathrm{d} \bar{\Gamma} \operatorname{Cos}(\theta)=\mathrm{ds}=\mathrm{rd} \theta ; \quad \mathrm{d} \bar{\Gamma} \frac{\mathrm{dr}}{\mathrm{dn}}=\mathrm{rd} \theta \\
& \mathrm{r}_{, 1}=\frac{\mathrm{x}(\mathrm{S})-\mathrm{x}(\mathrm{p})}{\mathrm{r}}=\operatorname{Cos}(\theta)=\frac{\delta}{\mathrm{r}} ; \quad \mathrm{r}_{, 2}=\frac{\mathrm{y}(\mathrm{S})-\mathrm{y}(\mathrm{p})}{\mathrm{r}}=\operatorname{Sen}(\theta)
\end{aligned}
$$

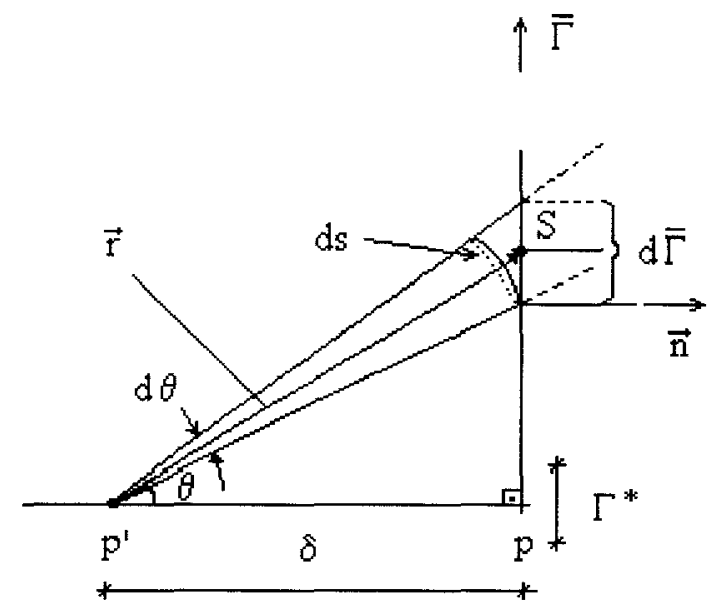

(A)

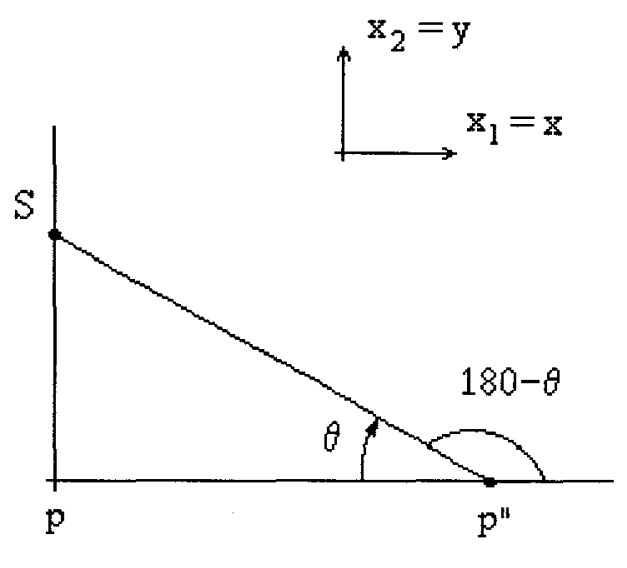

(B)

FIGURA 8.7 - Ponto de colocação nas proximidades de uma fratura vertical. (a) Pelo lado esquerdo. (b) Pelo lado direito. VENTURINI (1993). 
Analisando-se o último termo da eq. (8.25) quando um ponto p' do domínio $([\mathrm{c}]=[\mathrm{I}])$ tende à fratura $\left(\mathrm{p}^{\prime} \rightarrow \mathrm{p}\right)$, tem-se:

$$
\begin{aligned}
& \lim _{\mathbf{p}^{\prime} \rightarrow \mathrm{p}}\{u\}^{\mathrm{p}^{\prime}}=\underbrace{\lim _{\delta \rightarrow 0} \lim _{\Gamma^{*} \rightarrow 0} \int[\overline{\mathrm{K}}]\{\mathrm{q}\} \mathrm{d} \Gamma}_{\text {valor principal }}+\underbrace{\lim _{\delta \rightarrow 0} \lim _{\Gamma^{*} \rightarrow 0} \int[\overline{\mathrm{K}}]\{\mathrm{q}\} \mathrm{d} \Gamma}_{\text {termo independente }}= \\
& =\underbrace{\lim _{\delta \rightarrow 0} \lim _{\Gamma^{\prime \prime} \rightarrow 0} \int[\overline{\mathrm{K}}]\{\mathrm{q}\} \mathrm{d} \Gamma}_{\text {valor principal }}+\underbrace{\lim _{\delta \rightarrow 0} \lim _{\Gamma^{*} \rightarrow 0}\left(\iint_{\Gamma^{*}}[\overline{\mathrm{K}}] \mathrm{d} \bar{\Gamma}\right)\{\mathrm{q}\}^{\mathbf{p}}}_{\text {termo independente }}
\end{aligned}
$$

onde $\Gamma^{*}$ representa um segmento de $\bar{\Gamma}$ com centro em $\mathrm{p}$. No segundo membro da eq. (8.34), o primeiro termo representa a influência dos quadripolos aplicados em outros elementos de fratura e pode ser avaliado através do conceito de valor principal (cf. [3.4]). O segundo termo fornece a relação entre quadripolos aplicados e abertura de fratura em um ponto $\mathrm{p}$ da mesma. É possível demonstrar que o segundo termo produz:

$$
\{u\}^{p^{\prime}}=\left[\begin{array}{cc}
-\frac{(1-2 v)}{4 G(1-v)} & 0 \\
0 & -\frac{1}{2 G}
\end{array}\right]\left\{\begin{array}{c}
q_{1}^{1} \\
q_{2}^{1}
\end{array}\right\}^{p}
$$

Analogamente, considerando-se a aproximação pelo outro lado da fratura $\left(p^{\prime \prime} \rightarrow\right.$ p na fig. (8.7b)), tem-se

$$
\{u\}^{p^{\prime \prime}}=\left[\begin{array}{cc}
\frac{(1-2 v)}{4 G(1-v)} & 0 \\
0 & \frac{1}{2 G}
\end{array}\right]\left\{\begin{array}{l}
q_{1}^{1} \\
q_{2}^{1}
\end{array}\right\}^{p}
$$

O valor absoluto da diferença entre os dois deslocamentos fornece a relação entre abertura de fratura e quadripolos aplicados: 


$$
\{\Delta \mathrm{w}\}=\left\{\begin{array}{l}
\Delta \mathrm{w}_{1} \\
\Delta \mathrm{w}_{2}
\end{array}\right\}=\{u\}^{\mathrm{p}^{\prime}}-\{u\}^{\mathrm{p}^{\prime \prime}} \mid=\left[\begin{array}{cc}
\frac{(1-2 v)}{2 \mathrm{G}(1-v)} & 0 \\
0 & \frac{1}{\mathrm{G}}
\end{array}\right]\left\{\begin{array}{l}
\mathrm{q}_{1}^{1} \\
\mathrm{q}_{2}^{1}
\end{array}\right\}^{\mathrm{p}}
$$

Como este trabalho analisa o fraturamento em modo de abertura (modo I), apenas o primeiro coeficiente é utilizado, ou seja,

$$
\Delta \mathrm{w}_{1}=\frac{(1-2 v)}{2 \mathrm{G}(1-v)} \mathrm{q}_{1}^{1}
$$

que equivale à relação entre abertura de fratura e quadripolo normal aplicado.

\subsection{Equação Integral de Contorno Para o Cálculo de Tensões em Pontos Internos}

A equação integral de contorno para o cálculo de tensões pode ser escrita (VENTURINI (1995)):

$$
\begin{aligned}
\sigma_{\mathrm{im}}(\mathrm{p}) & =-\int_{\Gamma} \mathrm{S}_{\mathrm{imk}}(\mathrm{p}, \mathrm{S}) \mathrm{u}_{\mathrm{k}}(\mathrm{S}) \mathrm{d} \Gamma(\mathrm{S})+\int_{\Gamma} \mathrm{D}_{\mathrm{imk}}(\mathrm{p}, \mathrm{S}) \mathrm{p}_{\mathrm{k}}(\mathrm{S}) \mathrm{d} \Gamma(\mathrm{S})+\int_{\Gamma_{\mathrm{C}}} \mathrm{G}_{\ell \mathrm{j}}^{\mathrm{im}}(\mathrm{p}, \mathrm{S}) \mathrm{q}_{\mathrm{j}}^{\ell}(\mathrm{S}) \mathrm{d} \Gamma_{\mathrm{C}}(\mathrm{S})+ \\
& +\mathrm{g}_{\ell \mathrm{j}}^{\mathrm{im}}\left(\sigma_{\ell \mathrm{j}}(\mathrm{p})\right)
\end{aligned}
$$

onde o termo

$$
\mathrm{g}_{\ell j}^{\mathrm{im}}(\mathrm{p})=\left\{\begin{array}{c}
0 \\
\sigma_{\mathrm{im}}^{0}(\mathrm{p})
\end{array}\right.
$$


para o cálculo de tensão plástica ou elástica, respectivamente. Este termo é considerado ao se fazer a integral de parte finita no tratamento da hiper-singularidade Além disso (VENTURINI (1995)),

$$
\begin{aligned}
\mathrm{G}_{\ell \mathrm{j}}^{\mathrm{im}}(\mathrm{p}, \mathrm{S})= & \frac{1}{4 \pi(1-v) \mathrm{r}^{2}}\left\{(1-2 v)\left(\delta_{\mathrm{ij}} \delta_{\ell \mathrm{m}}+\delta_{\mathrm{jm}} \delta_{\mathrm{i} \ell}-\delta_{\mathrm{j} \ell} \delta_{\mathrm{im}}\right)-\right. \\
& -2(1-v)\left(\mathrm{r}_{, \mathrm{m}} \mathrm{r}_{\ell} \delta_{\mathrm{ij}}+\mathrm{r}_{, \mathrm{i}} \mathrm{r}_{\ell} \delta_{\mathrm{mj}}-\mathrm{r}_{\mathrm{j}, \mathrm{j}, \ell} \delta_{\mathrm{im}}\right)+2\left(\delta_{\mathrm{i} \ell} \mathrm{r}_{, j} \mathrm{r}_{, \mathrm{m}}+\delta_{\mathrm{m} \ell} \mathrm{r}_{, j} \mathrm{r}_{, \mathrm{i}}+\delta_{\mathrm{j} \ell} \mathrm{r}_{, \mathrm{i}} \mathrm{r}_{, \mathrm{m}}\right)- \\
& \left.-8 \mathrm{r}_{, \mathrm{i}} \mathrm{r}_{, j} \mathrm{r}_{, \mathrm{m}} \mathrm{r}_{, \ell}\right\}
\end{aligned}
$$

Reorganizando-se o penúltimo termo da eq. (8.39):

$$
\begin{aligned}
G_{\ell j}^{\mathrm{im}} q_{j}^{l} & =G_{11}^{\mathrm{im}} q_{1}^{1}+G_{12}^{\mathrm{im}} q_{2}^{1}+G_{21}^{\mathrm{im}} q_{1}^{2}+G_{22}^{\mathrm{im}} q_{2}^{2}= \\
& =G_{11}^{\mathrm{im}} q_{1}^{1}+\left(G_{12}^{\mathrm{im}}+G_{21}^{\mathrm{im}}\right) \mathrm{q}_{2}^{1}+\mathrm{G}_{22}^{\mathrm{im}} \mathrm{q}_{2}^{2}= \\
& =\left[\begin{array}{lll}
G_{11}^{\mathrm{im}} & \left(G_{12}^{\mathrm{im}}+G_{21}^{\mathrm{im}}\right) & \mathrm{G}_{22}^{\mathrm{im}}
\end{array}\right]\left\{\begin{array}{l}
\mathrm{q}_{1}^{1} \\
q_{2}^{1} \\
q_{2}^{2}
\end{array}\right\}=[\overline{\mathrm{K}} 2]\{q\}
\end{aligned}
$$

e a eq. (8.39), escrita em notação matricial, torna-se

$$
\{\sigma\}^{p}=-\int_{\Gamma}[S]^{\text {imk }}\{\mathrm{u}\} \mathrm{d} \Gamma+\int_{\Gamma}[\mathrm{D}]^{\mathrm{imk}}\{\mathrm{p}\} \mathrm{d} \Gamma+\int_{\Gamma}[\overline{\mathrm{K}} 2]\{\mathrm{q}\} \mathrm{d} \bar{\Gamma}
$$

onde $\bar{\Gamma}$ representa as descontinuidades existentes.

\subsubsection{Formulação em Elementos de Contorno e Elementos de Fratura}

Analisando-se o último termo da eq. (8.43) de forma semelhante ao exposto na seção [8.1.1]: 


$$
\int_{\Gamma}[\overline{\mathrm{K}} 2]\{\mathrm{q}\} \mathrm{d} \bar{\Gamma}=\sum_{\mathrm{j}=1}^{\text {nef }}\left(\int_{\Gamma_{\mathrm{j}}}[\overline{\mathrm{K}} 2][\Phi 2] \mathrm{d} \bar{\Gamma}_{\mathrm{j}}\right)\{\mathrm{q}\}_{\mathrm{n}}^{\mathrm{j}}=\sum_{\mathrm{j}=1}^{\mathrm{nef}}[\mathrm{KW} 2]^{\mathrm{pj}}\{\mathrm{q}\}_{\mathrm{n}}^{\mathrm{j}}
$$

onde

$$
[\mathrm{KW} 2]^{\mathrm{pj}}=\int_{\bar{\Gamma}_{\mathrm{j}}}[\overline{\mathrm{K}} 2][\Phi 2] \mathrm{d} \bar{\Gamma}_{\mathbf{j}}
$$

e nef representa o número de elementos de fratura. Os coeficientes da matriz [ $\overline{\mathrm{K}} 2]$ são dados por:

$$
\begin{aligned}
& \overline{\mathrm{K}} 2_{11}=\frac{1}{4 \pi(1-v) \mathrm{r}^{2}}\left\{1-2 v+4\left(\mathrm{r}_{, 1}\right)^{2}\left(1+v-2\left(\mathrm{r}_{, 1}\right)^{2}\right)\right\} \\
& \overline{\mathrm{K}} 2_{12}=\frac{1}{4 \pi(1-v) \mathrm{r}^{2}}\left\{\mathrm{r}_{, 1} \mathrm{r}_{, 2}\left(4-16\left(\mathrm{r}_{, 1}\right)^{2}\right)\right\} \\
& \overline{\mathrm{K}} 2_{13}=\frac{1}{4 \pi(1-v) \mathrm{r}^{2}}\left\{(1-2 v)\left(-1+2\left(\mathrm{r}_{, 2}\right)^{2}\right)+\left(\mathrm{r}_{, 1}\right)^{2}\left(2-8\left(\mathrm{r}_{, 2}\right)^{2}\right)\right\} \\
& \overline{\mathrm{K}} 2_{21}=\frac{1}{4 \pi(1-v) \mathrm{r}^{2}}\left\{\mathrm{r}_{, 1} \mathrm{r}_{, 2}\left(2+4 v-8\left(\mathrm{r}_{, 1}\right)^{2}\right)\right\} \\
& \overline{\mathrm{K}} 2_{22}=\frac{1}{4 \pi(1-v) \mathrm{r}^{2}}\left\{2-16\left(\mathrm{r}_{, 1}\right)^{2}\left(\mathrm{r}_{, 2}\right)^{2}\right\} \\
& \overline{\mathrm{K}} 2_{23}=\frac{1}{4 \pi(1-v) \mathrm{r}^{2}}\left\{\mathrm{r}_{, 1} \mathrm{r}_{, 2}\left(2+4 v-8\left(\mathrm{r}_{, 2}\right)^{2}\right)\right\} \\
& \overline{\mathrm{K}} 2_{31}=\frac{1}{4 \pi(1-v) \mathrm{r}^{2}}\left\{(1-2 v)\left(-1+2\left(\mathrm{r}_{, 1}\right)^{2}\right)+\left(\mathrm{r}_{, 2}\right)^{2}\left(2-8\left(\mathrm{r}_{, 1}\right)^{2}\right)\right\} \\
& \overline{\mathrm{K}} 2_{32}=\frac{1}{4 \pi(1-v) \mathrm{r}^{2}}\left\{\mathrm{r}_{, 1} \mathrm{r}_{, 2}\left(4-16\left(\mathrm{r}_{, 2}\right)^{2}\right)\right\} \\
& \overline{\mathrm{K}} 2_{33}=\frac{1}{4 \pi(1-v) \mathrm{r}^{2}}\left\{1-2 v+4\left(\mathrm{r}_{, 2}\right)^{2}\left(1+v-2\left(\mathrm{r}_{, 2}\right)^{2}\right)\right\}
\end{aligned}
$$


Discretizando-se o contorno e interpolando-se as variáveis a partir de valores nodais, a eq. (8.43) torna-se (cf. eq. (7.39))

$$
\begin{aligned}
\{\sigma\}^{\mathrm{p}} & =\left\{\begin{array}{l}
\sigma_{11} \\
\sigma_{12} \\
\sigma_{22}
\end{array}\right\}=\sum_{\mathrm{j}=1}^{\mathrm{pe}}\left(\int_{\Gamma_{\mathrm{j}}}[\mathrm{D}]^{\mathrm{kij}}[\Phi] \mathrm{d} \Gamma_{\mathrm{j}}\right)\{\mathrm{p}\}_{\mathrm{n}}^{\mathrm{j}}-\sum_{\mathrm{j}=1}^{\mathrm{ne}}\left(\int_{\Gamma_{\mathrm{j}}}[\mathrm{S}]^{\mathrm{kij}}[\Phi] \mathrm{d} \Gamma_{\mathrm{j}}\right)\{\mathrm{u}\}_{\mathrm{n}}^{\mathrm{j}}+ \\
& +\sum_{\mathrm{j}=1}^{\mathrm{nef}}\left(\int_{\bar{\Gamma}_{\mathrm{j}}}[\overline{\mathrm{K}} 2][\Phi 2] \mathrm{d} \bar{\Gamma}_{\mathrm{j}}\right)\{\mathrm{q}\}_{\mathrm{n}}^{\mathrm{j}}= \\
& =\sum_{\mathrm{j}=1}^{\mathrm{ne}}[\mathrm{DFI}]^{\mathrm{kij}}\{\mathrm{p}\}_{\mathrm{n}}^{\mathrm{j}}-\sum_{\mathrm{j}=1}^{\mathrm{ne}}[\mathrm{SFI}]^{\mathrm{kij}}\{\mathrm{u}\}_{\mathrm{n}}^{\mathrm{j}}+\sum_{\mathrm{j}=1}^{\mathrm{nef}}[\mathrm{KW} 2]^{\mathrm{pj}}\{\mathrm{q}\}_{\mathrm{n}}^{\mathrm{j}}
\end{aligned}
$$

onde nef representa o número de elementos de fratura. Logo, a eq. (8.43) torna-se:

$$
\{\sigma\}^{p}=-\left[\mathrm{H}^{\prime \prime \prime}\right]\{\mathrm{U}\}+\left[\mathrm{G}^{\prime \prime \prime}\right]\{\mathrm{P}\}+\left[\mathrm{K}^{\prime \prime \prime}\right]\{\mathrm{Q}\}
$$

que é a segunda equação utilizada para a análise não-linear e leva em conta o efeito dos quadripolos sobre tensões em pontos internos. As matrizes [H"'] e [G''] são idênticas às matrizes [H'] e [G'] da eq. (7.39).

\subsubsection{Tratamento das Integrais Hiper-singulares}

A eq. (8.48) pode ser utilizada para o cálculo das tensões nos elementos de fratura. Neste caso, entretanto, é preciso analisar a hiper-singularidade existente, pois tanto o ponto de colocação quanto os pontos de integração podem pertencer a um mesmo elemento de fratura e o integrando é função de $1 / \mathrm{r}^{2}$.

É possível utilizar uma abordagem semelhante à integração singular da seção [7.4.1] ( $2^{\circ}$ caso, fig. 7.6b) para o cálculo dos coeficientes da matriz [KW2]. Entretanto, as espressões da seção [8.1.3] para as funções de interpolação (eqs. (8.26)) não podem ser utilizadas, pelo motivo descrito a seguir. 
Neste caso, como na seção [8.1.3], as funções de interpolação têm a mesma forma (apresentam os mesmos valores como função da coordenada natural ao longo do elemento). Entretanto - eis aqui a diferença - estes valores não devem depender da posição do ponto de colocação, que pode ser qualquer um dos dois existentes. Em outras palavras, os valores das funções de interpolação não devem se alterar, quer o ponto de colocação utilizado seja o primeiro, quer o segundo (fig. (8.8)).

Para levar em conta esta particularidade, as eqs. (8.26) precisam ser modificadas para

$$
\phi_{3}=\frac{1}{2}\left(1-\frac{\xi}{|\bar{\xi}|}\right) . \quad \text { e } \quad \phi_{4}=\frac{1}{2}\left(1+\frac{\xi}{|\bar{\xi}|}\right)
$$

ou seja, quando $\bar{\xi}>0$, as eqs. (8.49) reproduzem as eqs. (8.26); porém, quando $\bar{\xi}<0$

$$
\phi_{3}=\frac{1}{2}\left(1+\frac{\xi}{\bar{\xi}}\right) . \quad \text { e } \quad \phi_{4}=\frac{1}{2}\left(1-\frac{\xi}{\bar{\xi}}\right)
$$

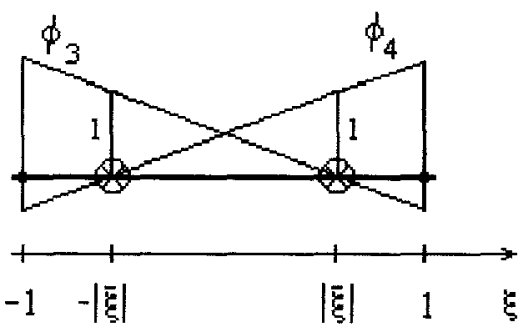

FIGURA 8.8 - Representação geométrica do elemento de fratura e caracterização das funções de interpolação para os quadripolos no caso da integração hiper-singular.

Portanto, dois casos serão considerados: 


\section{$\underline{1^{\circ} \text { Caso: }} \bar{\xi}<0$ (Primeiro ponto de colocação do elemento de fratura)}

$$
\begin{aligned}
\mathrm{KW} 2_{11} & =\int_{0}^{\ell} \phi_{1} \overline{\mathrm{K}} 2_{11} \mathrm{~d} \bar{\Gamma}= \\
& =\frac{1}{4 \pi(1-v) \ell}\left[1-2 v+4\left(\mathrm{r}_{, 1}\right)^{2}\left(1+v-2\left(\mathrm{r}_{, 1}\right)^{2}\right)\right]\left[\frac{1}{\bar{\xi}} \ln \left(\frac{1-\bar{\xi}}{1+\bar{\xi}}\right)-\frac{4}{1-\bar{\xi}^{2}}\right]= \\
& =\left[1-2 v+4\left(\mathrm{r}_{, 1}\right)^{2}\left(1+v-2\left(\mathrm{r}_{, 1}\right)^{2}\right)\right] \cdot \operatorname{aux} 3
\end{aligned}
$$

$\left(8.51 a^{*}\right)$

onde

$$
\operatorname{aux} 3=\frac{1}{4 \pi(1-v) \ell}\left[\frac{1}{\bar{\xi}} \ln \left(\frac{1-\bar{\xi}}{1+\bar{\xi}}\right)-\frac{4}{1-\bar{\xi}^{2}}\right]
$$

e o algoritmo de Kutt (cf. [3.9] e [8.3]) foi utilizado para tratar a hiper-singularidade como uma integral de parte finita. Os demais termos são:

$$
\begin{gathered}
\mathrm{KW} 2_{12}=\int_{0}^{\ell} \phi_{1} \overline{\mathrm{K}} 2_{12} \mathrm{~d} \bar{\Gamma}=\left[\mathrm{r}_{, 1} \mathrm{r}_{, 2}\left(4-16\left(\mathrm{r}_{, 1}\right)^{2}\right)\right] \cdot \text { aux } 3 \\
\mathrm{KW} 2_{13}=\int_{0}^{\ell} \phi_{1} \overline{\mathrm{K}} 2_{13} \mathrm{~d} \bar{\Gamma}=\left[(1-2 v)\left(-1+2\left(\mathrm{r}_{, 2}\right)^{2}\right)+\left(\mathrm{r}_{, 1}\right)^{2}\left(2-8\left(\mathrm{r}_{, 2}\right)^{2}\right)\right] \cdot \mathrm{aux} 3 \\
\mathrm{KW} 2_{21}=\int_{0}^{\ell} \phi_{1} \overline{\mathrm{K}} 2_{21} \mathrm{~d} \bar{\Gamma}=\left[\mathrm{r}_{, 1} \mathrm{r}_{, 2}\left(2+4 v-8\left(\mathrm{r}_{, 1}\right)^{2}\right)\right] \cdot \mathrm{aux} 3 \\
\mathrm{KW} 2_{22}=\int_{0}^{\ell} \phi_{1} \overline{\mathrm{K}} 2_{22} \mathrm{~d} \bar{\Gamma}=\left[2-16\left(\mathrm{r}_{, 1}\right)^{2}\left(\mathrm{r}_{, 2}\right)^{2}\right] \cdot \mathrm{aux} 3 \\
\mathrm{KW} 2_{23}=\int_{0}^{\ell} \phi_{1} \overline{\mathrm{K}} 2_{23} \mathrm{~d} \bar{\Gamma}=\left[\mathrm{r}_{, 1} \mathrm{r}_{, 2}\left(2+4 v-8\left(\mathrm{r}_{, 2}\right)^{2}\right)\right] \cdot \mathrm{aux} 3 \\
\mathrm{KW} 2_{31}=\int_{0}^{\ell} \phi_{1} \overline{\mathrm{K}} 2_{31} \mathrm{~d} \bar{\Gamma}=\left[(1-2 v)\left(-1+2\left(\mathrm{r}_{, 1}\right)^{2}\right)+\left(\mathrm{r}_{, 2}\right)^{2}\left(2-8\left(\mathrm{r}_{, 1}\right)^{2}\right)\right] \cdot \operatorname{aux} 3
\end{gathered}
$$




$$
\begin{aligned}
\mathrm{KW} 2_{32} & =\int_{0}^{\ell} \phi_{1} \overline{\mathrm{K}} 2_{32} \mathrm{~d} \bar{\Gamma}=\left[\mathrm{r}_{, 1} \mathrm{r}_{2,2}\left(4-16\left(\mathrm{r}_{, 2}\right)^{2}\right)\right] \cdot \operatorname{aux} 3 \\
\mathrm{KW} 2_{33} & =\int_{0}^{\ell} \phi_{1} \overline{\mathrm{K}} 2_{33} \mathrm{~d} \bar{\Gamma}=\left[1-2 v+4\left(\mathrm{r}_{, 2}\right)^{2}\left(1+v-2\left(\mathrm{r}_{, 2}\right)^{2}\right)\right] \cdot \operatorname{aux} 3
\end{aligned}
$$

Seguindo-se um raciocínio análogo, tem-se:

$$
\mathrm{KW} 2_{14}=\int_{0}^{\ell} \phi_{2} \overline{\mathrm{K}} 2_{11} \mathrm{~d} \bar{\Gamma}=\left[1-2 v+4\left(\mathrm{r}_{, 1}\right)^{2}\left(1+v-2\left(\mathrm{r}_{1,}\right)^{2}\right)\right] \cdot \operatorname{aux} 7
$$

(8.52a)

onde

$$
\operatorname{aux} 7=\frac{1}{4 \pi(1-v) \ell}\left[\frac{1}{\bar{\xi}} \ln \left(\frac{1+\bar{\xi}}{1-\bar{\xi}}\right)\right]
$$

e os demais termos são:

$$
\begin{aligned}
\mathrm{KW} 2_{15} & =\int_{0}^{l} \phi_{2} \overline{\mathrm{K}} 2_{12} \mathrm{~d} \bar{\Gamma}=\left[\mathrm{r}_{1,} \mathrm{r}_{, 2}\left(4-16\left(\mathrm{r}_{, 1}\right)^{2}\right)\right] \cdot \operatorname{aux} 7 \\
\mathrm{KW} 2_{16} & =\int_{0}^{l} \phi_{2} \overline{\mathrm{K}} 2_{13} \mathrm{~d} \bar{\Gamma}=\left[(1-2 v)\left(-1+2\left(\mathrm{r}_{, 2}\right)^{2}\right)+\left(\mathrm{r}_{, 1}\right)^{2}\left(2-8\left(\mathrm{r}_{, 2}\right)^{2}\right)\right] \cdot \operatorname{aux} 7 \\
\mathrm{KW} 2_{24} & =\int_{0}^{l} \phi_{2} \overline{\mathrm{K}} 2_{21} \mathrm{~d} \bar{\Gamma}=\left[\mathrm{r}_{, 1} \mathrm{r}_{, 2}\left(2+4 v-8\left(\mathrm{r}_{, 1}\right)^{2}\right)\right] \cdot \operatorname{aux} 7 \\
\mathrm{KW} 2_{25} & =\int_{0}^{\ell} \phi_{2} \overline{\mathrm{K}} 2_{22} \mathrm{~d} \bar{\Gamma}=\left[2-16\left(\mathrm{r}_{, 1}\right)^{2}\left(\mathrm{r}_{, 2}\right)^{2}\right] \cdot \operatorname{aux} 7 \\
\mathrm{KW} 2_{26} & =\int_{0}^{\ell} \phi_{2} \overline{\mathrm{K}} 2_{23} \mathrm{~d} \bar{\Gamma}=\left[\mathrm{r}_{, 1} \mathrm{r}_{, 2}\left(2+4 v-8\left(\mathrm{r}_{, 2}\right)^{2}\right)\right] \cdot \operatorname{aux} 7
\end{aligned}
$$




$$
\mathrm{KW} 2_{34}=\int_{0}^{\ell} \phi_{2} \overline{\mathrm{K}} 2_{31} \mathrm{~d} \bar{\Gamma}=\left[(1-2 v)\left(-1+2\left(\mathrm{r}_{, 1}\right)^{2}\right)+\left(\mathrm{r}_{, 2}\right)^{2}\left(2-8\left(\mathrm{r}_{, 1}\right)^{2}\right)\right] \cdot \operatorname{aux} 7
$$

$$
\begin{aligned}
& \mathrm{KW} 2_{35}=\int_{0}^{\ell} \phi_{2} \overline{\mathrm{K}} 2_{32} \mathrm{~d} \bar{\Gamma}=\left[\mathrm{r}_{, 1} \mathrm{r}_{, 2}\left(4-16\left(\mathrm{r}_{, 2}\right)^{2}\right)\right] \cdot \operatorname{aux} 7 \\
& \mathrm{KW} 2_{36}=\int_{0}^{\ell} \phi_{2} \overline{\mathrm{K}} 2_{33} \mathrm{~d} \bar{\Gamma}=\left[1-2 v+4\left(\mathrm{r}_{, 2}\right)^{2}\left(1+v-2\left(\mathrm{r}_{, 2}\right)^{2}\right)\right] \cdot \operatorname{aux} 7
\end{aligned}
$$

\section{$\underline{2^{\circ} \text { Caso: }} \bar{\xi}>0$ (Segundo ponto de colocação do elemento de fratura)}

Os coeficientes obtidos para o $2^{\circ}$ caso podem ser escritos, a partir dos anteriores, trocando-se aux 3 por aux 7 e vice-versa. Embora esta conclusão pudesse ser alcançada pela consideração da simetria do elemento de fratura, optou-se por refazer os cálculos como um meio de checagem dos resultados. 


\section{EXEMPLOS NUMÉRICOS}

A seguir, a formulação desenvolvida no capítulo anterior é aplicada à análise de problemas envolvendo o processo de fraturamento. Em cada exemplo, procura-se apresentar a geometria, o arquivo contendo os dados de entrada e os gráficos solicitação-deslocamento obtidos na análise. A configuração deformada, juntamente com o padrão de fraturamento observado, são representados nos dois últimos exemplos.

As unidades envolvidas em todos os problemas são coerentes. Todas as análises foram feitas admitindo-se estado plano de tensão (cf. [4.4.1]) e dividindo-se a solicitação em 200 incrementos.

\subsection{Exemplo Numérico 1}

\subsubsection{Geometria}

O primeiro exemplo é uma chapa retangular (10.0 x 2.5, fig. (9.1)), engastada na extremidade da esquerda (nós 9, 10 e 11) e submetida a um deslocamento horizontal prescrito de valor 2.5 na extremidade da direita (nós 0,1 e 2). Os valores adotados para os parâmetros físicos foram: $\mathrm{E}=2.0, v=0.0, f_{\mathrm{t}}=0.9, \mathrm{w}_{\mathrm{c}}=1.8 \mathrm{e}$ 
$1_{\mathrm{ef}}=0.5$. Foram utilizados 12 elementos de contorno e 6 nós duplos $(2,5,8,11,14 \mathrm{e}$ 17). Os nós duplos $2,5,8,11$ e 17 foram restringidos para o fraturamento.

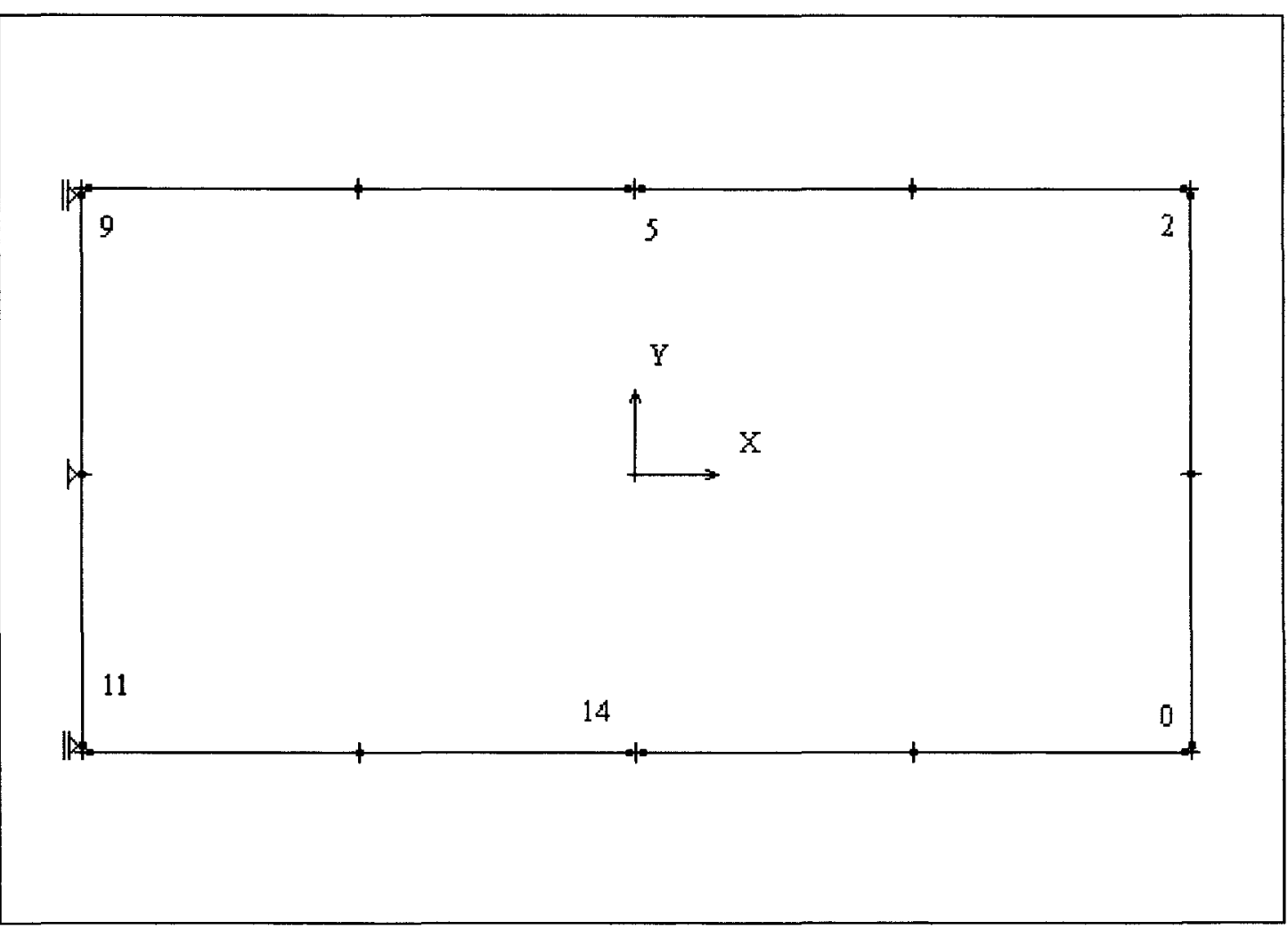

FIGURA 9.1 - Geometria do exemplo numérico 1.

\subsubsection{Dados de Entrada}

MEFRE04E.DAT - CHAPA SUBMETIDA A TRACAO HORIZONTAL. (13/05/96)

(ELEMENTOS LINEARES ISOPARAMETRICOS).

1246

2.00 .0

0.91 .8

0.5200

41

1.01 .01 .01 .01 .01 .01 .01 .01 .01 .0

1.01 .01 .01 .01 .01 .01 .01 .01 .01 .0

1.01 .01 .01 .01 .01 .01 .01 .01 .01 .0

1.01 .01 .01 .01 .01 .01 .01 .01 .01 .0

1.01 .01 .01 .01 .01 .01 .01 .01 .01 .0

1.01 .01 .01 .01 .01 .01 .01 .01 .01 .0

1.01 .01 .01 .01 .01 .01 .01 .01 .01 .0

1.01 .01 .01 .01 .01 .01 .01 .01 .01 .0

1.01 .01 .01 .01 .01 .01 .01 .01 .01 .0

1.01 .01 .01 .01 .01 .01 .01 .01 .01 .0 
1.01 .01 .01 .01 .01 .01 .01 .01 .01 .0 1.01 .01 .01 .01 .01 .01 .01 .01 .01 .0 1.01 .01 .01 .01 .01 .01 .01 .01 .01 .0 1.01 .01 .01 .01 .01 .01 .01 .01 .01 .0 1.01 .01 .01 .01 .01 .01 .01 .01 .01 .0 1.01 .01 .01 .01 .01 .01 .01 .01 .01 .0 1.01 .01 .01 .01 .01 .01 .01 .01 .01 .0 1.01 .01 .01 .01 .01 .01 .01 .01 .01 .0 1.01 .01 .01 .01 .01 .01 .01 .01 .01 .0 1.01 .01 .01 .01 .01 .01 .01 .01 .01 .0 $1.0-0.5$ 1.00 .0 1.00 .5 1.00 .5 0.50 .5 0.00 .5 0.00 .5

$-0.50 .5$

$-1.00 .5$

$-1.00 .5$

$-1.00 .0$

$-1.0-0.5$

$-1.0-0.5$

$-0.5-0.5$

$0.0-0.5$

$0.0-0.5$

$0.5-0.5$

$1.0-0.5$

02.510 .0

02.510 .0

02.510 .0

10.010 .0 10.010 .0 10.010 .0 10.010 .0 10.010 .0 10.010 .0 00.010 .0 00.000 .0 00.010 .0 10.010 .0 10.010 .0 10.010 .0 10.010 .0 10.010 .0 10.010 .0 $0.0-0.4125$ $0.0-0.0875$ 0.00 .0875 0.00 .4125 2 


\subsubsection{Resultados da Análise}

O gráfico da fig. (9.2) representa a relação entre ' $\mathrm{P}$ ' e ' $U$ ' na direção horizontal do nó 2 . Cumpre observar que o 'P' que aparece no eixo vertical deste gráfico representa, na verdade, força de superficie e, portanto, as grandezas de ambos os eixos são adimensionais.

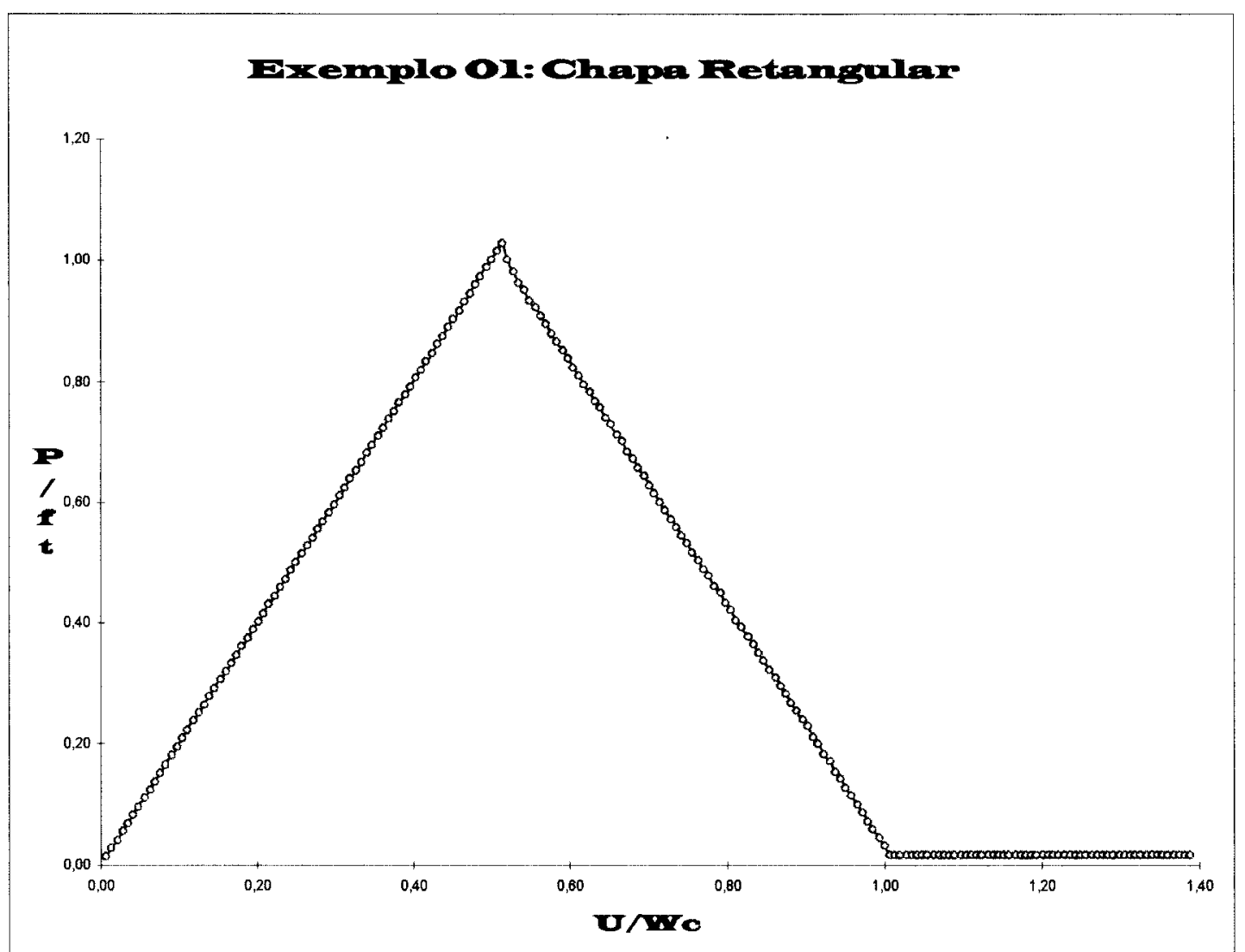

FIGURA 9.2 - Gráfico força de superfície-deslocamento para o exemplo numérico 1. 
A relação $P$ x U permanece linear até o ponto em que a tensão horizontal no contorno (nó 2$)$ atinge a resistência à tração $(0.5,1.0)$. Neste ponto, também a tensão horizontal no nó 14 assume o mesmo valor. Surgem, então, os elementos de fratura. O primeiro, no incremento 179 e o segundo, no incremento seguinte.

O amolecimento de tensões pode ser verificado através do trecho linear descendente do gráfico. É interessante observar o ponto final deste trecho: $(1.0,0.0)$. Neste ponto, $\mathrm{U} / \mathrm{w}_{\mathrm{c}}=1.0$ (ou seja, o deslocamento da extremidade direita é igual à abertura crítica de fratura). Também não há mais transferência de tensão, pois $\mathrm{P} / f_{\mathrm{t}} \cong$ $0.0 \Rightarrow \mathrm{P} \cong 0 \mathrm{e}$, por equilíbrio, as tensões na fratura também são nulas. Se não há tensões na fratura, a abertura da mesma é igual à abertura crítica de fratura. Isto significa que o deslocamento na região intermediária da chapa (que antes do fraturamento equivalia à metade do deslocamento da extremidade direita) é igual à abertura crítica de fratura e, conseqüentemente, ao deslocamento da extremidade direita. Ou seja, durante o processo de fraturamento, a região intermediária se deslocou $50 \%$ mais que a extremidade da direta. Após o término do processo (fraturamento completo), a metade direita da chapa está se movendo como um corpo rígido à parte da metade da esquerda, como seria de se esperar.

O gráfico não se anula devido ao critério de parada utilizado no processo iterativo: excessos de tensão menores que $1 \%$ da resistência à tração foram considerados irrelevantes e, por isso, deixaram de ser corrigidos.

A fig. (9.3) representa a relação tensão-abertura de fratura para o primeiro ponto de colocação do primeiro elemento de fratura. Mais uma vez, os dados foram normalizados, o que significa que as grandezas que aparecem nos eixos do gráfico são adimensionais.

É possível observar que o comportamento obedece ao modelo implementado, ou seja, o gráfico intercepta os eixos nos pontos $\left(0.0, f_{t}\right)$ e $\left(\mathrm{w}_{\mathrm{c}}, 0.0\right)$. 


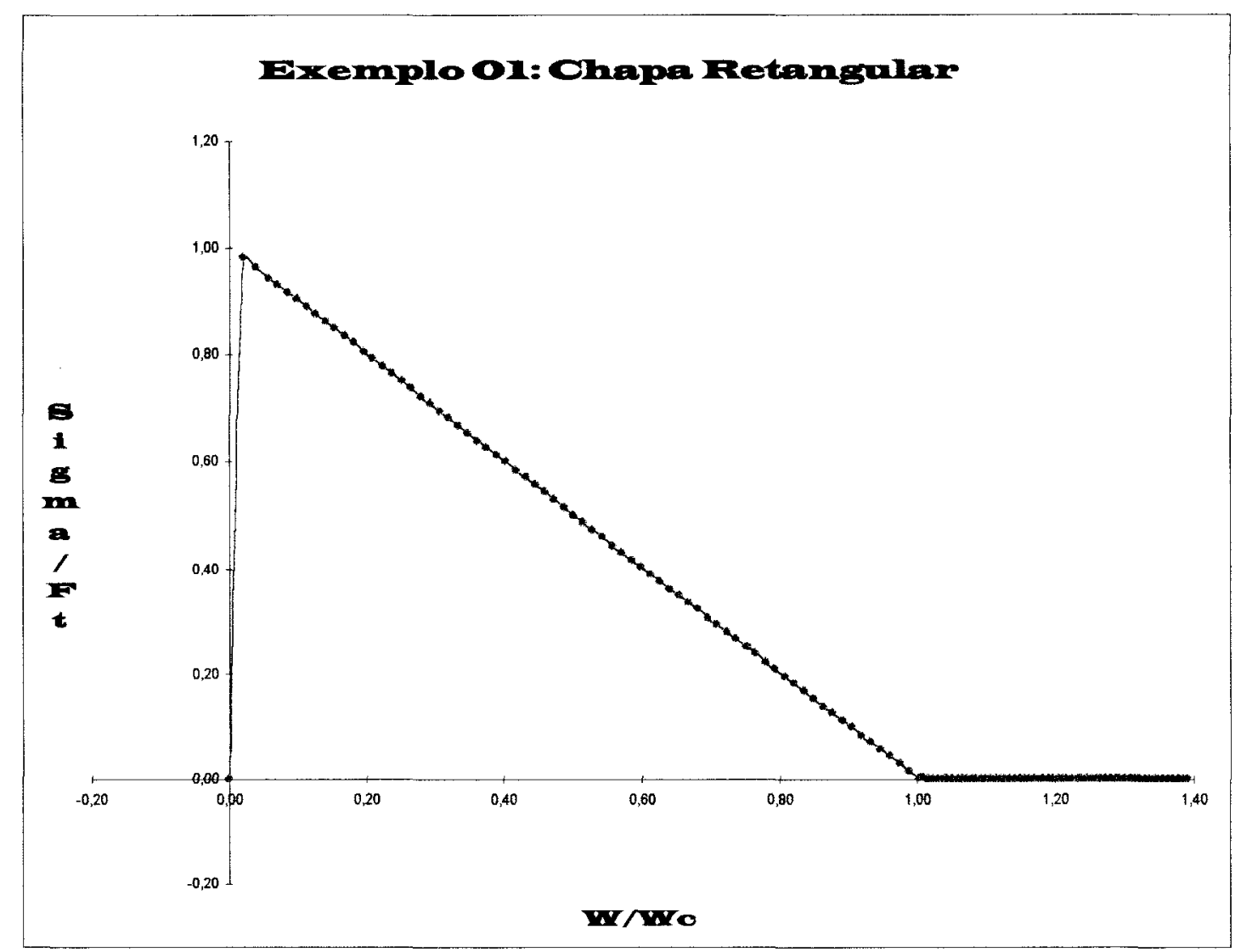

FIGURA 9.3 - Gráfico tensão-abertura de fratura para o exemplo numérico 1.

\subsection{Exemplo Numérico 2}

\subsubsection{Geometria}

O segundo exemplo é uma viga biapoiada (10.0 x 2.5, fig. (9.4)), submetida a flexão em 3 pontos. É prescrito um deslocamento vertical descendente de valor $6.0 \times 10^{-3}$ no nó duplo 16 . Os nós 33,34 e 57 impedem os 3 graus de liberdade do problema plano. Os valores adotados para os parâmetros físicos foram: $\mathrm{E}=$ $1386100.106, v=0.15, f_{\mathrm{t}}=230.0, \mathrm{w}_{\mathrm{c}}=2.76555301939 \times 10^{-3}$ e $1_{\mathrm{ef}}=0.25$. Foram utilizados 54 elementos de contorno e 4 nós duplos $(16,33,45$ e 57). Os nós duplos 16,33 e 57 foram restringidos para o fraturamento. 


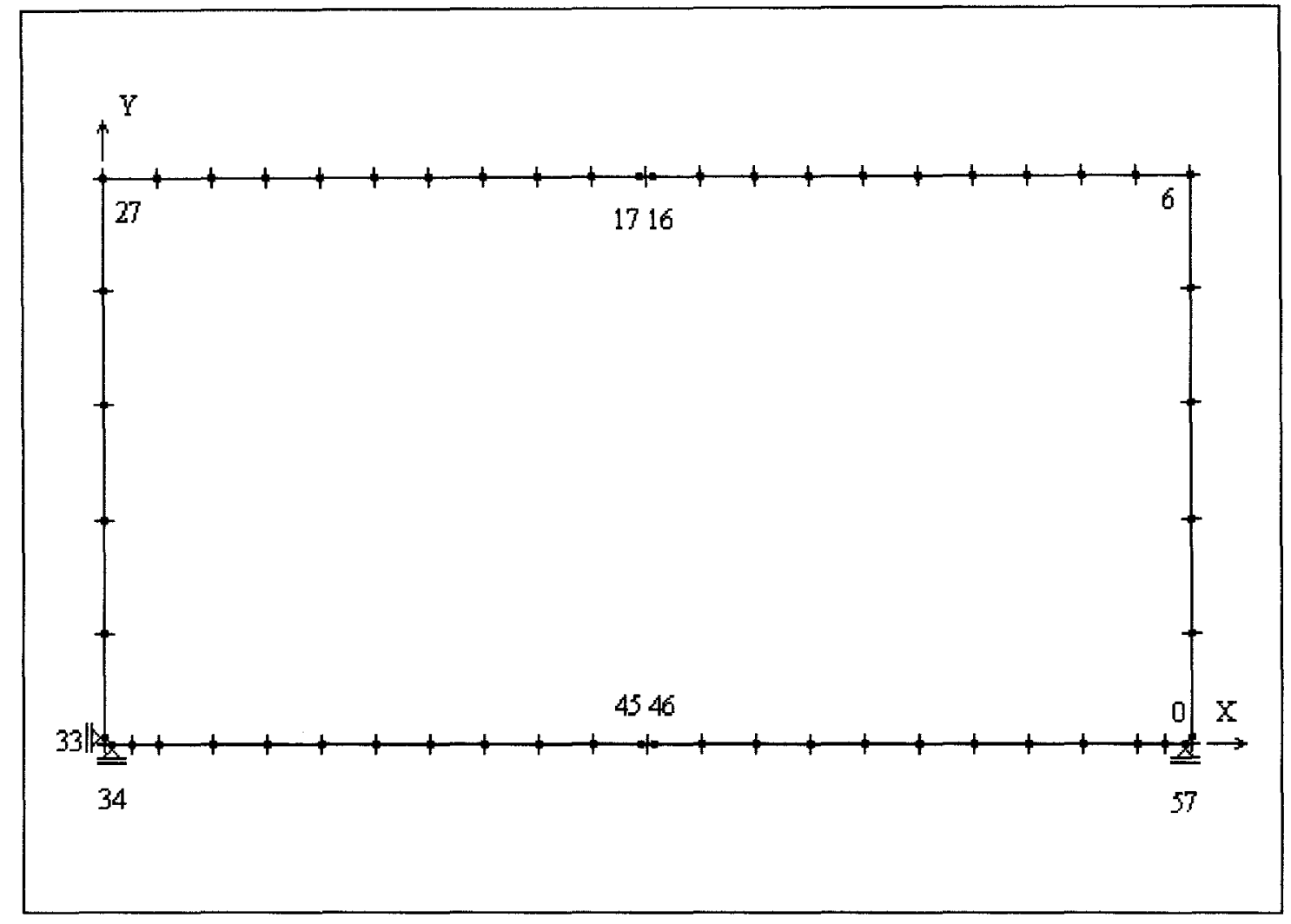

FIGURA 9.4 - Geometria do exemplo numérico 2.

Este exemplo foi retirado de LIANG \& LI (1991), sendo analisado também por VENTURINI (1995).

\subsubsection{Dados de Entrada}

MEFRE02E.DAT - FLEXAO EM TRES PONTOS. (13/05/96)

(ELEMENTOS LINEARES ISOPARAMETRICOS).

5404

1386100.1060 .15

$230.02 .76555301939 \mathrm{E}-3$

0.25200

21

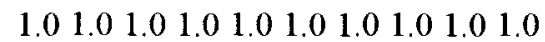

1.01 .01 .01 .01 .01 .01 .01 .01 .01 .0

1.01 .01 .01 .01 .01 .01 .01 .01 .01 .0

$\begin{array}{lllllllll}1.0 & 1.01 .01 .01 .01 .01 .01 .01 .01 .0\end{array}$

1.01 .01 .01 .01 .01 .01 .01 .01 .01 .0

1.01 .01 .01 .01 .01 .01 .01 .01 .01 .0

1.01 .01 .01 .01 .01 .01 .01 .01 .01 .0

1.01 .01 .01 .01 .01 .01 .01 .01 .01 .0

1.01 .01 .01 .01 .01 .01 .01 .01 .01 .0

1.01 .01 .01 .01 .01 .01 .01 .01 .01 .0 
1.01 .01 .01 .01 .01 .01 .01 .01 .01 .0 1.01 .01 .01 .01 .01 .01 .01 .01 .01 .0 1.01 .01 .01 .01 .01 .01 .01 .01 .01 .0 1.01 .01 .01 .01 .01 .01 .01 .01 .01 .0 1.01 .01 .01 .01 .01 .01 .01 .01 .01 .0 1.01 .01 .01 .01 .01 .01 .01 .01 .01 .0 1.01 .01 .01 .01 .01 .01 .01 .01 .01 .0 1.01 .01 .01 .01 .01 .01 .01 .01 .01 .0 1.01 .01 .01 .01 .01 .01 .01 .01 .01 .0 1.01 .01 .01 .01 .01 .01 .01 .01 .01 .0 10.00 .0

10.00 .25

10.00 .5

10.01 .0

10.01 .5

10.02 .0

10.02 .5

9.52 .5

9.02 .5

8.52 .5

8.02 .5

7.52 .5

7.02 .5

6.52 .5

6.02 .5

5.52 .5

5.02 .5

5.02 .5

4.52 .5

4.02 .5

3.52 .5

3.02 .5

2.52 .5

2.02 .5

1.52 .5

1.02 .5

0.52 .5

0.02 .5

0.02 .0

0.01 .5

0.01 .0

0.00 .5

0.00 .25

0.00 .0

0.00 .0

0.250 .0

0.50 .0

1.00 .0

1.50 .0

2.00 .0

2.50 .0

3.00 .0

3.50 .0

4.00 .0

4.50 .0

5.00 .0

5.00 .0

5.50 .0 
6.00 .0

6.50 .0

7.00 .0

7.50 .0

8.00 .0

8.50 .0

9.00 .0

9.50 .0

9.750 .0

10.00 .0

10.010 .0

10.010 .0

10.010 .0

10.010 .0

10.010 .0

10.010 .0

10.010 .0

10.010 .0

10.010 .0

10.010 .0

10.010 .0

10.010 .0

10.010 .0

10.010 .0

10.010 .0

10.010 .0

$10.00-6.0 \mathrm{E}-3$

$10.00-6.0 \mathrm{E}-3$

10.010 .0

10.010 .0

10.010 .0

10.010 .0

10.010 .0

10.010 .0

10.010 .0

10.010 .0

10.010 .0

10.010 .0

10.010 .0

10.010 .0

10.010 .0

10.010 .0

10.010 .0

00.010 .0

10.000 .0

10.010 .0

10.010 .0

10.010 .0

10.010 .0

10.010 .0

10.010 .0

10.010 .0

10.010 .0

10.010 .0

10.010 .0

10.010 .0

10.010 .0

10.010 .0 
10.010 .0

10.010 .0

10.010 .0

10.010 .0

10.010 .0

10.010 .0

10.010 .0

10.010 .0

10.010 .0

10.000 .0

16

33

45

57

01

12

23

34

45

56

67

78

89

910

1011

1112

1213

1314

1415

1516

1718

1819

1920

2021

2122

2223

2324

2425

2526

2627

2728

2829

2930

3031

3132

3233

3435

3536

3637

3738

3839

3940

4041

4142

4243

4344

4445

4647 


\subsubsection{Resultados da Análise}

Os gráficos da fig. (9.5) foram obtidos medindo-se o deslocamento vertical do nó duplo 45 e relacionando-o à força resultante ao longo dos elementos adjacentes aos nó duplo 16. Ambos são conseqüência do deslocamento prescrito neste nó. Bem entendido: a grandeza 'P' que aparece no eixo vertical deste gráfico (e no gráfico da fig. (9.8)) é uma força, pois resulta da integração das forças de superfície.

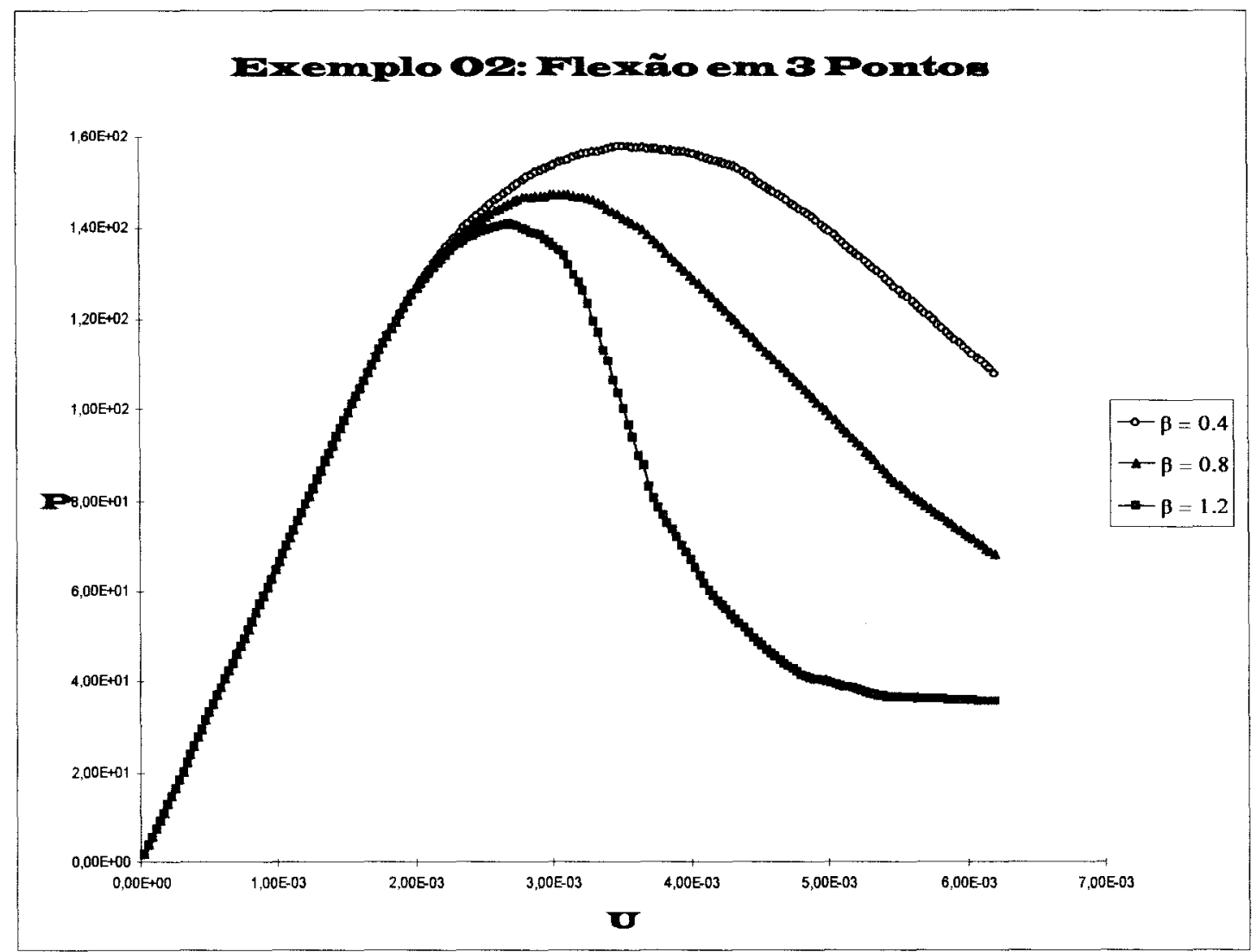

FIGURA 9.5 - Gráficos força-deslocamento para o exemplo numérico 2. 
Este gráfico apresenta concordância qualitativa com os resultados conhecidos da literatura (por exemplo, DI TOMMASO \& GYLLTOFT (1989)). É possível observar a tendência a aparecer o "snap back" à medida que o índice de fragilidade aumenta.

A fig. (9.6) representa as configurações inicial $(+)$ e deformada $(*)$ para o caso em que este exemplo foi analisado $\operatorname{com} \beta=1.2$. Os elementos de fratura são representados na configuração inicial e os deslocamentos dos nós foram ampliados 50 vezes. Esta figura foi capturada a partir da tela do microcomputador. Devido às limitações deste processo, a qualidade deixa a desejar. Isto pode ser comprovado pelo fato de que os elementos de fratura não aparecem perfeitamente verticais (tais como foram determinados). Os números dos elementos de fratura e o incremento em que cada um deles foi gerado aparecem, respectivamente, à esquerda e à direita de cada elemento. Estes dados foram introduzidos editando-se a figura após a captura e, portanto, não faziam parte da figura original.

É possível verificar, pela figura, que o nó duplo 45 fraturou.

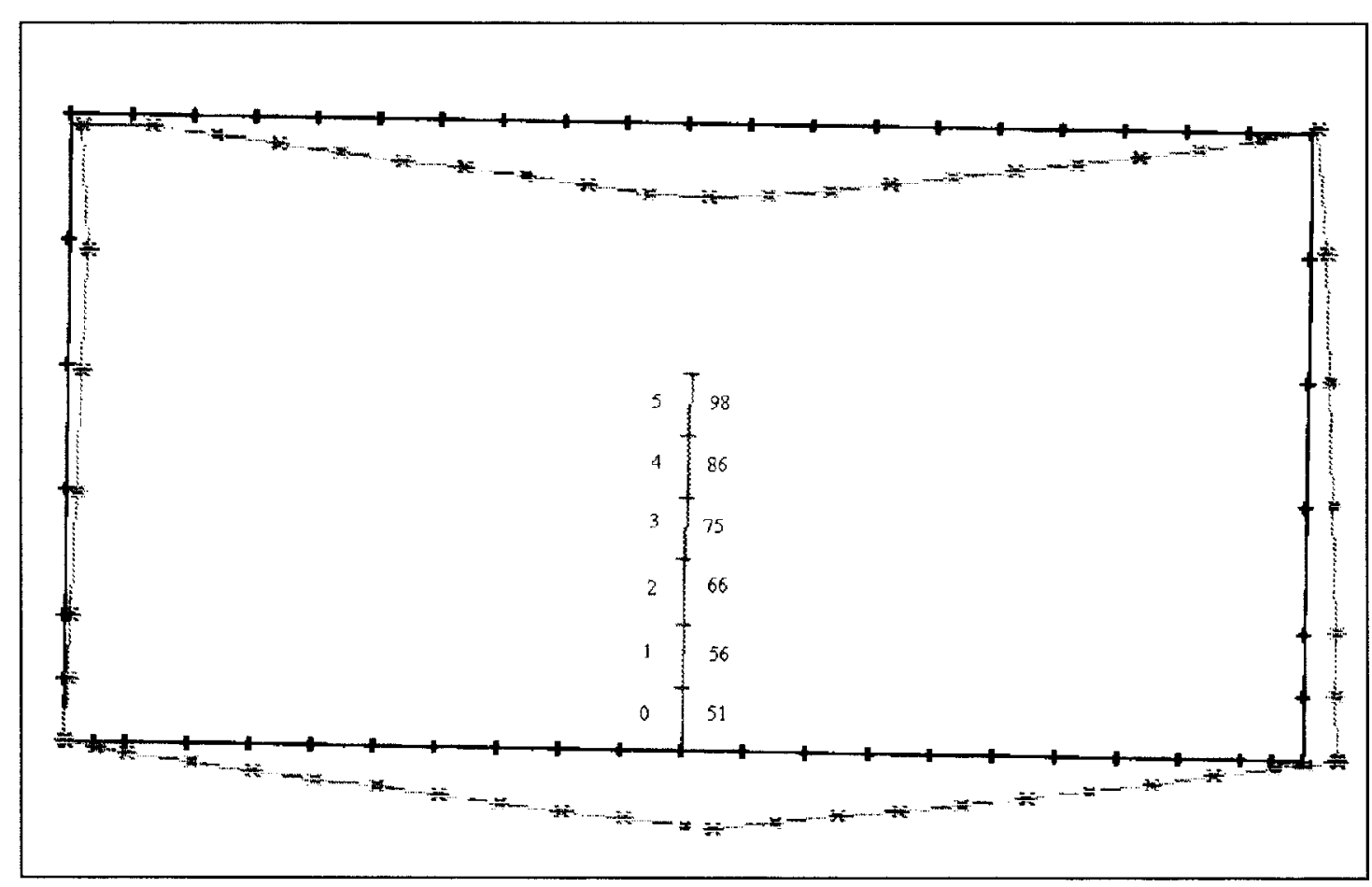

FIGURA 9.6 - Configuração deformada e padrão de fraturamento para o exemplo numérico 2. 


\subsection{Exemplo Numérico 3}

\subsubsection{Geometria}

O terceiro exemplo é uma viga biapoiada $(10.0 \times 2.5$, fig. (9.7)), submetida a flexão em 4 pontos. É prescrito um deslocamento vertical descendente de valor $6.0 \times 10^{-3}$ nos nós duplos 13 e 22. Os nós 36,37 e 61 impedem os 3 graus de liberdade do problema plano. Os valores adotados para os parâmetros físicos foram: $\mathrm{E}=$ $1386100.106, v=0.15, f_{\mathrm{t}}=230.0, \mathrm{w}_{\mathrm{c}}=2.76555301939 \times 10^{-3} \mathrm{e} 1_{\mathrm{ef}}=0.25$. Foram utilizados 56 elementos de contorno e 6 nós duplos $(13,22,36,42$ e 55). Os nós duplos $13,22,36$ e 61 foram restringidos para o fraturamento.

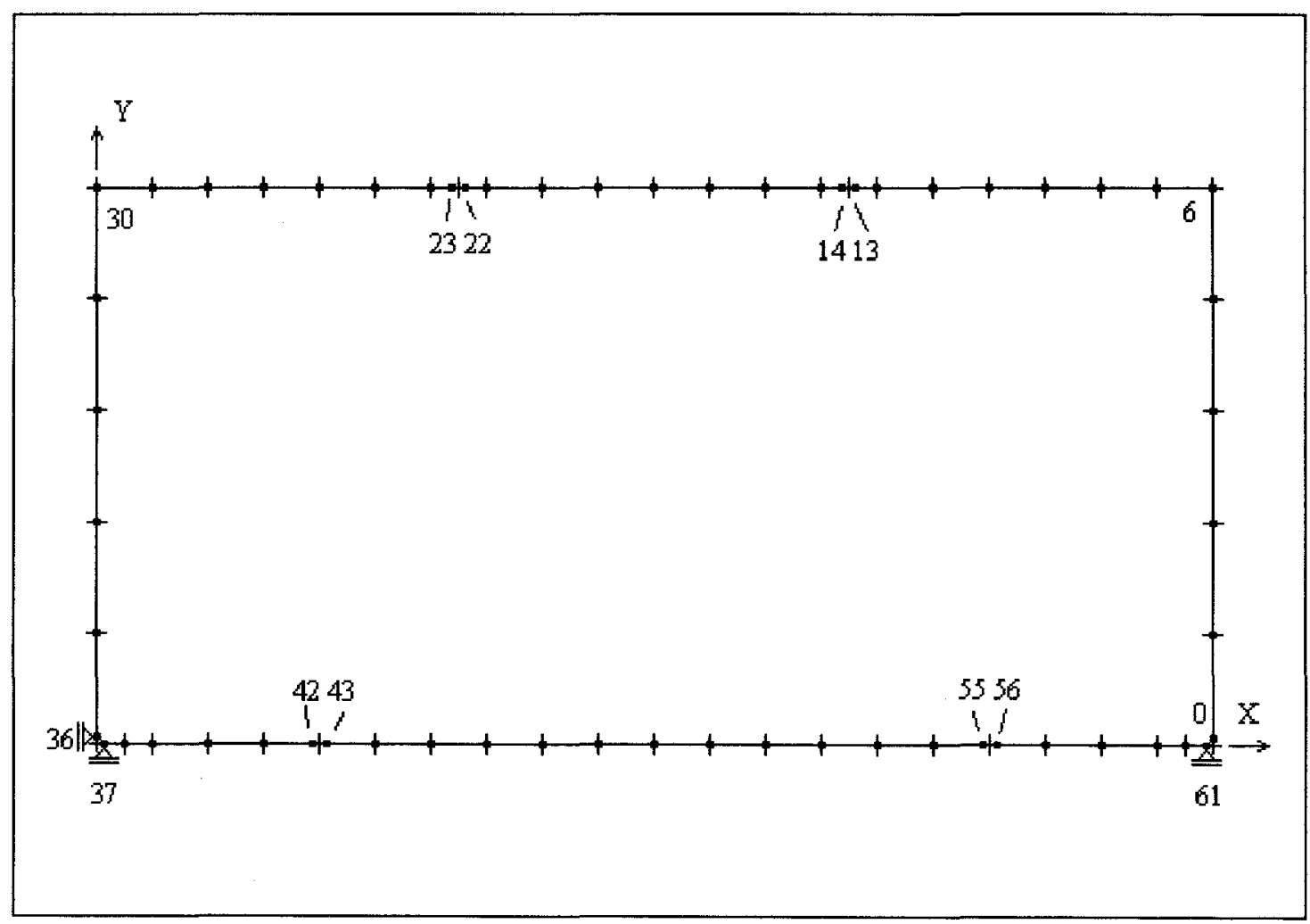

FIGURA 9.7 - Geometria do exemplo numérico 3. 


\subsubsection{Dados de Entrada}

MEFRE01E.DAT - FLEXAO EM QUATRO PONTOS. (13/05/96)

(ELEMENTOS LINEARES ISOPARAMETRICOS).

5606

1386100.1060 .15

$230.02 .76555301939 \mathrm{E}-3$

0.25200

11

1.01 .01 .01 .01 .01 .01 .01 .01 .01 .0

1.01 .01 .01 .01 .01 .01 .01 .01 .01 .0

1.01 .01 .01 .01 .01 .01 .01 .011 .01 .0

1.01 .01 .01 .01 .01 .01 .01 .01 .01 .0

1.01 .01 .01 .01 .01 .01 .01 .01 .01 .0

1.01 .01 .01 .01 .01 .01 .01 .011 .01 .0

1.01 .01 .01 .01 .01 .01 .01 .01 .01 .0

1.01 .01 .01 .01 .01 .01 .01 .01 .01 .0

1.01 .01 .01 .01 .01 .01 .01 .01 .01 .0

$\begin{array}{llll}1.0 & 1.01 .01 .01 .01 .01 .011 .01 .01 .0\end{array}$

1.01 .01 .01 .01 .01 .01 .01 .01 .01 .0

1.01 .01 .01 .01 .01 .01 .01 .01 .01 .0

1.01 .01 .01 .01 .01 .01 .01 .01 .01 .0

1.01 .01 .01 .01 .01 .01 .01 .01 .01 .0

1.01 .01 .01 .01 .01 .01 .01 .01 .01 .0

1.01 .01 .01 .01 .01 .01 .01 .01 .01 .0

1.01 .01 .01 .01 .01 .01 .01 .01 .01 .0

1.01 .01 .01 .01 .01 .01 .01 .01 .01 .0

1.01 .01 .01 .01 .01 .01 .01 .01 .01 .0

1.01 .01 .01 .01 .01 .01 .01 .01 .01 .0

10.00 .0

10.00 .25

10.00 .5

10.01 .0

10.01 .5

10.02 .0

10.02 .5

9.52 .5

9.02 .5

8.52 .5

8.02 .5

7.52 .5

7.02 .5

6.752 .5

6.752 .5

6.52 .5

6.02 .5

5.52 .5

5.02 .5

4.52 .5

4.02 .5

3.52 .5

3.252 .5

3.252 .5

3.02 .5

2.52 .5

2.02 .5 
1.52 .5

1.02 .5

0.52 .5

0.02 .5

0.02 .0

0.01 .5

0.01 .0

0.00 .5

0.00 .25

0.00 .0

0.00 .0

0.250 .0

0.50 .0

1.00 .0

1.50 .0

2.00 .0

2.00 .0

2.50 .0

3.00 .0

3.50 .0

4.00 .0

4.50 .0

5.00 .0

5.50 .0

6.00 .0

6.50 .0

7.00 .0

7.50 .0

8.00 .0

8.00 .0

8.50 .0

9.00 .0

9.50 .0

9.750 .0

10.00 .0

10.010 .0

10.010 .0

10.010 .0

10.010 .0

10.010 .0

10.010 .0

10.010 .0

10.010 .0

10.010 .0

10.010 .0

10.010 .0

10.010 .0

10.010 .0

$10.00-6.0 \mathrm{E}-3$

$10.00-6.0 \mathrm{E}-3$

10.010 .0

10.010 .0

10.010 .0

10.010 .0

10.010 .0

10.010 .0

10.010 .0

$10.00-6.0 \mathrm{E}-3$ 


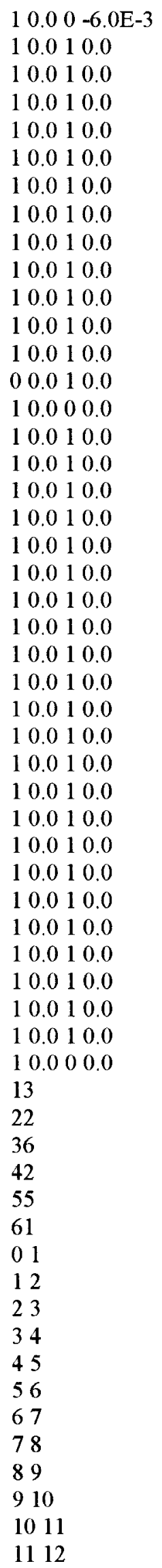




\subsubsection{Resultados da Análise}

O gráfico da fig. (9.8) foi obtido medindo-se o deslocamento vertical do nó duplo 55 e relacionando-o à força resultante ao longo dos elementos adjacentes ao nó duplo 13. Ambos são conseqüência do deslocamento prescrito nesse nó. 


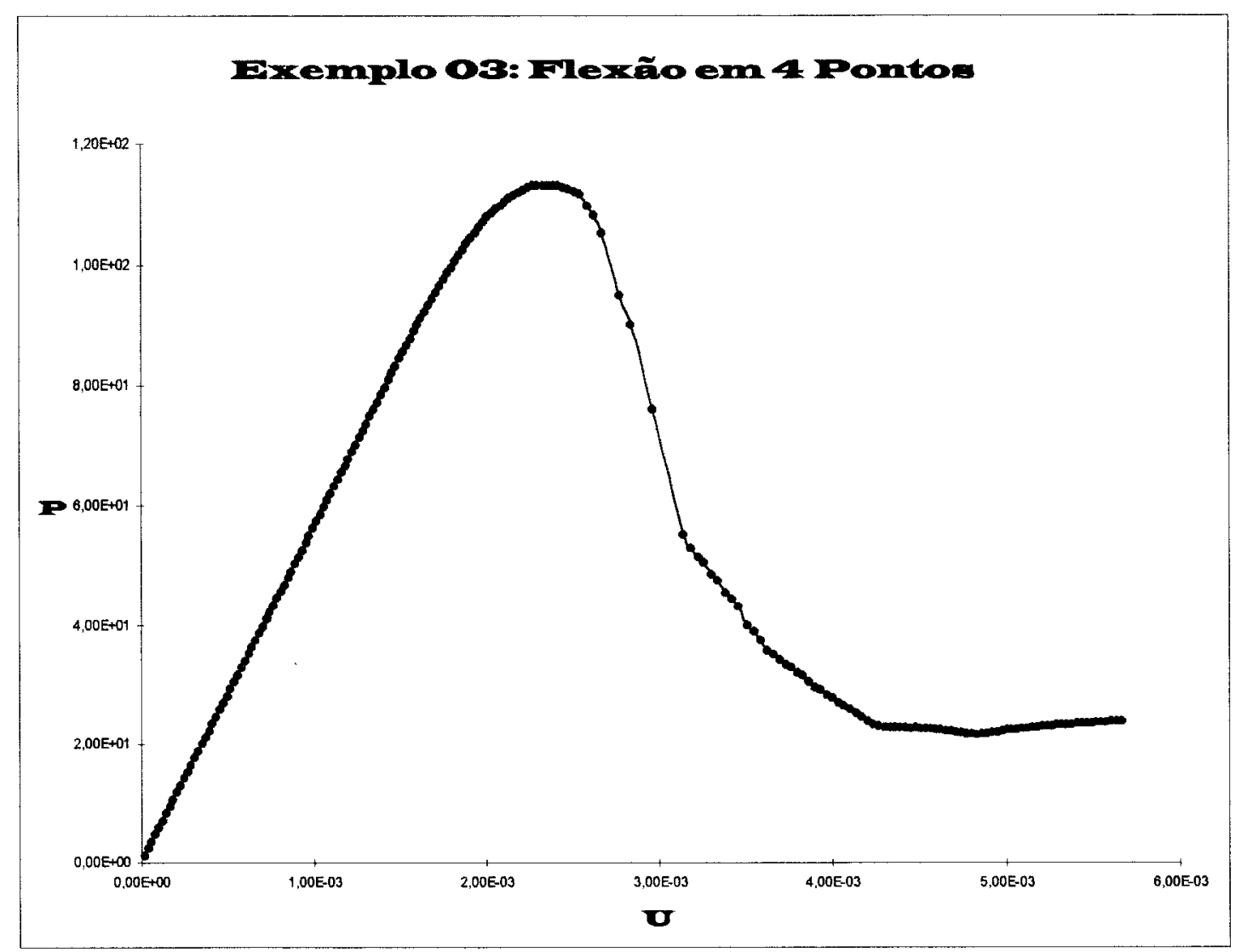

FIGURA 9.8 - Gráfico força-deslocamento para o exemplo numérico 3.

Este gráfico também apresenta concordância qualitativa com os resultados conhecidos da literatura (por exemplo, DI TOMMASO \& GYLLTOFT (1989)). Entretanto, a partir de cerca de $86 \%$ da solicitação, foi observada uma tendência do gráfico a elevação (o valor final da força é $10.14 \%$ maior do que o menor valor exibido no gráfico)

Isto pode ser justificado pelo seguinte: os nós duplos inferiores foram posicionados excentricamente (em relação aos pontos onde os deslocamentos foram impostos) para que se verificasse a capacidade de o modelo prever mudança de direção das fraturas existentes, o que foi observado. Nesse caso, entretanto, as fraturas se desenvolvem em uma região submetida a flexão simples e, portanto, onde o modo de fraturamento não é o modo I, mas um modo misto (devido à existência de cisalhamento) que não é levado em consideração no modelo utilizado para a análise. 
A fig. (9.9) representa as configurações inicial $(+)$ e deformada verdadeira $(*)$ para este exemplo. Os elementos de fratura são representados na configuração inicial e os deslocamentos dos nós foram ampliados 50 vezes. Esta figura foi capturada a partir da tela do microcomputador. Devido às limitações deste processo, a qualidade deixa a desejar. Os números dos elementos de fratura e o incremento em que cada um deles foi gerado aparecem, respectivamente, à esquerda e à direita de cada elemento. Estes dados foram introduzidos editando-se a figura após a captura e, portanto, não faziam parte da figura original.

É possível verificar, pela figura, que o nós duplos 42 e 55 fraturaram. Também é possível observar (a partir da ordem em que os elementos de fratura apareceram) que, a partir de uma assimetria inicial, o problema converge para a situação simétrica.

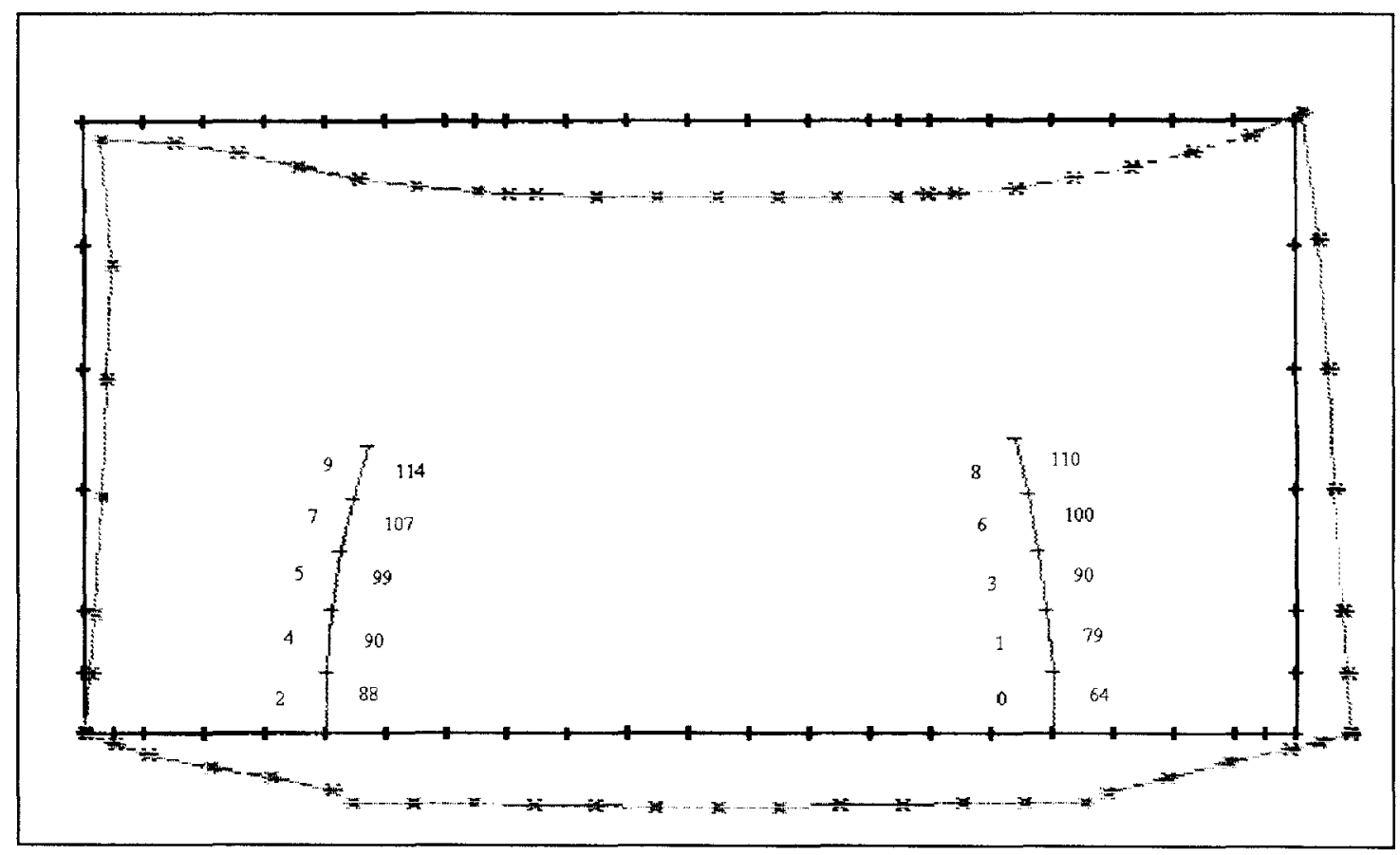

FIGURA 9.9 - Configuração deformada e padrão de fraturamento para o exemplo numérico 3. 


\section{CONCLUSÕES}

No que diz respeito aos objetivos deste trabalho, é possível dizer que todos foram atingidos.

O programa desenvolvido (cf. [ANEXO D]) foi capaz de realizar tanto a análise elástica linear quanto a análise via mecânica do fraturamento não-linear, de domínios bidimensionais, através de um procedimento misto (incremental-iterativo), onde uma aproximação linear do modelo coesivo é empregada. Entenda-se, também, por análise, a previsão do surgimento (incremento de carga e local do início do processo de fraturamento) e crescimento (incremento de carga e direção em que acontece a propagação, se houver) de fraturas múltiplas.

O comportamento pós-pico das estruturas analisadas foi qualitativamente satisfatório, exceção feita à situação onde as limitações do modelo não permitem uma análise precisa.

A formulação do MEC para modelagem de fraturamento a partir de um estado inicial de tensões foi apresentada no capítulo 8, onde foi desenvolvido um elemento de fratura linear isoparamétrico descontínuo.

As possibilidades imediatas de utilização são várias: o estudo do comportamento de barragens e a análise de vigas-parede são alguns exemplos. 
A principal limitação do programa desenvolvido é concernente à nãoimplementação do fechamento de fraturas. Isto traz duas conseqüências. Em primeiro lugar, não é possível analisar carregamentos cíclicos ou, mais geralmente, carregamentos que não sejam monotonicamente crescentes. Em segundo lugar, é de se esperar que o surgimento de uma fratura contribua imediatamente para $o$ fechamento das demais. Este efeito não foi considerado. Note-se que esta limitação não se aplica ao efeito dos quadripolos aplicados, mas sim à região entre o gráfico $\sigma$ w e os eixos, que não foi tratada (quando $\Delta \sigma<0$, fazia-se $\Delta \sigma=0$ ). Uma outra limitação diz respeito à consideração apenas do modo I de fraturamento.

As possibilidades futuras de continuação desta pesquisa são várias. Em primeiro lugar, as limitações acima expostas são de eliminação relativamente fácil. A implementação de sub-regiões (em especial combinada à consideração de materiais com comportamento dúctil) possibilitará a análise de concreto armado. A formulação também pode ser adaptada a domínios tridimensionias. 


\section{ANEXOS}

A seguir, encontram-se a formulação matricial e o algoritmo utilizados na análise do processo de fraturamento. Em seguida, estão a estrutura do projeto computacional MEFRECLI e os códigos-fonte dos arquivos constituintes do projeto.

A apresentação da formulação matricial facilita o entendimento do códigofonte e o algoritmo permite observar o roteiro de como a análise é efetuada. A estrutura do projeto computacional serve para esclarecer visualmente os arquivos que fazem parte do projeto, bem como o relacionamento entre os mesmos. Os códigosfonte foram incluídos, principalmente, em respeito ao caráter de domínio público do trabalho, mas também para viabilizar o desenvolvimento de novas pesquisas notadamente aquelas que possam significar a continuação desta. 


\section{A Formulação Matricial da Análise}

A manipulação matricial utilizada na análise foi dividida em dois tópicos: análise elástica linear e análise não-linear. Em cada um deles, a formulação matricial é descrita e são comentados apenas os arranjos cuja descrição não aparece na documentação interna.

\section{A.1 Análise Elástica Linear}

\section{Equação de Deslocamentos}

A partir do sistema de equações

$$
[\mathrm{H}]\{\mathrm{U}\}=[\mathrm{G}]\{\mathrm{P}\}
$$

é possível rearranjar as colunas das matrizes $[\mathrm{H}]$ e $[\mathrm{G}]$, obtendo-se:

$$
[\mathrm{B}]\{\mathrm{VP}\}=[\mathrm{A}]\{\mathrm{M}\}
$$

onde $\{\mathrm{VP}\}$ é um vetor contendo os valores prescritos e $\{\mathrm{M}\}$ é o vetor de incógnitas elásticas. Portanto:

$$
\{\mathrm{M}\}=[\mathrm{A}]^{-1}([\mathrm{~B}]\{\mathrm{VP}\})=[\mathrm{A}]^{-1}\{\mathrm{~F}\}
$$

\section{Equação de Tensões}

As tensões em pontos internos são calculadas pelos somatórios da eq. (7.39), onde deslocamentos e forças de superficie nodais são multiplicados pelas matrizes de influência correspondentes. 


\section{A.2 Análise Não-linear}

\section{Equação de Deslocamentos}

A partir do sistema de equações (8.32):

$$
[\mathrm{H}]\left\{\mathrm{U}_{-} \mathrm{V}\right\}=[\mathrm{G}]\left\{\mathrm{P}_{-} \mathrm{V}\right\}+[\mathrm{K}]\{\mathrm{Q}\}
$$

onde $\left\{U_{-} V\right\}$ e $\left\{P_{-} V\right\}$ são os vetores de deslocamentos e forças de superfície verdadeiros, ou seja, levando-se em consideração o efeito dos quadripolos aplicados (vetor $\{\mathrm{Q}\}$ ). Após o rearranjamento:

$$
[\mathrm{B}]\left\{\mathrm{VP} \_\mathrm{V}\right\}=[\mathrm{A}]\{\mathrm{X}\}+[\mathrm{K}]\{\mathrm{Q}\}
$$

ou

$$
[\mathrm{A}]\{\mathrm{X}\}=[\mathrm{B}]\{\mathrm{VP}+\mathrm{V}\}-[\mathrm{K}]\{\mathrm{Q}\}
$$

onde $\{\mathrm{X}\}$ é o vetor de incógnitas verdadeiras. Definindo-se

$$
\left\{\mathrm{F}_{-} \mathrm{V}\right\}=[\mathrm{B}]\left\{\mathrm{VP} \_\mathrm{V}\right\}=[\mathrm{B}] \alpha\{\mathrm{VP}\}=\alpha[\mathrm{B}]\{\mathrm{VP}\}=\alpha\{\mathrm{F}\}
$$

onde $\alpha$ representa o somatório dos incrementos percentuais de carga. Substituindo-se o resultado em (A.6), tem-se:

$$
\begin{aligned}
\{\mathrm{X}\} & =[\mathrm{A}]^{-1}(\alpha\{\mathrm{F}\}-[\mathrm{K}]\{\mathrm{Q}\})=\alpha[\mathrm{A}]^{-1}\{\mathrm{~F}\}-[\mathrm{A}]^{-1}[\mathrm{~K}]\{\mathrm{Q}\}= \\
& =\alpha\{\mathrm{M}\}-[\mathrm{R}]\{\mathrm{Q}\}
\end{aligned}
$$

onde

$$
\{\mathrm{M}\}=[\mathrm{A}]^{-1}\{\mathrm{~F}\} \quad \text { e } \quad[\mathrm{R}]=[\mathrm{A}]^{-1}[\mathrm{~K}]
$$

\section{Equação de Tensões}

A partir da eq. (8.48):

$$
\{\sigma\}=-\left[\mathrm{H}^{\prime \prime \prime}\right]\left\{\mathrm{U}_{-} \mathrm{V}\right\}+\left[\mathrm{G}^{\prime \prime \prime}\right]\left\{\mathrm{P}_{-} \mathrm{V}\right\}+\left[\mathrm{K}^{\prime \prime \prime}\right]\{\mathrm{Q}\},
$$

que é o mesmo que

$$
\{\sigma\}+\left[\mathrm{H}^{\prime \prime \prime}\right]\left\{\mathrm{U}_{-} \mathrm{V}\right\}=\left[\mathrm{G}^{\prime \prime \prime}\right]\left\{\mathrm{P}_{-} \mathrm{V}\right\}+\left[\mathrm{K}^{\prime \prime}\right]\{\mathrm{Q}\} .
$$

Após o rearranjamento:

$$
\{\sigma\}+\left[\mathrm{B}^{\prime \prime \prime}\right]\{\mathrm{VP}\}=\left[\mathrm{A}^{\prime \prime \prime}\right]\{\mathrm{X}\}+\left[\mathrm{K}^{\prime \prime \prime}\right]\{\mathrm{Q}\} .
$$




\section{Definindo-se}

$$
\left\{\mathrm{F}^{\prime \prime \prime} \mathrm{V}_{-}\right\}=\left[\mathrm{B}^{\prime \prime \prime}\right]\left\{\mathrm{VP}_{-} \mathrm{V}\right\}=\left[\mathrm{B}^{\prime \prime \prime}\right] \alpha\{\mathrm{VP}\}=\alpha\left[\mathrm{B}^{\prime \prime \prime}\right]\{\mathrm{VP}\}=\alpha\left\{\mathrm{F}^{\prime \prime \prime}\right\}
$$

e substituindo-se em (A.12) o vetor $\{X\}$ definido em (A.8), tem-se:

$$
\{\sigma\}+\alpha\left\{\mathrm{F}^{\prime \prime \prime}\right\}=\left[\mathrm{A}^{\prime \prime \prime}\right](\alpha\{\mathrm{M}\}-[\mathrm{R}]\{\mathrm{Q}\})+\left[\mathrm{K}^{\prime \prime \prime}\right]\{\mathrm{Q}\}
$$

de onde:

$$
\begin{aligned}
\{\sigma\} & =\alpha\left(\left[\mathrm{A}^{\prime \prime \prime}\right]\{\mathrm{M}\}-\left\{\mathrm{F}^{\prime \prime \prime}\right\}\right)+\left(\left[\mathrm{K}^{\prime \prime \prime}\right]-\left[\mathrm{A}^{\prime \prime \prime}\right][\mathrm{R}]\right)\{\mathrm{Q}\}= \\
& =\alpha\{\mathrm{N}\}+[\mathrm{S}]\{\mathrm{Q}\}
\end{aligned}
$$

onde

$$
\{\mathrm{N}\}=\left[\mathrm{A}^{\prime \prime \prime}\right]\{\mathrm{M}\}-\left\{\mathrm{F}^{\prime \prime \prime}\right\} \quad \text { e } \quad[\mathrm{S}]=\left[\mathrm{K}^{\prime \prime \prime}\right]-\left[\mathrm{A}^{\prime \prime \prime}\right][\mathrm{R}] \text {. }
$$

(A.16a,b) 


\section{B Algoritmo Utilizado na Análise}

Início

1 Entrada de Dados:

1.1 Parâmetros Básicos: ne, npi, nnd, E, $v, f_{\mathrm{t}}, \omega_{\mathrm{c}}$, lef, ninc, exemplo, tipo

1.2 Alocação Semi-dinâmica de Memória

$\{\mathrm{ND}\},\{\mathrm{NF}\},\{\mathrm{INCINI}\},\{\mathrm{XN}\},\{\mathrm{YN}\},\{\mathrm{XC}\},\{\mathrm{YC}\},\{\mathrm{XI}\},\{\mathrm{YI}\},\{\mathrm{U}\},\left\{\mathrm{U} \_\mathrm{V}\right\},\{\mathrm{P}\},\left\{\mathrm{P} \_\mathrm{V}\right\},\{\mathrm{F}\}$,

$\{\mathrm{F} 3 \mathrm{~L}\},\{\mathrm{M}\},\{\mathrm{X}\},\{\mathrm{N}\},\{\mathrm{LAMBDA}\},\{\mathrm{Q}\},\{\mathrm{RQ}\},\{\mathrm{SQ}\},\{$ SIGMACON $\},\{$ SIGMACON_V, ,

\{SIGMAFRA\}, \{WFRA\}, \{SIGMAPI\}, \{DELTAPI\}, \{ELEM $\},[$ CONDCON], [CONE $],[M C]$,

[VP], [G], [G3L], [H], [H3L], [K], [K3L], [A], [A3L], [R], [S]

1.3 Correção dos Valores de $\mathrm{E}$ e $\vee$ Para o Caso de Estado Plano de Tensão

$\mathrm{E}^{\prime}=(1+2 v)^{*} \mathrm{E} /(1+v)^{2} \quad v^{\prime}=v /(1+v)$

1.4 Impressão dos Dados Iniciais Para a Representação Gráfica: ne, npi, nnd, ninc

1.5 Incrementos de Solicitação: \{LAMBDA\}

1.6 Coordenadas Nodais: $\{\mathrm{XN}\},\{\mathrm{YN}\}$

1.7 Condições de Contorno: [CONDCON], [VP]

1.8 Coordenadas dos Pontos Internos, se houver: $\{\mathrm{XI}\},\{\mathrm{YI}\}$

1.9 Nós Duplos: $\{$ ND $\}$

1.10 Conectividades: [CONEC]

2 Análise Elástica Linear

2.1 Cálculo das Matrizes $[\mathrm{H}]$ e $[\mathrm{G}]$ :

A Determinação do Tipo e da Posição dos Pontos de Colocação

B Cálculo das Coordenadas dos Pontos de Colocação

C Inicialização

D Cálculo e Encaixe das Matrizes de Influência e [CFI]

2.2 Cálculo das Incógnitas Elásticas no Contorno:

A Reordenamento das Colunas Entre as Matrizes [H] e [G]

$\mathrm{B}[\mathrm{A}] \leftarrow[\mathrm{G}]$

$\mathrm{C}\{\mathrm{F}\} \leftarrow[\mathrm{H}]^{*}\{\mathrm{VP}\},\{\mathrm{U}\} \leftarrow\{\mathrm{F}\}$

D Resolução do Sistema $[A]^{*}\{M\}=\{F\}$ (Armazenado na Forma $[G]^{*}\{X\}=\{U\}$ )

$\mathrm{E}\{\mathrm{M}\} \leftarrow\{\mathrm{U}\}$

2.3 Organização dos Valores Elásticos Totais de Forças de Superficie e Deslocamentos do Contorno: $\{P\}$ e $\{U\}$

2.4 Cálculo das Tensões Elásticas Totais no Contorno:

$\{$ SIGMACON $\} \leftarrow f(\{\mathrm{U}\},\{\mathrm{P}\})$

2.5 Cálculo de Deslocamentos e Tensões Elásticas Totais nos Pontos Internos, se houver:

$\{$ DELTAPI $\} \leftarrow \Sigma\left[\mathrm{HW}^{\wedge}\right]\left\{\mathbf{u}^{\prime}+\Sigma[\mathrm{GW}]\{\mathrm{p}\} ; \quad\{\right.$ SIGMAPI $\} \leftarrow-\left[\mathrm{H}^{\prime}\right]\{\mathrm{u}\}+\left[\mathrm{G}^{\prime}\right]\{\mathrm{P}\}$

3 Impressão dos Resultados da Análise Elástica Linear

$\{\mathrm{U}\},\{\mathrm{P}\},\{$ SIGMACON\}, \{DELTAPI], \{SIGMAPI\}

4 Análise do Processo de Fraturamento

4.1 Inicialização das Variáveis Relacionadas:

nef $\leftarrow 0,\{\mathrm{NF}\} \leftarrow\{0\}, \mathrm{NF}[\mathrm{i}] \leftarrow 1$, se i corresponde a nó duplo de vértice ou a nó não-fraturável, $\{\mathrm{INCINI}\} \leftarrow\{1\},\{$ SIGMAFRA $\} \leftarrow\{0\},\{$ SQ $\} \leftarrow\{0\},\{$ WFRA $\} \leftarrow\{0\}$,

LAMBDA $[i] \leftarrow$ LAMBDA $[\mathrm{i}] / \Sigma($ LAMBDA[i] $),\left\{\mathrm{P}_{-} \mathrm{V}\right\} \leftarrow\{0\},\left\{\mathrm{U}_{-} \mathrm{V}\right\} \leftarrow\{0\}$,

$\{$ SIGMACON_V $\} \leftarrow\{0\}, \alpha \leftarrow 0$

4.2 Inversão Local da Matriz [A]

Para inc de 0 a ninc-1 (Incremento de Solicitação)

| 4.3 Aplicação do Incremento de Solicitação:

$\alpha \leftarrow \alpha+\lambda[$ inc]

$\{\mathrm{X}\} \leftarrow \alpha^{*}\{\mathrm{M}\}-[\mathrm{R}]^{*}\{\mathrm{SQ}\}$

4.4 Determinação dos Valores Verdadeiros de Força de Superfície e Deslocamento no Contorno: Para i de 0 a nn-1 (Nó) 


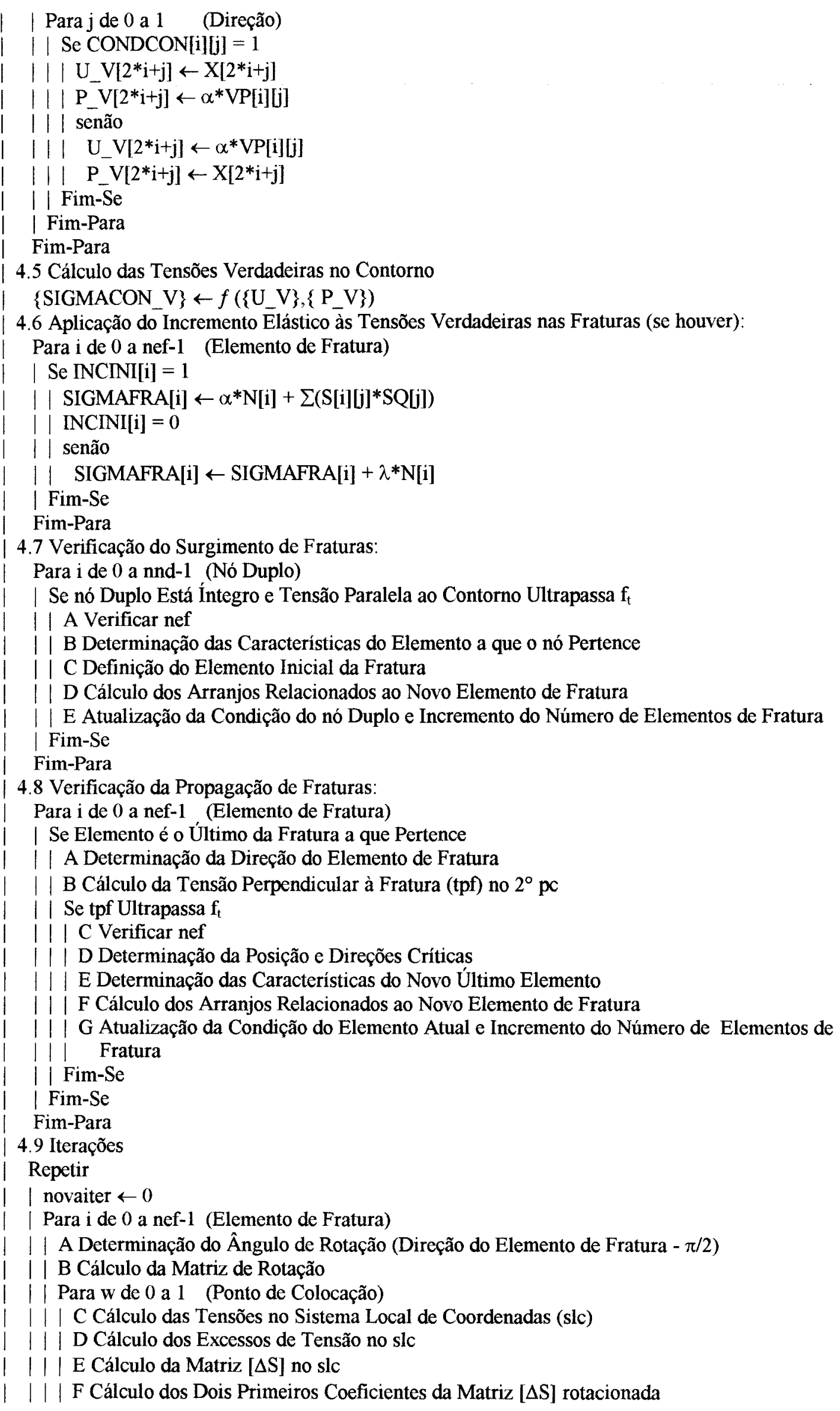


| | | G Cálculo dos Quadripolos equivalentes aos Excessos de Tensão, no slc

| || H Atualização da Abertura de Fratura com a Aplicação dos Quadripolos com Sinal

| | | Trocado

| | I Cálculo dos Quadripolos equivalentes no Sistema Global de Coordenadas

| | Fim-Para

| || J Verificação do Critério de Parada:

| || Se (Tensão Normal em Qualquer dos Doi Pontos de Colocação) > tol

| | | | novaiter $\leftarrow 1$

||||$\{Q\} \leftarrow-\{\Delta Q\}$

| || | senão

| ||$\quad\{Q\} \leftarrow\{0\}$

||||$\{\mathrm{RQ}\} \leftarrow-\{\Delta \mathrm{Q}\}$

| || Fim-Se

| Fim-Para

| L Aplicação dos Quadripolos Equivalentes Como Incremento Elástico ou Como Resíduo e

Acúmulo dos Quadripolos Aplicados:

Se novaiter $=1$

| | SIGMAFRA[i] $\leftarrow$ SIGMAFRA $[\mathrm{i}]+\Sigma \mathrm{S}[\mathrm{i}][\mathrm{j}] * \mathrm{Q}[\mathrm{j}]$

$\mid \quad\{\mathrm{SQ}\} \leftarrow\{\mathrm{SQ}\}+\{\mathrm{Q}\}$

| | | senão

| | | $\mid$ SIGMAFRA $[\mathrm{i}] \leftarrow$ SIGMAFRA[i] $+\Sigma \mathrm{S}[\mathrm{i}][\mathrm{j}] * \mathrm{RQ}[\mathrm{j}]$

| $\mid \quad\{\mathrm{SQ}\} \leftarrow\{\mathrm{SQ}\}+\{\mathrm{RQ}\}$

I I Fim-Se

Enquanto novaiter $=1$

4.10 Saída de Dados Para o Gráfico P x D

Fim-Para

5 Impressão do Restante dos Dados Utilizados na Representação Gráfica

$\{\mathrm{XN}\},\{\mathrm{YN}\},[\mathrm{CONDCON}],[\mathrm{VP}],\{\mathrm{XI}\},\{\mathrm{YI}\}$ (se houver), $\{\mathrm{ND}\},[\mathrm{CONEC}],\{\mathrm{NF}\}$, nef, $\{\mathrm{ELEM}\},\{\mathrm{U}\},\left\{\mathrm{U}_{-} \mathrm{V}\right\}$

6 Liberação da Memória Alocada Semi-dinamicamente

Fim 


\section{Organização do Projeto MEFRECLI}

A interdependência entre os arquivos constituintes do projeto MEFRECLI é a seguinte:

\begin{tabular}{|l|c|c|c|c|c|c|c|l|}
\hline mefrecli & -- & + & -- & $>$ & mefre01.c & & & \\
\hline & & $\mid$ & & & & & & \\
\hline & & + & -- & $>$ & mefre02.c & -- & $>$ & mefre02.h \\
\hline & & & & & & & & \\
\hline & + & -- & $>$ & mefre03.c & -- & $>$ & mefre03.h \\
\hline & & 1 & & & & & & \\
\hline & & + & -- & $>$ & mefre04.c & -- & $>$ & mefre04.h \\
\hline & & 1 & & & & & \\
\hline & & + & --- & $>$ & mefre05.c & -- & $>$ & mefre05.h \\
\hline
\end{tabular}

TABELA C.1 - Relacionamento entre os arquivos do projeto computacional desenvolvido.

Os arquivos do projeto encontram-se em disquete disponivel na Biblioteca do Departamento de Engenharia de Estruturas, da Escola de Engenharia de São Carlos, da Universidade de São Paulo. 


\section{Códigos-Fonte do Programa MEFRECLI}

\section{D.1 Mefre01.c}

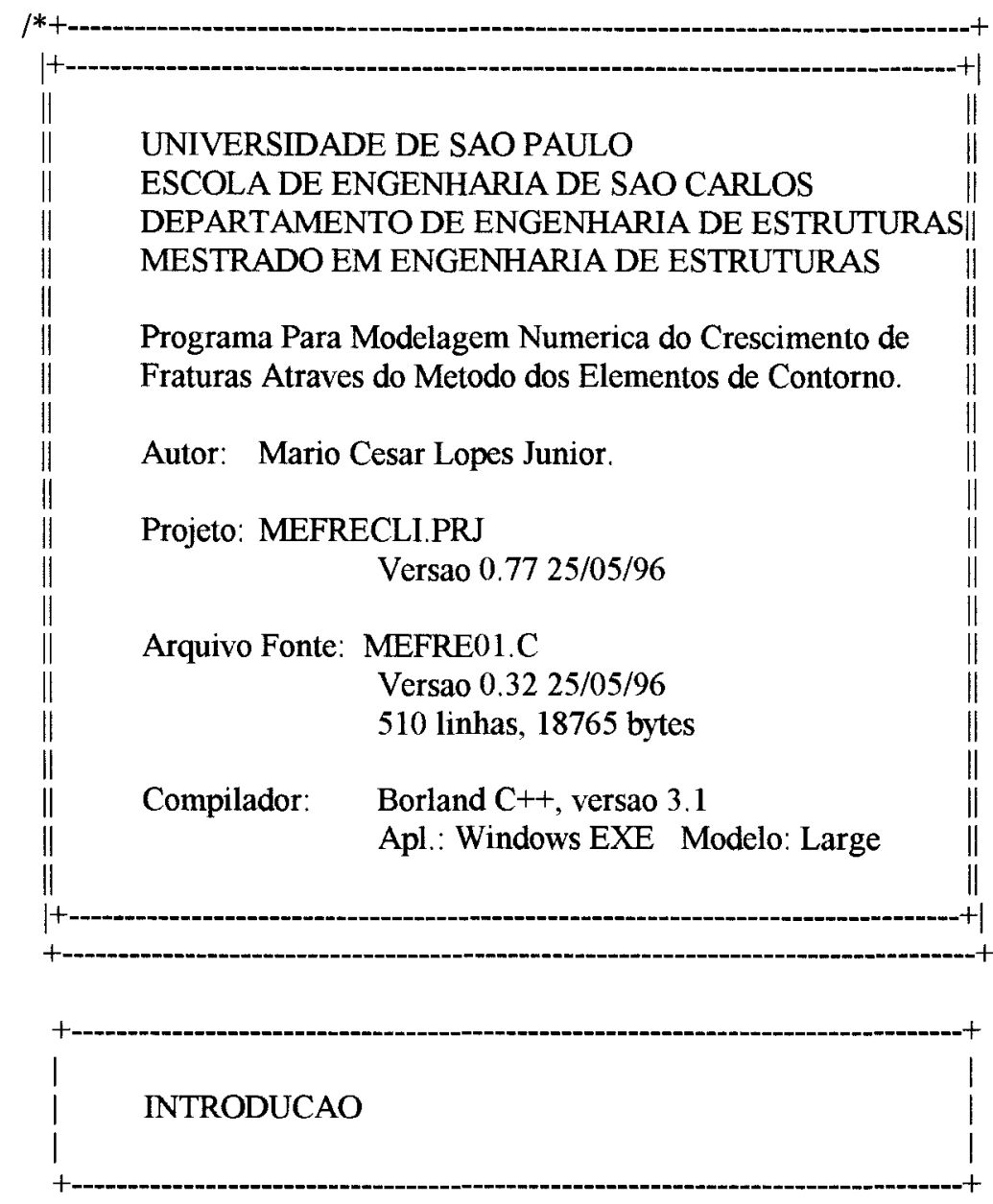

Foram utilizadas aspas simples ('), para representar a acentuacao, apenas nos pontos dos comentarios onde a pronuncia da letra 'e' ou a existencia de crase pudesse dificultar o entendimento dos mesmos.

O programa MEFRECLI.C ((ME)ecanica da (FR)atura usando (E)lementos de (C)ontorno (L)ineares (I)soparametricos) resolve problemas bidimensionais de mecanica da fratura atraves do metodo dos elementos de contorno.

O contorno e' discretizado atraves de elementos lineares isoparametricos. A fratura e' simulada atraves de elementos do mesmo tipo, porem ficticios e, portanto, nao incorporados ao contorno.

$\mathrm{O}$ diagrama de fluxo funcional nivelar, que mostra o relacionamento entre as funcoes, e' o seguinte:
Principal
2. Nivel
3. Nivel
4. Nivel
5. Nivel

MEFRE01.C MEFRE02.C MEFRE03.C MEFRE04.C MEFRE05.C




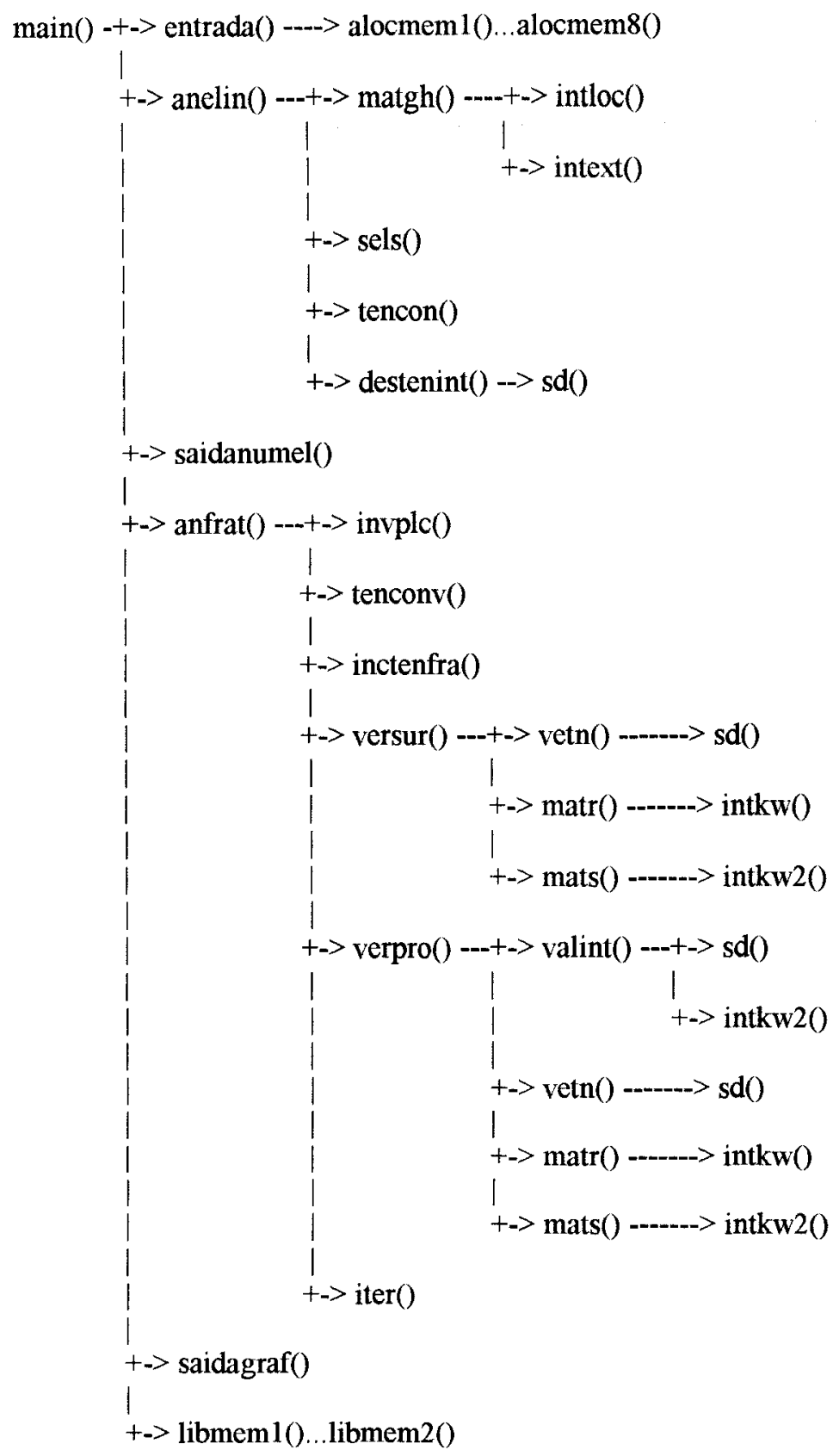

\section{DOCUMENTACAO INTERNA}

O que segue, $\mathrm{e}^{\prime}$ uma descricao das variaveis utilizadas no programa com enfase nos tipos utilizados e espacos necessarios para armazenamento.

\section{A) Variavel Caractere}


$\operatorname{ch}$

Utilizada para pausa durante a execucao.

B) Variaveis Inteiras

$\begin{array}{ll}\text { ne: } & \text { Numero de elementos de contorno. } \\ \text { npi: } & \text { Numero de pontos internos. } \\ \text { nnd: } & \text { Numero de nos duplos. } \\ \text { nn: } & \text { Numero de nos. } \\ \text { nef: } & \text { Numero de elementos de fratura. } \\ \text { inc: } & \text { Indexador para os incrementos de solicitacao. } \\ \text { ninc: } & \text { Numero de incrementos em que a aplicacao da solicitacao e' } \\ & \text { dividida. } \\ \text { pos: } & \text { Indicador da posicao do ponto de colocacao no elemento, lo- } \\ \text { i, j, k, w: } & \text { cal. } \\ \text { exemplo: } & \text { Indexadores. } \\ \text { tipo: } & \text { Tipo do problema (1 = tensao plana, } 0=\text { deformacao plana) } \\ \text { auxl, aux }: & \text { Auxiliares, locais. } \\ \text { aux6: } & \text { Idem. } \\ \text { pl: } & \text { Linha do pivo na estrategia de pivoteamento parcial do me- } \\ & \text { todo de eliminacao de Gauss (MEG), local. } \\ \text { novaiter: } & \text { Sinalizador indicando a necessidade de uma nova iteracao, } \\ & \text { local. } \\ \text { nsubel: } & \text { Numero de sub-elementos empregados no calculo de uma inte- } \\ & \text { gral quase singular, local. }\end{array}$

C) Variaveis Reais

Todas foram armazenadas com precisao dupla.

\begin{tabular}{|c|c|}
\hline E: & Modulo de elasticidade. \\
\hline GE: & Modulo de cisalhamento. \\
\hline NI: & Coeficiente de Poisson para deformacao plana. \\
\hline $\mathrm{ft}:$ & Resistencia 'a tracao do material. \\
\hline wc: & Abertura critica de fratura. \\
\hline alfa: & Acumulador para os incrementos relativos de solicitacao. \\
\hline r: & Modulo do vetor posicao. \\
\hline drx,dry,drn: & $\begin{array}{l}\text { Derivadas do vetor posicao em relacao a } \mathrm{x}, \mathrm{y} \text { e 'a normal ao } \\
\text { elemento, respectivamente. }\end{array}$ \\
\hline $\mathbf{x}, \mathbf{y}:$ & $\begin{array}{l}\text { Coordenadas (abscissa e ordenada, respectivamente) do ponto } \\
\text { de integracao ao longo do elemento de contorno. }\end{array}$ \\
\hline $\mathrm{xc}, \mathrm{yc}:$ & $\begin{array}{l}\text { Coordenadas (abscissa e ordenada, respectivamente) do ponto } \\
\text { de colocacao, parametros formais. }\end{array}$ \\
\hline xef,yef: & $\begin{array}{l}\text { Coordenadas (abscissa e ordenada, respectivamente) do ponto } \\
\text { de colocacao situado no elemento de fratura, locais. }\end{array}$ \\
\hline xi,yi: & $\begin{array}{l}\text { Coordenadas (abscissa e ordenada, respectivamente) do ponto } \\
\text { situado 'a frente da extremidade de fratura, locais. }\end{array}$ \\
\hline $\mathrm{x} 1, \mathrm{y} 1, \mathrm{x} 2, \mathrm{y} 2$ : & $\begin{array}{l}\text { Coordenadas (abscissa e ordenada, respectivamente) nodais } \\
\text { do elemento, locais ou parametros formais. }\end{array}$ \\
\hline xlint, ylint: & $\begin{array}{l}\text { Coordenadas do primeiro ponto de um sub-elemento para } \\
\text { calculo de integrais quase-singulares, locais. }\end{array}$ \\
\hline x2int, y2int: & $\begin{array}{l}\text { Coordenadas do ultimo ponto de um sub-elemento para o cal } \\
\text { culo de integrais quase-singulares, locais. }\end{array}$ \\
\hline fi1,fi2: & Funcoes de forma para interpolacao em termos de CSI. \\
\hline fi3,fi4: & $\begin{array}{l}\text { Funcoes de forma para interpolacao dos quadripolos em ter- } \\
\text { mos de CSI. }\end{array}$ \\
\hline 1: & Comprimento de qualquer elemento de contorno. \\
\hline & Comprimento padrao dos elementos de fratura. \\
\hline
\end{tabular}




\begin{tabular}{|c|c|}
\hline jac: & Jacobiano. \\
\hline enex,eney: & Componentes do versor normal ao elemento. \\
\hline aux3, aux7: & Auxiliares, locais. \\
\hline tol: & Zero numerico utilizado no MEG, local. \\
\hline pivo: & $\begin{array}{l}\text { Pivo utilizado na estrategia de pivoteamento parcial do } \\
\text { MEG, local. }\end{array}$ \\
\hline c: & Pivo utilizado na diagonalizacao do MEG, local. \\
\hline a: & $\begin{array}{l}\text { Distancia do ponto de colocacao ao inicio do elemento, lo- } \\
\text { cal. }\end{array}$ \\
\hline csib: & Coordenada homogenea do ponto de colocacao, local. \\
\hline sigmal1: & $\begin{array}{l}\text { Tensao nodal (sigma_x) no sistema local de coordenadas, } \\
\text { local. }\end{array}$ \\
\hline sigma12: & $\begin{array}{l}\text { Tensao nodal (tau_xy) no sistema local de coordenadas, lo- } \\
\text { cal. }\end{array}$ \\
\hline sigma22: & $\begin{array}{l}\text { Tensao nodal (sigma_y) no sistema local de coordenadas, lo- } \\
\text { cal. }\end{array}$ \\
\hline e22: & $\begin{array}{l}\text { Deformacao especifica na direcao tangente ao elemento, lo- } \\
\text { cal. }\end{array}$ \\
\hline \multicolumn{2}{|c|}{$\begin{array}{l}\text { ux1,uyl:Deslocamentos do primeiro no do elemento, no sistema global } \\
\text { de coordenadas, locais. }\end{array}$} \\
\hline \multicolumn{2}{|c|}{ ux2,uy2:Idem, para o segundo no. } \\
\hline $\operatorname{csn}, \operatorname{sn}:$ & $\begin{array}{l}\text { Co-senos diretores da normal ao elemento (componentes do } \\
\text { versor normal) ou razoes trigonometricas de algum angulo, } \\
\text { locais. }\end{array}$ \\
\hline px,py: & $\begin{array}{l}\text { Forcas de superficie nodais no sistema global de coordena- } \\
\text { das, locais. }\end{array}$ \\
\hline $\mathbf{t} 1, \mathrm{t} 2:$ & $\begin{array}{l}\text { Forcas de superficia nodais no sistema local de coordena- } \\
\text { das, mencionadas em comentarios. }\end{array}$ \\
\hline dl: & $\begin{array}{l}\text { Distancia do ponto de colocacao ao inicio do elemento onde } \\
\text { sera feita a integracao. Utilizada na avaliacao da quase- } \\
\text { singularidade, local. }\end{array}$ \\
\hline d2: & $\begin{array}{l}\text { Distancia do ponto de colocacao ao final do elemento onde } \\
\text { sera feita a integracao. Utilizada na avaliacao da quase- } \\
\text { singularidade, local. }\end{array}$ \\
\hline alfaint: & $\begin{array}{l}\text { Angulo utilizado na determinacao da direcao do elemento a- } \\
\text { dicional de fratura, local. }\end{array}$ \\
\hline sigmamax: & $\begin{array}{l}\text { Maxima tensao principal nos pontos 'a frente da extremidade } \\
\text { de uma fratura, local. }\end{array}$ \\
\hline alfamax: & $\begin{array}{l}\text { Algulo formado entre o elemento adicional de fratura (que } \\
\text { contem o ponto onde sigmamax ocorre) e o ultimo elemento } \\
\text { da mesma, local. }\end{array}$ \\
\hline sl00, s111: & $\begin{array}{l}\text { Primeiros coeficientes da diagonal principal da matriz } \\
\text { [DELTAS] rotacionada, locais. }\end{array}$ \\
\hline
\end{tabular}

D) Variavel Composta Heterogenea

ELEMFRA: Gabarito de estrutura para os elementos de fratura. ult: Indica se o elemento e' o ultimo da fratura a que pertence. Inteiro.

$\mathrm{x} 1, \mathrm{yl}$ : Coordenadas do ponto inicial do elemento. Reais, precisao dupla.

$\mathrm{x} 2, \mathrm{y} 2$ : Coordenadas do ponto final do elemento. Reais, precisao dupla.

E) Variaveis Compostas Homogeneas (Arranjos) Unidimensionais (Vetores) $\mathrm{Ca}$ ractere

FILENAME: [30] Nome utilizado para o arquivo de entrada ou para os 
arquivos de saida.

TEXTO: [82] Qualquer linha de texto presente no arquivo de entrada, local.

F) Variaveis Compostas Homogeneas Unidimensionais Inteiras

ND: [max_nnd] Nos duplos

NF: [max_nnd] Nos fraturados

INCINI: [max_nef] Vetor indicando se o proximo incremento de solicitacao, a ser aplicado ao elemento de fratura, e' o primeiro.

AUX5: [] Auxiliar, local.

G) Variaveis Compostas Homogeneas Unidimensionais Reais

Todas foram armazenadas com precisao dupla.

\begin{tabular}{|c|c|}
\hline $\mathrm{XN}$ : & [max_nn] Abscissas dos nos. \\
\hline YN: & [max_nn] Ordenadas dos nos. \\
\hline $\mathrm{XC}:$ & [max_nn] Abscissas dos pontos de colocacao. \\
\hline YC: & [max nn] Ordenadas dos pontos de colocacao. \\
\hline XI: & [max_npi] Abscissas dos pontos internos. \\
\hline YI: & [max_npi] Ordenadas dos pontos internos. \\
\hline $\mathrm{U}:$ & $\begin{array}{l}\text { [2*max_nn] Deslocamentos elasticos totais dos nos do con- } \\
\text { torno. }\end{array}$ \\
\hline U_V: & [2*max_nn] Deslocamentos verdadeiros dos nos do contorno. \\
\hline P: & $\begin{array}{l}\text { [2*max_nn] Forcas de superficie elasticas totais nos nos do } \\
\text { contorno. }\end{array}$ \\
\hline P_V: & $\begin{array}{l}\text { [2*max_nn] Forcas de superficie verdadeiras nos nos do con- } \\
\text { torno. }\end{array}$ \\
\hline F: & {$\left[2^{*} \max \_n n\right]$ Vetor $\{F\}$ dos termos independentes. } \\
\hline F3L: & [6*max_nef] Vetor $\left\{\mathrm{F}^{\prime \prime}\right\}$ \\
\hline M: & $\begin{array}{l}\text { [2*maxnn] Vetor }\{M\} \text { correspondente 'a parte elastica total } \\
\text { das incognitas do contorno. }\end{array}$ \\
\hline $\mathrm{X}:$ & $\begin{array}{l}\text { [2*max_nn] Vetor contendo os valores verdadeiros das incog- } \\
\text { nitas no contorno. }\end{array}$ \\
\hline $\mathrm{N}:$ & $\begin{array}{l}\text { [6*max_nef] Vetor contendo os valores elasticos totais das } \\
\text { tensoes nas fraturas. }\end{array}$ \\
\hline LAMBDA: & [max_ninc] Vetor dos incrementos de solicitacao. \\
\hline Q: $\quad$ & [6*max_nef] Vetor de quadripolos. \\
\hline RQ: & [6*max_nef] Vetor dos residuos de quadripolos. \\
\hline SQ: & [6*max_nef] Vetor de quadripolos acumulados. \\
\hline SIGMACON: & $\begin{array}{l}\text { [6*max_nn] Valores elasticos totais das tensoes globais (3) } \\
\text { e principais (2) e valor da direcao principal nos nos do } \\
\text { contorno. }\end{array}$ \\
\hline \multicolumn{2}{|r|}{$\begin{array}{l}\text { [4*max_nn] Valores verdadeiros das tensoes globais }(3) \text { e da } \\
\text { componente de tensao paralela ao contorno nos nos do con- } \\
\text { torno. }\end{array}$} \\
\hline SIGMAFRA: & $\begin{array}{l}\text { [6*max_nef] Valores verdadeiros das tensoes globais nos } \\
\text { elementos de fratura ( } 6 \text { por elemento). }\end{array}$ \\
\hline WFRA: & $\begin{array}{l}{[2 * \max \text { nef] Aberturas nos elementos de fratura ( } 2 \text { por ele- }} \\
\text { mento). }\end{array}$ \\
\hline SIGMAPI: & $\begin{array}{l}\text { [6*max npi] Tensoes globais (3) e principais (2) e direcao } \\
\text { principal nos pontos internos. }\end{array}$ \\
\hline DELTAPI: & $\begin{array}{l}\text { [2*max_npi] Deslocamentos nos pontos internos ( } 2 \text { por } \\
\text { ponto). }\end{array}$ \\
\hline
\end{tabular}

CSI: [12] Coordenadas homogeneas dos pontos utilizados para a quadratura de Gauss. 
OME: [12] Fatores de ponderacao para a quadratura de Gauss.

AUX4: [ ] Auxiliar, local.

UJ, PJ: [4] Deslocamentos e forcas de superficie nodais do elemento j.

DELTASIGMA: [4] Excessos de tensao no elemento de fratura.

DELTAQ: [6] Quadripolos correspondentes aos excessos de tensao existentes em um elemento de fratura, posteriormente expandidos.

SIGMAINT: [21] Vetor utilizado na determinacao das tensoes 'a frente da extremidade de fratura.

H) Variavel Composta Homogenea Unidimensional Estrutura

ELEM: [max_nef] Vetor dos elementos de fratura.

I) Variaveis Compostas Homogeneas Bidimensionais (Matrizes) Inteiras

CONDCON: [max_nn][2] Condicoes de contorno dos nos.

CONEC: [max_ne][2] Conectividades.

MC: [max_nn][2] Matriz de colocacao.

J) Variaveis Compostas Homogeneas Bidimensionais Reais

Todas armazenadas com precisao dupla.

CFI: $\quad$ [2][4] Matriz-produto da matriz [C] pela matriz [FI].

GW: $\quad$ [2][4] Matriz de influencia para o calculo da matriz [G].

HW: $\quad$ [2][4] Matriz de influencia para o calculo da matriz [H].

$\mathrm{KW}: \quad$ [2][6] Matriz de influencia para o calculo da matriz [K]

KW2: [3][6] Matriz de influencia para o calculo da matriz [K"'].

MP: $\quad[2][2]$ Matriz [P*].

MU: $\quad$ [2][2] Matriz [U*].

FI: $\quad[2][4]$ Matriz de funcoes de interpolacao para a formulacao isoparametrica.

FI2: [3][6] Matriz de funcoes de interpolacao para os quadripolos lineares.

ESSE: $\quad[3][2]$ Matriz [S] da formulacao elastica.

DE: [3][2] Matriz [D] da formulacao elastica.

KB: [2][3] Matriz utilizada no calculo da matriz [KW].

KB2: $\quad$ [3][3] Matriz utilizada no calculo da matriz [KW2].

SFI: $\quad$ [3][4] Matriz produto da matriz [ESSE] pela matriz [FI].

DFI: $\quad$ [3][4] Matriz produto da matriz [DE] pela matriz [FI].

DELTAS: [3][3] Matriz que relaciona tensoes a quadripolos em um ponto de colocacao de qualquer elemento de fratura.

ROT: [3][3] Matriz de mudanca de coordenadas (rotacao).

VP: [max_nn][2] Valores prescritos das condicoes de contorno.

G: $\quad$ [2*max_nn][2*max_nn] Matriz [G].

G3L: $\quad$ [6*max_nef][2*max_nn] Matriz [G'"], relaciona tensoes nas

fraturas a forcas de superficie no contorno.

$\mathrm{H}: \quad \quad\left[2^{*} \max \_n n\right]\left[2 * \max \_n n\right]$ Matriz $[\mathrm{H}]$.

H3L: $\quad$ [6*max_nef] [2*max_nn] Matriz [H"'], relaciona tensoes nas fraturas a deslocamentos no contorno.

$\mathrm{K}: \quad\left[2^{*} \max \_n n\right]\left[6^{*} \max \_\right.$nef] Matriz que relaciona deslocamentos $\mathrm{e}$

K3L: $\quad$ forcas de superficie do contorno a quadripolos. fratura a quadripolos.

A: $\quad\left[2 * \max \_n n\right][2 * \max n n]$ Matriz $[\mathrm{A}]$ 
A3L: $\quad$ [6*max_nef][2*max_nn] Matriz [A"'].

$\mathrm{R}: \quad\left[2^{*} \max n n\right]\left[6^{*} \max \_\right.$nef] Matriz que relaciona incognitas no contorno a quadripolos acumulados.

S: $\quad$ [6*max_nef] $6 *$ max_nef] Matriz que relaciona tensoes verdadeiras nas fraturas a quadripolos acumulados.

L) Variaveis Apontadores

FILEIN: $\quad$ Ponteiro para o arquivo de entrada.

FILEOUT: $\quad$ Ponteiro para o arquivo de saida da analise elastica.

FILEGRAF: Ponteiro para o arquivo de saida da analise do processo de

fraturamento, a ser utilizado na representacao grafica

das configuracoes final e inicial e do diagrama P x D.

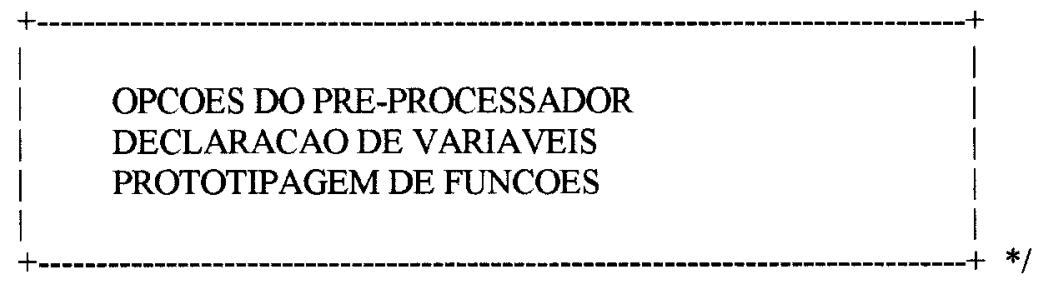

\#include $<$ stdio.h $>$

\#include $<$ conio. $\mathrm{h}>$

\#include $<$ stdlib.h $>$

\#include $<$ math.h $>$

\#define PI 3.141592653589794

\#define max_ne 60

\#define max_npi 10

\#define max_nnd 25

\#define max_nn 85

\#define max_nef 50

\#define max_ninc 1000

char ch:

int ne, npi, nnd, nn, nef, inc, ninc, i, j, k, w, exemplo, tipo;

double E, GE, NI, ft, wc, alfa, r, drx, dry, drn, $x, y, f i 1, f i 2, f i 3, f i 4$,

struct ELEMFRA

I, lef, jac, enex, eney;

\{

int ult;

double $\mathrm{xl}, \mathrm{y1}, \mathrm{x} 2, \mathrm{y} 2$;

\} ;

char FILENAME[30];

int *ND, *NF, *INCINI;

double *XN, *YN, *XC, *YC, *XI, *YI, *U, *U V, *P, *P V, *F, *F3L, *M, *X,

${ }^{*} \mathrm{~N},{ }^{*} \mathrm{LAMBDA}, * \mathrm{Q},{ }^{*} \mathrm{RQ},{ }^{*} \mathrm{SQ}, *$ SIGMACON, *SIGMACON_V, *SIGMAFRA,

*WFRA, *SIGMAPI, *DELTAPI;

double CSI $[12]=\{-0.981560634246719,-0.904117256370475$,

$-0.769902674194305,-0.587317954286617$,

$-0.367831498998180,-0.125233408511469$,

$0.125233408511469,0.367831498998180$,

$0.587317954286617,0.769902674194305$,

$0.904117256370475,0.981560634246719\}$; 
$\begin{aligned} \text { double OME }[12]= & \{0.047175336386512,0.106939325995318, \\ & 0.160078328543346,0.203167426723066, \\ & 0.233492536538355,0.249147045813403, \\ & 0.249147045813403,0.233492536538355 \\ & 0.203167426723066,0.160078328543346, \\ & 0.106939325995318,0.047175336386512\}\end{aligned}$

double UJ[4], PJ[4], DELTASIGMA[4], DELTAQ[6], SIGMAINT[21];

struct ELEMFRA *ELEM;

int $* *$ CONDCON, ${ }^{* *} \mathrm{CONEC},{ }^{* *} \mathrm{MC}$;

double CFI[2][4], GW[2][4], HW[2][4], KW[2][6], KW2[3][6], MP[2][2],

MU[2][2], FI[2][4], FI2[3][6], ESSE[3][2], DE[3][2], KB[2][3],

KB2[3][3], SFI[3][4], DFI[3][4], DELTAS[3][3], ROT[3][3];

double ${ }^{* *} \mathrm{VP},{ }^{* *} \mathrm{G},{ }^{* *} \mathrm{G} 3 \mathrm{~L},{ }^{* *} \mathrm{H},{ }^{* *} \mathrm{H} 3 \mathrm{~L},{ }^{* *} \mathrm{~K},{ }^{* *} \mathrm{~K} 3 \mathrm{~L},{ }^{* *} \mathrm{~A},{ }^{* *} \mathrm{~A} 3 \mathrm{~L},{ }^{* *} \mathrm{R},{ }^{* *} \mathrm{~S}$;

FILE *FILEIN, *FILEOUT, *FILEGRAF;

void main(int argc, char *argv[l);

void entrada(void), anelin(void), saidanumel(void), anfrat(void),

saidagraf(void), libmem1(void), libmem2(void);

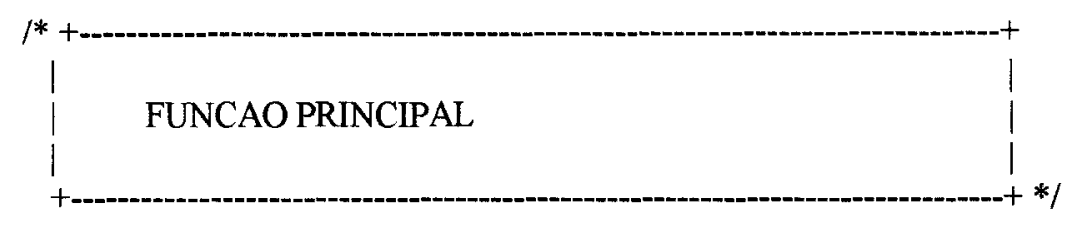

void main(int argc, char *argv[])

\{

clrscr();

/* LIMPEZA DA TELA */

/* OBTENCAO DO NOME E ABERTURA DO ARQUIVO DE ENTRADA *

if $(\operatorname{argc}<2)$

\{

puts("Digite o nome do arquivo de entrada, via inclusa (maximo de 29 "

"caracteres):");

gets(FILENAME);

if $($ FILEIN $=$ fopen(FILENAME,"rt") $)==$ NULL $)$

\{

printf("Nao e' possivel abrir o arquivo de entrada \%s. In",FILENAME);

$\mathrm{ch}=\operatorname{getch}() ; \operatorname{exit}(1)$;

\}

\}

else

if $(($ FILEIN $=$ fopen $(\operatorname{argv}[1], " r t "))==$ NULL $)$

\{

printf("Nao e' possivel abrir o arquivo de entrada \%s. In",FILENAME);

ch $=\operatorname{getch}() ; \operatorname{exit}(1)$;

\}

if $(\operatorname{argc}<3)$

\{

puts("'nDigite o nome do arquivo de saida, via inclusa (maximo de 29 "

"caracteres):");

gets(FILENAME); 


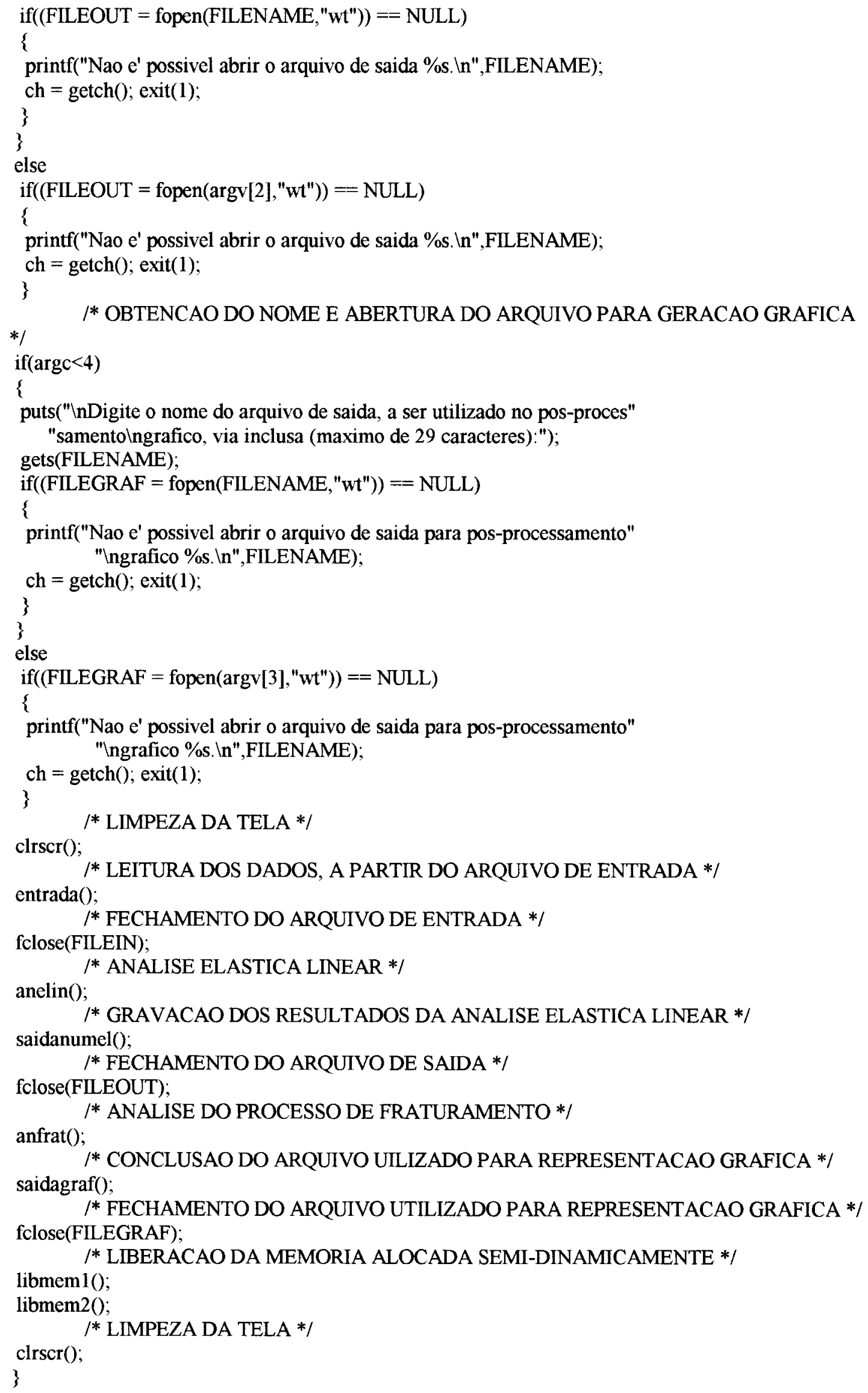




\section{D.2 Mefre02.c}

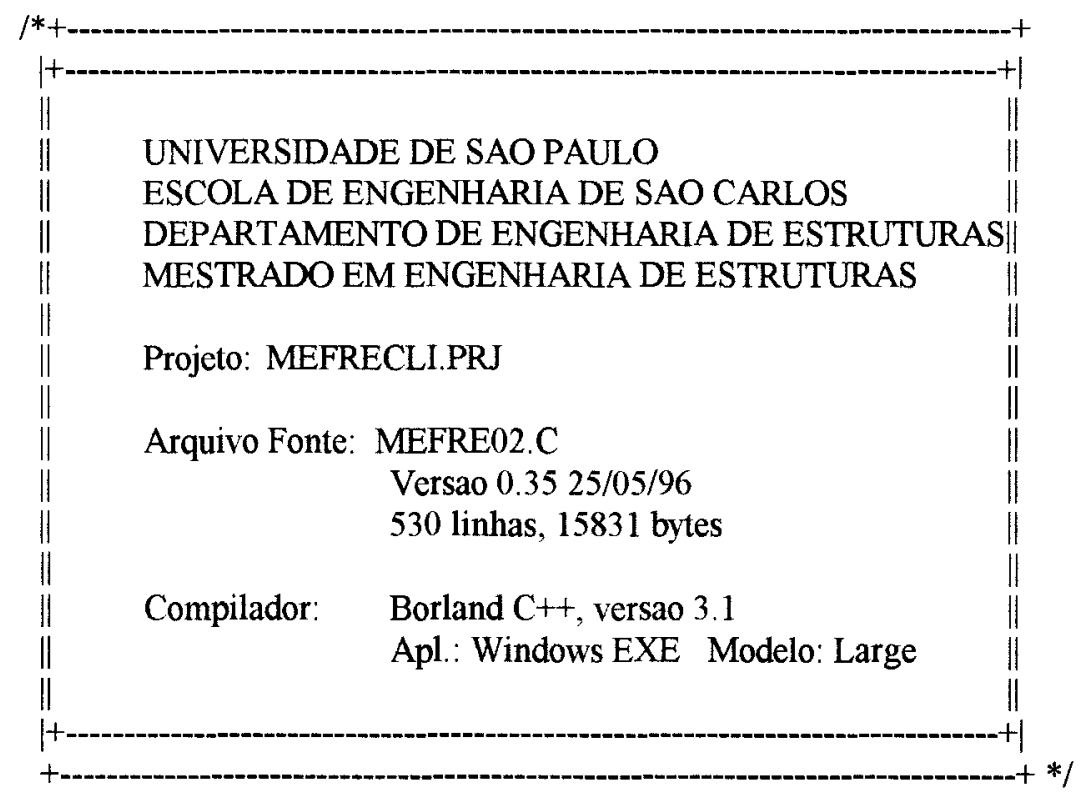

\#include $<$ stdio.h $>$ \#include $<$ conio. $\mathrm{h}>$ \#include $<$ stdlib.h $>$ \#include $<$ math. $\mathrm{h}>$ \#include "mefre02.h"

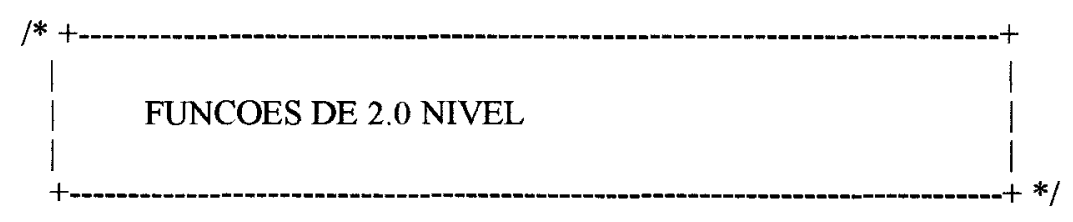

void entrada(void)

\{

char TEXTO[82]

puts("Entrada de dados... In");

/* CABECALHO DO ARQUIVO DE SAIDA */

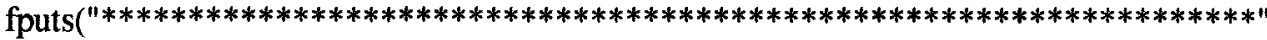

"**********,FILEOUT);

$1 *$ LINHA DE TITULO */

fgets(TEXTO,81,FILEIN);

fprintf(FILEOUT, "Inไn\%s", TEXTO);

/* LINHA DE COMENTARIO */

fgets(TEXTO,81,FILEIN);

fprintf(FILEOUT, "\%s\n",TEXTO);

fputs $(" * * * * * * * * * * * * * * * * * * * * * * * * * * * * * * * * * * * * * * * * * * * * * * * * * * * * * * * * * * * * * * * * * * * * * * "$

"*********",FILEOUT);

/* PARAMETROS BASICOS */

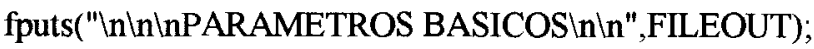

fscanf(FILEIN, "\%d \%d \%dln",\&ne,\&npi,\&nnd);

fscanf(FILEIN, "\%lf \%lfn",\&E,\&NI);

fscanf(FILEIN, "\%lf \%lfn", \&ft,\&wc); 


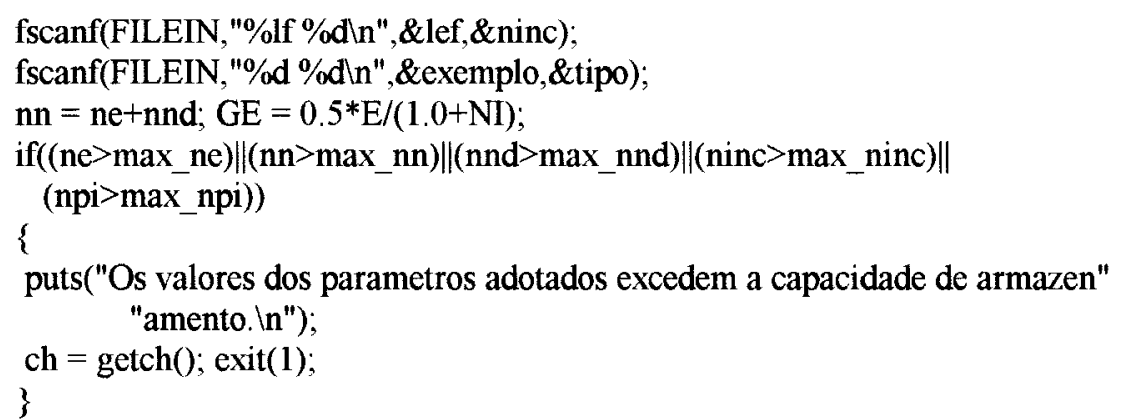

alocmem 1()

alocmem2();

alocmem3();

alocmem4();

alocmem5();

alocmem6();

alocmem 7();

alocmem8();

fprintf(FILEOUT, "NUMERO DE ELEMENTOS DE CONTORNO =\%dln",ne);

fprintf(FILEOUT,"NUMERO DE PONTOS INTERNOS $\quad=\% \mathrm{~d} / n$ ",npi);

fprintf(FILEOUT, "NUMERO DE NOS DUPLOS $\quad=\%$ din",nnd);

fprintf(FILEOUT, "MODULO DE ELASTICIDADE $\quad=\%$-11.4leln",E);

fprintf(FILEOUT, "COEFICIENTE DE POISSON $\quad=\%-11.4$ leln",NI);

fprintf(FILEOUT,"RESISTENCIA A TRACAO =\%-11.4leln",ft);

fprintf(FILEOUT,"ABERTURA CRITICA DE FRATURA $\quad=\%$-11.4leln",wc);

fprintf(FILEOUT,"COMP. DOS ELEMENTOS DE FRATURA $\quad=\%$-11.4leln",lef);

fprintf(FILEOUT,"NUMERO DE INCREMENTOS =\%dln",ninc);

if(tipo)

\{

fprintf(FILEOUT,"ESTADO PLANO DE TENSAO: $\backslash \mathbf{n} ")$;

$\mathrm{E}^{*}=\left(1.0+2.0^{*} \mathrm{NI}\right) /((1.0+\mathrm{NI}) *(1.0+\mathrm{NI}))$;

$\mathrm{NI} /=(1.0+\mathrm{NI})$

fprintf(FILEOUT,"MODULO DE ELASTICIDADE CORRIGIDO = \%-11.4le!n",E); fprintf(FILEOUT,"COEFICIENTE DE POISSON CORRIGIDO = \%-11.4leln $\backslash n \backslash n ", N I)$; \}

else

fprintf(FILEOUT,"ESTADO PLANO DE DEFORMACAO. $\ln \backslash n$ in");

fprintf(FILEGRAF,"\%d \%d \%d \%d \%dln",ne,npi,nnd,nn,ninc); $1 *$ INCREMENTOS DE SOLICITACAO *

for $(\mathrm{i}=0 ; \mathrm{i}<$ ninc; $\mathrm{i}++)$

fscanf(FILEIN, "\%lfn",\&LAMBDA[i]); * COORDENADAS NODAIS *

fputs("COORDENADAS NODAISInไn",FILEOUT);

fputs("NO $\quad X \quad Y \backslash n ", F I L E O U T)$;

for $(\mathrm{i}=0 ; \mathrm{i}<\mathrm{nn} ; \mathrm{i}++)$

fscanf(FILEIN, "\%lf \%lfn",\&XN[i],\&YN[i]);

for $(\mathrm{i}=0 ; \mathrm{i}<\mathrm{nn} ; \mathrm{i}++)$

fprintf(FILEOUT,"\%2d \%11.4le \%11.4leln",i,XN[i],YN[i]);

/* CONDICOES DE CONTORNO */

fputs("'nn'nCONDICOES DE CONTORNO'nin",FILEOUT);

fputs("NO| DIRECAOX | DIRECAOY |n",FILEOUT);

fputs(" |CONDICAO | V. PRESC.|CONDICAO | V. PRESC.|In",FILEOUT);

for $(i=0 ; i<n n ; i++)$

fscanf(FILEIN,"\%d \%lf \%d \%lfn",\&CONDCON[i][0],\&VP[i][0],\&CONDCON[i][1], $\& \mathrm{VP}[\mathrm{i}][1])$

for $(\mathrm{i}=0 ; \mathrm{i}<\mathrm{nn} ; \mathrm{i}++)$

fprintf(FILEOUT,"\%2d \%1d \%11.4le \%1d \%11.4leln",i, 


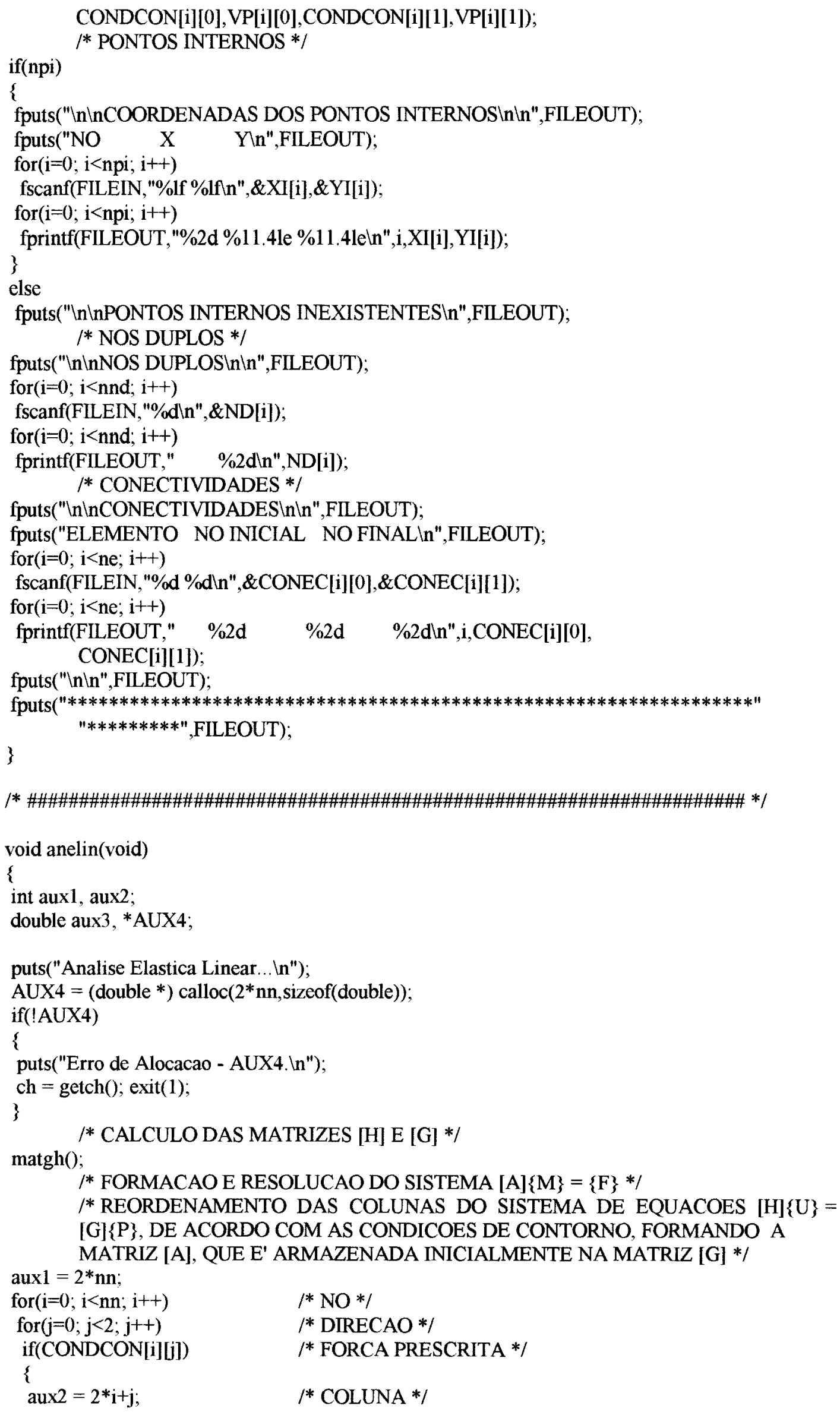




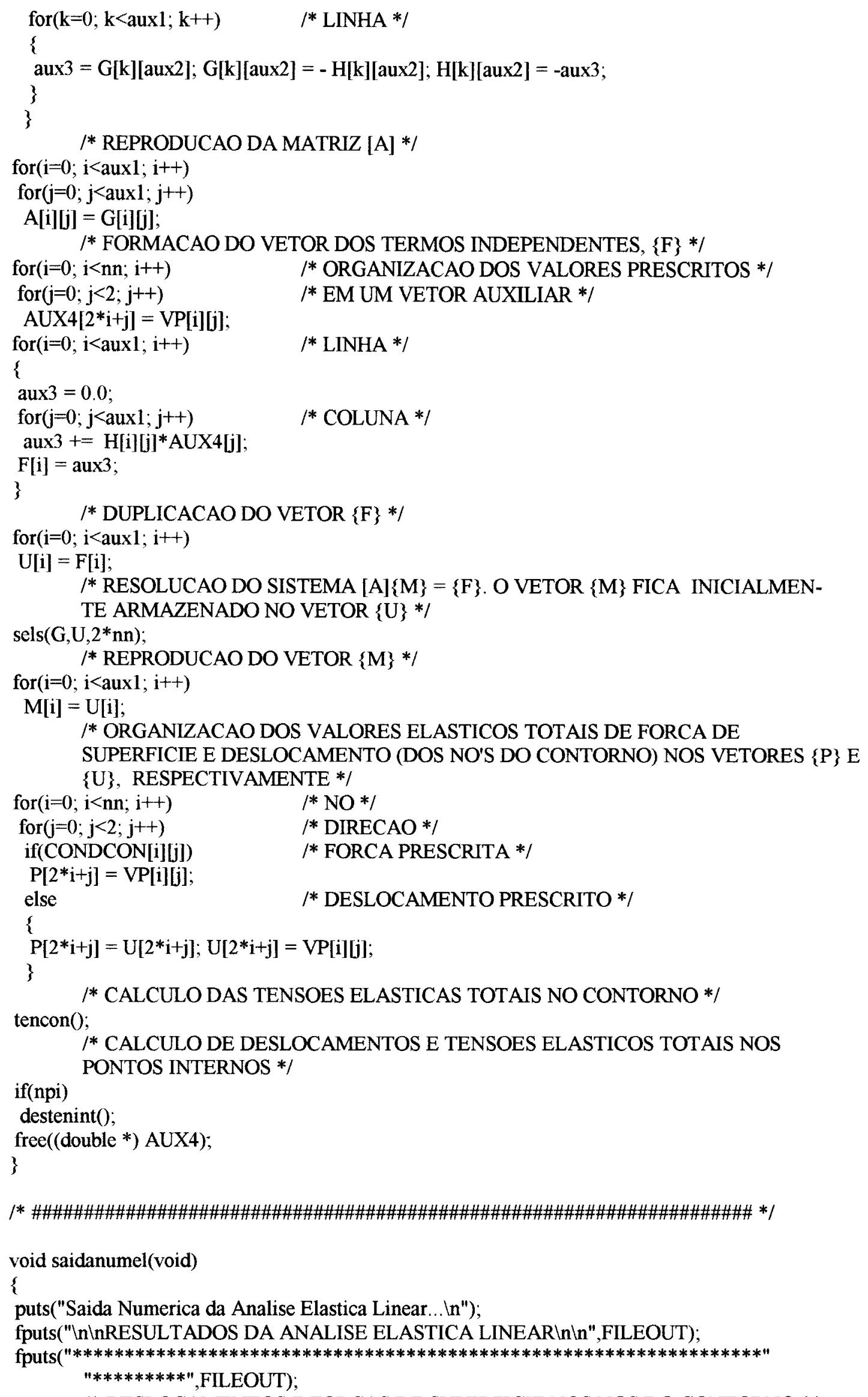




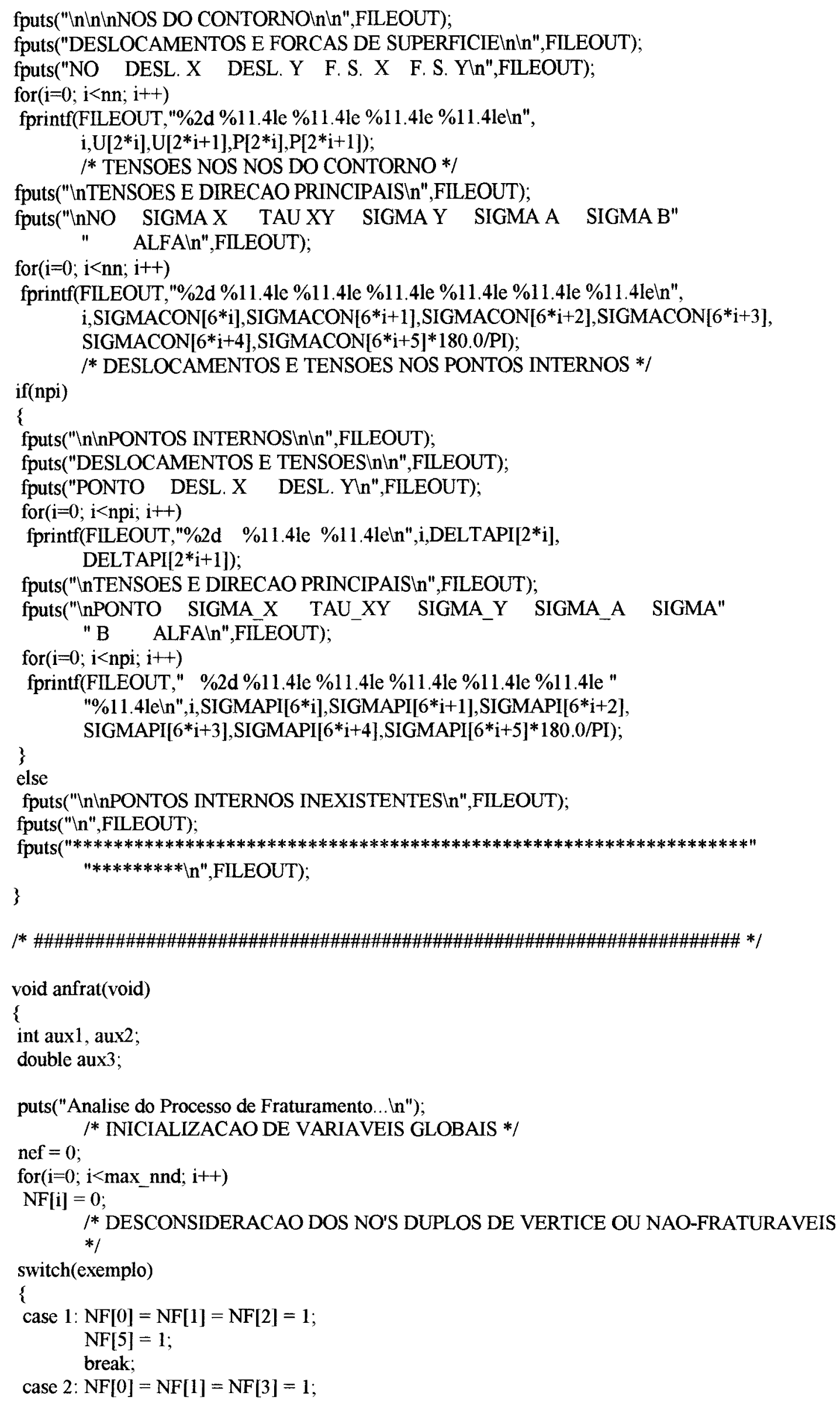


break;

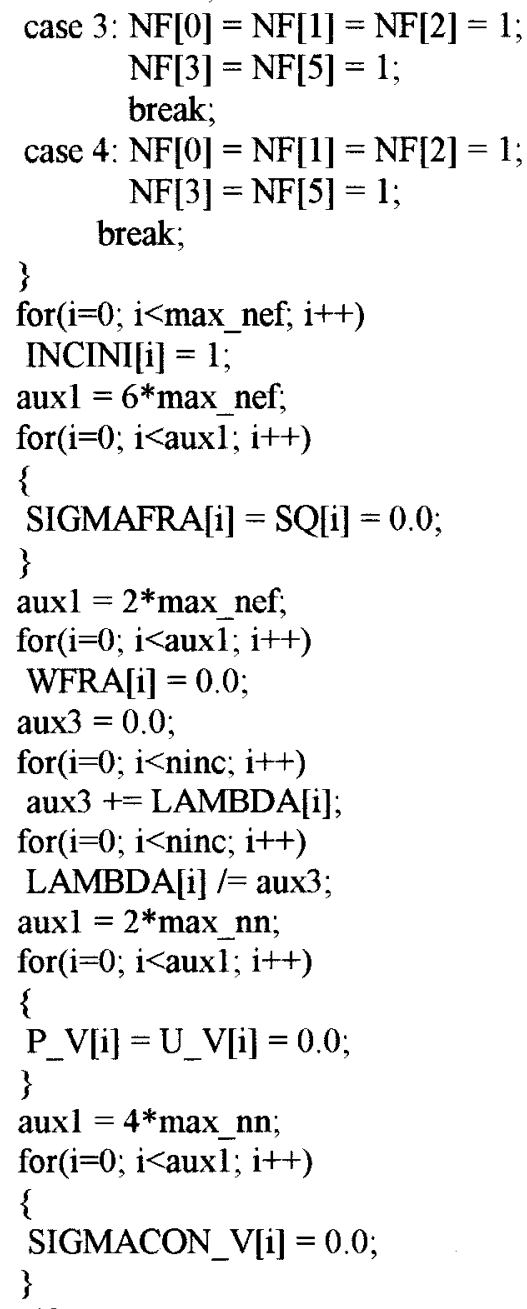




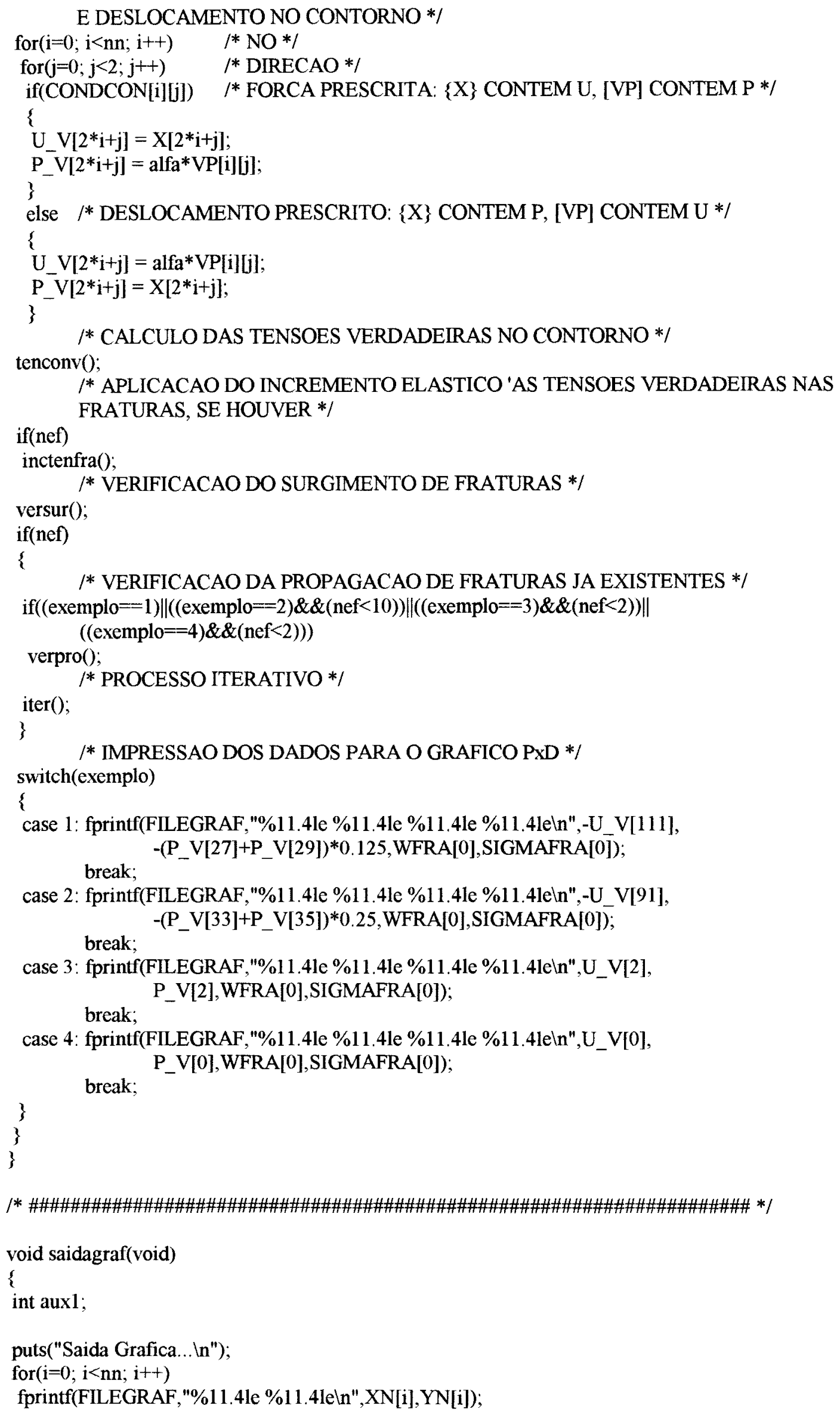




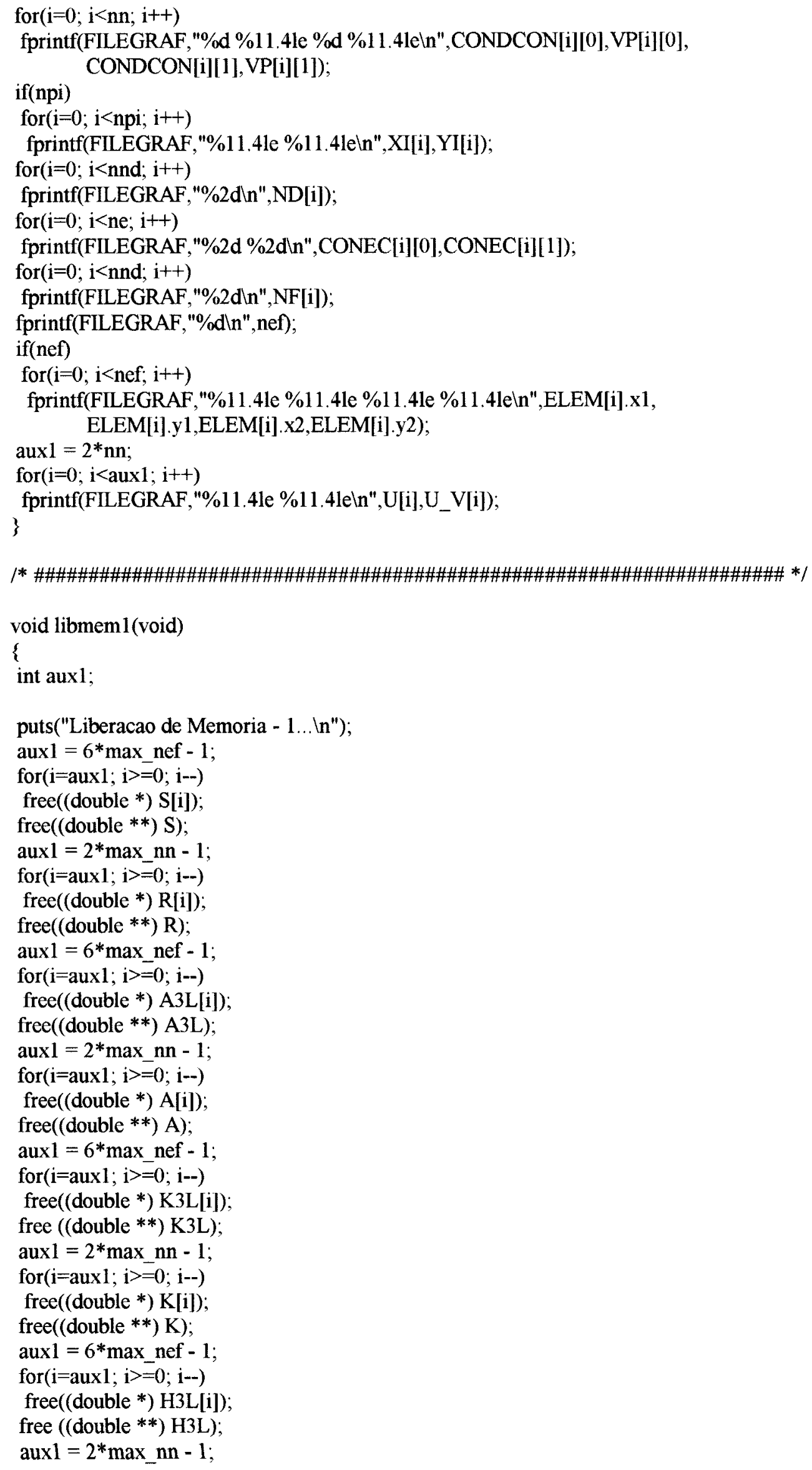




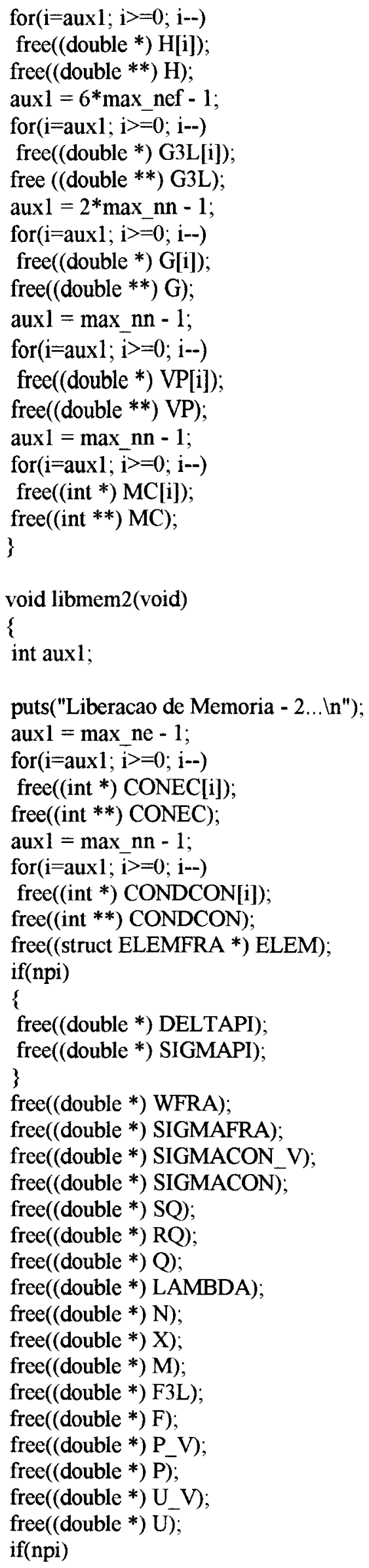


\{

free((double *) YI);

free((double *) XI);

\}

free((double *) YC);

free((double *) XC);

free((double *) YN);

free $\left(\left(\right.\right.$ double $\left.\left.^{*}\right) \mathrm{XN}\right)$;

free((int *) INCINI);

free((int *) NF);

free((int *) ND);

\}

\section{D.3 Mefre03.c}

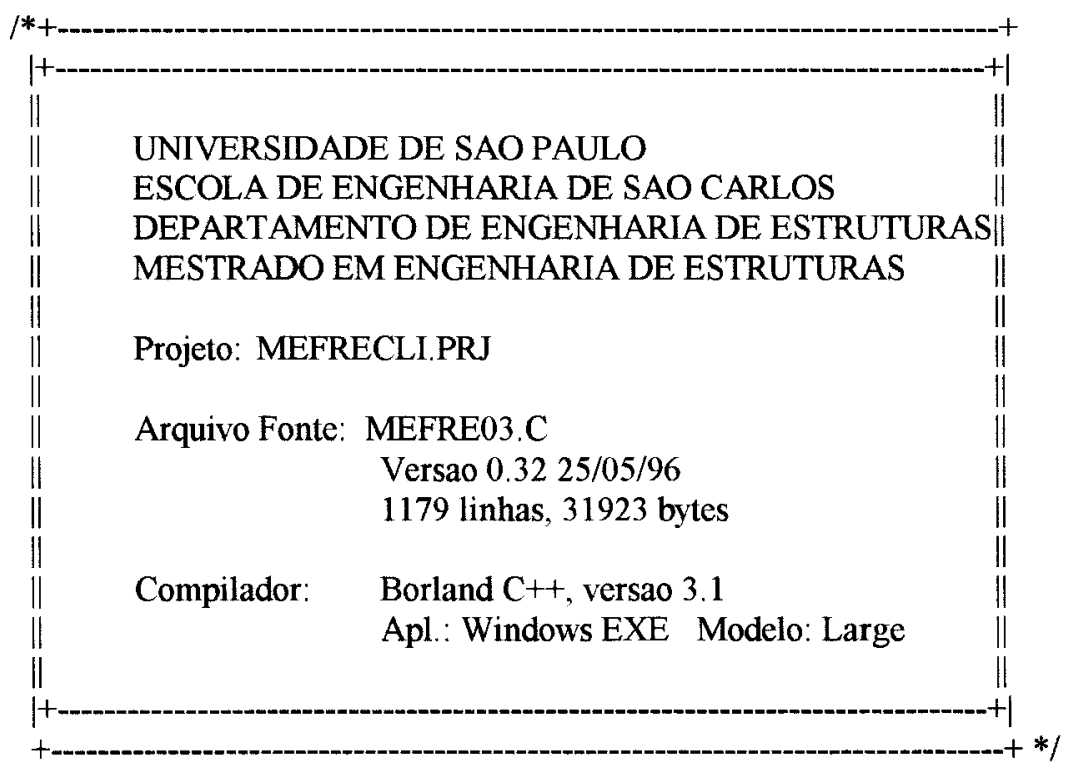

\#include $<$ stdio.h $>$

\#include $<$ conio. $\mathrm{h}>$

\#include $<$ stdlib.h $>$

\#include $<$ math. $\mathrm{h}>$

\#include "mefre03.h"

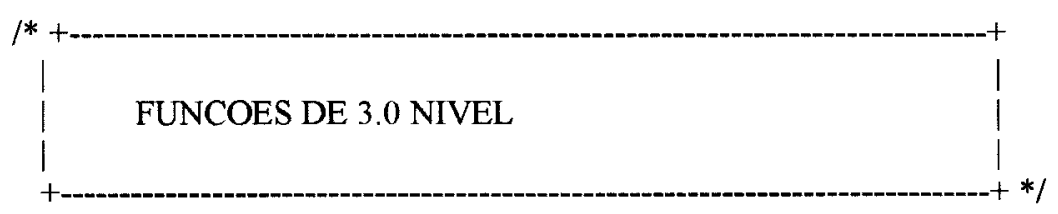

void alocmem 1(void)

\{

puts("Alocacao de Memoria - 1... In");

$\mathrm{ND}=($ int $*)$ calloc(max_nnd,sizeof(int));

if (!ND)

\{ 


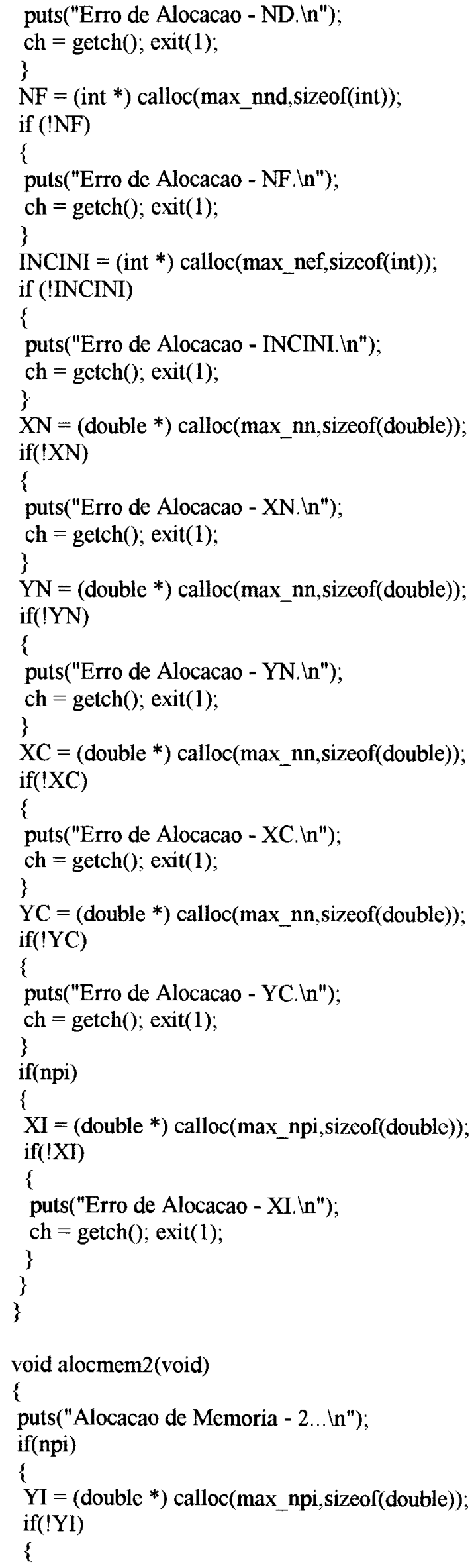




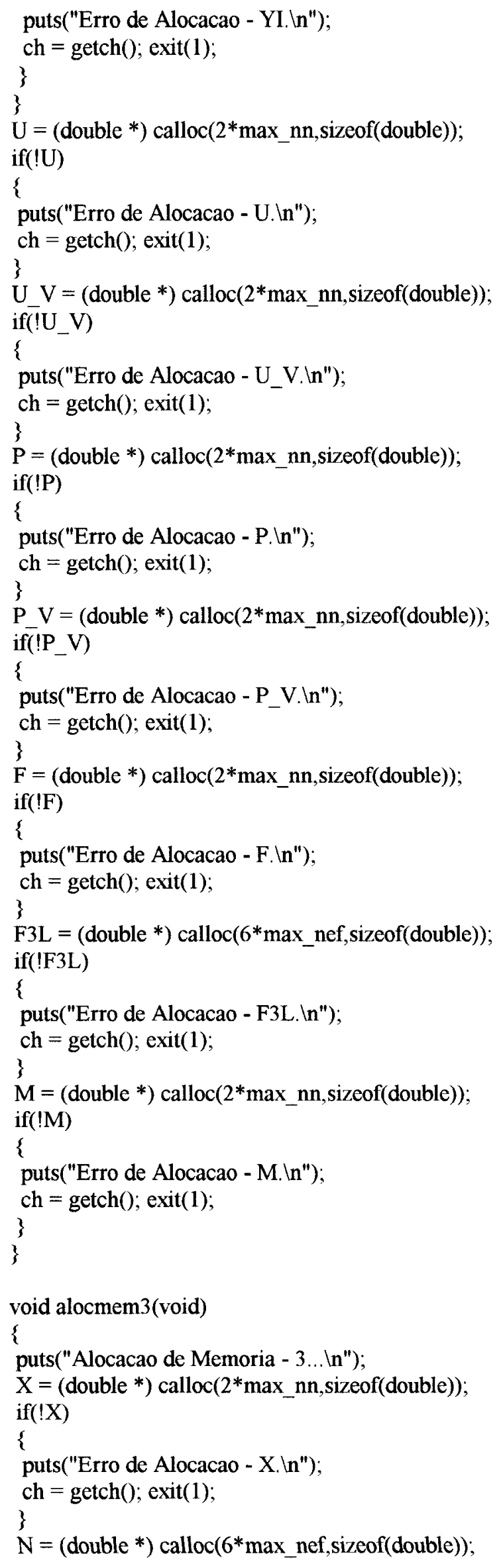




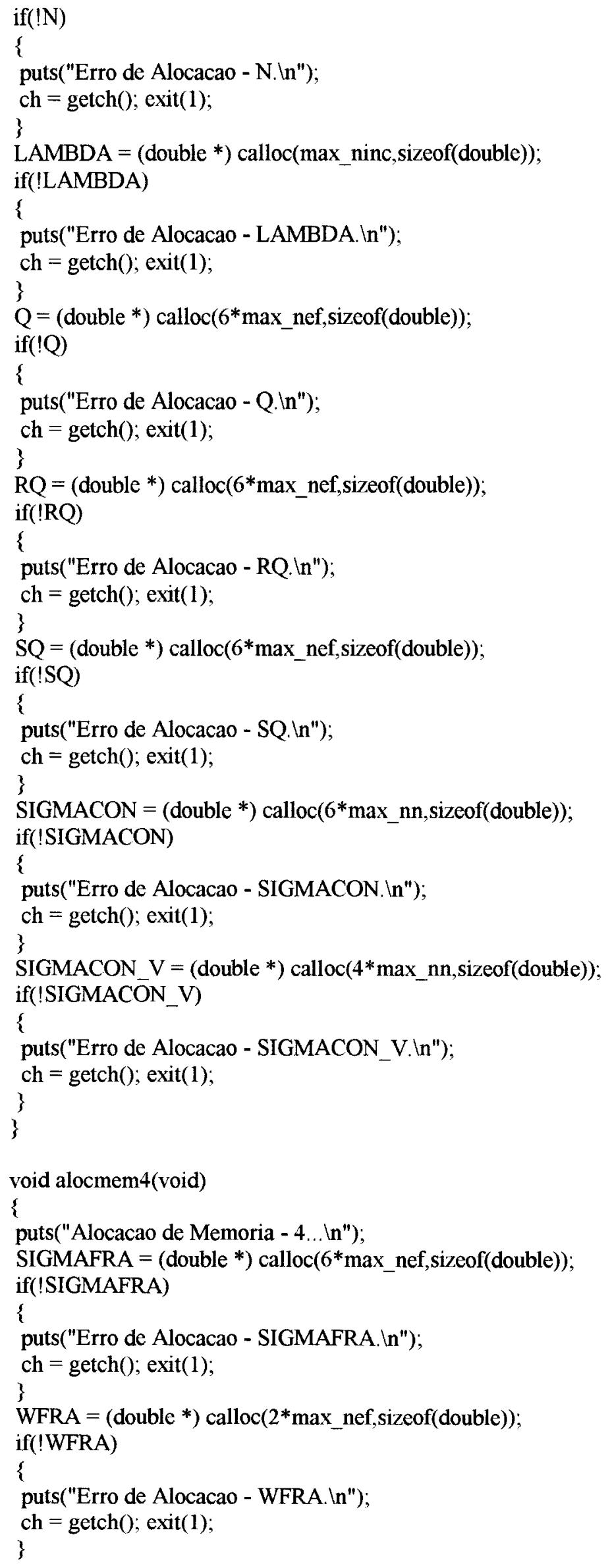




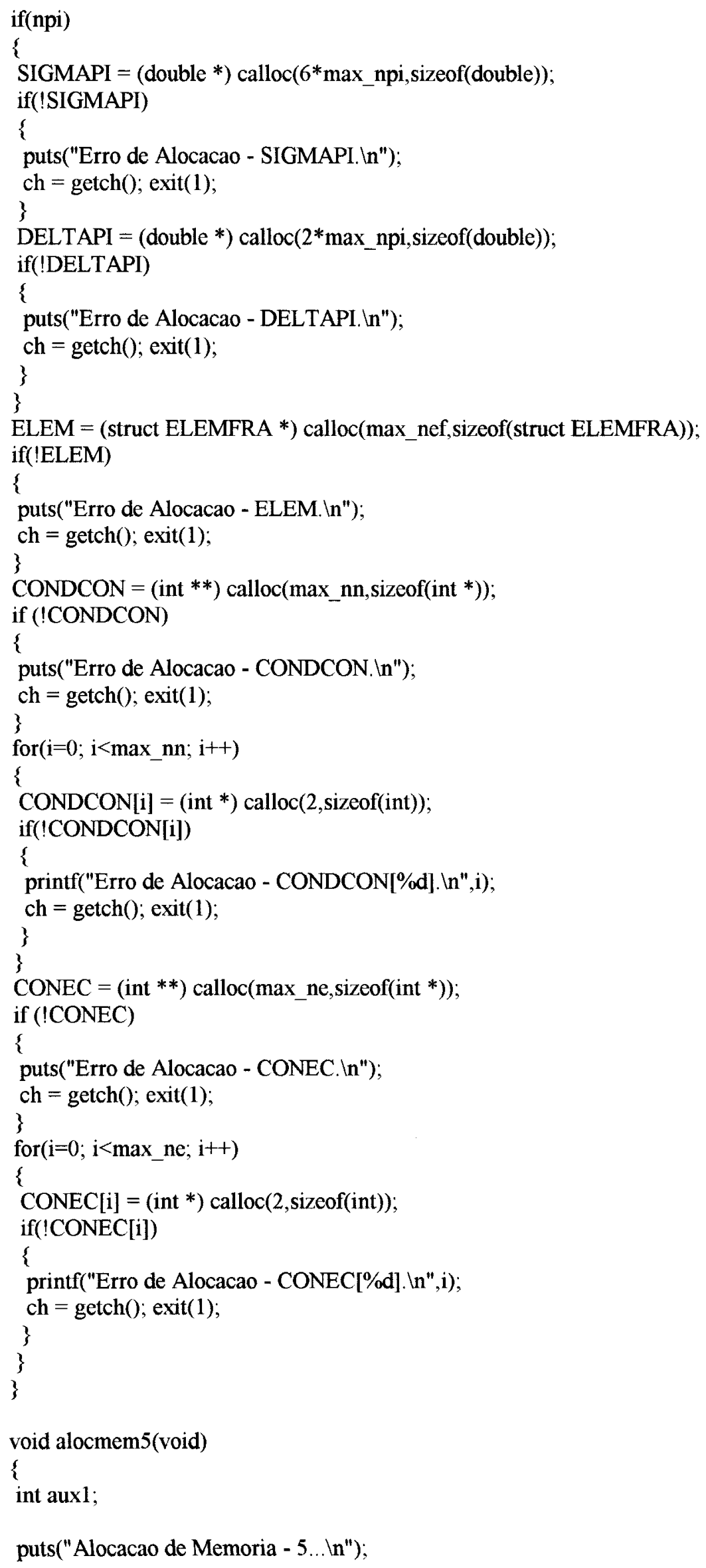




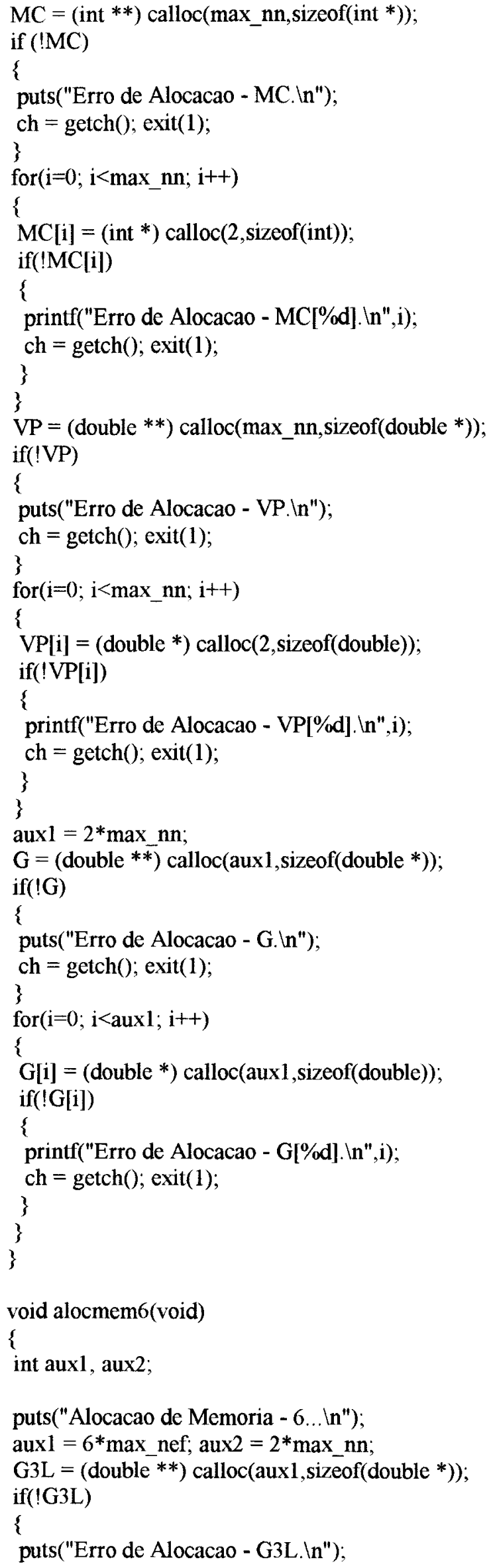




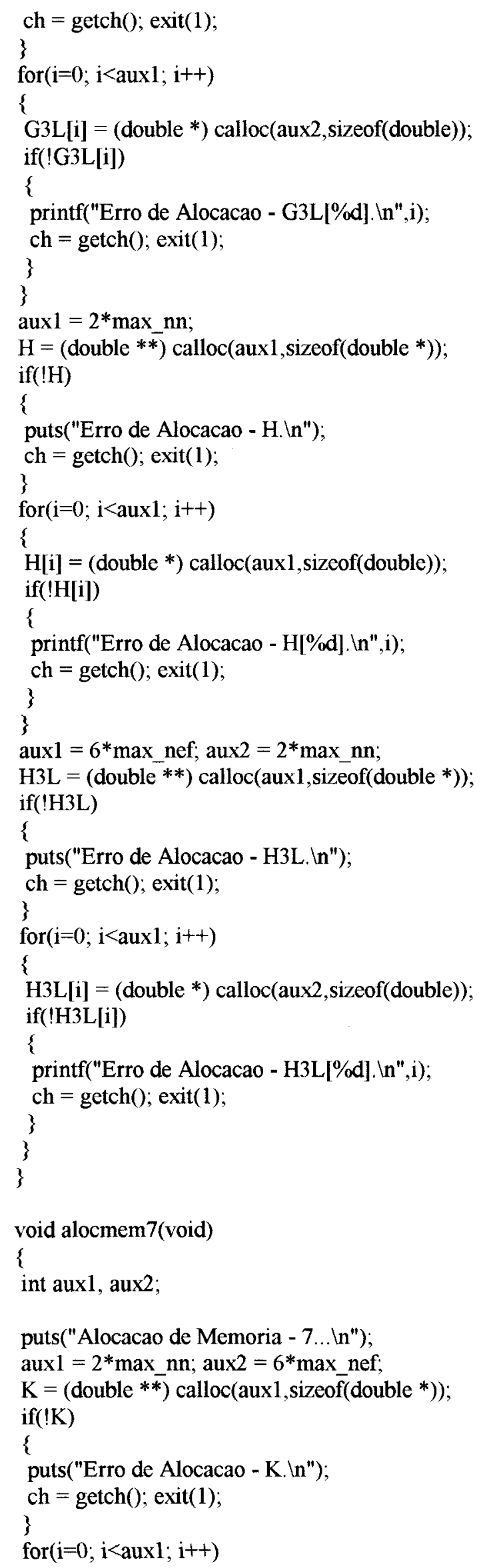




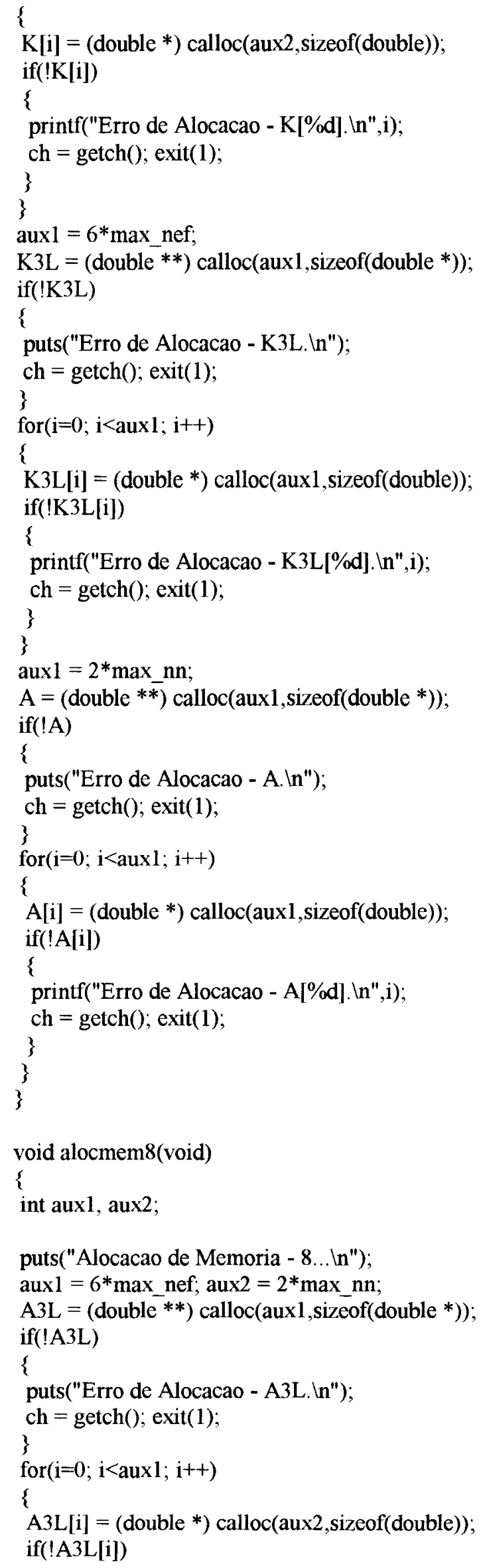




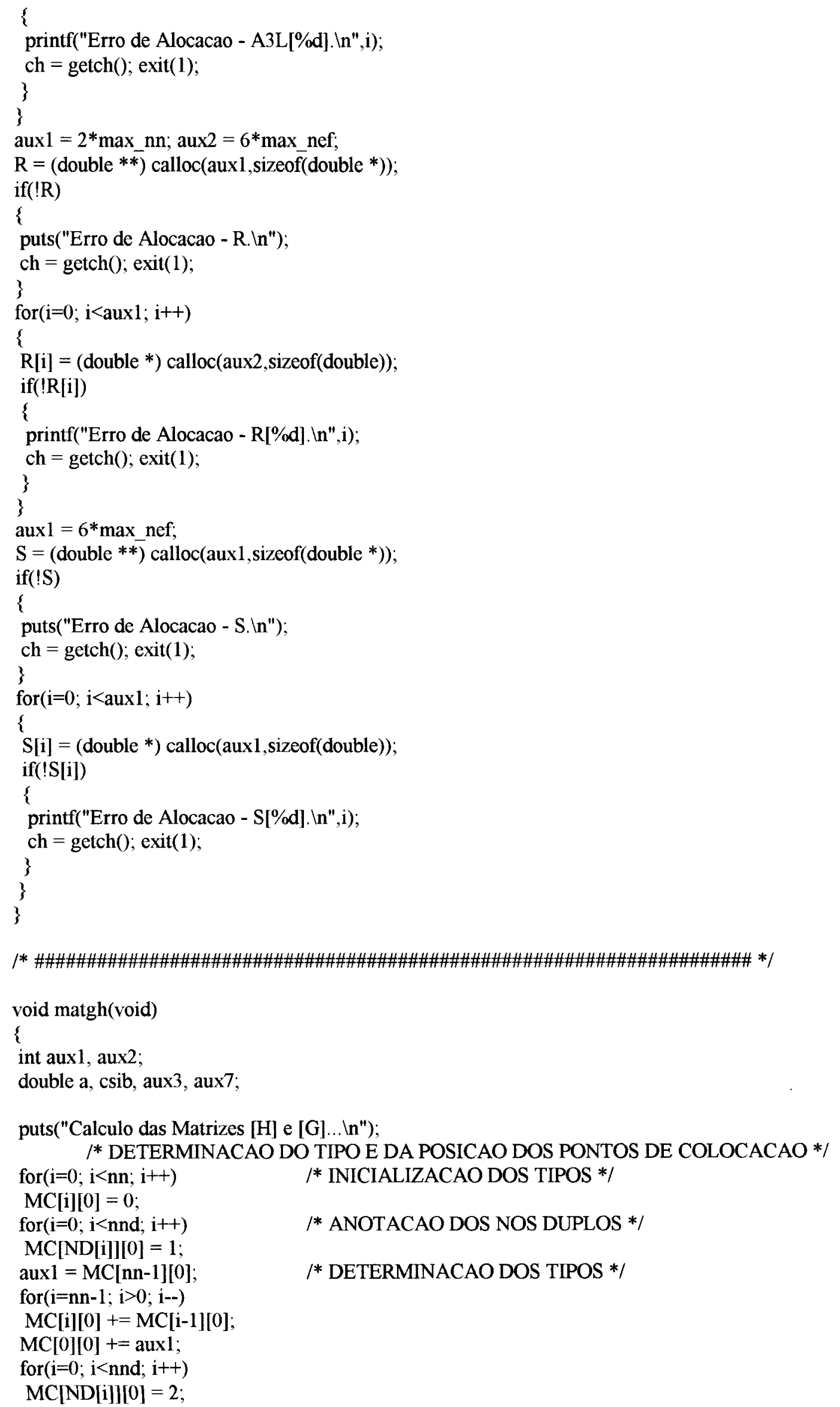




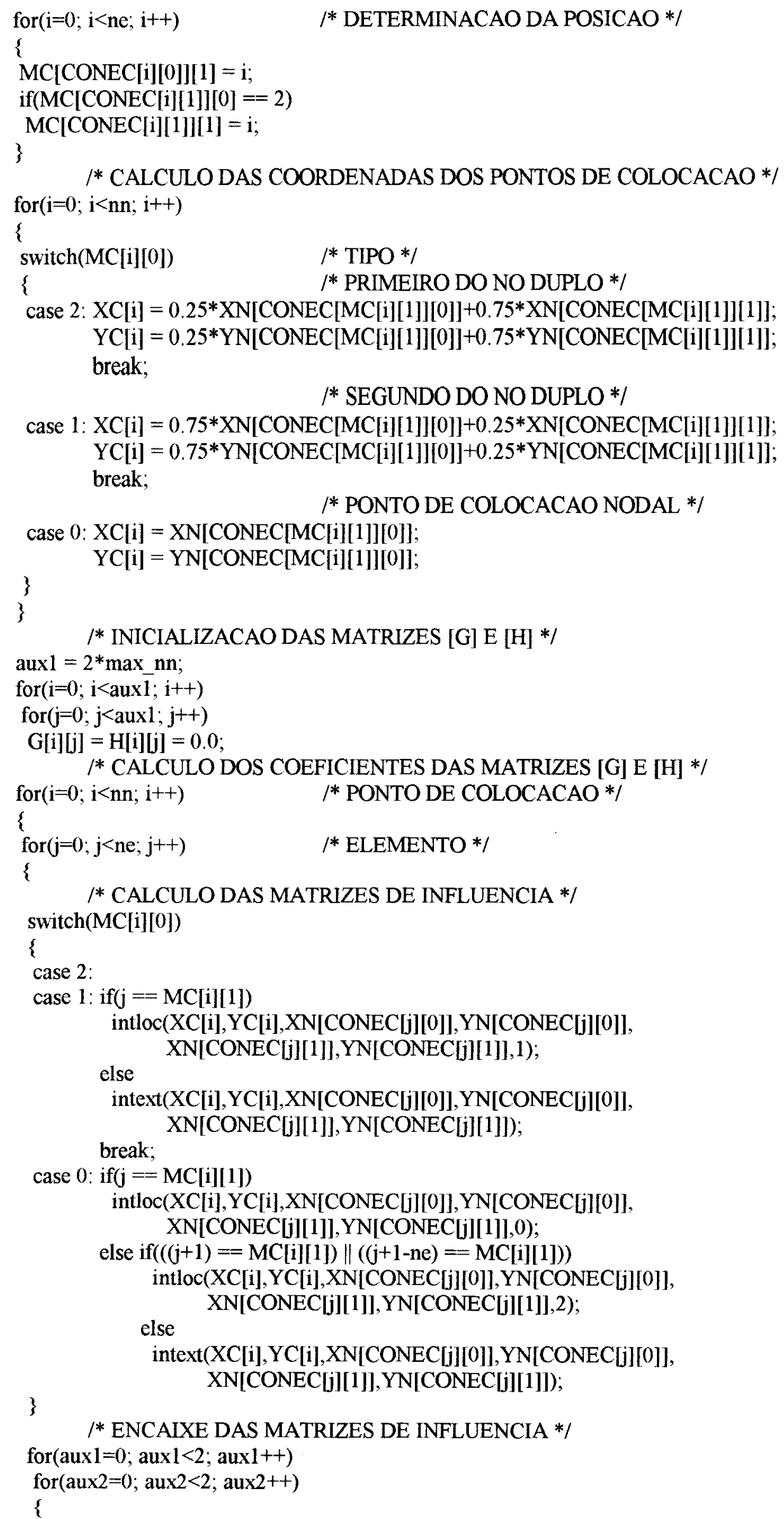




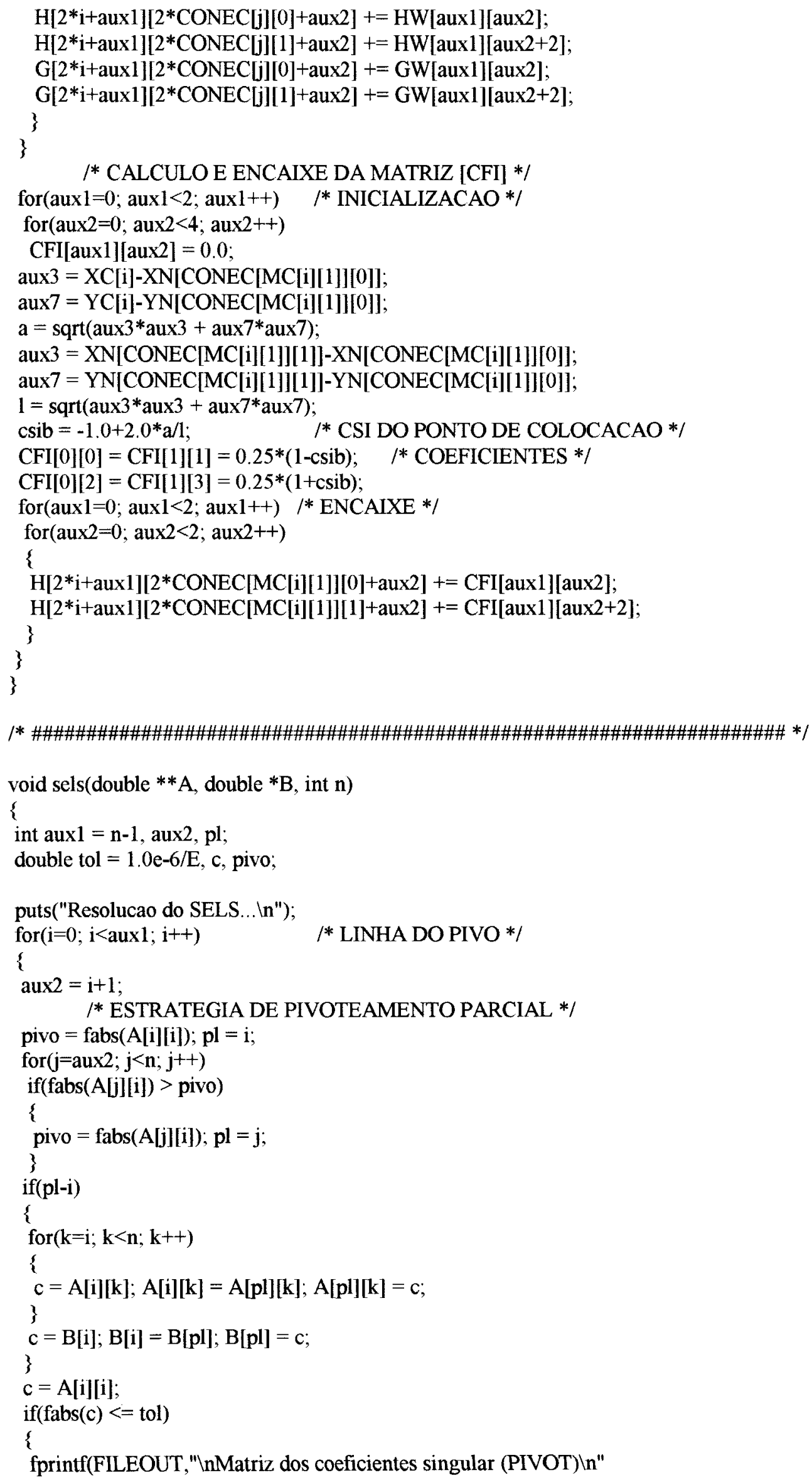




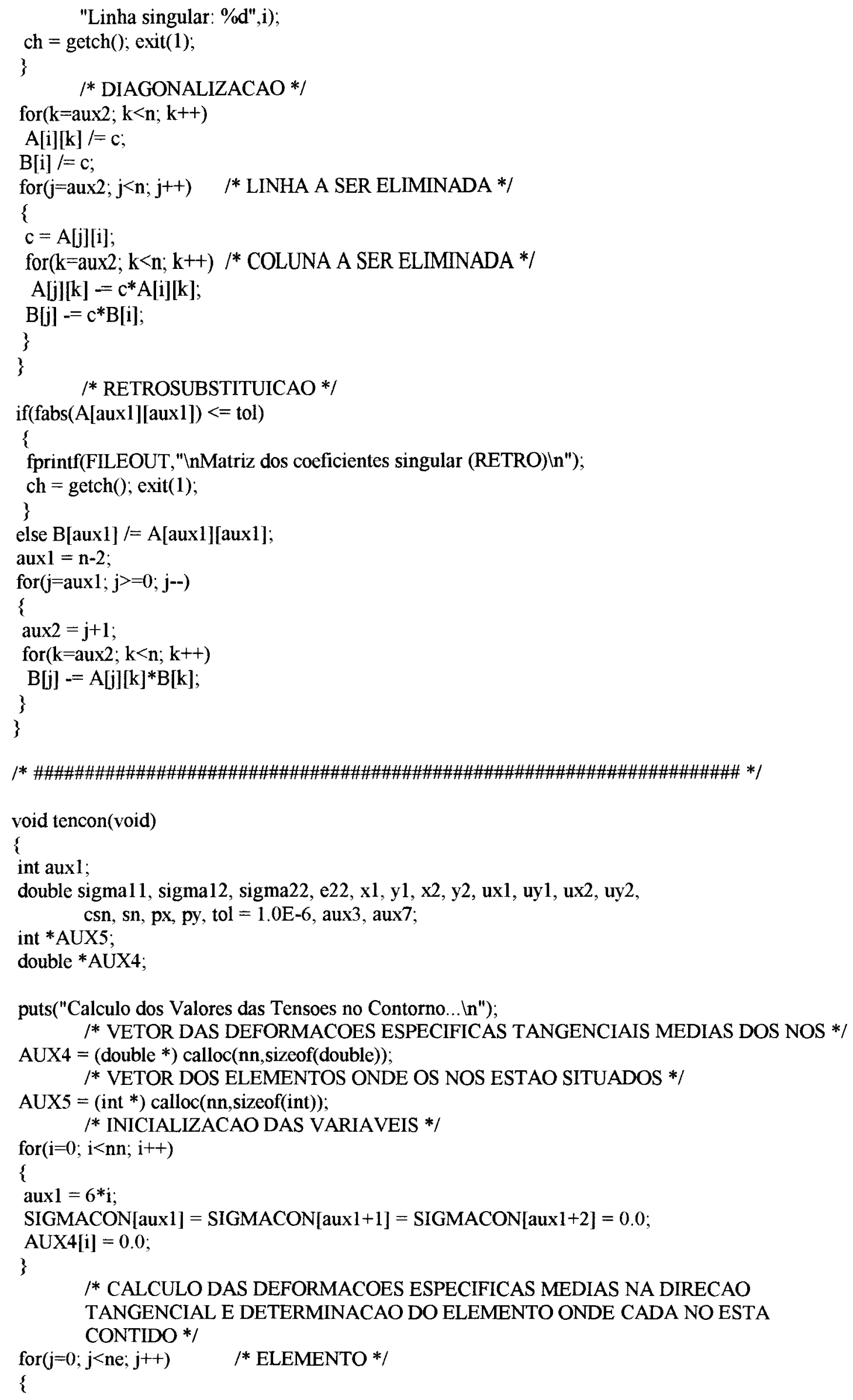


$\mathrm{ux} 1=\mathrm{U}[2 * \operatorname{CONEC}[\mathrm{j}][0]] ; \mathrm{uy} 1=\mathrm{U}[2 * \operatorname{CONEC}[\mathrm{j}][0]+1] ;$

$\mathrm{ux} 2=\mathrm{U}[2 * \operatorname{CONEC}[\mathrm{j}][1]] ;$ uy $2=\mathrm{U}[2 * \operatorname{CONEC}[\mathrm{j}][1]+1]$;

$\mathrm{xl}=\mathrm{XN}[\mathrm{CONEC}[\mathrm{j}][0]] ; \mathrm{y} \mathbf{l}=\mathrm{YN}[\mathrm{CONEC}[\mathrm{j}][0]] ;$

$\mathrm{x} 2=\mathrm{XN}[\mathrm{CONEC}[\mathrm{j}][1]] ; \mathrm{y} 2=\mathrm{YN}[\mathrm{CONEC}[\mathrm{j}][1]]$;

$1=\operatorname{sqrt}\left((\mathrm{x} 2-\mathrm{x} 1)^{*}(\mathrm{x} 2-\mathrm{x} 1)+(\mathrm{y} 2-\mathrm{y} 1)^{*}(\mathrm{y} 2-\mathrm{y} 1)\right)$;

e22 $=(($ ux2-ux1 $) *(x 2-x 1)+($ uy2-uy 1$) *(y 2-y 1)) /(1 * 1) ;$

/* ACUMULO DAS CONTRIBUICOES DE CADA ELEMENTO *

AUX4[CONEC[j][0]] += e22; AUX4[CONEC[j][1]] += e22;

/* DETERMINACAO DOS ELEMENTOS */

AUX5[CONEC[j][0]] $=\mathrm{j}$;

if(MC[CONEC $[\mathrm{j}][1]][0]==2$ )

AUX5 $[$ CONEC $[\mathrm{j}][1]]=\mathrm{j}$;

\}

for $(\mathrm{i}=0 ; \mathrm{i}<\mathrm{nnd} ; \mathrm{i}++)$

/ NO DUPLO */

\{

AUX4[ND[i]] *=2.0;

if $((\mathrm{ND}[\mathrm{i}]+1)<\mathrm{nn})$

AUX4 $[\mathrm{ND}[\mathrm{i}]+1] *=2.0$;

else

$\operatorname{AUX} 4[0] *=2.0$;

\}

/* MEDIA DAS CONTRIBUICOES 'A DEFORMACAO EM CADA NO */

for $(\mathrm{i}=0 ; \mathrm{i}<\mathrm{nn} ; \mathrm{i}++)$

$\mathrm{AUX} 4[\mathrm{i}] /=2.0$

/* CALCULO DAS TENSOES NODAIS */

for $(\mathrm{i}=0 ; \mathrm{i}<\mathrm{nn} ; \mathrm{i}++) \quad / * \mathrm{NO} * /$

\{

$/ *$ CO-SENOS DIRETORES DO VERSOR NORMAL AO ELEMENTO $* /$

$\mathrm{x} 1=\mathrm{XN}[\mathrm{CONEC}[\mathrm{AUX} 5[\mathrm{i}]][0]] ; \mathrm{y} 1=\mathrm{YN}[\mathrm{CONEC}[\mathrm{AUX}$ 5[i]][0]];

$\mathrm{x} 2=\mathrm{XN}[\mathrm{CONEC}[\mathrm{AUX} 5[\mathrm{i}]][1]] ; \mathrm{y} 2=\mathrm{YN}[\mathrm{CONEC}[\mathrm{AUX} 5[\mathrm{i}]][1]]$;

$1=\operatorname{sqrt}((\mathrm{x} 2-\mathrm{x} 1) *(\mathrm{x} 2-\mathrm{x} 1)+(\mathrm{y} 2-\mathrm{y} 1) *(\mathrm{y} 2-\mathrm{y} 1))$

$\operatorname{csn}=(\mathrm{y} 2-\mathrm{y} 1) / 1 ; \mathrm{sn}=(\mathrm{x} 1-\mathrm{x} 2) / 1 ;$

* FORCAS DE SUPERFICIE NODAIS */

$\mathrm{px}=\mathrm{P}[2 * \mathrm{i}] ; \mathrm{py}=\mathrm{P}[2 * \mathrm{i}+1]$;

* TENSOES NAS DIRECOES LOCAIS *

sigmall $=\mathrm{px}^{*} \operatorname{csn}+\mathrm{py}^{*} \mathrm{sn} ; \quad / * \mathrm{t} 1 * /$

sigma12 $=-\mathrm{px}^{*} \mathrm{sn}+\mathrm{py}{ }^{*} \mathrm{csn} ; \quad / * \mathrm{t} 2 * /$

sigma22 $=$ sigma $11 * \mathrm{NI} /(1.0-\mathrm{NI})+\mathrm{AUX} 4[\mathrm{i}] * \mathrm{E} /(1.0-\mathrm{NI} * \mathrm{NI})$;

$1 *$ TENSOES NAS DIRECOES GLOBAIS *

auxl $=6 * i$;

SIGMACON $[\operatorname{aux} 1]=\operatorname{csn} * \operatorname{csn} * \operatorname{sigma} 11-2.0 * \mathrm{sn} * \operatorname{csn} * \operatorname{sigma} 12+\mathrm{sn} * \mathrm{sn} * \operatorname{sigma} 22 ;$

SIGMACON $[\operatorname{aux} 1+1]=\operatorname{sn} * \operatorname{csn} *(\operatorname{sigma1} 1$-sigma 22$)+(\operatorname{csn} * \operatorname{csn}-\mathrm{sn} * \operatorname{sn}) * \operatorname{sigma} 12$;

SIGMACON $[$ aux $1+2]=\operatorname{sn} * \operatorname{sn} * \operatorname{sigmal} 1+2.0 * \operatorname{sn} * \operatorname{csn} * \operatorname{sigma} 12+\operatorname{csn} * \operatorname{csn} * \operatorname{sigma} 22$;

$1 *$ TENSOES E DIRECAO PRINCIPAIS */

aux3 = SIGMACON[aux1] - SIGMACON[aux1+2];

$\operatorname{aux} 7=$ SIGMACON $[\mathrm{aux} 1+1]$;

SIGMACON $[\operatorname{auxl} 1+3]=0.5 *(\operatorname{SIGMACON}[\operatorname{aux} 1]+\operatorname{SIGMACON}[\operatorname{aux} 1+2]+$ sqrt(aux3*aux3 + 4.0*aux7*aux7));

SIGMACON $[$ aux $1+4]=0.5 *(\operatorname{SIGMACON}[\operatorname{aux} 1]+\operatorname{SIGMACON}[\operatorname{aux} 1+2]-$ sqrt(aux3*aux3 + 4.0*aux7*aux7));

if $(($ fabs $($ SIGMACON[auxl+3]-SIGMACON[auxl+2]) $>$ tol) $\|$

(fabs(SIGMACON[auxl+1]) $>$ tol))

SIGMACON $[\operatorname{aux} 1+5]=\operatorname{atan} 2(\operatorname{SIGMACON}[\mathrm{aux} 1+1]$, SIGMACON[aux1+3]-SIGMACON[aux1+2]);

else if(fabs(SIGMACON[auxl]-SIGMACON[auxl+2]) $>$ tol)

SIGMACON $[a u x 1+5]=\mathrm{PI} / 2.0$;

else

SIGMACON $[\operatorname{auxl}+5]=0.0$; 


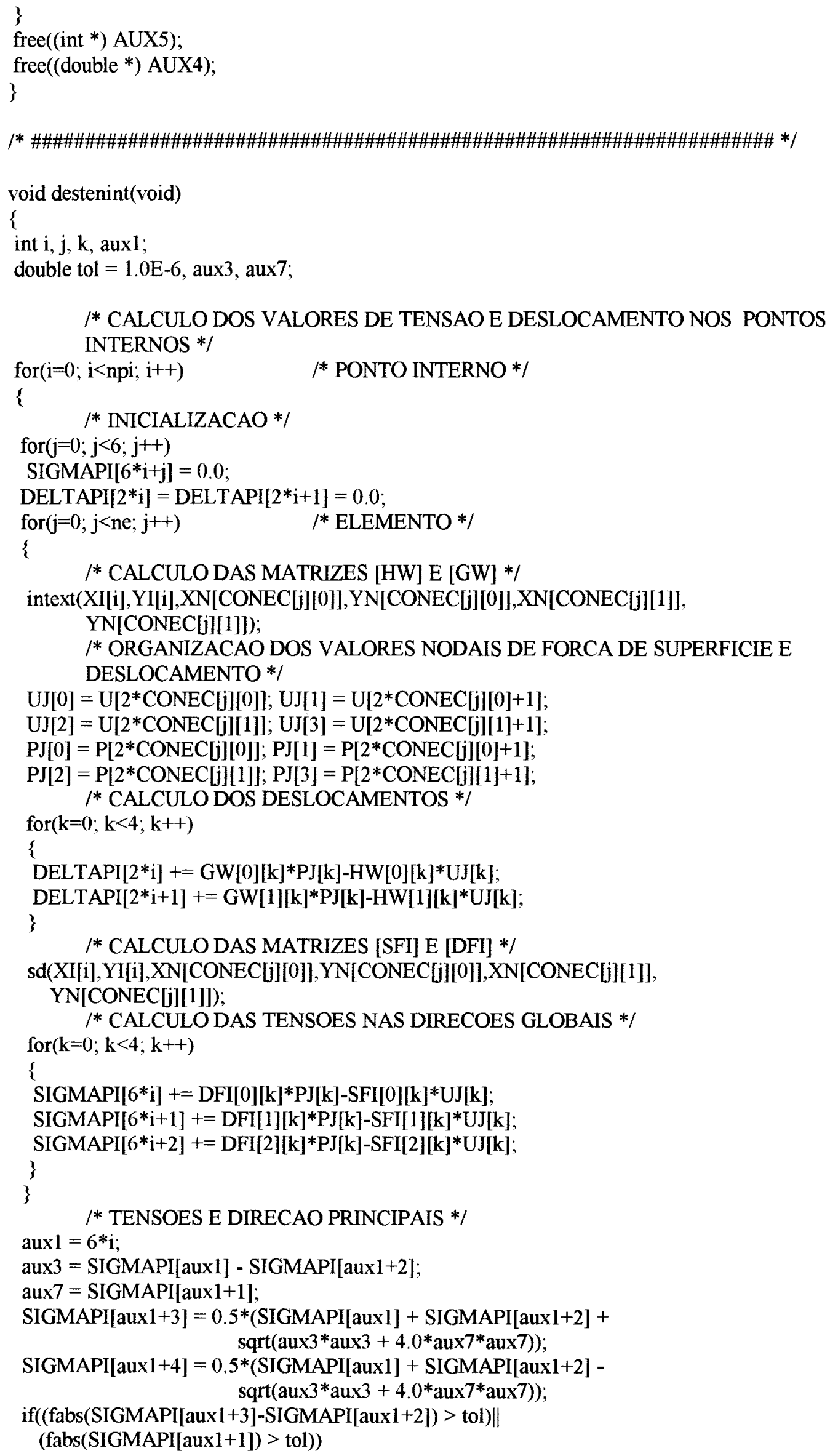




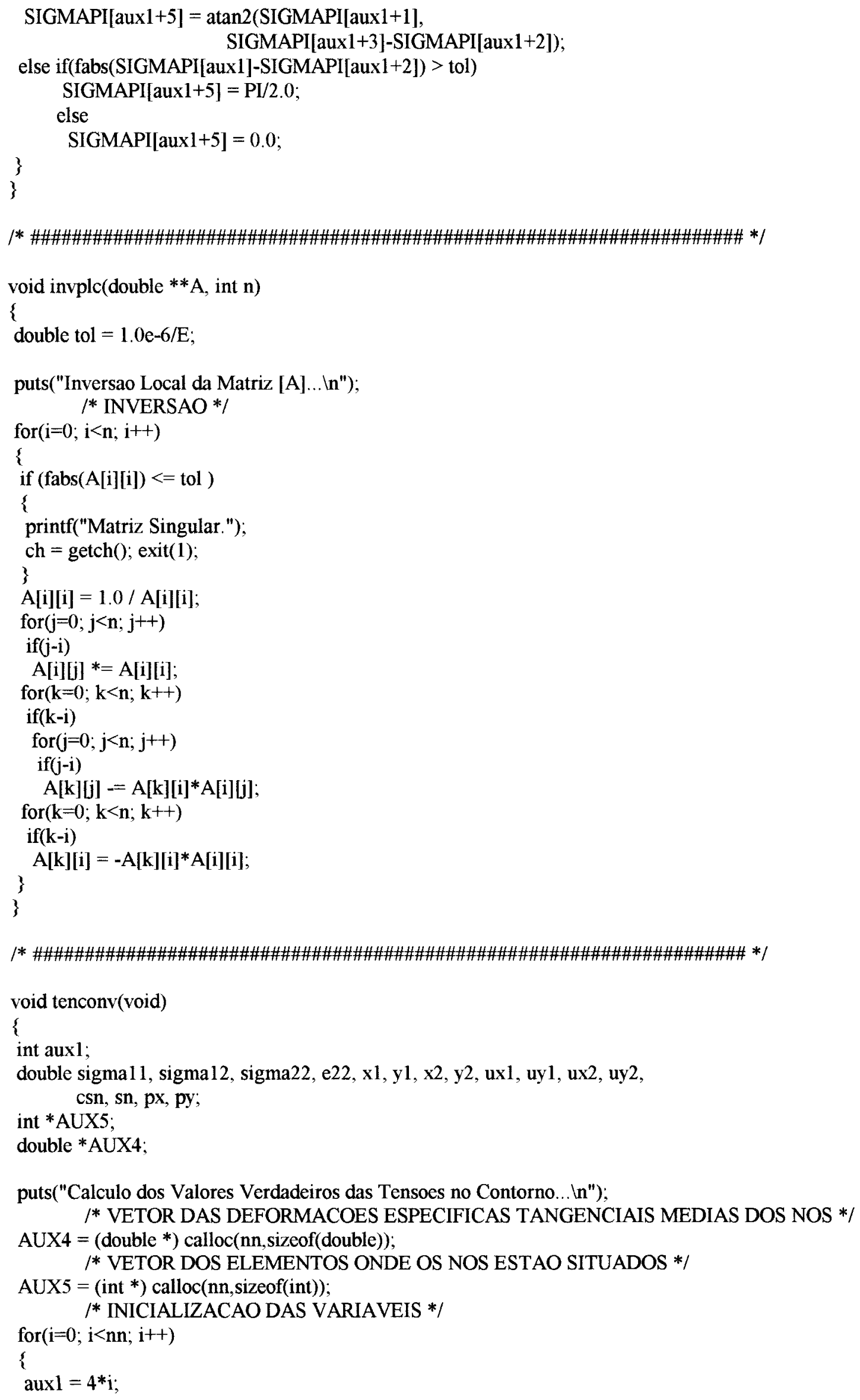




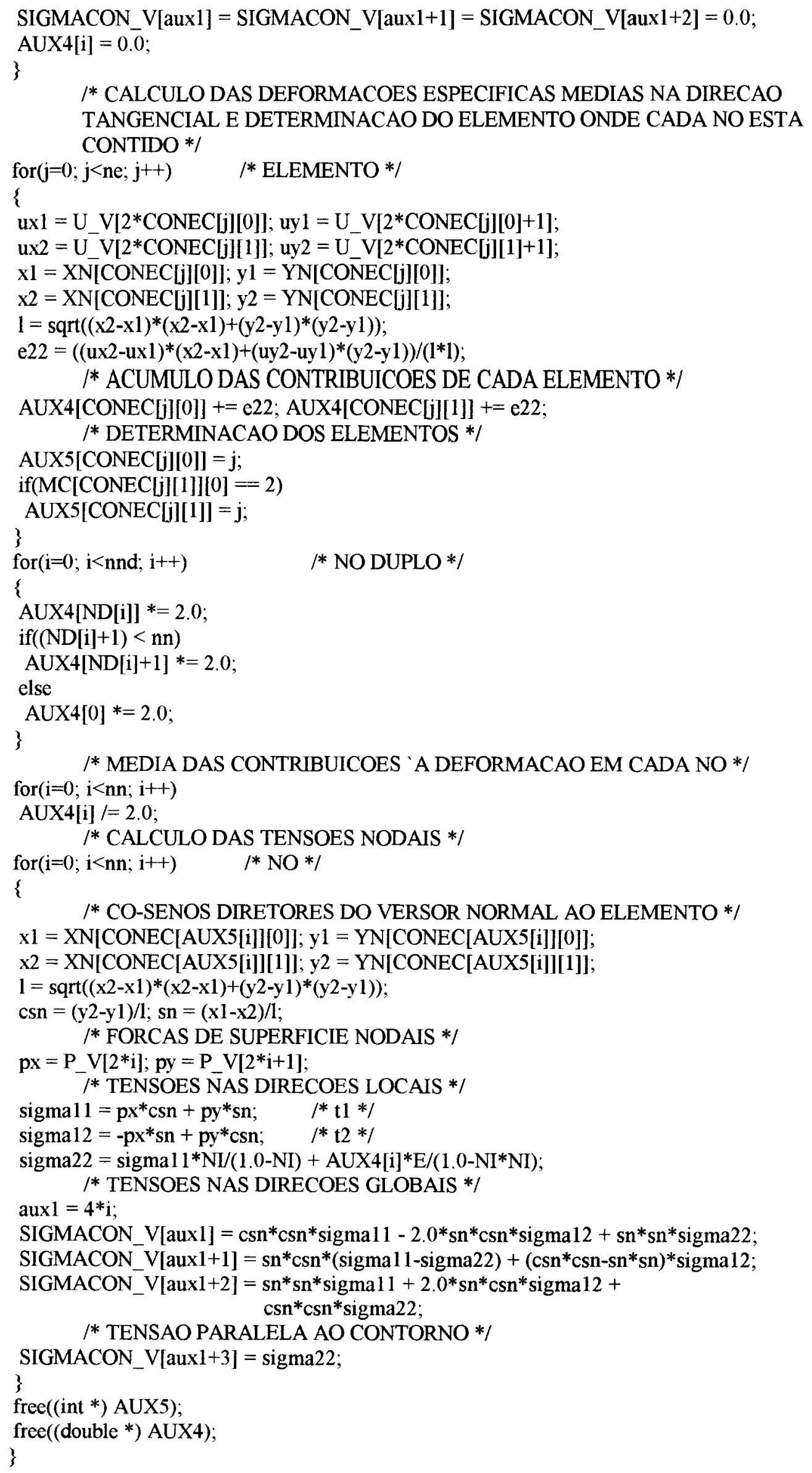




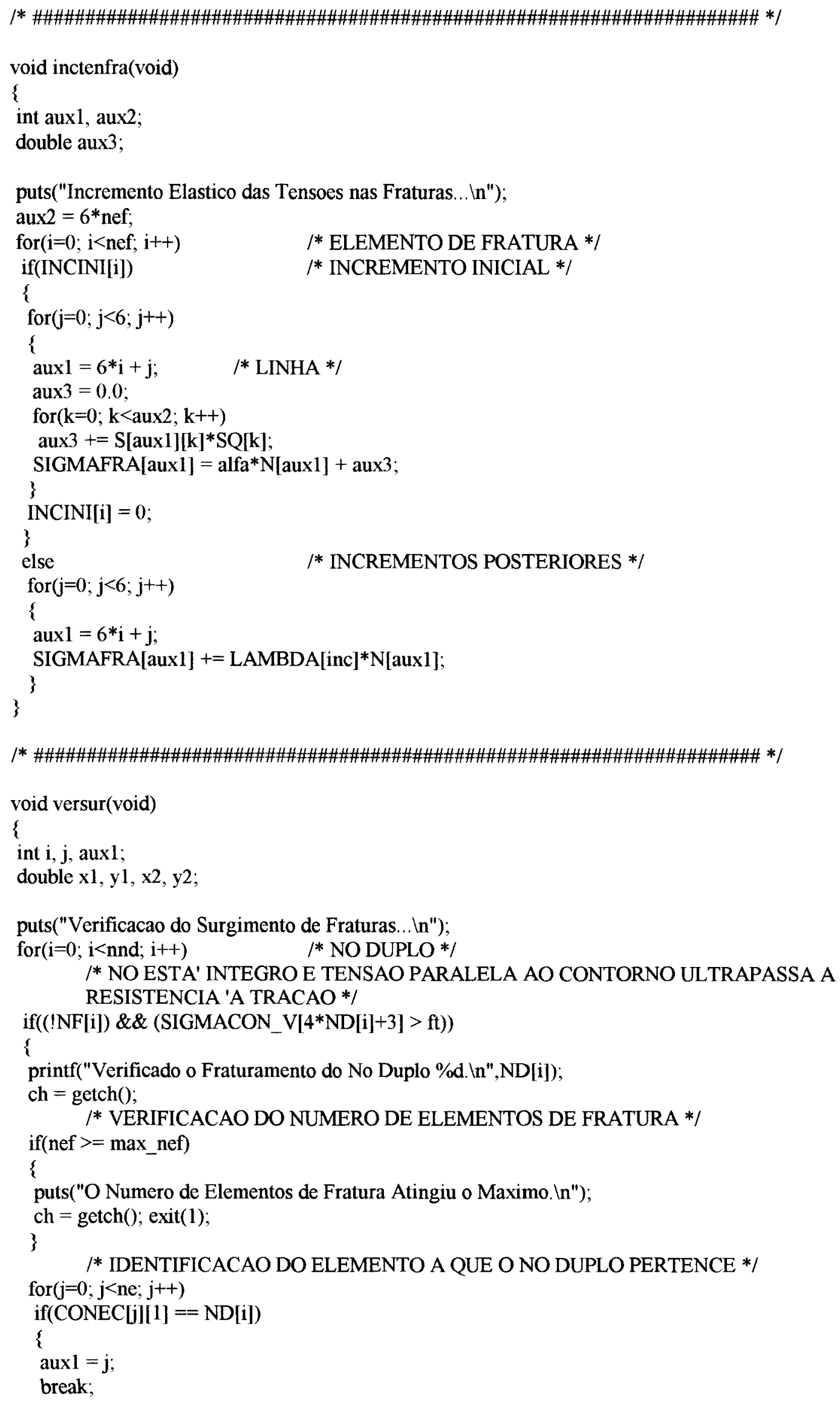




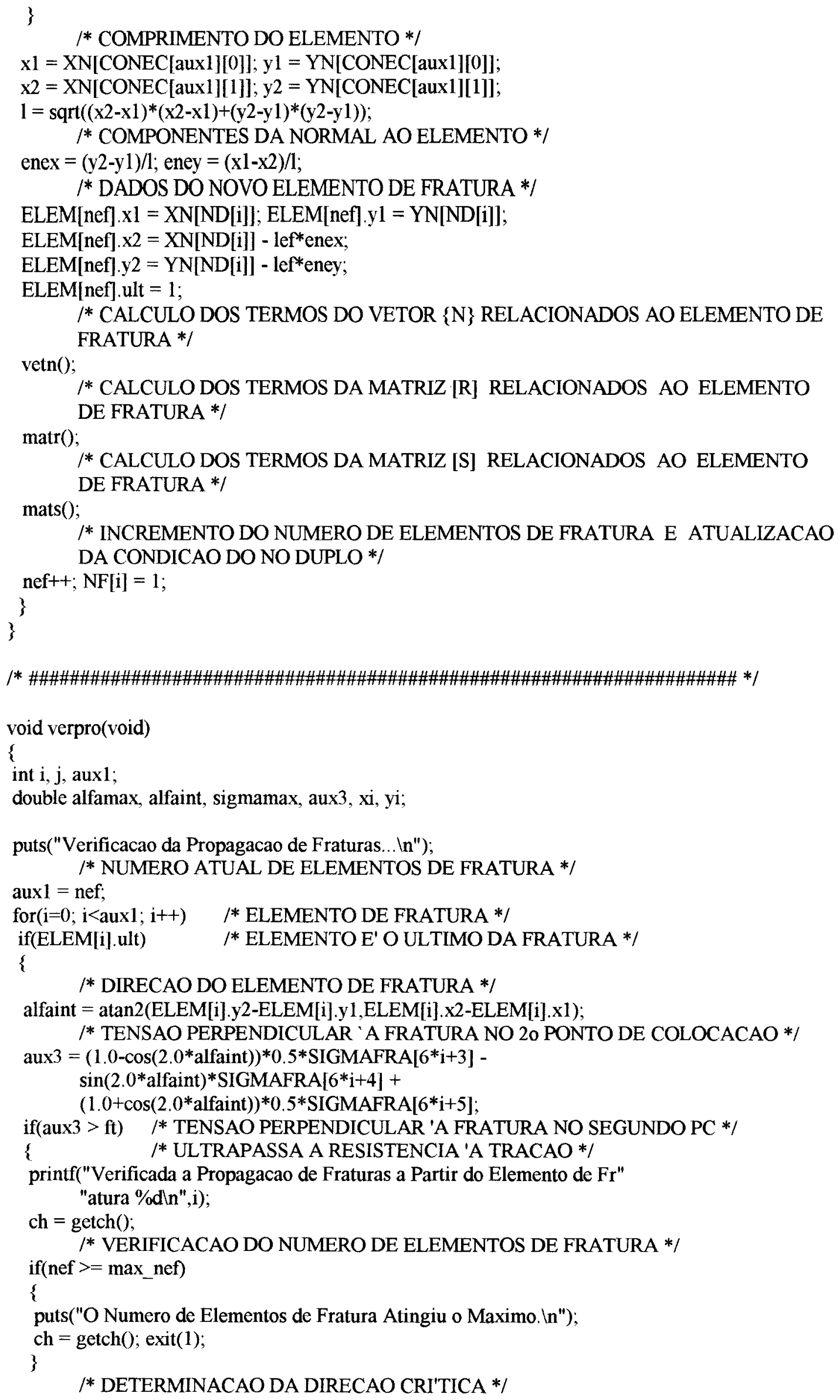




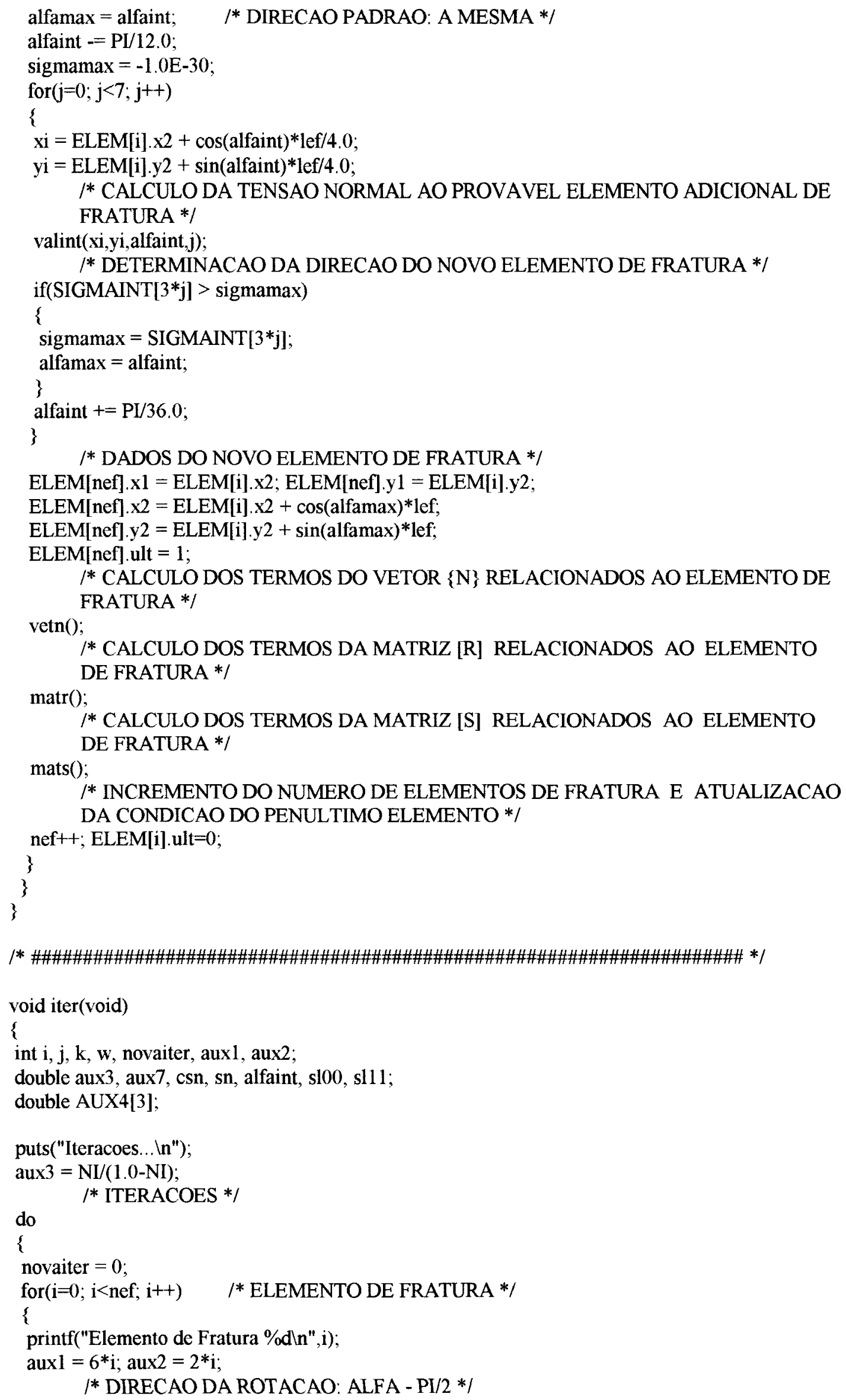




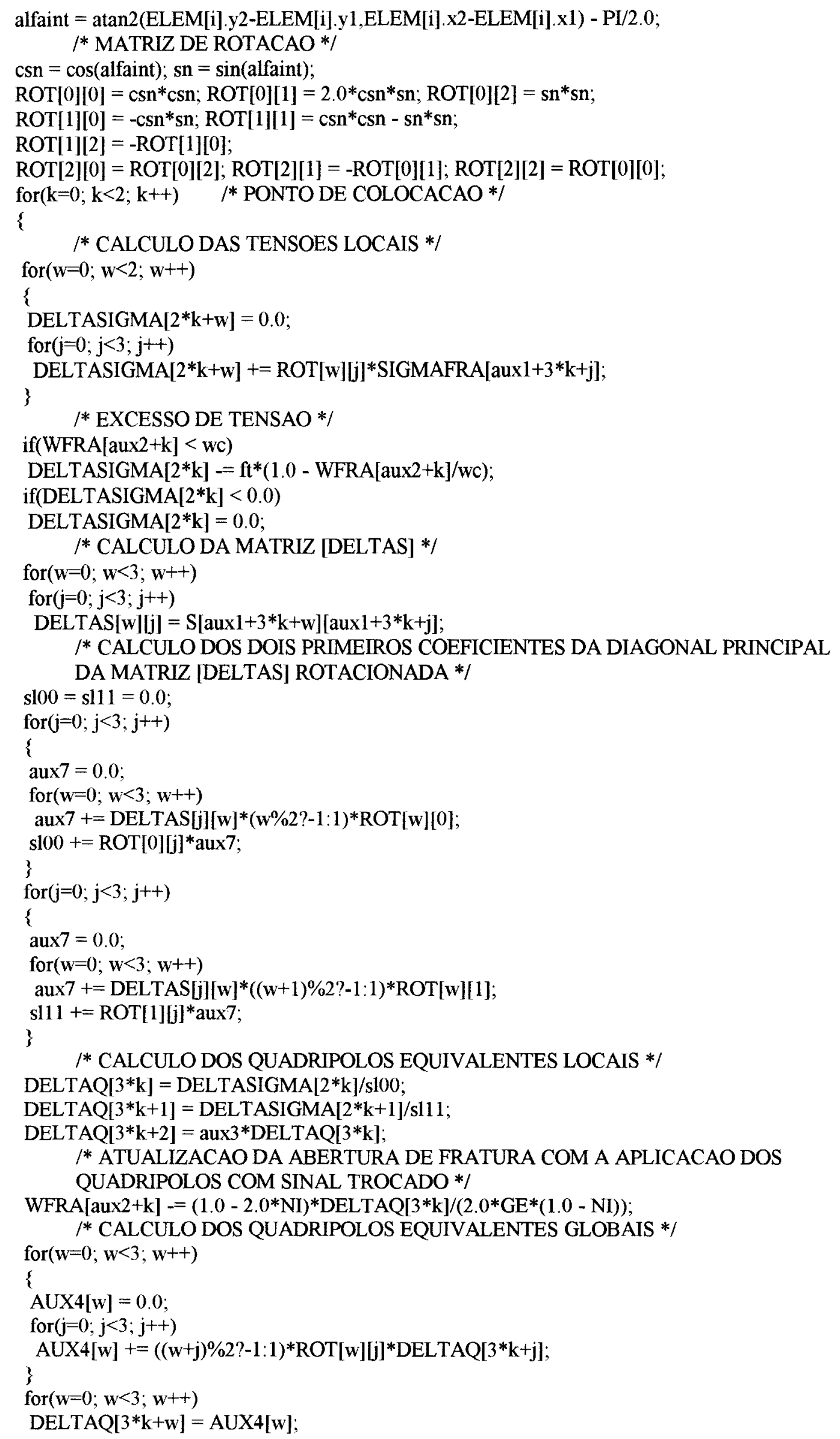




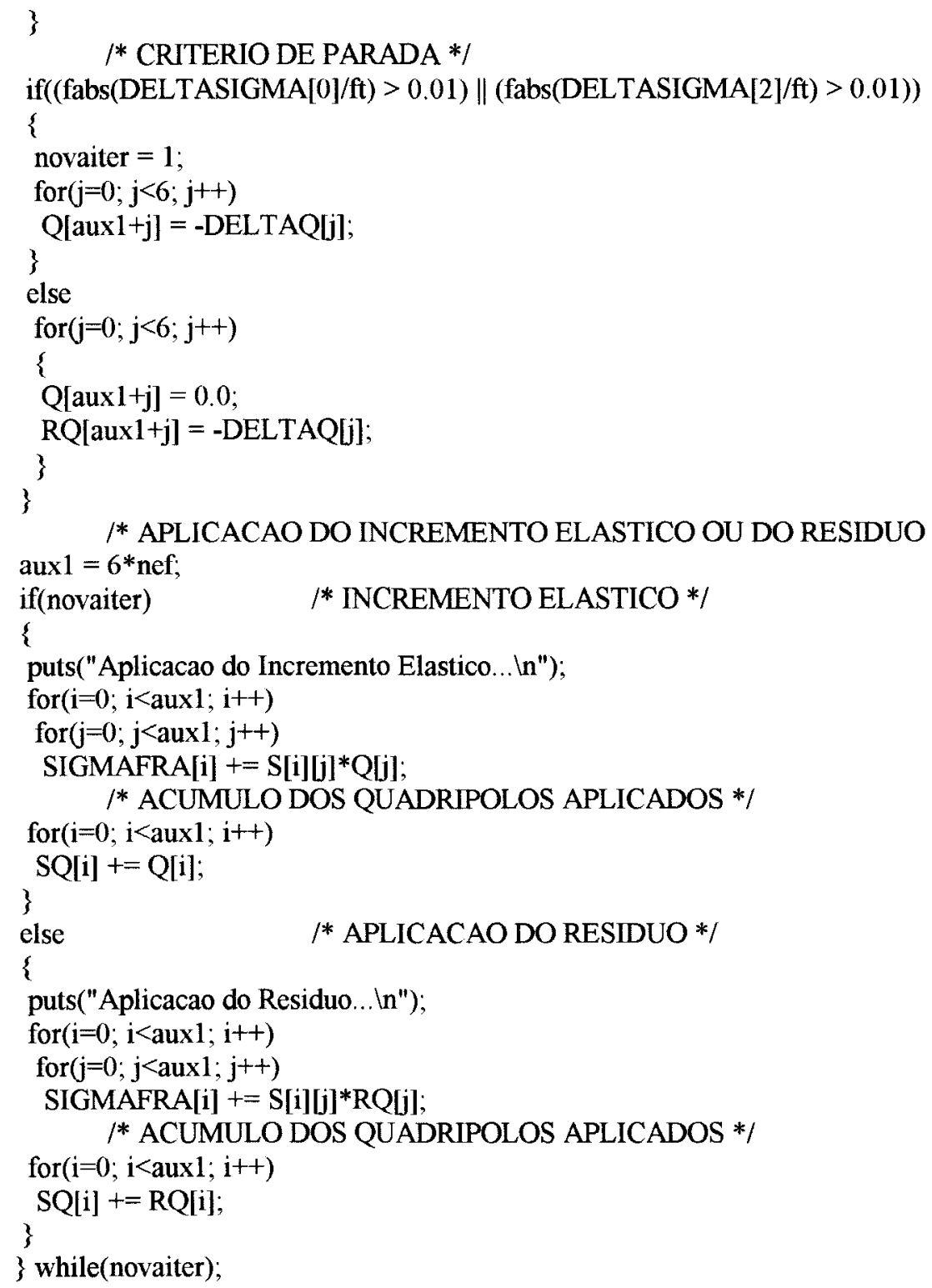




\section{D.4 Mefre04.c}

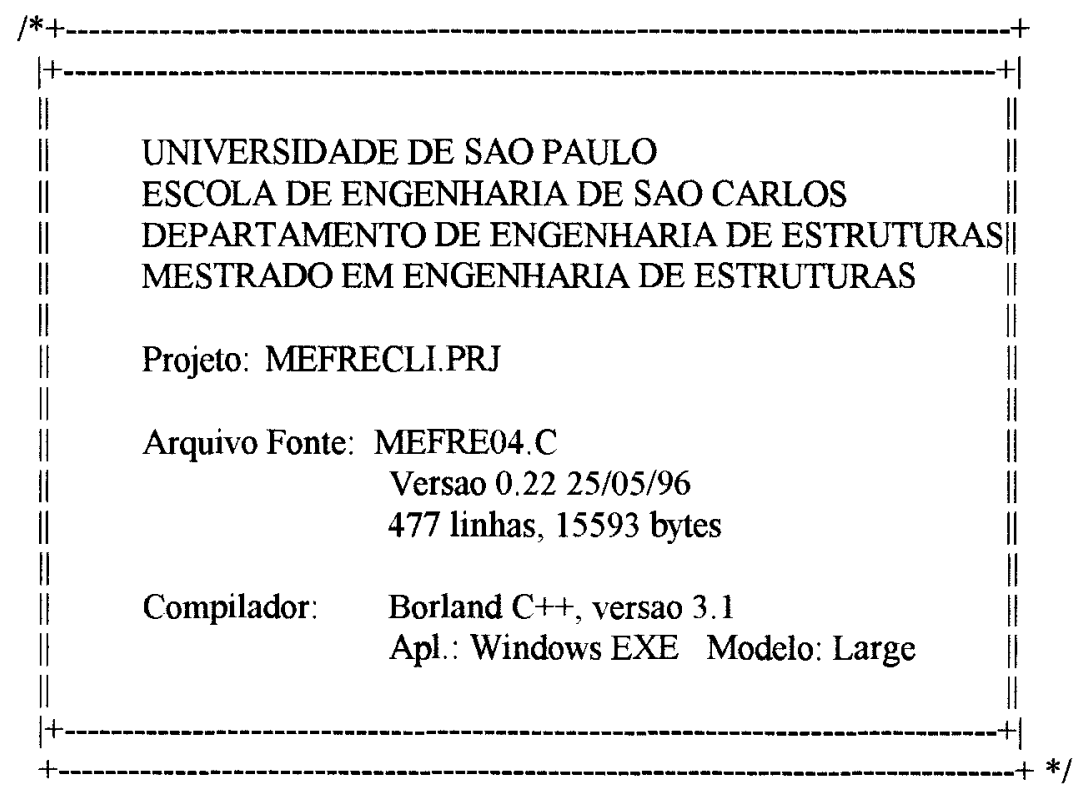

\#include $<$ stdio.h $>$ \#include $<$ conio. $\mathrm{h}>$ \#include $<$ stdlib.h $>$ \#include $<$ math. $\mathrm{h}>$ \#include "mefre04.h"

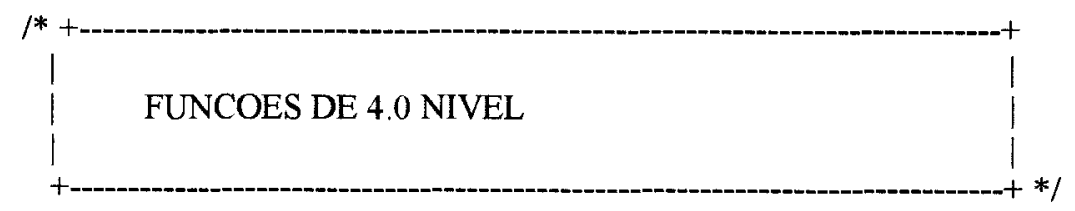

void intloc(double $\mathrm{xc}$, double yc, double $\mathrm{x} 1$, double $\mathrm{y} 1$, double $\mathrm{x} 2$, double y2, int pos)

\{

double aux3, a, csib;

* CALCULO DAS PROPRIEDADES GEOMETRICAS */

$1=\operatorname{sqrt}((\mathrm{x} 2-\mathrm{x} 1) *(\mathrm{x} 2-\mathrm{x} 1)+(\mathrm{y} 2-\mathrm{y} 1) *(\mathrm{y} 2-\mathrm{y} 1))$;

$\mathrm{drx}=(\mathrm{x} 2-\mathrm{x} 1) / 1 ; \mathrm{dry}=(\mathrm{y} 2-\mathrm{y} 1) / 1 ;$

/* CALCULO DOS COEFICIENTES */

switch(pos)

\{

case 0 : aux $3=1 /\left(16.0^{*} \mathrm{PI}^{*} \mathrm{GE}^{*}(1.0-\mathrm{NI})\right)$;

$\mathrm{GW}[0][0]=\operatorname{aux} 3 *((3 \cdot 0-4.0 * \mathrm{NI}) *(1.5-\log (1))+\mathrm{drx} * \mathrm{drx})$;

$\mathrm{GW}[0][1]=$ aux $3 * \mathrm{drx} * \mathrm{dry}$;

$\mathrm{GW}[1][0]=\mathrm{GW}[0][1]$

$\mathrm{GW}[1][1]=\operatorname{aux} 3 *((3.0-4.0 * \mathrm{NI}) *(1.5-\log (1))+\mathrm{dry} * \mathrm{dry}) ;$

$\mathrm{GW}[0][2]=\operatorname{aux} 3 *((3.0-4.0 * \mathrm{NI}) *(0.5-\log (1))+\mathrm{drx} * \mathrm{drx})$;

GW[0][3] = aux $3 *$ drx*dry;

GW[1][2] $=$ GW[0][3];

$\mathrm{GW}[1][3]=\operatorname{aux} 3 *((3.0-4.0 * \mathrm{NI}) *(0.5-\log (1))+\mathrm{dry} * \mathrm{dry})$;

aux3 $=(1.0-2.0 * \mathrm{NI}) /(4.0 * \mathrm{PI} *(1.0-\mathrm{NI}))$; 


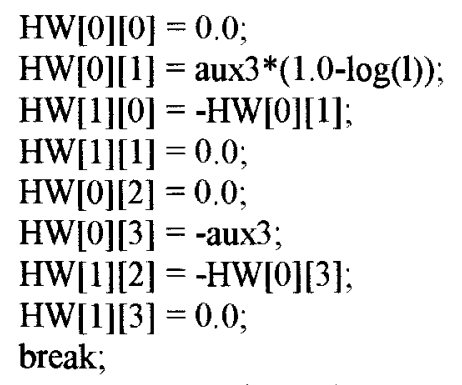

case 1: a $=\operatorname{sqrt}((\mathrm{xc}-\mathrm{x} 1) *(\mathrm{xc}-\mathrm{x} 1)+(\mathrm{yc}-\mathrm{y} 1) *(\mathrm{yc}-\mathrm{y} 1))$;

$\mathrm{csib}=-1.0+2.0 * \mathrm{a} / \mathrm{l}$

aux3 $=1 /(64.0 * \mathrm{PI} * \mathrm{GE} *(1.0-\mathrm{NI}))$;

$\mathrm{GW}[0][0]=\operatorname{aux} 3 *(4.0 * \operatorname{drx} * \mathrm{drx}-(3.0-4.0 * \mathrm{NI}) *(4.0 * \log (1 * 0.5)+2.0 *$ $\left(\right.$ csib-2.0) $+\left(3.0+2.0^{*}\right.$ csib-csib*csib)* $\log (1.0+$ csib $)+$ $(1.0$-csib)*(1.0-csib)* $\log (1,0$-csib) $))$;

$\mathrm{GW}[0][1]=\operatorname{aux} 3 * 4.0 * \mathrm{drx} * \mathrm{dry}$,

$\mathrm{GW}[1][0]=\mathrm{GW}[0][1]$;

$\mathrm{GW}[1][1]=\operatorname{aux} 3 *(4.0 * \mathrm{dry} * \mathrm{dry}-(3.0-4.0 * \mathrm{NI}) *(4.0 * \log (1 * 0.5)+2.0 *$ $($ csib-2.0)+(3.0+2.0*csib-csib*csib $* \log (1.0+$ csib $)+$ $(1.0-\mathrm{csib}) *(1.0-\mathrm{csib}) * \log (1.0-\mathrm{csib})))$;

$\mathrm{GW}[0][2]=\operatorname{aux} 3 *\left(4.0 * \operatorname{dr} x^{*} \operatorname{drx}-(3.0-4.0 * \mathrm{NI}) *(4.0 * \log (1 * 0.5)-2.0 *\right.$ $(\mathrm{csib}+2.0)+(3.0-2.0 * \mathrm{csib}-\mathrm{csib} * \mathrm{csib}) * \log (1.0-\mathrm{csib})+$ $(1.0+$ csib $) *(1.0+c s i b) * \log (1.0+$ csib $))$;

$\mathrm{GW}[0][3]=\operatorname{aux} 3 * 4.0 * \mathrm{dr} x^{*} \mathrm{dry}$

$\mathrm{GW}[1][2]=\mathrm{GW}[0][3]$;

$\mathrm{GW}[1][3]=\operatorname{aux} 3 *\left(4.0 *\right.$ dry $* \mathrm{dry}-(3.0-4.0 * \mathrm{NI}) *\left(4.0^{*} \log (1 * 0.5)-2.0 *\right.$ $(\mathrm{csib}+2.0)+\left(3.0-2.0 * \mathrm{csib}-\mathrm{csib}^{*} \mathrm{csib}\right) * \log (1.0-\mathrm{csib})+$

$\operatorname{aux} 3=(1.0-2.0 * \mathrm{NI}) /(4.0 * \mathrm{PI} *(1.0-\mathrm{NI}))$; $(1.0+\mathrm{csib}) *(1.0+\mathrm{csib}) * \log (1.0+\mathrm{csib})))$;

$\mathrm{HW}[0][0]=0.0$;

$\mathrm{HW}[0][1]=\operatorname{aux} 3 *(1.0-(1.0-\mathrm{csib}) * 0.5 * \log ((1.0-\mathrm{csib}) /(1.0+\mathrm{csib})))$;

HW[1][0] = -HW[0][1];

$\mathrm{HW}[1][1]=0.0$;

$\mathrm{HW}[0][2]=0.0$;

HW[0][3] $=-$ aux $3 *(1.0+(1.0+\mathrm{csib}) * 0.5 * \log ((1.0-\mathrm{csib}) /(1.0+\mathrm{csib})))$;

$\mathrm{HW}[1][2]=-\mathrm{HW}[0][3]$;

$\mathrm{HW}[1][3]=0.0$;

break;

case $2:$ aux3 $=1 /(16.0 * \mathrm{PI} * \mathrm{GE} *(1.0-\mathrm{NI}))$;

$\mathrm{GW}[0][0]=\operatorname{aux} 3 *((3.0-4.0 * \mathrm{NI}) *(0.5-\log (1))+\mathrm{drx} * \mathrm{drx})$;

$\mathrm{GW}[0][1]=\operatorname{aux} 3 * \mathrm{drx} * \mathrm{dry}$;

$\mathrm{GW}[1][0]=\mathrm{GW}[0][1]$;

$\mathrm{GW}[1][1]=\operatorname{aux} 3 *((3.0-4.0 * \mathrm{NI}) *(0.5-\log (1))+\mathrm{dry} * \mathrm{dry})$;

$\mathrm{GW}[0][2]=\operatorname{aux} 3 *((3.0-4.0 * \mathrm{NI}) *(1.5-\log (1))+\mathrm{dr} x * \mathrm{drx})$;

$\mathrm{GW}[0][3]=\operatorname{aux} 3 * \mathrm{drx} * \mathrm{dry}$;

$\mathrm{GW}[1][2]=\mathrm{GW}[0][3]$;

GW[1][3] $=\operatorname{aux} 3 *((3.0-4.0 * \mathrm{NI}) *(1.5-\log (1))+$ dry $*$ dry $)$;

$\operatorname{aux} 3=(1.0-2.0 * \mathrm{NI}) /(4.0 * \mathrm{PI} *(1.0-\mathrm{NI}))$;

$\mathrm{HW}[0][0]=0.0$;

$\mathrm{HW}[0][1]=\operatorname{aux} 3$;

$\mathrm{HW}[1][0]=-\mathrm{HW}[0][1]$;

$\mathrm{HW}[1][1]=0.0$;

HW[0][2] $=0.0$;

HW[0][3] $=\operatorname{aux} 3 *(\log (1)-1.0)$;

HW[1][2] = -HW[0][3];

$\mathrm{HW}[1][3]=0.0$;

break; 
/* \#\#\#\#\#\#\#\#\#\#\#\#\#\#\#\#\#\#\#\#\#\#\#\#\#\#\#\#\#\#\#\#\#\#\#\#\#\#\#\#\#\#\#\#\#\#\#\#\#\#\#\#\#\#\#\#\#\#\#\# */

void intext(double $\mathrm{xc}$, double yc, double $\mathrm{x} 1$, double $\mathrm{y} 1$, double $\mathrm{x} 2$, double y2)

\{

int $\mathrm{i}, \mathrm{j}, \mathrm{k}, \mathrm{w}$, auxl, nsubel;

double aux3, d1, d2, csi;

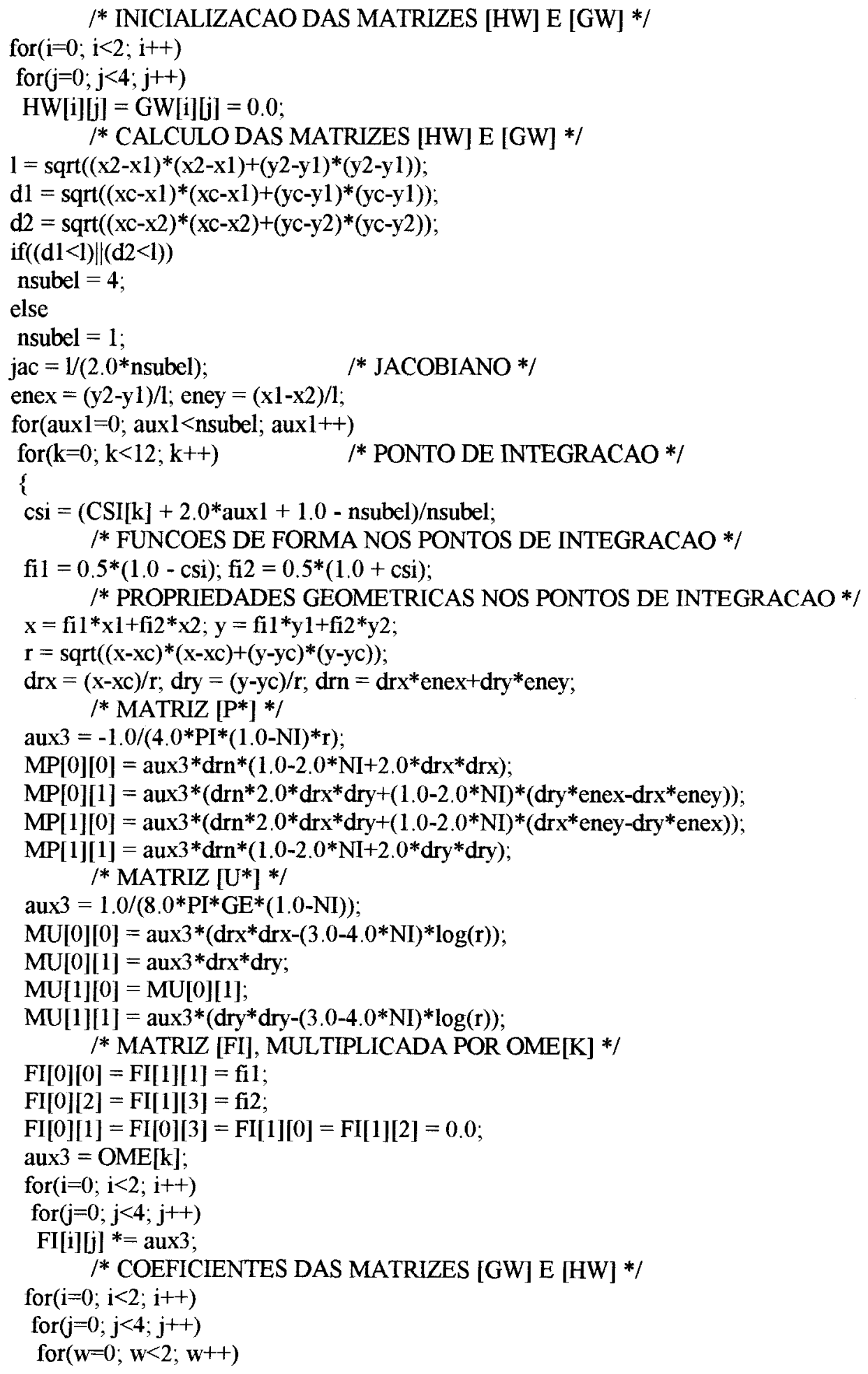




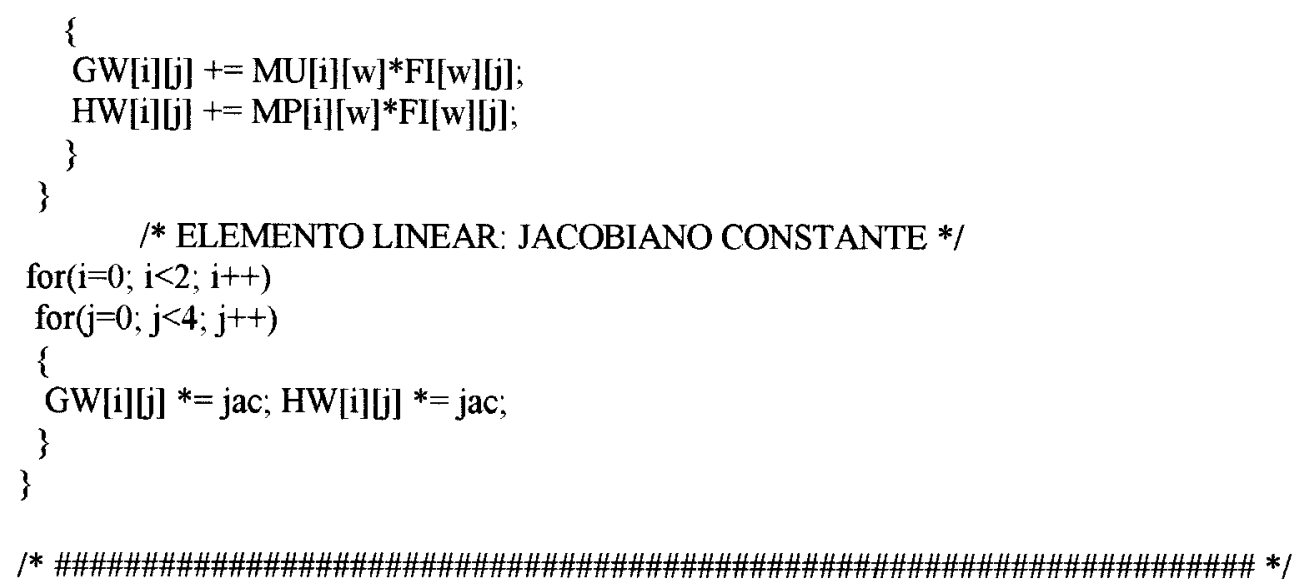

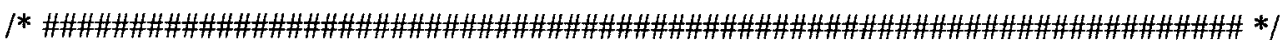

void sd(double $\mathrm{xc}$, double $\mathrm{yc}$, double $\mathrm{x} 1$, double $\mathrm{y} 1$, double $\mathrm{x} 2$, double $\mathrm{y} 2$ )

int $\mathrm{i}, \mathrm{j}, \mathrm{k}, \mathrm{w}$, auxl, nsubel;

double aux $3, \mathrm{dl}, \mathrm{d} 2$, csi;

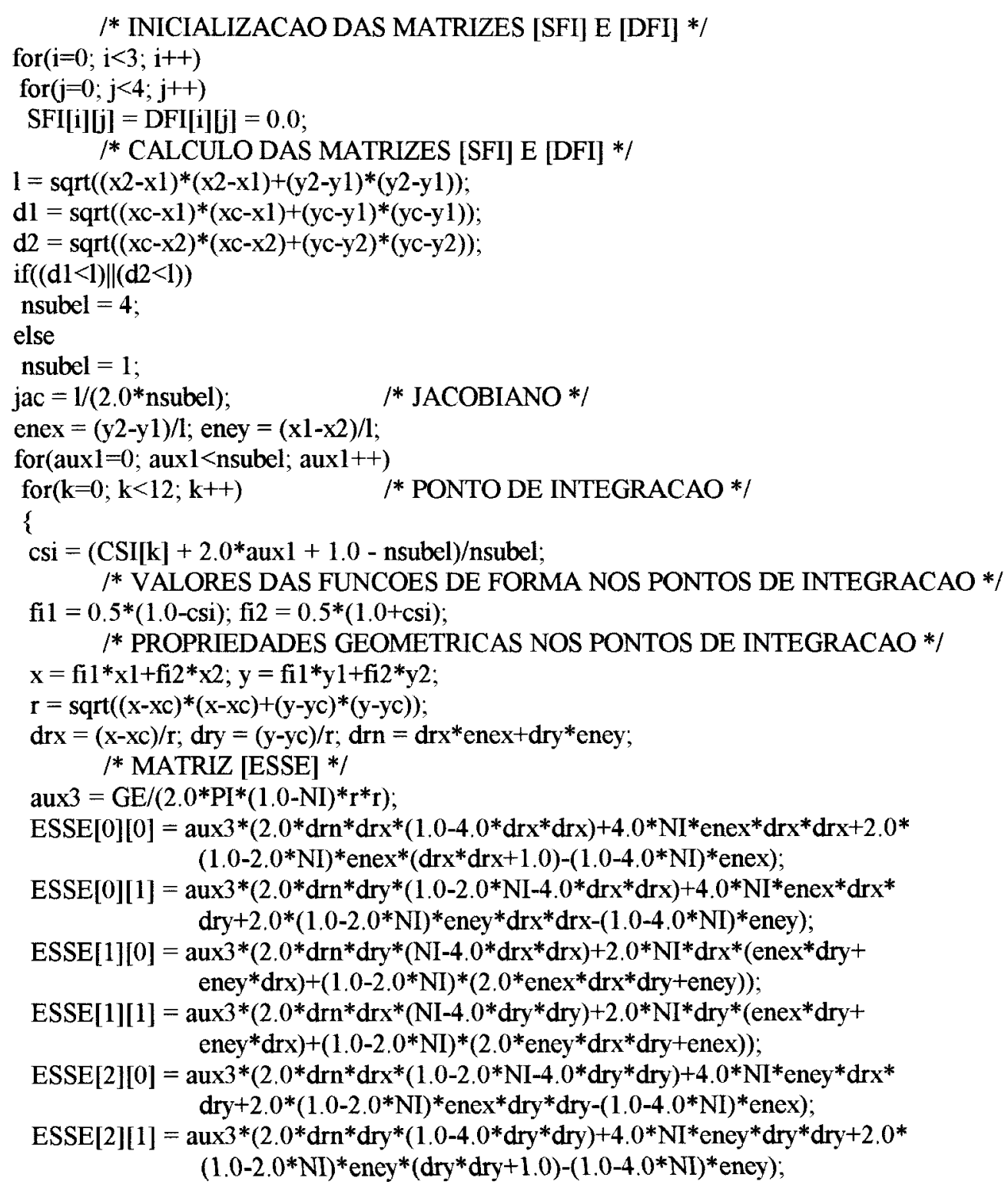




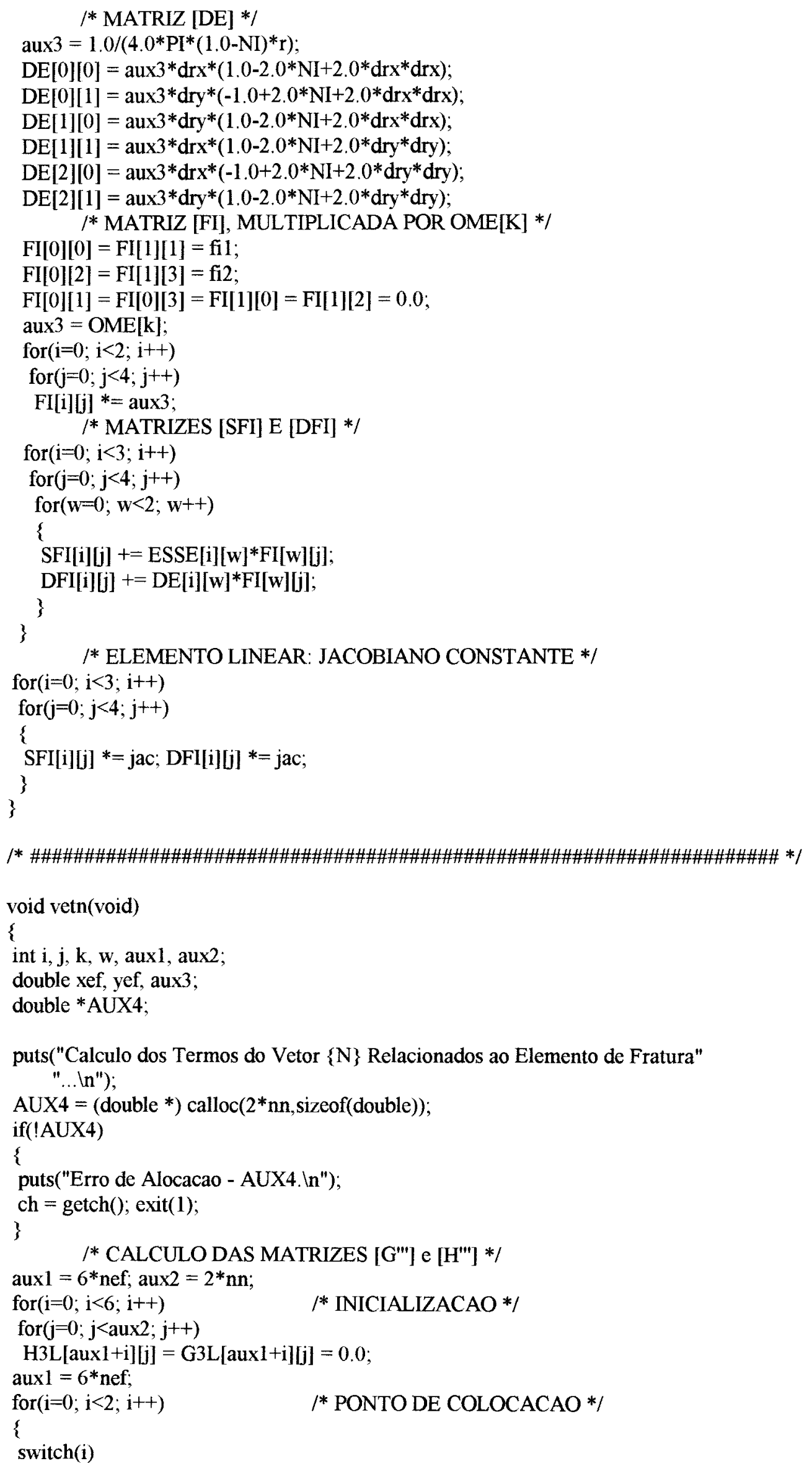




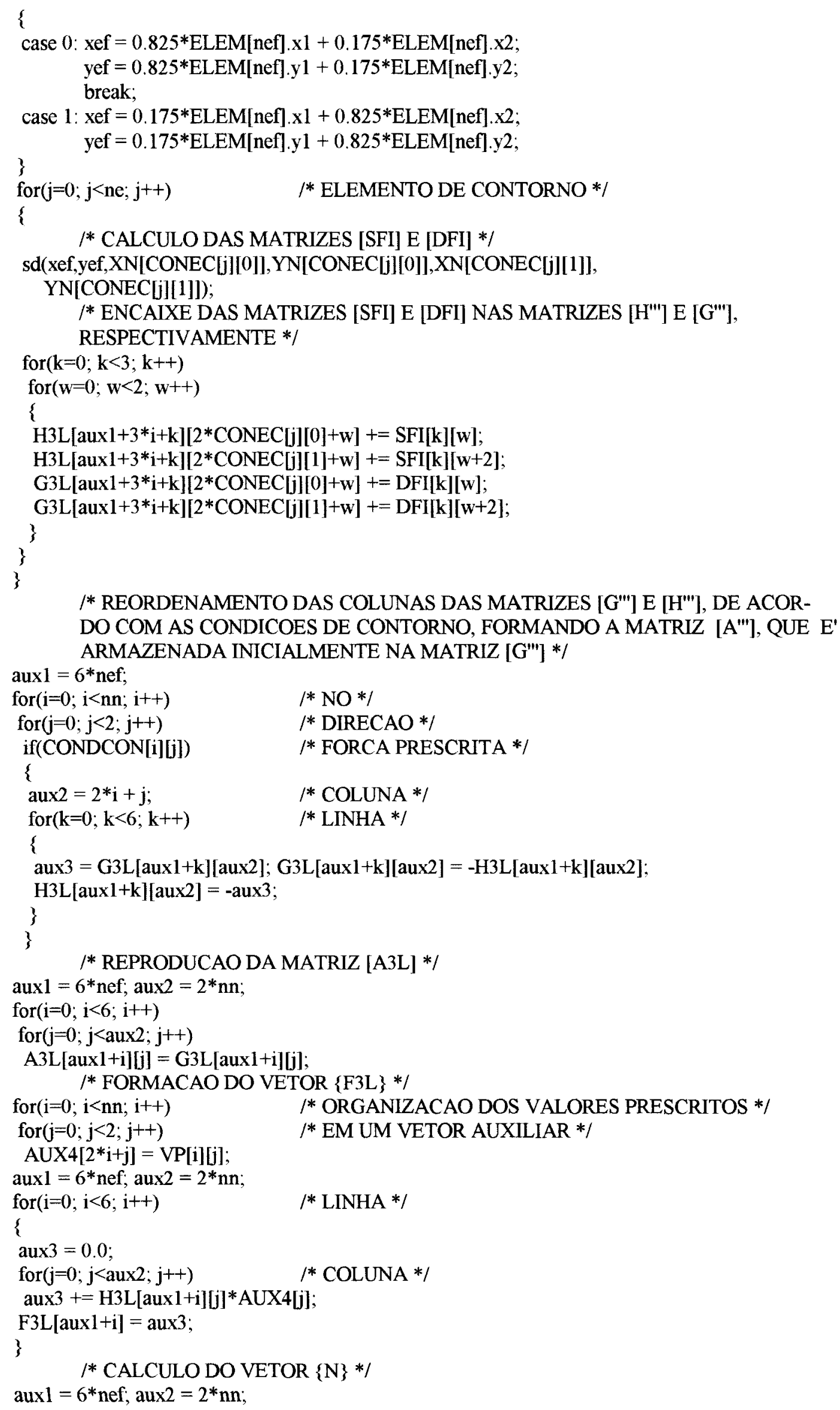

/* REORDENAMENTO DAS COLUNAS DAS MATRIZES [G"'] E [H"'], DE ACORDO COM AS CONDICOES DE CONTORNO, FORMANDO A MATRIZ [A"'], QUE E' auxl $=6 *$ nef; ARMAZENADA INICIALMENTE NA MATRIZ [G"'] */ 


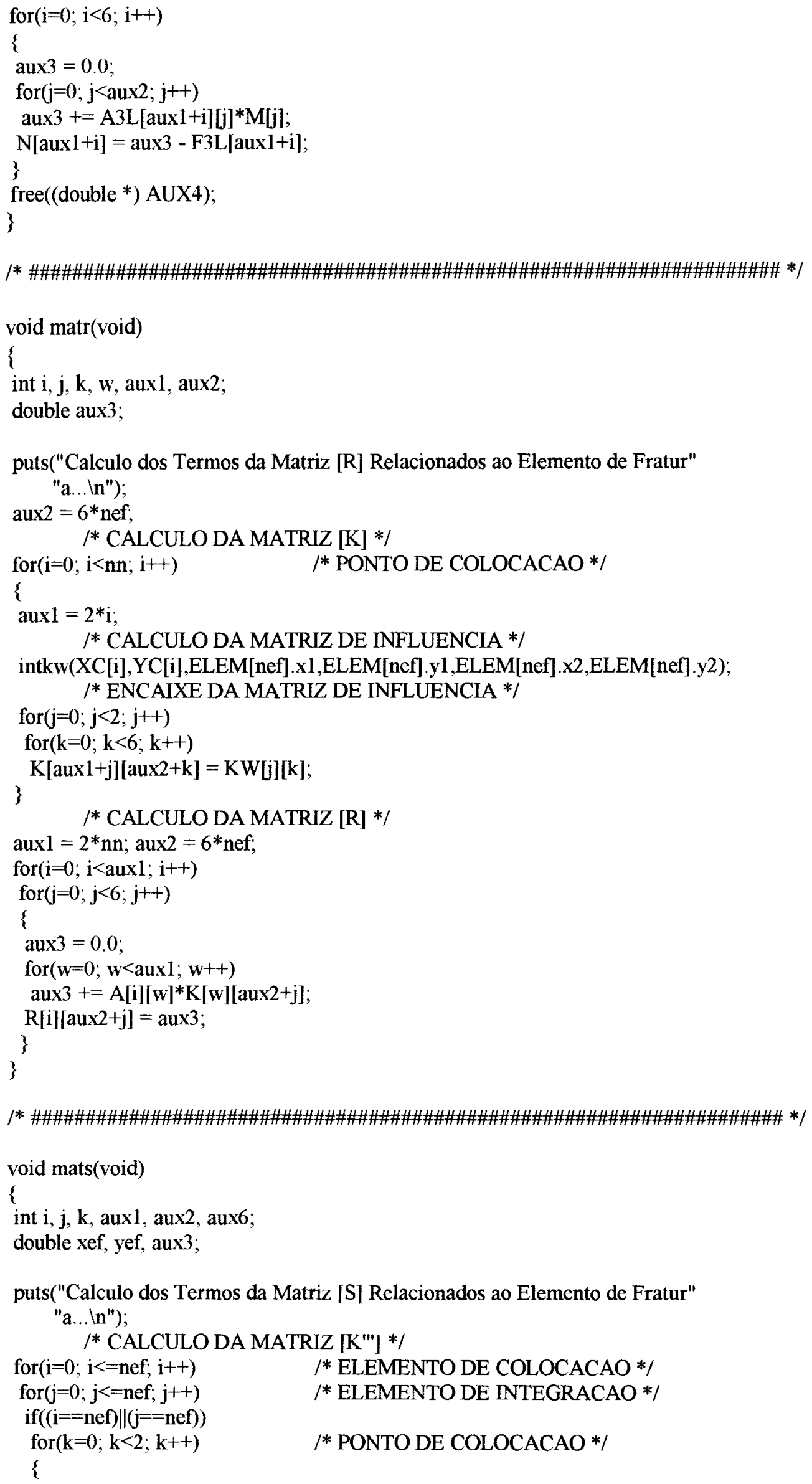




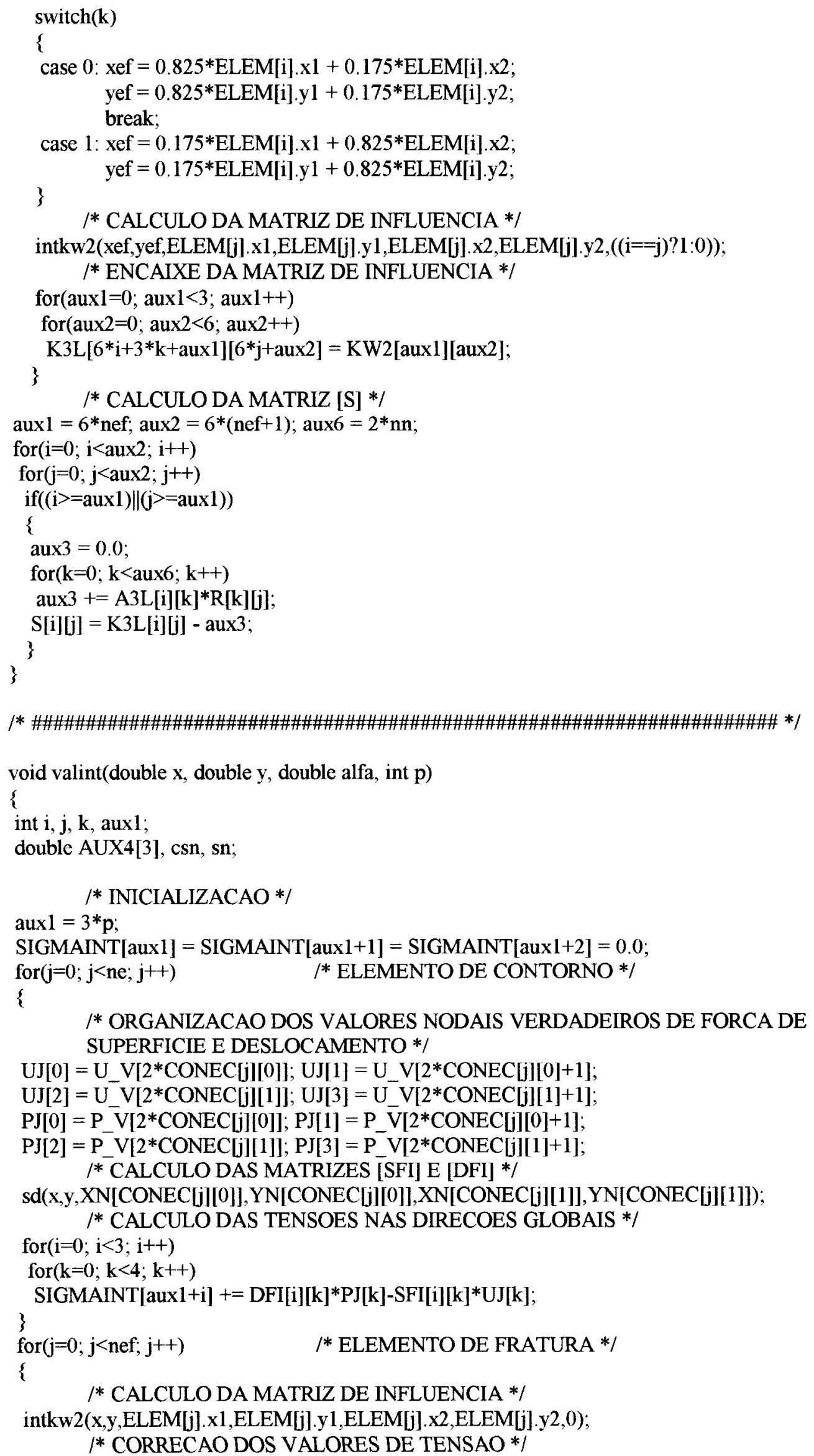




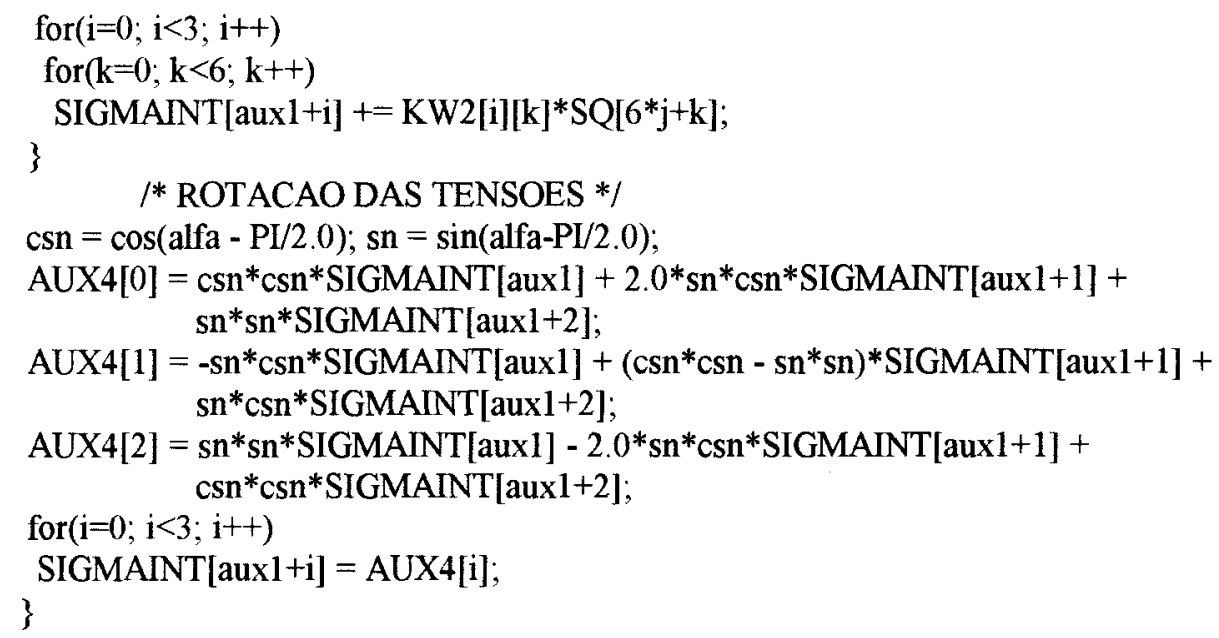

\section{D.5 Mefre05.c}

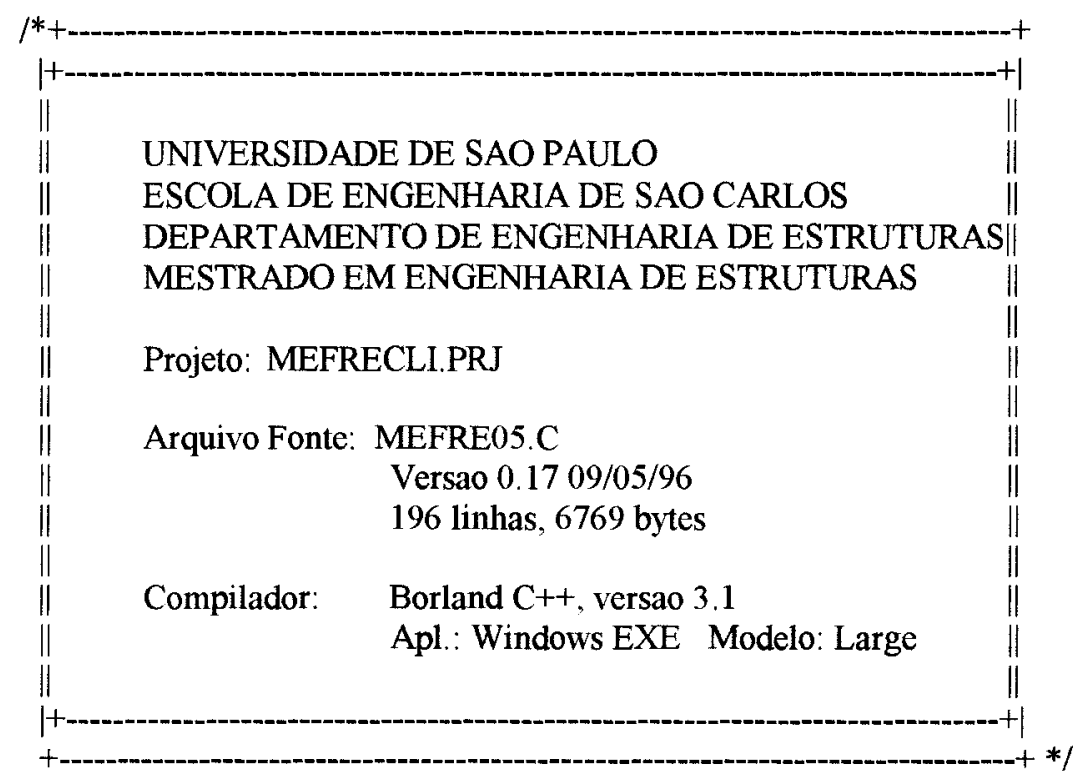

\#include $<$ stdio.h $>$ \#include $<$ conio. $\mathrm{h}>$ \#include $<$ stdlib.h $>$ \#include $<$ math, $h>$ \#include "mefre05.h"

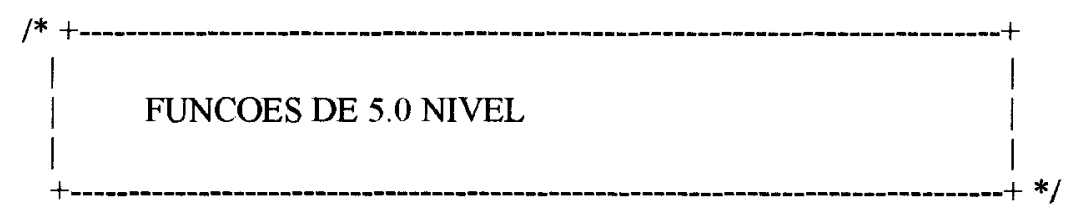

void intkw(double $\mathrm{xc}$, double yc, double $\mathrm{x} 1$, double $\mathrm{y} 1$, double $\mathrm{x} 2$, double y2) 
int $\mathrm{i}, \mathrm{j}, \mathrm{k}, \mathrm{w}$, auxl, nsubel;

double aux $3, \mathrm{~d} 1, \mathrm{~d} 2$, csi;

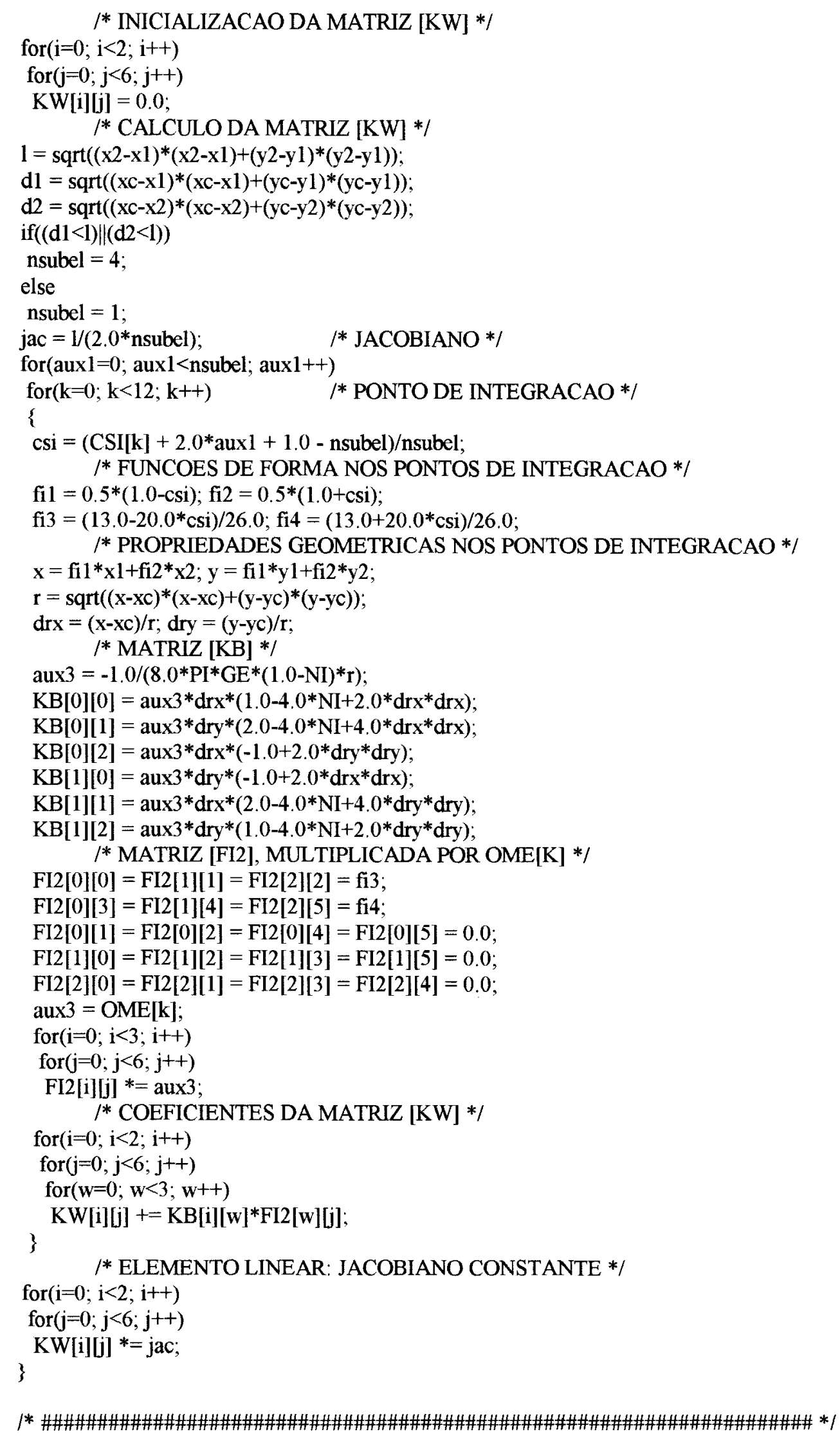


void intkw2(double xc, double yc, double x1, double y1, double $\mathrm{x}$, double $y 2$, int singular)

\{ int $i, j, k, w$, aux 1 , nsubel;

double aux3, aux7, a, csib, d1, d2, csi;

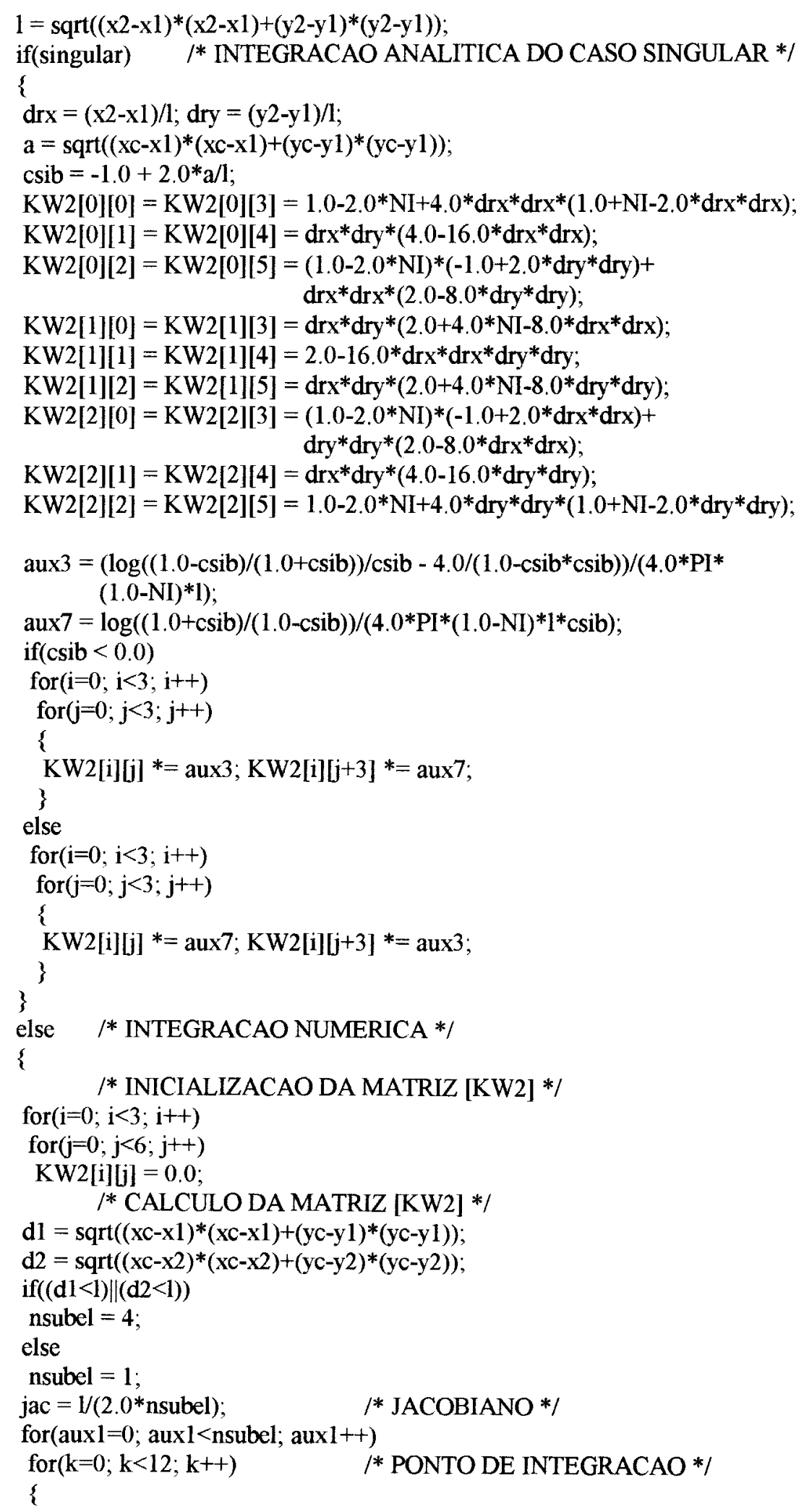




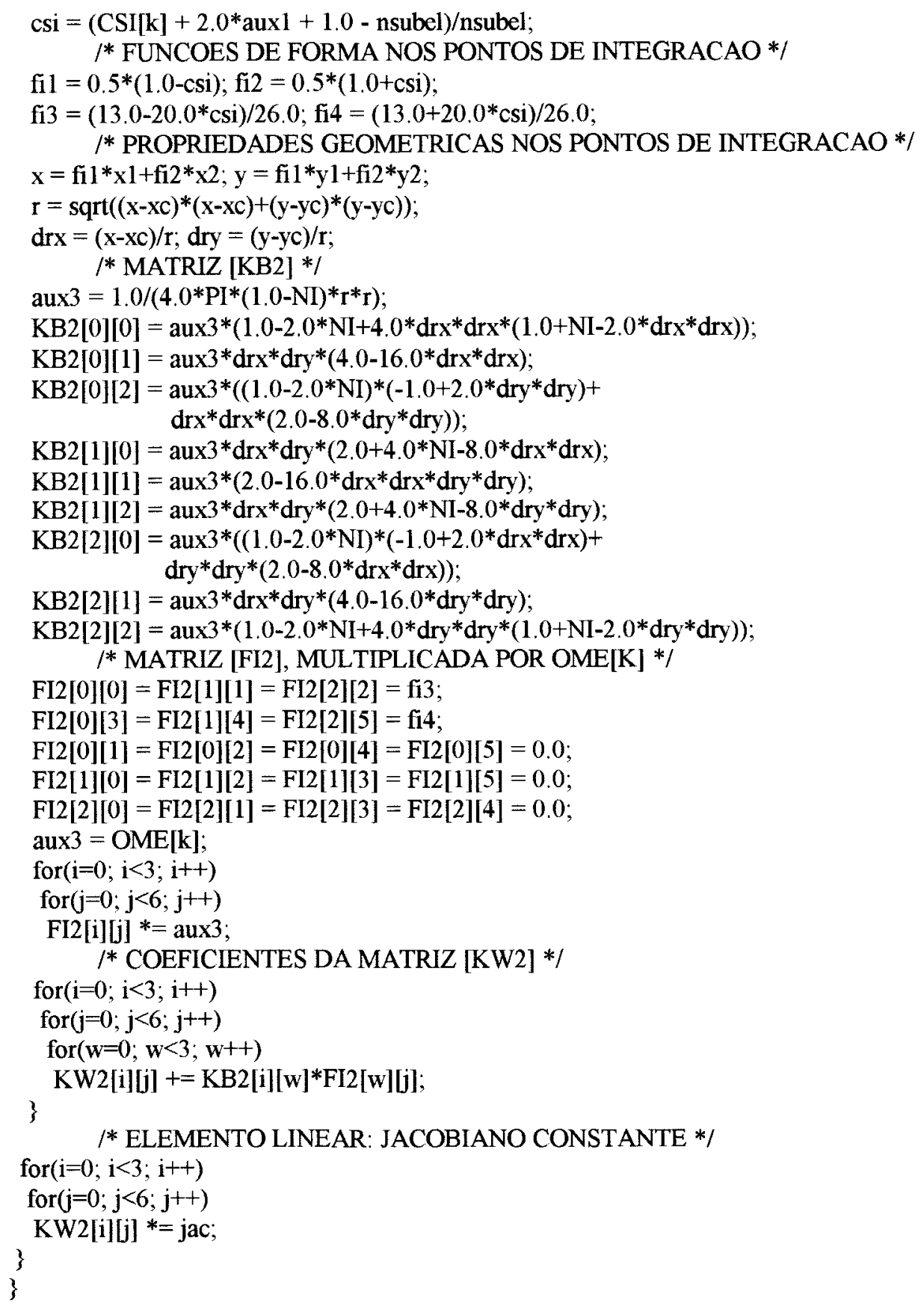

\section{D.6 Mefre02.h}

UNIVERSIDADE DE SAO PAULO 


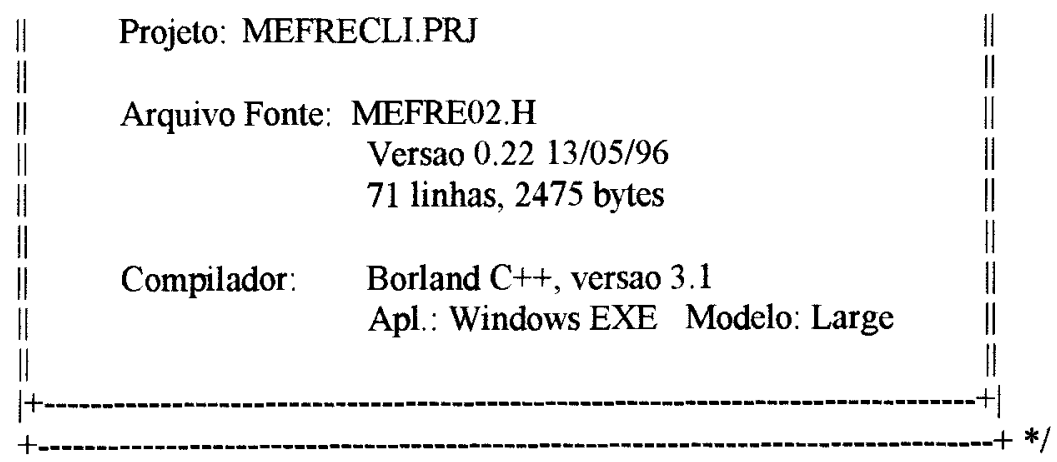

\#include $<$ stdio.h $>$

\#include $<$ conio.h $>$

\#include $<$ stdlib.h $>$

\#include $<$ math.h $>$

\#define PI 3.141592653589794

\#define max_ne 60

\#define max_npi 10

\#define max nnd 25

\#define max_nn 85

\#define max_nef 50

\#define max_ninc 1000

extern char ch;

extern int ne, npi, nnd, nn, nef, inc, ninc, i, j, k, w, exemplo, tipo; extern double E, GE, NI, ft, wc, alfa, r, drx, dry, drn, $x, y, f i 1, f i 2$, struct ELEMFRA

fi3, fi4, l, lef, jac, enex, eney;

\{

int ult;

double $\mathrm{x} 1, \mathrm{y} 1, \mathrm{x} 2, \mathrm{y} 2$;

;

extern char FILENAME[30];

extern int $* \mathrm{ND}, * \mathrm{NF},{ }^{*} \mathrm{INCINI}$

extern double *XN, *YN, *XC, *YC, *XI, *YI, *U, *U V, *P, *P V, *F, *F3L,

${ }^{*} \mathrm{M},{ }^{*} \mathrm{X},{ }^{*} \mathrm{~N},{ }^{*} \mathrm{LAMBDA}, * \mathrm{Q},{ }^{*} \mathrm{RQ}, * \mathrm{SQ},{ }^{*} \mathrm{SIGM}$ ACON, ${ }^{*}$ SIGMACON_V

*SIGMAFRA, *WFRA, *SIGMAPI, *DELTAPI;

extern double CSI[12], OME[12];

extern double UJ[4], PJ[4], DELTASIGMA[4], DELTAQ[6], SIGMAINT[21];

extern struct ELEMFRA *ELEM;

extern int ${ }^{* *} \mathrm{CONDCON},{ }^{*} \mathrm{CONEC},{ }^{* *} \mathrm{MC}$;

extern double CFI[2][4], GW[2][4], HW[2][4], KW[2][6], KW2[3][6], MP[2][2],

MU[2][2], FI[2][4], FI2[3][6], ESSE[3][2], DE[3][2], KB[2][3],

KB2[3][3], SFI[3][4], DFI[3][4], DELTAS[3][3], ROT[3][3];

extern double ${ }^{* *} \mathrm{VP},{ }^{* *} \mathrm{G},{ }^{* *} \mathrm{G} 3 \mathrm{~L},{ }^{* *} \mathrm{H},{ }^{* *} \mathrm{H} 3 \mathrm{~L},{ }^{* *} \mathrm{~K},{ }^{* *} \mathrm{~K} 3 \mathrm{~L},{ }^{* *} \mathrm{~A},{ }^{* *} \mathrm{~A} 3 \mathrm{~L},{ }^{* *} \mathrm{R}$, ${ }^{* *} \mathrm{~S}$;

extern FILE *FILEIN, *FILEOUT, *FILEGRAF;

void entrada(void), anelin(void), saidanumel(void), anfrat(void),

saidagraf(void), libmem1(void), libmem2(void);

void alocmem1(void), alocmem2(void), alocmem3(void), alocmem4(void), 
alocmem5(void), alocmem6(void), alocmem7(void), alocmem8(void), matgh(void), sels(double ${ }^{* *} \mathrm{~A}$, double ${ }^{*} \mathrm{~B}$, int $\mathrm{n}$ ), tencon(void), destenint(void), invplc(double $* * A$, int $\mathrm{n}$ ), tenconv(void), inctenfra(void), versur(void), verpro(void), iter(void);

\section{D.7 Mefre03.h}

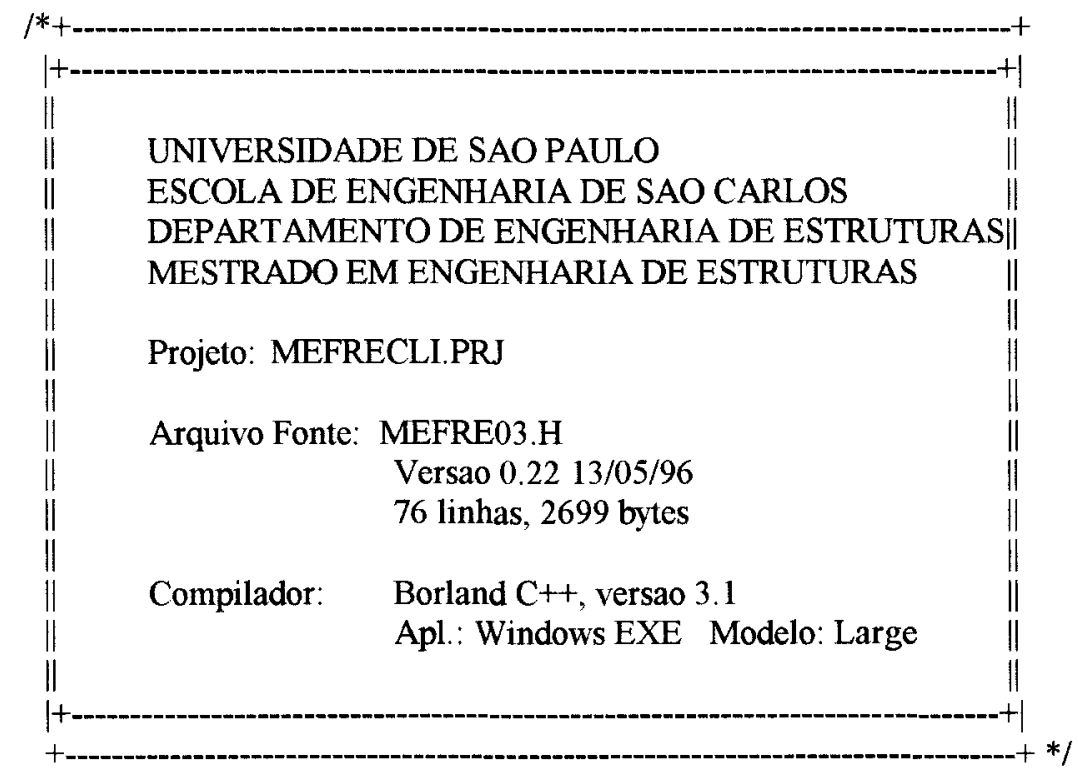

\#include $<$ stdio.h $>$

\#include $<$ conio.h $>$

\#include $<$ stdlib.h $>$

\#include $<$ math.h $>$

\#define PI 3.141592653589794

\#define max_ne 60

\#define max npi 10

\#define max nnd 25

\#define max_nn 85

\#define max_nef 50

\#define max ninc 1000

extern char ch;

extern int ne, npi, nnd, nn, nef, inc, ninc, i, j, k, w, exemplo, tipo;

extern double E, GE, NI, ft, wc, alfa, r, drx, dry, drn, x, y, fil, fi2,

struct ELEMFRA

fi3, fi4, l, lef, jac, enex, eney;

\{

int ult;

double $x 1, y 1, x 2, y 2$;

\}

extern char FILENAME[30];

extern int *ND, *NF, *INCINI;

extern double *XN, *YN, *XC, *YC, *XI, *YI, *U, *U_V, *P, *P_V, *F, *F3L, 
*M, *X, *N, *LAMBDA, *Q, *RQ, *SQ, *SIGMACON, *SIGMACON_V,

*SIGMAFRA, *WFRA, *SIGMAPI, *DELTAPI;

extern double CSI[12], OME[12];

extern double UJ[4], PJ[4], DELTASIGMA[4], DELTAQ[6], SIGMAINT[21];

extern struct ELEMFRA *ELEM;

extern int ${ }^{* *} \mathrm{CONDCON},{ }^{* *} \mathrm{CONEC},{ }^{* *} \mathrm{MC}$;

extern double CFI[2][4], GW[2][4], HW[2][4], KW[2][6], KW2[3][6], MP[2][2],

MU[2][2], FI[2][4], FI2[3][6], ESSE[3][2], DE[3][2], KB[2][3],

KB2[3][3], SFI[3][4], DFI[3][4], DELTAS[3][3], ROT[3][3];

extern double ${ }^{* *} \mathrm{VP},{ }^{* *} \mathrm{G},{ }^{* *} \mathrm{G} 3 \mathrm{~L},{ }^{* *} \mathrm{H},{ }^{* *} \mathrm{H} 3 \mathrm{~L},{ }^{* *} \mathrm{~K},{ }^{* *} \mathrm{~K} 3 \mathrm{~L},{ }^{* *} \mathrm{~A},{ }^{* *} \mathrm{~A} 3 \mathrm{~L},{ }^{* *} \mathrm{R}$,

$* * S$;

extern FILE *FILEIN, *FILEOUT, *FILEGRAF;

void alocmem 1(void), alocmem2(void), alocmem3(void), alocmem4(void), alocmem5(void), alocmem6(void), alocmem7(void), alocmem8(void), matgh(void), sels(double ${ }^{* *}$, double $* B$, int $n$ ), tencon(void), destenint(void), invplc(double **A, int $\mathrm{n}$ ), tenconv(void), inctenfra(void), versur(void), verpro(void), iter(void);

void intloc(double $\mathrm{xc}$, double $\mathrm{yc}$, double $\mathrm{x} 1$, double $\mathrm{yl}$, double $\mathrm{x} 2$, double y2, int pos),

intext(double xc, double yc, double x1, double y1, double x2, double y2),

sd(double xc, double yc, double xl, double yl, double x2, double y2), vetn(void), matr(void), mats(void),

valint(double $x$, double $y$, double alfa, int $\mathrm{p}$ );

\section{D.8 Mefre04.h}

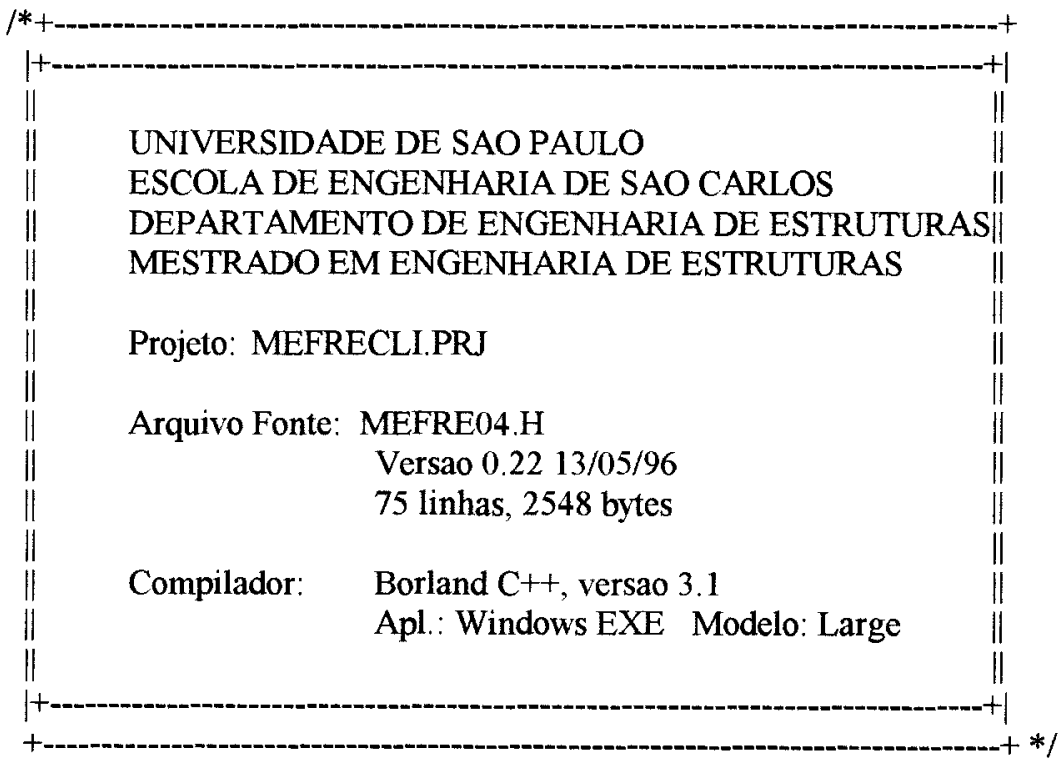

\#include $<$ stdio. $\mathrm{h}>$

\#include $<$ conio. $\mathrm{h}>$ 
\#include $<$ stdlib.h $>$

\#include $<$ math.h $>$

\#define PI 3.141592653589794

\#define max_ne 60

\#define max npi 10

\#define max_nnd 25

\#define max_nn 85

\#define max_nef 50

\#define max_ninc 1000

extern char ch;

extern int ne, npi, nnd, nn, nef, inc, ninc, i, j, k, w, exemplo, tipo;

extern double E, GE, NI, ft, wc, alfa, r, drx, dry, drn, x, y, fil, fi2,

struct ELEMFRA

fi3, fi4, 1, lef, jac, enex, eney;

\{

int ult;

double $\mathrm{x} 1, \mathrm{y} 1, \mathrm{x} 2, \mathrm{y} 2$;

\}

extern char FILENAME[30];

extern int *ND, *NF, *INCINI;

extern double *XN, *YN, *XC, *YC, *XI, *YI, *U, *U_V, *P, *P_V, *F, *F3L,

${ }^{*} \mathrm{M},{ }^{*} \mathrm{X},{ }^{*} \mathrm{~N},{ }^{*} \mathrm{LAMBDA},{ }^{*} \mathrm{Q},{ }^{*} \mathrm{RQ},{ }^{*} \mathrm{SQ},{ }^{*}$ SIGMACON, ${ }^{*}$ SIGMACON_V,

*SIGMAFRA, *WFRA, *SIGMAPI, *DELTAPI;

extern double CSI[12], OME[12];

extern double UJ[4], PJ[4], DELTASIGMA[4], DELTAQ[6], SIGMAINT[21];

extern struct ELEMFRA *ELEM;

extern int ${ }^{* *} \mathrm{CONDCON},{ }^{* *} \mathrm{CONEC},{ }^{* *} \mathrm{MC}$;

extern double CFI[2][4], GW[2][4], HW[2][4], KW[2][6], KW2[3][6], MP[2][2],

MU[2][2], FI[2][4], FI2[3][6], ESSE[3][2], DE[3][2], KB[2][3],

KB2[3][3], SFI[3][4], DFI[3][4], DELTAS[3][3], ROT[3][3];

extern double ${ }^{* *} \mathrm{VP},{ }^{* *} \mathrm{G},{ }^{* *} \mathrm{G} 3 \mathrm{~L},{ }^{* *} \mathrm{H},{ }^{* *} \mathrm{H} 3 \mathrm{~L},{ }^{* *} \mathrm{~K},{ }^{* *} \mathrm{~K} 3 \mathrm{~L},{ }^{* *} \mathrm{~A},{ }^{* *} \mathrm{~A} 3 \mathrm{~L},{ }^{* *} \mathrm{R}$, $* * \mathrm{~S}$

extern FILE *FILEIN, *FILEOUT, *FILEGRAF;

void intloc(double xc, double yc, double $\mathrm{x} 1$, double $\mathrm{y} 1$, double $\mathrm{x} 2$, double $\mathrm{y} 2$, int pos),

intext(double xc, double yc, double $\mathrm{x} 1$, double $\mathrm{y} 1$, double $\mathrm{x} 2$, double y2),

sd(double xc, double yc, double $\mathrm{x} 1$, double $\mathrm{y} 1$, double $\mathrm{x} 2$, double $\mathrm{y} 2$ ),

vetn(void), matr(void), mats(void),

valint(double $x$, double $y$, double alfa, int $p$ );

void intkw(double xc, double yc, double x1, double y1, double x2, double y2),

intkw2(double xc, double yc, double x1, double y1, double x2, double y2, int singular); 


\section{D.9 Mefre05.h}

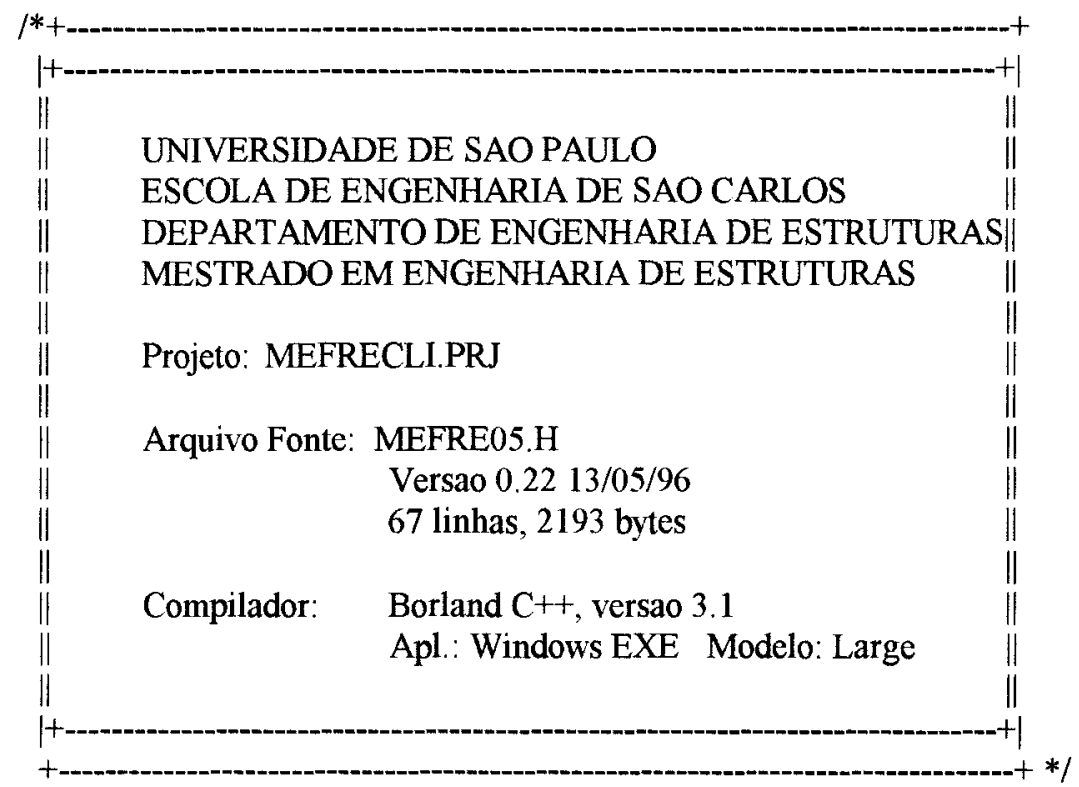

\#include $<$ stdio.h $>$ \#include $<$ conio. $\mathrm{h}>$ \#include $<$ stdlib.h> \#include $<$ math.h $>$

\#define PI 3.141592653589794

\#define max ne 60

\#define max_npi 10

\#define max nnd 25

\#define max_nn 85

\#define max_nef 50

\#define max_ninc 1000

extern char ch;

extern int ne, npi, nnd, nn, nef, inc, ninc, i, j, k, w, exemplo, tipo;

extern double E, GE, NI, ft, wc, alfa, r, drx, dry, drn, $x, y$, fi1, fi2, fi3, fi4, 1, lef, jac, enex, eney;

struct ELEMFRA

\{

int ult;

double $x 1, y 1, x 2, y 2$;

;

extern char FILENAME[30];

extern int *ND, *NF, *INCINI;

extern double *XN, *YN, *XC, ${ }^{*} \mathrm{YC}, * \mathrm{XI}, * \mathrm{YI},{ }^{*} \mathrm{U},{ }^{*} \mathrm{U} \_\mathrm{V},{ }^{*} \mathrm{P},{ }^{*} \mathrm{P} \_\mathrm{V}, * \mathrm{~F},{ }^{*} \mathrm{~F} 3 \mathrm{~L}$,

${ }^{*} \mathrm{M},{ }^{*} \mathrm{X},{ }^{*} \mathrm{~N},{ }^{*} \mathrm{LAMBDA},{ }^{*} \mathrm{Q},{ }^{*} \mathrm{RQ},{ }^{*} \mathrm{SQ},{ }^{*} \mathrm{SIGMACON},{ }^{*}$ SIGMACON_V,

*SIGMAFRA, *WFRA, *SIGMAPI, *DELTAPI;

extern double CSI[12], OME[12];

extern double UJ[4], PJ[4], DELTASIGMA[4], DELTAQ[6], SIGMAINT[21];

extern struct ELEMFRA *ELEM;

extern int **CONDCON, **CONEC,**MC;

extern double CFI[2][4], GW[2]|4]. HW[2][4], KW[2]!6], KW2[3!!6! MPI2!2]. 
MU[2][2], FI[2][4], FI2[3][6], ESSE[3][2], DE[3][2], KB[2][3],

KB2[3][3], SFI[3][4], DFI[3][4], DELTAS[3][3], ROT[3][3];

extern double ${ }^{* *} \mathrm{VP},{ }^{* *} \mathrm{G},{ }^{* *} \mathrm{G} 3 \mathrm{~L},{ }^{* *} \mathrm{H},{ }^{* *} \mathrm{H} 3 \mathrm{~L},{ }^{* *} \mathrm{~K},{ }^{* *} \mathrm{~K} 3 \mathrm{~L},{ }^{* *} \mathrm{~A},{ }^{* *} \mathrm{~A} 3 \mathrm{~L},{ }^{* *} \mathrm{R}$,

**S;

extern FILE *FILEIN, *FILEOUT, *FILEGRAF;

void intkw(double $\mathrm{xc}$, double yc, double $\mathrm{xl}$, double $\mathrm{y} 1$, double $\mathrm{x} 2$, double y2),

intkw2(double xc, double yc, double $\mathrm{x} 1$, double $\mathrm{y} 1$, double $\mathrm{x} 2$, double y2, int singular); 


\section{REFERÊNCIAS BIBLIOGRÁFICAS}

ALIABADI, M. H. An enhanced boundary element method for determining fracture parameters. In: CRUSE, T. A., ed. Numerical methods in fracture mechanics, Proc. 4th Int. Conf.. San Antonio, Pineridge Press, 1987. p. 27-39.

ALIABADI, M. H.; ROOKE, D. P. Numerical fracture mechanics. Norwell / Southampton, Kluwer / CMP, 1991.

AMERICAN CONCRETE INSTITUTE. State-of-Art report, part I. 1989.

BAJPAI, A. C.; CALUS, I. M.; FAIRLEY, J. A. Numerical methods for engineers and scientists. London, Wiley, 1977.

BANERJEE, P. K.; BUTTERFIELD, R. Boundary element method in geomechanics. In: GUDEHUS, G., ed. Finite elements in geomechanics. London, Wiley, 1981. p. $529-570$.

BARSOUM, R. S. Application of quadratic isoparametric finite elements in linear fracture mechanics. Int. J. Frac., v. 10, p. 603-605, 1974.

BAZANT, Z. P. Instability, ductility and size effect in strain-softening concrete. J. Eng. Mech. Div., ASCE, v. 102, p. 331-344, 1976.

BAZANT, Z. P. Size effect in blunt fracture: concrete, rock, metal. J. Eng. Mech. Div., ASCE, v. 110, p. 518-535, 1984. 
BAZANT, Z. P., ed. Mechanics of geomaterials. New York, Wiley, 1985.

BAZANT, Z. P., ed. Mechanics of distributed cracking. Applied Mechanics Reviews, v. 39, n. 5, p. 675-705, 1986.

BAZANT, Z. P.; CEDOLIN, L. Blunt crack band propagation in finite element analysis. J. Eng. Mech. Div., ASCE, v. 105, p. 297-315, 1979.

BAZANT, Z. P.; CEDOLIN, L. Fracture mechanics of reinforced concrete. J. Eng. Mech. Div., ASCE, v. 106, p. 1287-1306, 1980.

BAZANT, Z. P.; CEDOLIN, L. Finite element modelling of crack band propagation. J. Struct. Div., ASCE, v. 109, p. 69-92, 1983.

BAZANT, Z. P.; OH, B. H. Crack band theory for fracture of concrete. Materials and Structures, RILEM, v. 16, n. 93, p. 155-177, 1983.

BECKER, A. A. The boundary element method in engineering. London, McGraw-Hill, 1992.

BEER, F. P.; JOHNSTON, Jr., E. R. Resistência dos materiais. 2. ed. Rio de Janeiro, McGraw-Hill, 1989.

BESUNER, P. M; SNOW, D. W. Application of the two-dimensional boundaryintegral equation method to engineering problems. In: ASME Symposium on the Boundary-Integral Equation Method, 1975.

BREBBIA, C. A; DOMINGUEZ, J. Boundary element methods for potential problems. Appl. Math. Modelling, v. 1, p. 372-378, 1977.

BREBBIA, C. A.; DOMINGUEZ, J. Boundary elements: an introductory course. Southampton / New York, CMP / McGraw-Hill, 1989. 
BREBBIA, C. A.; TELLES, J. C.; WROBEL, L. C. Boundary elements techniques. Theory and applications in engineering. Berlin / New York, Springer-Verlag, 1984.

BREBBIA, C. A.; WALKER, S. Boundary element techniques in engineering. London, Newnes-Butterworths, 1980.

CAKMAK, A. S.; BOTHA, J. F.; GRAY, W. G. Computational and applied mathematics for engineering analysis. Southampton / Berlin, CMP / SpringerVerlag, 1987.

CARPINTERI, A. Mechanical damage and crack growth in concrete: plastic collapse to brittle failure. Dordrecht, Martinus Nijhoff, 1986.

CARPINTERI, A.; INGRAFFEA, A. R., eds. Fracture mechanics of concrete: material caracterization and testing. The Hague, Martinus Nijhoff, 1984.

COHEN-TANOUDJI, C.; DIU, B.; LALOË, F. Mecanique quantique. tome II Paris, Hermann, 1973.

COOK, R. D.; MALKUS, D. S.; PLESHA, M. E. Concepts and applications of finite element analysis. 3. ed. New York, Wiley, 1989.

CRISFIELD, M. A. Non-linear finite element analysis of solid and structures. v 1. Chichester, Wiley, 1991.

CRUSE, T. A. A direct formulation and numerical solution of the general transient elastodynamic problem - II. J. Math. Analysis and Applications, v. 22, p. 341$355,1968$.

CRUSE, T. A. Numerical solutions in three dimensional elastostatics. Int. J. Solids and Structures, v. 5, p. 1259-1274, 1969 
CRUSE, T. A. Numerical evaluation of elastic stress intensity factors by the boundary integral equation method. In: SWEDLOW, J. L., ed. The surface crack: physical problems and computational solutions. New York, 1972. p. $153-170$

CRUSE, T. A. Application of the boundary integral equation method to threedimensional stress analysis. Computers and Structures, v. 3, p. 509-527, 1973.

CRUSE, T. A. An improved boundary integral equation method for threedimensional elastic stress analysis. Computers and Structures, v. 4, p. 741-754, 1974.

CRUSE, T. A. Two-dimensional fracture mechanics analysis. Appl. Math. Modelling, v. 2, p. 287-293, 1978.

CRUSE, T. A.; MEYERS, G. J. Three-dimensional fracture mechanics analysis. J. Struct. Div., ASCE, v. 103, p. 309-320, 1977.

CRUSE, T. A.; RIZZO, F. J. A direct formulation and numerical solution of the general transient elastodynamic problem - I. J. Math. Analysis and Applications, v. 22, p. 244-259, 1968.

CRUSE, T. A; VAN BUREN, W. Three-dimensional elastic stress analysis of a fracture specimen with an edge crack. Int. J. Fracture Mechanics, v. 7, p. 1-16, 1971.

CRUSE, T. A.; WILSON, R. B. Boundary integral equation method for elastic fracture mechanics analysis. AFSOR-TR-0355, ac. n. ADA 051992, p. 10-11, 1977.

DI TOMMASO, A. Size effects and brittleness. In: ELFGREN, L., ed. Fracture mechanics of concrete structures - rilem report. London, Chapman and Hall, 1989. p. 191-207. 
DI TOMMASO, A.; GYLLTOFT, K. Bending. In: ELFGREN, L., ed. Fracture mechanics of concrete structures - rilem report. London, Chapman and Hall, 1989. p. 208-220.

DOMINGUEZ, J. Computation of stress near anchor plates: an application of the boundary element method. Seville, 1977. Thesis (Ph. D.) - University of Seville (em espanhol).

DOMINGUEZ, J. Boundary elements in dynamics. Southampton / London, CMP / Elsevier, 1993.

ELFGREN, L. Introduction. In: ELFGREN, L., ed. Fracture mechanics of concrete structures - rilem report. London, Chapman and Hall, 1989a. p. 1666.

ELFGREN, L. Concluding remarks. In: ELFGREN, L., ed. Fracture mechanics of concrete structures - rilem report. London, Chapman and Hall, 1989b. p. 399401.

ELICES, M.; PLANAS, J. Material models. In: ELFGREN, L., ed. Fracture mechanics of concrete structures - rilem report. London, Chapman and Hall, 1989. p. 16-66.

FUNG, Y. L. Foundations of solid mechanics. Engelwood Cliffs, Prentice-Hall, 1965.

FUSCO, P. B. Estruturas de concreto - fundamentos do projeto estrutural. São Paulo, EDUSP / McGraw-Hill, 1976.

HARRINGTON, R. F. et al. Computation of laplacian potentials by an equivalent source method. Proc. IEE, v. 116, p. 1715-1720, 1969. 
HENSHELL, R. D.; SHAW, K. G. Crack tip finite elements are unnecessary. Int. J. Num. Meth. Eng., v. 9, p. 495-507, 1975.

HESS, J. L.; SMITH, A. M. O. Calculation of potential flow about arbitrary bodies. In: KUCHEMANN, D., ed. Progress in aeronautical sciences. Oxford, Pergamon Press, 1967. v. 8.

HILLERBORG, A. Analysis of one single crack. In: WITTMANN, F., ed. Fracture mechanics of concrete. Elsevier, 1983. p. 223-250.

HILlERBORG, A.; MODÉER, M; PETERSSON, P. E. Analysis of crack formation and crack growth in concrete by means of fracture mechanics and finite elements. Cement and Concrete Res., p. 773-782, 1976.

HILLERBORG, A.; ROTS, J. Crack concepts and numerical modelling. In: ELFGREN, L., ed. Fracture mechanics of concrete structures - rilem report. London, Chapman and Hall, 1989. p. 128-146.

IRWIN, G. R. Analysis of stress ans strain near the end of a crack transversing a plate. J. Appl. Mech., Trans. ASME, v. 24, p. 361-3644, 1957.

JASWON, M. A.; PONTER, A. R. An integral equation solution of the torsion problem. Proc. Roy. Soc. London, v. A275, p. 237-246, 1963.

JENG, G.; WEXLER, A. Isoparametric, finite element, variational solution of integral equations for three-dimensional fields. Int. J. Numer. Meth. Eng., v. 11, p. $1455-1471,1977$.

JENQ, Y. S.; SHAH, S. P. Two parameter fracture model for concrete. J. Eng. Mech. Div., ASCE, v. 111, p. 1227-1241, 1985.

KELLOG, O. D. Foundations of potential theory. Berlin, Springer-Verlag, 1929. 
KANE, J. H. Boundary element analysis in engineering continuum mechanics. Englewood Cliffs, Prentice-Hall, 1994.

KREYSZIG, E. Advanced engineering mathematics. 6. ed. New York, Wiley, 1988.

KUPRADZE, O. D. Potential methods in the theory of elasticity. New York, Daniel Davy, 1965.

KUTT, H. R. Report WISK 178 quadrature formulae for finite-part integrals. Pretoria, National research institue for matnematical sciences, 1975.

LACHAT, J. C.; WATSON, J.. O. A second generation boundary integral equation program for three-dimensional elastic analysis. In: ASME APPLIED MECHANICS DIVISION NATIONAL CONFERENCE, New York, 1975.

LAI, W.M.; RUBIN, D.; KREMPL, E. Introduction to continuum mechanics. Oxford, Pergamon Press, 1986.

LIANG, R. Y.; LI, Y. Study of size effect in concrete using fictitious crack model. J. Eng. Mech., ASCE, v. 117, p. 1631-1651, 1991.

LIN, C. S.; SCORDELIS, A. C. Nonlinear analysis of RC shells of general forms. J. Struct. Div., ASCE, v. 101, p. 523-538, 1975.

MACKERLE, J.; BREBBIA, C. A., ed. The boundary element reference book. Southampton / Berlin, CMP / Springer-Verlag, 1988.

MEGUID, S. A. Engineering fracture mechanics. London, Elsevier, 1989

MEHTA, P. K.: MONTEIRO, P. J. M. Concreto: estrutura, propriedades, materiais. 2. ed. São Paulo, PINI, 1994. 
MEWS, H. Calculation of stress intensity factors for various crack problems with the boundary element method. In: BREBBIA, C. A.; WENDLAND, W. L.; KUHN, G., eds. Boundary elements IX, Proc. 9th Int. Conf. on Boundary Elements. Berlin, Springer-Verlag, 1987. p. 259-278.

MIKHLIN, S. G. Integral equations. Oxford, Pergamon Press, 1957.

MINDESS, S. The application of fracture mechanics to cement and concrete: a historical review. In: WITTMANN, F. H., ed. Fracture mechanics of concrete. Amsterdam, Elsevier, 1983a. p. 1-30.

MINDESS, S. The cracking and fracture of concrete: an annotated bibliography 1928 - 1981. In: WITTMANN, F. H., ed. Fracture mechanics of concrete. Amsterdam, Elsevier, 1983b. p. 539-680.

MUSKHELISHVILI, N. I. Some basic problems of the mathematical theory of elasticity. Holland, Noordhoff, 1953.

RASHID, Y. R. Analysis of pre-stressed concrete pressure vessels. Nuclear Eng. Des., v. 7, p. 334-355, 1968.

RAVEENDRA, S. T.; CRUSE, T. A. BEM analysis of problems of fracture mechanics. In: BANERJEE, P. K; WILSON, R. B., eds. Developments in boundary elements methods. London, Elsevier, 1989. v. 5, p. 187-204.

REDDY, J. N. An introduction to the finite element method. 2 ed. New York, McGraw-Hill, 1993.

REINHARDT, H. W. Basic types of failure. In: ELFGREN, L., ed. Fracture mechanics of concrete structures - rilem report. London, Chapman and Hall, 1989. p. 6-15. 
RIZZO, F. J. An integral equation approach to boundary value problems of classical elastostatics. Q. Appl. Math., v. 25, p. 83-95, 1967.

RIZZO, F. J.; SHIPPY, D. J. A formulation and solution procedure for the general non-homogeneous elastic inclusion problem. Int. J. Solids and Structures, v. 4, p. $1161-1179,1968$

ROCHA, F. S. Análise de descontinuidades pelo método dos elementos de contorno. São Carlos, 1988. 224p. Tese (Doutorado) - Escola de Engenharia de São Carlos, Universidade de São Paulo.

ROCHA, F. S.; VENTURINI, W. S. Boundary element algorithm to solve discontinuity problems. In: BREBBIA, C. A., ed. Boundary elements X Southampton / Berlin, CMP / Springer-Verlag, 1988. v. 3, p. 107-118.

SCANLON, A. Time dependent deflections of reinforced concrete slabs. Edmonton, 1971. Thesis (Doctoral) - University of Alberta.

SIH, G. C.; DI TOMMASO, A., eds. Fracture mechanics of concrete: structural application and numerical calculation. The Hague, Martinus Nijhoff, 1985

SMITH, R. N. L. From rags to riches? - developments in the BEM for the solution of elastic fracture problems. In: BREBBIA, C. A., ed. Boundary elements $X$. Springer-Verlag, 1988. v. 3, p. 155-176.

SNYDER, M. D.; CRUSE, T. A. Boundary integral equation analysis of cracked anisotropic plates, a contour integral computation of mixed-mode stress intensity factors. Int. J. Frac., v. 11, p. 315-328, 1975.

SOMIGLIANA, C. Sopra l'equilibrio di un corpo elastico isotropo. Il nuovo cimento, p. 17-19, 1886. 
STEPHAN, E; WENDLAND, W. L. Boundary element method for membrane and torsion crack problems. Comp. Meth. Appl. Mech. Eng., v. 36, p. 331-358, 1983

SÜSSEKIND, J. C. Curso de concreto. 6. ed. São Paulo, Globo, 1989. v. 1.

SYMM, G. T. Treatment of singularities in the solution of Laplace's equation by an integral equation method. U. K., National Physical Laboratory, 1973. NPL report

SWEDLOW, J. L.; CRUSE, T. A. Formulation of boundary integral equations for three-dimensional elasto-plastic flow. Int. J. Solids and Structures, v. 7, p. 1673-1683, 1971.

TANG, W. Transforming domain into boundary integrals in BEM. eds. BREBBIA, C. A. \& ORSZAG, S. A. Berlin, Springer-Verlag, 1988.

TIMOSHENKO, S. P. History of strenght of materials. New York, McGraw-Hill, 1953.

TIMOSHENKO, S. P.; GOODIER, J. N. Teoria da elasticidade. 6. ed. Rio de Janeiro, Guanabara Dois, 1980

VALLIAPPAN, S. Continuum mechanics fundamentals. Rotterdam, A. A. Balkema, 1981.

VENTURINI, W. S. Relatório de atividades apresentado à Escola de Engenharia de São Carlos da Universidade de São Paulo, 1993.

VENTURINI, W. S. Análise de problemas de fratura coesiva usando o método dos elementos de contorno. In: CONGRESSO IBERO LATINO AMERICANO SOBRE MÉTODOS COMPUTACIONAIS PARA ENGENHARIA, 16., Curitiba, 1995. Anais. v. 2, p. 1012-1021. 
WASHIZU, K. Variational methods in elasticity and plasticity. 2. ed. New York, Pergamon Press, 1975.

WILLIAMS, M. L. On the stress distribution at the base of a stationary crack. J. Appl. Mech., v. 24, p. 109-114, 1957.

WITTMANN, F. H. Structure of concrete with respect to crack formation. In: WITTMANN, F. H., ed. Fracture mechanics of concrete. Amsterdam, Elsevier, 1983. p. $43-74$.

WITTMANN, F. H., ed. Fracture toughness and fracture energy of concrete. Amsterdam, Oxford, 1986

ZAGOTIS, D. Fundamentos da teoria das estruturas. cap. 5 - cálculo tensorial. Escola Politécnica, Universidade de São Paulo, 1984.

ZIEGELDORF, S. Phenomenological aspects of the fracture of concrete. In: WITTMANN, F. H., ed. Fracture mechanics of concrete. Amsterdam, Elsevier, 1983. p. $31-41$.

ZIENKIEWICZ, O. C.; TAYLOR, P. L. The finite element method. 4. ed., v. 2. London, Mc-Graww-Hill, 1991. 


\section{OBRAS CONSULTADAS}

ADDEY, R. A.; BREBBIA, C. A. Basic computational techniques for engineers. London, Pentech Press, 1983.

ALIABADI, M. H. BREBBIA, C. A. eds. Advances in boundary element methods for fracture mechanics. Southampton / London, CMP / Elsevier, 1993.

ALIABADI, M. H.; ROOKE, D. P. Numerical fracture mechanics. Norwell / Southampton, Kluwer / CMP, 1991.

AMERICAN CONCRETE INSTITUTE Manual of concrete practice, part 3 . 1987.

AMERICAN CONCRETE INSTITUTE Fracture mechanics of concrete: concepts, models and determination of material properties. 1989.

ANDERSON, T. L. Fracture mechanics - fundamentals and applications. 2. ed. Boca Raton, CRC Press, 1995.

ANNAND, V. B. Computer graphics and geometric modelling for engineers. New York, Wiley, 1993.

BECKER, A. A. The boundary element method in engineering. London, McGraw-Hill, 1992. 
BREBBIA, C. A. The boundary element method for engineers. London, Pentech Press, 1984.

BREBBIA, C.A., ed. Boundary element research. Southampton, CMP, 1985.

BREBBIA, C. A.; DOMINGUEZ, J. Boundary elements: an introductory course. Southampton / New York, CMP/ McGraw-Hill, 1989.

BREBBIA, C. A; WALKER, S. Boundary element techniques in engineering. London, Newnes-Butterworths, 1980.

CAKMAK, A. S.; BOTHA, J. F.; GRAY, W. G. Computational and applied mathematics for engineering analysis. Southampton / Berlin, CMP / SpringerVerlag, 1987.

COOK, R. D.; MALKUS, D. S.; PLESHA, M. E. Concepts and applications of finite element analysis. 3. ed. New York, Wiley, 1989.

COMITÉ EURO-INTERNATIONAL DU BÉTON. Design manual on cracking and deformations. Bulletin d'information n. 158-E, 1985.

ELFGREN, L., ed. Fracture mechanics of concrete structures - rilem report. London, Chapman and Hall, 1989. p. 16-66.

KREYSZIG, E. Advanced engineering mathematics. 6. ed. New York, Wiley, 1988.

LAI, W.M.; RUBIN, D.; KREMPL, E. Introduction to continuum mechanics. Oxford, Pergamon Press, 1986.

LAKATOS, E. M.; MARCONI, M. A. Metodologia do trabalho científico. 4. ed. São Paulo, Atlas, 1992.

MEGUID, S. A. Engineering fracture mechanics. London, Elsevier, 1989. 
MEHTA, P. K.: MONTEIRO, P. J. M. Concreto: estrutura, propriedades, materiais. 2. ed. São Paulo, PINI, 1994.

MUSKHELISHVILI, N.I. Singular integral equations. 2. ed. New York, Dover, 1992

TIMOSHENKO, S.P.; GOODIER, J.N. Teoria da elasticidade. 3.ed. Rio de Janeiro, Guanabara Dois, 1980.

VALLIAPPAN, S. Continuum mechanics fundamentals. Rotterdam, A. A. Balkema, 1981

VENTURINI, W.S. Application of the boundary element formulation to solve geomechanical problems. Southampton, 1982. 272 p. Thesis (Ph. D.) Faculty of Engineering and Applied Science, University of Southampton.

VENTURINI, W.S. Um estudo sobre o método dos elementos de contorno e suas aplicações em problemas de engenharia. São Carlos, 1988. 349 p. Tese (Livre Docência) - Escola de Engenharia de São Carlos, Universidade de São Paulo.

WITTMANN, F. H., ed. Fracture mechanics of concrete. Amsterdam, Oxford, 1983 


\section{APÊNDICE}

\section{Dedução de Algumas Equações do Texto}

\section{Equação (7.2)}

$\sigma_{\mathrm{kj}} \varepsilon_{\mathrm{kj}}^{*}=\sigma_{\mathrm{kj}} \frac{1}{2}\left(\mathrm{u}_{\mathrm{k}, \mathrm{j}}^{*}+\mathrm{u}_{\mathrm{j}, \mathrm{k}}^{*}\right)=\frac{1}{2} \sigma_{\mathrm{kj}} \mathrm{u}_{\mathrm{k}, \mathrm{j}}^{*}+\frac{1}{2} \sigma_{\mathrm{kj}} \mathrm{u}_{\mathrm{j}, \mathrm{k}}^{*}=\frac{1}{2} \sigma_{\mathrm{kj}} \mathrm{u}_{\mathrm{k}, \mathrm{j}}^{*}+\frac{1}{2} \sigma_{\mathrm{jk}} \mathrm{u}_{\mathrm{j}, \mathrm{k}}^{*}=\sigma_{\mathrm{kj}} \mathrm{u}_{\mathrm{k}, \mathrm{j}}^{*}$

\section{Equação (7.4)}

$\int_{\Omega} \sigma_{\mathrm{kj}} \mathrm{u}_{\mathrm{k}, \mathrm{j}}^{*} \mathrm{~d} \Omega=\int_{\Omega} \vec{\sigma}_{\mathrm{k}} \cdot \nabla \mathrm{u}_{\mathrm{k}}^{*} \mathrm{~d} \Omega$

Utilizando-se a eq. (3.26b)

$\int_{\Omega} \overrightarrow{\mathrm{G}} \cdot(\nabla \mathrm{F}) \mathrm{d} \Omega=-\int_{\Omega} \mathrm{F}(\nabla \cdot \overrightarrow{\mathrm{G}}) \mathrm{d} \Omega+\oint_{\Gamma} \mathrm{F}(\overrightarrow{\mathrm{G}} \cdot \overrightarrow{\mathrm{n}}) \mathrm{d} \Gamma$

$\int_{\Omega} \underbrace{\vec{\sigma}_{k}}_{\vec{G}} \cdot \underbrace{\nabla u_{k}^{*}}_{\nabla F} \mathrm{~d} \Omega=-\int_{\Omega} \underbrace{u_{k}^{*}}_{F}(\underbrace{\nabla \cdot \vec{\sigma}_{k}}_{\nabla \cdot \vec{G}}) \mathrm{d} \Omega+\oint_{\Gamma} \underbrace{u_{k}^{*}}_{F} \underbrace{\vec{\sigma}_{k}}_{\vec{G}} \cdot \vec{n} \mathrm{~d} \Gamma=-\int_{\Omega} \sigma_{k j, j} u_{k}^{*} \mathrm{~d} \Omega+\int_{\Gamma} p_{k} u_{k}^{*} \mathrm{~d} \Gamma$,

onde

$\vec{\sigma}_{k}=\left\langle\sigma_{k 1}, \sigma_{k 2}, \sigma_{k 3}\right\rangle \quad$ e $\quad \vec{p}=\vec{\sigma} \cdot \vec{n} \quad \therefore \quad p_{k}=\sigma_{k j} n_{j}$. 


\section{Equação (7.16)}

$$
\begin{aligned}
& \mathrm{I}=\lim _{\varepsilon \rightarrow 0}\left\{\int_{\Gamma_{\varepsilon}} \mathrm{p}_{\ell \mathrm{k}}^{*} \mathrm{~d} \Gamma_{\varepsilon}\right\}= \\
& =\lim _{\varepsilon \rightarrow 0}\left\{\int_{\theta_{\mathrm{E}}-\pi}^{\theta_{\mathrm{E}}}-\frac{1}{4 \pi(1-v) \&}\left(\mathrm{r}_{, \mathrm{n}}\left[(1-2 v) \delta_{\ell \mathrm{k}}+2 \mathrm{r}_{, \ell} \mathrm{r}_{\mathrm{k}}\right]+(1-2 v)\left[\mathrm{n}_{\ell} \mathrm{r}_{, \mathrm{k}}-\mathrm{n}_{\mathrm{k}} \mathrm{r}_{, \ell}\right]\right) \& \mathrm{~d} \theta\right\} \\
& \mathrm{r}_{, \mathrm{n}}=\left(\frac{1}{\mathrm{r}}\right) \overrightarrow{\mathrm{r}} \cdot \overrightarrow{\mathrm{n}}=1 ; \quad \mathrm{r}_{\ell}=\operatorname{Cos}(\theta) \delta_{\ell 1}+\operatorname{Sen}(\theta) \delta_{\ell 2} ; \quad \mathrm{r}_{, \mathrm{k}}=\operatorname{Cos}(\theta) \delta_{\mathrm{k} 1}+\operatorname{Sen}(\theta) \delta_{\mathrm{k} 2} \\
& \mathrm{n}_{\ell}=\operatorname{Cos}(\theta) \delta_{\ell 1}+\operatorname{Sen}(\theta) \delta_{\ell 2} ; \quad \mathrm{n}_{\mathrm{k}}=\operatorname{Cos}(\theta) \delta_{\mathrm{k} 1}+\operatorname{Sen}(\theta) \delta_{\mathrm{k} 2} ; \quad \mathrm{n}_{\ell} \mathrm{r}_{, \mathrm{k}}-\mathrm{n}_{\mathrm{k}} \mathrm{r}_{, \ell}=0 \\
& \mathrm{r}_{, \ell} \mathrm{r}_{, \mathrm{k}}=\operatorname{Cos}^{2}(\theta) \delta_{\ell 1} \delta_{\mathrm{k} 1}+\operatorname{Cos}(\theta) \operatorname{Sen}(\theta)\left(\delta_{\ell 1} \delta_{\mathrm{k} 2}+\delta_{\ell 2} \delta_{\mathrm{k} 1}\right)+\operatorname{Sen}^{2}(\theta) \delta_{\ell 2} \delta_{\mathrm{k} 2}= \\
& =1 / 2\left[(1+\operatorname{Cos}(2 \theta))\left(\delta_{\ell \mathrm{k}}-\delta_{\ell 2} \delta_{\mathrm{k} 2}\right)+\operatorname{Sen}(2 \theta)\left(\delta_{\ell 1} \delta_{\mathrm{k} 2}+\delta_{\ell 2} \delta_{\mathrm{k} 1}\right)+(1-\operatorname{Cos}(2 \theta)) \delta_{\ell 2} \delta_{\mathrm{k} 2}\right]= \\
& =1 / 2\left[\operatorname{Cos}(2 \theta)\left(\delta_{\ell \mathrm{k}}-2 \delta_{\ell 2} \delta_{\mathrm{k} 2}\right)+\delta_{\ell \mathrm{k}}+\operatorname{Sen}(2 \theta)\left(\delta_{\ell 1} \delta_{\mathrm{k} 2}+\delta_{\ell 2} \delta_{\mathrm{k} 1}\right)\right] \\
& \mathrm{I}=-\frac{1}{4 \pi(1-v)} \int_{\theta_{\mathrm{E}}-\pi}^{\theta_{\mathrm{E}}}\left[2(1-v) \delta_{\ell \mathrm{k}}+\operatorname{Cos}(2 \theta)\left(\delta_{\ell \mathrm{k}}-2 \delta_{\ell 2} \delta_{\mathrm{k} 2}\right)+\operatorname{Sen}(2 \theta)\left(\delta_{\ell 1} \delta_{\mathrm{k} 2}+\delta_{\ell 2} \delta_{\mathrm{k} 1}\right)\right] \mathrm{d} \theta= \\
& =-\frac{1}{4 \pi(1-v)}[2(1-v) \delta_{\ell \mathrm{k}} \theta+\underbrace{\operatorname{Sen}(2 \theta) / 2}_{\rightarrow 0}\left(\delta_{\ell \mathrm{k}}-2 \delta_{\ell 2} \delta_{\mathrm{k} 2}\right)-\underbrace{\operatorname{Cos}(2 \theta) / 2}_{\rightarrow 0}\left(\delta_{\ell 1} \delta_{\mathrm{k} 2}+\delta_{\ell 2} \delta_{\mathrm{k} 1}\right)]_{\theta_{\mathrm{E}}-\pi}^{\theta_{\mathrm{E}}}= \\
& =-\frac{1}{4 \pi(1-v)} \cdot 2(1-v) \delta_{\ell \mathrm{k}} \pi=-\frac{1}{2} \delta_{\ell \mathrm{k}}
\end{aligned}
$$

\section{Equação (7.42)}

Vetor tangente ao elemento:

$$
\overrightarrow{\mathrm{M}}=\left\langle\frac{\mathrm{dx}(\xi)}{\mathrm{d} \xi}, \frac{\mathrm{dy}(\xi)}{\mathrm{d} \xi}\right\rangle \quad\|\overrightarrow{\mathrm{M}}\|=\mathrm{J}(\xi)=\sqrt{\left(\frac{\mathrm{dx}(\xi)}{\mathrm{d} \xi}\right)^{2}+\left(\frac{\mathrm{dy}(\xi)}{\mathrm{d} \xi}\right)^{2}}
$$

Versor tangente ao elemento:

$$
\overrightarrow{\mathrm{m}}=\frac{\overrightarrow{\mathrm{M}}}{\|\overrightarrow{\mathrm{M}}\|}=\left\langle\mathrm{m}_{\mathrm{x}}, \mathrm{m}_{\mathrm{y}}\right\rangle=\left\langle\frac{1}{\mathrm{~J}(\xi)} \frac{\mathrm{dx}(\xi)}{\mathrm{d} \xi}, \frac{1}{\mathrm{~J}(\xi)} \frac{\mathrm{dy}(\xi)}{\mathrm{d} \xi}\right\rangle
$$

Para um elemento linear:

$$
\frac{\mathrm{dx}(\xi)}{\mathrm{d} \xi}=\frac{\mathrm{d}}{\mathrm{d} \xi}\left(\phi_{\mathrm{i}} \mathrm{x}^{\mathrm{i}}\right)=\frac{\mathrm{d}}{\mathrm{d} \xi}\left(\phi_{1} \mathrm{x}^{1}+\phi_{2} \mathrm{x}^{2}\right)=\frac{\mathrm{d} \phi_{1}}{\mathrm{~d} \xi} \mathrm{x}^{1}+\frac{\mathrm{d} \phi_{2}}{\mathrm{~d} \xi} \mathrm{x}^{2}=\frac{\mathrm{x}^{2}-\mathrm{x}^{1}}{2}
$$


Analogamente:

$\frac{\mathrm{dy}(\xi)}{\mathrm{d} \xi}=\frac{\mathrm{y}^{2}-\mathrm{y}^{1}}{2}$

Jacobiano:

$$
J(\xi)=\sqrt{\left(\frac{x^{2}-x^{1}}{2}\right)^{2}+\left(\frac{y^{2}-y^{1}}{2}\right)^{2}}=\frac{\ell}{2}
$$

Portanto,

$$
\overrightarrow{\mathrm{m}}=\frac{1}{\ell}\left\langle\mathrm{x}^{2}-\mathrm{x}^{1}, \mathrm{y}^{2}-\mathrm{y}^{1}\right\rangle
$$

Deslocamento na direção tangencial:

$$
\begin{aligned}
& \overrightarrow{\mathrm{u}}=\left\langle\mathrm{u}_{\mathrm{x}}(\xi), \mathrm{u}_{\mathrm{y}}(\xi)\right\rangle=\left\langle\left[\phi_{\mathrm{i}} \mathrm{u}_{\mathrm{x}}^{\mathrm{i}}\right],\left[\phi_{\mathrm{i}} \mathrm{u}_{\mathrm{y}}^{\mathrm{i}}\right]\right\rangle \therefore \\
& \mathrm{u}_{2}=\overrightarrow{\mathrm{u}} \cdot \overrightarrow{\mathrm{m}}=\left[\phi_{\mathrm{i}} \mathrm{u}_{\mathrm{x}}^{\mathrm{i}}\right] \mathrm{m}_{\mathrm{x}}+\left[\phi_{\mathrm{i}} \mathrm{u}_{\mathrm{y}}^{\mathrm{i}}\right] \mathrm{m}_{\mathrm{y}}
\end{aligned}
$$

Deformação na direção tangencial:

$$
\begin{aligned}
\varepsilon_{22} & =\frac{\mathrm{du}_{2}}{\mathrm{~d} \Gamma}=\frac{\mathrm{du}}{\mathrm{d} \xi} \frac{\mathrm{d} \xi}{\mathrm{d} \Gamma}=\frac{1}{\mathrm{~J}(\xi)}\left(\left[\frac{\partial \phi_{\mathrm{i}}}{\partial \xi} \mathrm{u}_{\mathrm{x}}^{\mathrm{i}}\right] \mathrm{m}_{\mathrm{x}}+\left[\frac{\partial \phi_{\mathrm{i}}}{\partial \xi} \mathrm{u}_{\mathrm{y}}^{\mathrm{i}}\right] \mathrm{m}_{\mathrm{y}}\right)= \\
& =\frac{2}{\ell}\left\{\left[-\frac{1}{2} \cdot \mathrm{u}_{\mathrm{x}}^{1}+\frac{1}{2} \cdot \mathrm{u}_{\mathrm{x}}^{2}\right]\left(\frac{\mathrm{x}^{2}-\mathrm{x}^{1}}{\ell}\right)+\left[-\frac{1}{2} \cdot \mathrm{u}_{\mathrm{y}}^{1}+\frac{1}{2} \cdot \mathrm{u}_{\mathrm{y}}^{2}\right]\left(\frac{\mathrm{y}^{2}-\mathrm{y}^{1}}{\ell}\right)\right\}= \\
& =\frac{\left(\mathrm{u}_{\mathrm{x}}^{2}-\mathrm{u}_{\mathrm{x}}^{1}\right)\left(\mathrm{x}^{2}-\mathrm{x}^{1}\right)+\left(\mathrm{u}_{\mathrm{y}}^{2}-\mathrm{u}_{\mathrm{y}}^{1}\right)\left(\mathrm{y}^{2}-\mathrm{y}^{1}\right)}{\ell^{2}}
\end{aligned}
$$

\section{Equação (7.44)}

Lei de Hooke (eq. (4.19)):

$$
\begin{aligned}
\sigma_{i j} & =\lambda \varepsilon_{\mathrm{kk}} \delta_{\mathrm{ij}}+2 \mathrm{G} \varepsilon_{\mathrm{ij}} \therefore \\
\sigma_{11} & =\lambda\left(\varepsilon_{11}+\varepsilon_{22}\right)+2 \mathrm{G} \varepsilon_{11} \Rightarrow \varepsilon_{11}=\frac{\sigma_{11}-\lambda \varepsilon_{22}}{\lambda+2 \mathrm{G}} \\
\sigma_{22} & =\lambda\left(\varepsilon_{11}+\varepsilon_{22}\right)+2 \mathrm{G} \varepsilon_{22}=\lambda \varepsilon_{11}+(\lambda+2 \mathrm{G}) \varepsilon_{22}= \\
& =\lambda \frac{\sigma_{11}-\lambda \varepsilon_{22}}{\lambda+2 \mathrm{G}}+(\lambda+2 \mathrm{G}) \varepsilon_{22}=\left(\frac{\lambda}{\lambda+2 \mathrm{G}}\right) \sigma_{11}+\left(\lambda+2 \mathrm{G}-\frac{\lambda^{2}}{\lambda+2 \mathrm{G}}\right) \varepsilon_{22} \therefore
\end{aligned}
$$


$\sigma_{22}=\left(\frac{v}{1-v}\right) \sigma_{11}+\left(\frac{E}{1-v^{2}}\right) \varepsilon_{22}$

\section{Equação (7.49a)}

$$
\begin{aligned}
& \mathrm{GW}_{11}=\int_{0}^{\ell} \phi_{1} \mathrm{u}_{11}^{*} \mathrm{~d} \Gamma=\int_{0}^{\mathrm{a}} \phi_{1} \mathrm{u}_{11}^{*} \mathrm{~d} \Gamma+\int_{\mathrm{a}}^{\ell} \phi_{1} \mathrm{u}_{11}^{*} \mathrm{~d} \Gamma=\lim _{\varepsilon \rightarrow 0}\left\{\int_{\mathrm{a}}^{\varepsilon}-\phi_{1} \mathrm{u}_{11}^{*} \mathrm{dr}+\int_{\varepsilon}^{\mathrm{b}} \phi_{1} \mathrm{u}_{11}^{*} \mathrm{dr}\right\}= \\
& =\lim _{\varepsilon \rightarrow 0}\left\{\int_{\varepsilon}^{a} \frac{1}{\ell}(r+b) \frac{1}{8 \pi G(1-v)}\left[(3-4 v) \ln \left(\frac{1}{r}\right)+\left(\frac{d r}{d x}\right)^{2}\right] d r\right\}+ \\
& +\lim _{\varepsilon \rightarrow 0}\left\{\int_{\varepsilon}^{b}-\frac{1}{\ell}(r-b) \frac{1}{8 \pi G(1-v)}\left[(3-4 v) \ln \left(\frac{1}{r}\right)+\left(\frac{d r}{d x}\right)^{2}\right] d r\right\}= \\
& =\frac{1}{8 \pi \ell G(1-v)} \lim _{\varepsilon \rightarrow 0} \int_{\varepsilon}^{a}(r+b)\left[-(3-4 v) \ln (r)+\left(\frac{d r}{d x}\right)^{2}\right] d r+ \\
& \left.+\int_{\varepsilon}^{b}(b-r)\left[-(3-4 v) \ln (r)+\left(\frac{d r}{d x}\right)^{2}\right] d r\right\}= \\
& =\frac{1}{8 \pi \ell \mathrm{G}(1-v)} \lim _{\varepsilon \rightarrow 0}\left\{\left(\frac{\mathrm{dr}}{\mathrm{dx}}\right)^{2}\left[\int_{\varepsilon}^{\mathrm{a}}(\mathrm{r}+\mathrm{b}) \mathrm{dr}+\int_{\varepsilon}^{\mathrm{b}}(\mathrm{b}-\mathrm{r}) \mathrm{dr}\right]-\right. \\
& \left.-(3-4 v)\left[\int_{\varepsilon}^{a}(\mathrm{r}+\mathrm{b}) \ln (\mathrm{r}) \mathrm{dr}+\int_{\varepsilon}^{\mathrm{b}}(\mathrm{b}-\mathrm{r}) \ln (\mathrm{r}) \mathrm{dr}\right]\right\}= \\
& =\frac{1}{8 \pi \ell G(1-v)} \lim _{\varepsilon \rightarrow 0}\left\{\left(\frac{d r}{d x}\right)^{2}\left(\left[\frac{r^{2}}{2}+b r\right]_{\varepsilon}^{a}+\left[b r-\frac{r^{2}}{2}\right]_{\varepsilon}^{b}\right)-\right. \\
& \left.-(3-4 v)\left[\int_{\varepsilon}^{a}(\mathrm{r} \ln (\mathrm{r})+\mathrm{b} \ln (\mathrm{r})) \mathrm{dr}+\int_{\varepsilon}^{b}(-\mathrm{r} \ln (\mathrm{r})+\mathrm{b} \ln (\mathrm{r})) \mathrm{dr}\right]\right\}= \\
& =\frac{1}{8 \pi \ell \mathrm{G}(1-v)} \lim _{\varepsilon \rightarrow 0}\left\{\left(\frac{\mathrm{dr}}{\mathrm{dx}}\right)^{2}\left(\frac{\mathrm{a}^{2}}{2}+\mathrm{ab}+\frac{\mathrm{b}^{2}}{2}\right)-\right. \\
& \left.-(3-4 v)\left(\left[\frac{\mathrm{r}^{2} \ln (\mathrm{r})}{2}-\frac{\mathrm{r}^{2}}{4}\right]_{\varepsilon}^{\mathrm{a}}+\mathrm{b}[\mathrm{r} \ln (\mathrm{r})-\mathrm{r}]_{\varepsilon}^{\mathrm{a}}+\mathrm{b}[\mathrm{r} \ln (\mathrm{r})-\mathrm{r}]_{\varepsilon}^{\mathrm{b}}-\left[\frac{\mathrm{r}^{2} \ln (\mathrm{r})}{2}-\frac{\mathrm{r}^{2}}{4}\right]_{\varepsilon}^{\mathrm{b}}\right)\right\}=
\end{aligned}
$$




$$
\begin{aligned}
& =\frac{1}{8 \pi \ell \mathrm{G}(1-v)}\left\{\left(\frac{\mathrm{dr}}{\mathrm{dx}}\right)^{2} \cdot \frac{\ell^{2}}{2}-\right. \\
& \left.-(3-4 v)\left(\frac{\mathrm{a}^{2} \ln (\mathrm{a})}{2}-\frac{\mathrm{a}^{2}}{4}+\mathrm{ab} \ln (\mathrm{a})-\mathrm{ab}+\mathrm{b}^{2} \ln (\mathrm{b})-\mathrm{b}^{2}-\frac{\mathrm{b}^{2} \ln (\mathrm{b})}{2}+\frac{\mathrm{b}^{2}}{4}\right)\right\}= \\
& =\frac{1}{8 \pi \ell \mathrm{G}(1-v)}\left\{-(3-4 v)\left[\ln (\mathrm{a})\left(\frac{\mathrm{a}^{2}}{2}+\mathrm{ab}\right)+\ln (\mathrm{b})\left(\frac{\mathrm{b}^{2}}{2}\right)-\left(\frac{\mathrm{a}^{2}}{4}+a b+\frac{3}{4} \mathrm{~b}^{2}\right)\right]+\frac{\ell^{2}}{2}\left(\frac{\mathrm{dr}}{\mathrm{dx}}\right)^{2}\right\}
\end{aligned}
$$

\section{Equação (7.50b)}

$$
\begin{aligned}
& \mathrm{HW}_{12}=\int_{0}^{\ell} \phi_{1} \mathrm{p}_{12}^{*} \mathrm{~d} \Gamma=\int_{0}^{\mathrm{a}} \phi_{1} \mathrm{p}_{12}^{*} \mathrm{~d} \Gamma+\int_{\mathrm{a}}^{\ell} \phi_{1} \mathrm{p}_{12}^{*} \mathrm{~d} \Gamma=\lim _{\varepsilon \rightarrow 0}\left\{\int_{\mathrm{a}}^{\varepsilon}-\phi_{1} \mathrm{p}_{12}^{*} \mathrm{dr}+\int_{\varepsilon}^{\mathrm{b}} \phi_{1} \mathrm{p}_{12}^{*} \mathrm{dr}\right\}= \\
& =\lim _{\varepsilon \rightarrow 0}\left\{\int_{\varepsilon}^{\mathrm{a}} \frac{1}{\ell}(\mathrm{r}+\mathrm{b}) \cdot \frac{-1}{4 \pi(1-v) \mathrm{r}}[\underbrace{\mathrm{r}_{\mathrm{n}}}_{\rightarrow \rightarrow 0}\left(2 \mathrm{r}_{, \mathrm{x}} \mathrm{r}_{\mathrm{y}}\right)+(1-2 v) \underbrace{\left(\mathrm{r}_{, y} \mathrm{n}_{\mathrm{x}}-\mathrm{r}_{, \mathrm{x}} \mathrm{n}_{\mathrm{y}}\right)}_{\rightarrow-1}] \mathrm{dr}\right\}+ \\
& +\lim _{\varepsilon \rightarrow 0}\left\{\int_{\varepsilon}^{\mathrm{b}} \frac{(\mathrm{b}-\mathrm{r})}{\ell} \cdot \frac{-1}{4 \pi(1-v) \mathrm{r}}[\underbrace{r_{, \mathrm{n}}}_{\rightarrow 0}\left(2 \mathrm{r}_{, \mathrm{x}} \mathrm{r}_{\mathrm{y}}\right)+(1-2 v) \underbrace{\left(\mathrm{r}_{\mathrm{r}, \mathrm{n}} \mathrm{n}_{\mathrm{x}}-\mathrm{r}_{, \mathrm{x}} \mathrm{n}_{\mathrm{y}}\right)}_{\rightarrow 1}] \mathrm{dr}\right\}= \\
& =\frac{(1-2 v)}{4 \pi \ell(1-v)} \cdot \lim _{\varepsilon \rightarrow 0}\left\{\int_{\varepsilon}^{\mathrm{a}}\left(1+\frac{\mathrm{b}}{\mathrm{r}}\right) \mathrm{dr}-\int_{\varepsilon}^{\mathrm{b}}\left(\frac{\mathrm{b}}{\mathrm{r}}-1\right) \mathrm{dr}\right\}= \\
& =\frac{(1-2 v)}{4 \pi \ell(1-v)} \cdot \lim _{\varepsilon \rightarrow 0}\left\{[\mathrm{r}+\mathrm{b} \ln (\mathrm{r})]_{\varepsilon}^{\mathrm{a}}-[\mathrm{b} \ln (\mathrm{r})-\mathrm{r}]_{\varepsilon}^{\mathrm{b}}\right\}= \\
& =\frac{(1-2 v)}{4 \pi \ell(1-v)} \cdot \lim _{\varepsilon \rightarrow 0}\{\mathrm{a}+\mathrm{b} \ln (\mathrm{a})-\mathrm{b} \ln (\varepsilon)-\mathrm{b} \ln (\mathrm{b})+\mathrm{b}+\mathrm{b} \ln (\varepsilon)\}= \\
& =\frac{(1-2 v)}{4 \pi \ell(1-v)}\left\{\ell-\mathrm{b} \ln \left(\frac{\mathrm{b}}{\mathrm{a}}\right)\right\}
\end{aligned}
$$

\section{Equação (8.1)}

A partir do teorema de Betti (eq. (3.28)) e considerando-se a existência de tensões iniciais (eqs. (4.25) e (4.26)) e a fig. (4.5b): 
$\int_{\Omega} \sigma_{\mathrm{kj}}^{\mathrm{e}} \varepsilon_{\mathrm{kj}}^{*} \mathrm{~d} \Omega=\int_{\Omega} \sigma_{\mathrm{kj}}^{*} \varepsilon_{\mathrm{kj}} \mathrm{d} \Omega$

Separando-se tensão e deformação em componentes:

$$
\begin{aligned}
& \sigma_{\mathrm{kj}}=\sigma_{\mathrm{kj}}^{\mathrm{e}}-\sigma_{\mathrm{kj}}^{0} \quad \text { e } \quad \varepsilon_{\mathrm{kj}}=\varepsilon_{\mathrm{kj}}^{\mathrm{e}}+\varepsilon_{\mathrm{kj}}^{0} \\
& \int_{\Omega}\left(\sigma_{\mathrm{kj}}^{0}+\sigma_{\mathrm{kj}}\right) \varepsilon_{\mathrm{kj}}^{*} \mathrm{~d} \Omega=\int_{\Omega} \sigma_{\mathrm{kj}}^{*} \varepsilon_{\mathrm{kj}} \mathrm{d} \Omega . \\
& \int_{\Omega} \sigma_{\mathrm{k} j}^{0} \varepsilon_{\mathrm{kj}}^{*} \mathrm{~d} \Omega+\int_{\Omega} \sigma_{\mathrm{k} j} \varepsilon_{\mathrm{kj}}^{*} \mathrm{~d} \Omega=\int_{\Omega} \sigma_{\mathrm{kj}}^{*} \varepsilon_{\mathrm{k} j} \mathrm{~d} \Omega . \\
& \int_{\Omega} \sigma_{\mathrm{kj}}^{0} \varepsilon_{\mathrm{kj}}^{*} \mathrm{~d} \Omega+\int_{\Omega} \sigma_{\mathrm{kj}} \mathrm{u}_{\mathrm{k}, \mathrm{j}}^{*} \mathrm{~d} \Omega=\int_{\Omega} \sigma_{\mathrm{kj}}^{*} \mathrm{u}_{\mathrm{k}, \mathrm{j}}^{*} \mathrm{~d} \Omega \\
& \int_{\Omega} \sigma_{\mathrm{kj}}^{0} \varepsilon_{\mathrm{kj}}^{*} \mathrm{~d} \Omega-\int_{\Omega} \sigma_{\mathrm{kj}, \mathrm{j}} \mathrm{u}_{\mathrm{k}}^{*} \mathrm{~d} \Omega+\int_{\Gamma} \mathrm{p}_{\mathrm{k}} \mathrm{u}_{\mathrm{k}}^{*} \mathrm{~d} \Gamma=-\int_{\Omega} \sigma_{\mathrm{k}, \mathrm{j}}^{*} \mathrm{u}_{\mathrm{k}}^{*} \mathrm{~d} \Omega+\int_{\Gamma} \mathrm{p}_{\mathrm{k}}^{*} \mathrm{u}_{\mathrm{k}} \mathrm{d} \Gamma
\end{aligned}
$$

Da solução fundamental:

$$
\sigma_{\mathrm{k}, \mathrm{j}}^{*}+\Delta^{\mathrm{p}} \delta_{\mathrm{k} \ell}=0 \therefore \int_{\Omega} \sigma_{\mathrm{k}, \mathrm{j}}^{*} \mathrm{u}_{\mathrm{k}} \mathrm{d} \Omega=\int_{\Omega}-\Delta^{\mathrm{p}} \delta_{\mathrm{k} \ell} \mathrm{u}_{\mathrm{k}} \mathrm{d} \Omega=-\int_{\Omega} \Delta^{\mathrm{p}} \mathrm{u}_{\ell} \mathrm{d} \Omega=-\mathrm{u}_{\ell}^{\mathrm{p}}
$$

A partir da equação de equilíbrio:

$$
\begin{aligned}
& \sigma_{\mathrm{k}, \mathrm{j}}+\mathrm{b}_{\mathrm{k}}=0 \therefore \int_{\Omega} \sigma_{\mathrm{k}, \mathrm{j}, \mathrm{u}} \mathrm{u}_{\mathrm{k}}^{*} \mathrm{~d} \Omega=\int_{\Omega}\left(-\mathrm{b}_{\mathrm{k}}\right) \mathrm{u}_{\mathrm{k}}^{*} \mathrm{~d} \Omega=-\int_{\Omega} b_{\mathrm{k}} \mathrm{u}_{\mathrm{k}}^{*} \mathrm{~d} \Omega \\
& \int_{\Omega} \sigma_{\mathrm{kj}}^{0} \varepsilon_{\mathrm{kj}}^{*} \mathrm{~d} \Omega+\int_{\Omega} b_{\mathrm{k}} \mathrm{u}_{\mathrm{k}}^{*} \mathrm{~d} \Omega+\int_{\Gamma} \mathrm{p}_{\mathrm{k}} \mathrm{u}_{\mathrm{k}}^{*} \mathrm{~d} \Gamma=\mathrm{u}_{\ell}^{\mathrm{p}}+\int_{\Gamma} p_{\mathrm{k}}^{*} \mathrm{u}_{\mathrm{k}} \mathrm{d} \Gamma
\end{aligned}
$$

Interpretando-se geometricamente os componentes da solução fundamental:

$$
\mathrm{u}_{\mathrm{k}}^{*}=\mathrm{u}_{\mathrm{wk}}^{*} \delta_{\ell \mathrm{w}}=\mathrm{u}_{\mathrm{lk}}^{*} ; \quad \mathrm{p}_{\mathrm{k}}^{*}=\mathrm{p}_{\mathrm{wk}}^{*} \delta_{\ell \mathrm{w}}=\mathrm{p}_{\mathrm{lk}}^{*} ; \quad \varepsilon_{\mathrm{kj}}^{*}=\varepsilon_{\mathrm{wkj}}^{*} \delta_{\ell \mathrm{w}}=\varepsilon_{\mathrm{lkj}}^{*}
$$

Portanto:

$$
\mathrm{u}_{\ell}^{\mathrm{p}}=-\int_{\Gamma} \mathrm{p}_{\ell \mathrm{k}}^{*} \mathrm{u}_{\mathrm{k}} \mathrm{d} \Gamma+\int_{\Gamma} \mathrm{u}_{\ell \mathrm{k}}^{*} \mathrm{p}_{\mathrm{k}} \mathrm{d} \Gamma+\int_{\Omega} \mathrm{u}_{\ell \mathrm{k}}^{*} \mathrm{~b}_{\mathrm{k}} \mathrm{d} \Omega+\int_{\Omega} \sigma_{\mathrm{kj}}^{0} \varepsilon_{1 \mathrm{kj}}^{*} \mathrm{~d} \Omega
$$

\section{Equação (8.2)}

$$
\begin{aligned}
& \varepsilon_{\mathrm{kj}}=\frac{1}{2}\left(\mathrm{u}_{\mathrm{k}, \mathrm{j}}+\mathrm{u}_{\mathrm{j}, \mathrm{k}}\right)=\varepsilon_{\mathrm{jk}} \\
& \varepsilon_{\ell \mathrm{kj}}^{*}=\frac{1}{2}\left(u_{\ell \mathrm{k}, \mathrm{j}}^{*}+u_{\ell j \mathrm{k}, \mathrm{k}}^{*}\right)=\varepsilon_{\ell \mathrm{jk}}^{*}
\end{aligned}
$$


7

$$
\begin{aligned}
& \mathrm{u}_{\ell \mathrm{k}}^{*}=\frac{1}{8 \pi(1-v) \mathrm{G}}\left[\mathrm{r}_{\ell} \mathrm{r}_{, \mathrm{k}}-(3-4 v) \delta_{\ell \mathrm{k}} \ln (\mathrm{r})\right] \\
& \mathrm{u}_{\ell \mathrm{j}}^{*}=\frac{1}{8 \pi(1-v) \mathrm{G}}\left[\mathrm{r}_{, \ell} \mathrm{r}_{\mathrm{j}}-(3-4 v) \delta_{\ell \mathrm{j}} \ln (\mathrm{r})\right] \\
& \varepsilon_{\ell \mathrm{kj}}^{*}=\frac{1}{2}\left\{\frac{\partial}{\partial \mathrm{x}_{\mathrm{j}}}\left(\frac{1}{8 \pi(1-v) \mathrm{G}}\left[\mathrm{r}_{\ell} \mathrm{r}_{, \mathbf{k}}-(3-4 v) \delta_{\ell \mathrm{k}} \ln (\mathrm{r})\right]\right)+\right. \\
& \left.+\frac{\partial}{\partial \mathrm{x}_{\mathbf{k}}}\left(\frac{1}{8 \pi(1-v) \mathrm{G}}\left[\mathrm{r}_{\ell} \mathrm{r}_{\mathrm{j}}-(3-4 v) \delta_{\ell \mathrm{j}} \ln (\mathrm{r})\right]\right)\right\}= \\
& =\frac{1}{16 \pi(1-v) G}\left\{\frac{\partial}{\partial x_{j}}\left(\left[r_{\ell}, r_{, k}-(3-4 v) \delta_{\ell k} \ln (r)\right]\right)+\frac{\partial}{\partial x_{k}}\left(\left[r_{, \ell} r_{j}-(3-4 v) \delta_{\ell j} \ln (r)\right]\right)\right\}= \\
& =\frac{-1}{8 \pi(1-v) \mathrm{Gr}} \cdot \frac{-\mathrm{r}}{2}\left\{\frac{\partial}{\partial \mathrm{x}_{\mathbf{j}}}\left(\mathrm{r}_{\ell} \mathrm{r}_{, \mathrm{k}}\right)+\frac{\partial}{\partial \mathrm{x}_{\mathbf{k}}}\left(\mathrm{r}_{\ell} \mathrm{r}_{\mathrm{j}}\right)-(3-4 v)\left[\frac{\delta_{\ell \mathrm{k}}}{\mathrm{r}} \mathrm{r}_{, \mathrm{j}}+\frac{\delta_{\ell \mathrm{j}}}{\mathrm{r}} \mathrm{r}_{, \mathbf{k}}\right]\right\}= \\
& =\frac{-1}{8 \pi(1-v) \mathrm{Gr}}\left\{\frac{(3-4 v)}{2}\left[\delta_{\ell \mathrm{k}} \mathrm{r}_{, \mathbf{j}}+\delta_{\ell \mathrm{j}, \mathrm{k}}\right]-\frac{\mathrm{r}}{2}\left[\mathrm{r}_{\ell, \mathrm{j}} \mathrm{r}_{\mathrm{k}}+2 \mathrm{r}_{\ell, \mathrm{r}_{, \mathbf{j}}}+\mathrm{r}_{, \ell \mathrm{k}} \mathrm{r}_{\mathrm{j}}\right]\right\}
\end{aligned}
$$

Mas,

$$
\mathrm{r}_{\ell, \mathrm{j}}=\frac{\partial}{\partial \mathrm{x}_{\ell}}\left(\left.\mathrm{r}_{\mathrm{j}}\right|_{\mathrm{s}}\right)=\frac{\partial}{\partial \mathrm{x}_{\ell}(\mathrm{S})}\left(\frac{\mathrm{x}_{\mathrm{j}}(\mathrm{S})-\mathrm{x}_{\mathrm{j}}(\mathrm{p})}{\mathrm{r}}\right)=\frac{1}{\mathrm{r}} \delta_{\ell \mathrm{j}}-\frac{\left(\mathrm{x}_{\mathrm{j}}(\mathrm{S})-\mathrm{x}_{\mathrm{j}}(\mathrm{p})\right)}{\mathrm{r}^{2}} \mathrm{r}_{\ell}=\frac{1}{\mathrm{r}}\left[\delta_{\ell \mathrm{j}}-\mathrm{r}_{\ell} \mathrm{r}_{, \mathrm{j}}\right]
$$

Analogamente:

$$
\begin{aligned}
& \mathrm{r}_{, \mathrm{kj}}=\frac{1}{\mathrm{r}}\left[\delta_{\mathrm{kj}}-\mathrm{r}_{, \mathrm{k}} \mathrm{r}_{, \mathrm{j}}\right] ; \quad \mathrm{r}_{, \ell \mathrm{k}}=\frac{1}{\mathrm{r}}\left[\delta_{\ell \mathrm{k}}-\mathrm{r}_{, \ell} \mathrm{r}_{, \mathrm{k}}\right] \\
& \varepsilon_{\ell \mathrm{jk}}^{*}=\frac{-1}{8 \pi(1-v) \mathrm{Gr}}\left\{\frac{(3-4 v)}{2}\left[\delta_{\ell \mathbf{k}} \mathrm{r}_{, \mathrm{j}}+\delta_{\ell \mathrm{j}, \mathrm{r}, \mathrm{r}}\right]-\right. \\
& \left.-\frac{\mathrm{r}}{2}\left[\frac{1}{\mathrm{r}}\left(\delta_{\ell \mathbf{j}}-\mathrm{r}_{, \ell} \mathrm{r}_{, \mathbf{j}}\right) \mathrm{r}_{, \mathbf{k}}+2 \frac{1}{\mathrm{r}}\left(\delta_{\mathbf{k j}}-\mathrm{r}_{, \mathbf{k}} \mathrm{r}_{\mathrm{j}}\right) \mathrm{r}_{, \ell}+\frac{1}{\mathrm{r}}\left(\delta_{\ell \mathbf{k}}-\mathrm{r}_{\ell} \mathrm{r}_{, \mathbf{k}}\right) \mathrm{r}_{, \mathbf{j}}\right]\right\}= \\
& =\frac{-1}{8 \pi(1-v) \mathrm{Gr}}\left\{\frac{(3-4 v)}{2}\left[\delta_{\ell \mathrm{k}} \mathrm{r}_{, j}+\delta_{\ell \mathrm{j}, \mathrm{r}}\right]-\frac{1}{2}\left[\delta_{\ell \mathrm{j}} \mathrm{r}_{, \mathbf{k}}+\delta_{\ell \mathrm{k}} \mathrm{r}_{\mathrm{j}, \mathrm{j}}\right]-\mathrm{r}_{\ell \ell} \delta_{\mathrm{kj}}+2 \mathrm{r}_{\ell,} \mathrm{r}_{, j} \mathrm{r}_{, \mathbf{k}}\right\}= \\
& =\frac{-1}{8 \pi(1-v) \mathrm{Gr}}\left\{(1-2 v)\left[\delta_{\ell \mathrm{k}} \mathrm{r}_{, j}+\delta_{\ell \mathrm{j}} \mathrm{r}_{\mathrm{k}}\right]-\mathrm{r}_{\ell \ell} \delta_{j \mathbf{k}}+2 \mathrm{r}_{, \ell} \mathrm{r}_{, j} \mathrm{r}_{, \mathrm{k}}\right\}
\end{aligned}
$$




\section{Equação (8.35)}

Aplicando-se a eq. (8.20) na eq. (8.24):

$$
\begin{aligned}
\mathrm{G}_{\ell \mathrm{j}}^{\mathrm{k}} \mathrm{q}_{\mathrm{j}}^{\mathrm{k}}=[\overline{\mathrm{K}}]\{\mathrm{q}\}=\left[\left(\mathrm{G}_{\ell 1}^{1}+\frac{v}{(1-v)} \mathrm{G}_{\ell 2}^{2}\right)\left(\mathrm{G}_{\ell 2}^{1}+\mathrm{G}_{\ell 1}^{2}\right)\right]\left\{\begin{array}{l}
\mathrm{q}_{1}^{1} \\
\mathrm{q}_{2}^{1}
\end{array}\right\}=\left[\overline{\mathrm{K}}_{11}^{*} \quad \overline{\mathrm{K}}_{12}^{*}\right]\left\{\begin{array}{l}
\mathrm{q}_{1}^{1} \\
\mathrm{q}_{2}^{1}
\end{array}\right\} \\
\mathrm{G}_{\ell 1}^{1}=-\frac{1}{8 \pi \mathrm{G}(1-v) \mathrm{r}}\left\{(3-4 v) \mathrm{r}_{, 1} \delta_{\ell 1}-\mathrm{r}_{, 1} \delta_{\ell 1}-\mathrm{r}_{, \ell}+2 \mathrm{r}_{, \ell}\left(\mathrm{r}_{, 1}\right)^{2}\right\}= \\
=-\frac{1}{8 \pi \mathrm{G}(1-v) \mathrm{r}}\left\{2(1-2 v) \mathrm{r}_{, 1} \delta_{\ell 1}+\mathrm{r}_{, \ell}\left(-1+2\left(\mathrm{r}_{, 1}\right)^{2}\right)\right\} \\
\mathrm{G}_{\ell 2}^{2}=-\frac{1}{8 \pi \mathrm{G}(1-v) \mathrm{r}}\left\{(3-4 v) \mathrm{r}_{, 2} \delta_{\ell 2}-\mathrm{r}_{, 2} \delta_{\ell 2}-\mathrm{r}_{, \ell}+2 \mathrm{r}_{, \ell}\left(\mathrm{r}_{, 2}\right)^{2}\right\}= \\
=-\frac{1}{8 \pi \mathrm{G}(1-v) \mathrm{r}}\left\{2(1-2 v) \mathrm{r}_{, 2} \delta_{\ell 2}+\mathrm{r}_{, \ell}\left(-1+2\left(\mathrm{r}_{, 2}\right)^{2}\right)\right\}
\end{aligned}
$$

Para $\ell=1$ :

$$
\begin{aligned}
\mathrm{I} & =\lim _{\delta \rightarrow 0} \lim _{\Gamma^{*} \rightarrow 0}\left\{\int_{\Gamma^{*}} \overline{\mathrm{K}}_{11}^{*} \mathrm{~d} \Gamma^{*}\right\}=\lim _{\delta \rightarrow 0} \lim _{\Gamma^{*} \rightarrow 0}\left\{\int_{\Gamma^{*}}-\frac{1}{8 \pi \mathrm{G}(1-v) \mathrm{r}}\left(2(1-2 v) \mathrm{r}_{, 1}+\mathrm{r}_{, 1}\left(-1+2\left(\mathrm{r}_{, 1}\right)^{2}\right)+\right.\right. \\
& \left.\left.+\frac{v}{1-v}\left[\mathrm{r}_{, 1}\left(-1+2\left(\mathrm{r}_{, 2}\right)^{2}\right)\right]\right) \mathrm{d} \Gamma^{*}\right\}= \\
& =-\frac{1}{8 \pi \mathrm{G}(1-v)} \lim _{\delta \rightarrow 0} \lim _{\Gamma^{*} \rightarrow 0}\left\{\int_{\Gamma^{*}} \frac{1}{\mathrm{r}} \mathrm{r}_{1}\left(2(1-2 v)-1+2\left(\mathrm{r}_{, 1}\right)^{2}\right)+\frac{v}{1-v}\left[-1+2\left(\mathrm{r}_{, 2}\right)^{2}\right] \mathrm{d} \Gamma^{*}\right\}
\end{aligned}
$$

Mas,

$\frac{1}{r} r_{, 1}=\frac{\operatorname{Cos}(\theta)}{\delta} \cdot \operatorname{Cos}(\theta)=\operatorname{Cos}^{2}(\theta) ; \quad \frac{1}{r} r_{, 2}=\frac{\operatorname{Cos}(\theta)}{\delta} \cdot \operatorname{Sen}(\theta) ; \quad\left(r_{, 2}\right)^{2}=\operatorname{Sen}^{2}(\theta)$

$\left(\mathrm{r}_{, 1}\right)^{2}=\operatorname{Cos}^{2}(\theta) ; \quad \mathrm{d} \Gamma^{*}=\frac{\mathrm{rd} \theta}{\operatorname{Cos}(\theta)}=\frac{\delta}{\operatorname{Cos}(\theta)} \cdot \frac{\mathrm{d} \theta}{\operatorname{Cos}(\theta)}=\frac{\delta \mathrm{d} \theta}{\operatorname{Cos}^{2}(\theta)} \therefore$

$I=-\frac{1}{8 \pi G(1-v)}$

$\cdot \lim _{\delta \rightarrow 0} \lim _{\Gamma^{*} \rightarrow 0}\left\{\int_{\Gamma^{*}} \frac{\operatorname{Cos}^{2}(\theta)}{\delta}\left(2(1-2 v)-1+2 \operatorname{Cos}^{2}(\theta)\right)+\frac{v}{1-v}\left[-1+2 \operatorname{Sen}^{2}(\theta)\right] \frac{\delta \mathrm{d} \theta}{\operatorname{Cos}^{2}(\theta)}\right\}=$ 


$$
\begin{aligned}
& =-\frac{1}{8 \pi \mathrm{G}(1-v)} . \\
& \cdot \lim _{\delta \rightarrow 0} \lim _{\Gamma^{*} \rightarrow 0}\left[(1-4 v) \theta+\theta+\frac{\operatorname{Sen}(2 \theta)}{2}+\frac{v}{1-v}\left(-\theta+\theta-\frac{\operatorname{Sen}(2 \theta)}{2}\right)\right]_{-\frac{\pi}{2}}^{\frac{\pi}{2}}= \\
& =-\frac{1}{8 \pi G(1-v)^{\prime}} \lim _{\delta \rightarrow 0} \lim _{\Gamma^{*} \rightarrow 0}\{(1-4 v) \pi+\pi\}=-\frac{1}{8 \pi G(1-v)} 2(1-2 v) \pi=-\frac{(1-2 v)}{4 G(1-v)}
\end{aligned}
$$

\section{Equação (8.51a)}

$$
\begin{aligned}
\mathrm{KW} 2_{11} & =\int_{0}^{\ell} \phi_{1} \overline{\mathrm{K}} 2_{11} \mathrm{~d} \bar{\Gamma}=\int_{0}^{\mathrm{a}} \phi_{1} \overline{\mathrm{K}} 2_{11} \mathrm{~d} \bar{\Gamma}+\int_{\mathrm{a}}^{\ell} \phi_{1} \overline{\mathrm{K}} 2_{11} \mathrm{~d} \bar{\Gamma}=\lim _{\varepsilon \rightarrow 0}\left\{\int_{\mathrm{a}}^{\varepsilon}-\phi_{1} \overline{\mathrm{K}} 2_{11} \mathrm{dr}+\int_{\varepsilon}^{\mathrm{b}} \phi_{1} \overline{\mathrm{K}} 2_{11} \mathrm{dr}\right\}= \\
& =\lim _{\varepsilon \rightarrow 0}\left\{\int_{\varepsilon}^{\mathrm{a}}\left(1-\frac{\mathrm{r}}{\bar{\xi} \ell}\right) \frac{1}{4 \pi(1-v) \mathrm{r}^{2}}\left[1-2 v+4\left(\mathrm{r}_{, 1}\right)^{2}\left(1+v-2\left(\mathrm{r}_{, 1}\right)^{2}\right)\right] \mathrm{dr}+\right. \\
& \left.+\int_{\varepsilon}^{\mathrm{b}}\left(1+\frac{\mathrm{r}}{\bar{\xi} \ell}\right) \frac{1}{4 \pi(1-v) \mathrm{r}^{2}}\left[1-2 v+4\left(\mathrm{r}_{, 1}\right)^{2}\left(1+v-2\left(\mathrm{r}_{, 1}\right)^{2}\right)\right] \mathrm{dr}\right\}= \\
& =\frac{1}{4 \pi(1-v)}\left[1-2 v+4\left(\mathrm{r}_{, 1}\right)^{2}\left(1+v-2\left(\mathrm{r}_{, 1}\right)^{2}\right)\right] \cdot \lim _{\varepsilon \rightarrow 0}\left\{\int_{\varepsilon}^{\mathrm{a}}\left(1-\frac{\mathrm{r}}{\bar{\xi} \ell}\right) \frac{\mathrm{dr}}{\mathrm{r}^{2}}+\int_{\varepsilon}^{\mathrm{b}}\left(1+\frac{\mathrm{r}}{\bar{\xi} \ell}\right) \frac{\mathrm{dr}}{\mathrm{r}^{2}}\right\}= \\
& =\frac{1}{4 \pi(1-v)}\left[1-2 v+4\left(\mathrm{r}_{, 1}\right)^{2}\left(1+v-2\left(\mathrm{r}_{, 1}\right)^{2}\right)\right] \cdot \mathrm{I}
\end{aligned}
$$

onde

$$
\begin{aligned}
\mathrm{I} & =\lim _{\varepsilon \rightarrow 0}\left\{\int_{\varepsilon}^{\mathrm{a}} \frac{\mathrm{dr}}{\mathrm{r}^{2}}+\int_{\varepsilon}^{\mathrm{b}} \frac{\mathrm{dr}}{\mathrm{r}^{2}}+\frac{1}{\bar{\xi} \ell}\left(-\int_{\varepsilon}^{\mathrm{a}} \frac{\mathrm{dr}}{\mathrm{r}}+\int_{\varepsilon}^{\mathrm{b}} \frac{\mathrm{dr}}{\mathrm{r}}\right)\right\}=-\frac{1}{\mathrm{a}}-\frac{1}{\mathrm{~b}}+\frac{1}{\bar{\xi} \ell} \cdot \lim _{\varepsilon \rightarrow 0}\left\{[\ln |\mathrm{r}|]_{\varepsilon}^{\mathrm{b}}-[\ln |\mathrm{r}|]_{E}^{\mathrm{a}}\right\}= \\
& =\frac{1}{\bar{\xi} \ell} \cdot \lim _{\varepsilon \rightarrow 0}\{\ln (\mathrm{b})-\ln (\varepsilon)-\ln (\mathrm{a})+\ln (\varepsilon)\}-\frac{\ell}{\mathrm{ab}}=\frac{1}{\bar{\xi} \ell} \cdot \ln \left(\frac{\mathrm{b}}{\mathrm{a}}\right)-\frac{\ell}{\mathrm{ab}}= \\
& =\frac{1}{\bar{\xi} \ell} \cdot \ln \left(\frac{\frac{(1-\bar{\xi})}{2} \ell}{\frac{(1+\bar{\xi})}{2} \ell}\right)-\frac{\ell}{\frac{(1+\bar{\xi})}{2} \ell \frac{(1-\bar{\xi})}{2} \ell}=\frac{1}{\bar{\xi} \ell} \cdot \ln \left(\frac{(1-\bar{\xi})}{(1+\bar{\xi})}\right)-\frac{4}{\left(1-\bar{\xi}^{2}\right) \ell}
\end{aligned}
$$

de onde: 


$$
\mathrm{KW} 2_{11}=\frac{1}{4 \pi(1-v) \ell}\left[1-2 v+4\left(\mathrm{r}_{, 1}\right)^{2}\left(1+v-2\left(\mathrm{r}_{, 1}\right)^{2}\right)\right] \cdot\left[\frac{1}{\bar{\xi}} \cdot \ln \left(\frac{(1-\bar{\xi})}{(1+\bar{\xi})}\right)-\frac{4}{\left(1-\bar{\xi}^{2}\right)}\right]
$$

